TESIS DOCTORAL

\title{
INFLUENCIA DEL APOYO SOCIAL EN LA ANSIEDAD Y EL ESTRÉS DEL PACIENTE INTERVENIDO DE CIRUGÍA ENDOSCÓPICA NASOSINUSAL
}

\section{Pedro Raúl Castellano Santana}

José Enrique Hernández Rodríguez (Director) Fernando Calvo Francés (Codirector)

Castellón de la Plana, abril de 2019 



\title{
INFLUENCIA DEL APOYO SOCIAL EN LA ANSIEDAD Y EL ESTRÉS DEL PACIENTE INTERVENIDO DE CIRUGÍA ENDOSCÓPICA NASOSINUSAL
}

\author{
Memoria presentada por \\ Pedro Raúl Castellano Santana \\ para optar al grado de doctor \\ por Universidad Jaume I

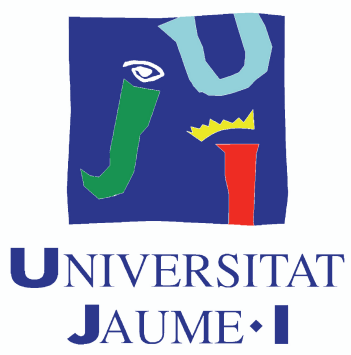

Programa de Doctorado en

Ciencias de la Enfermería

Escuela de Doctorado de la Universidad Jaume I

Doctorando

Pedro Raúl

Castellano Santana

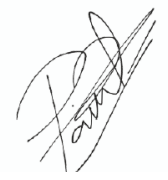

Director

José Enrique

Hernández Rodríguez

HERNANDEZ

RODRIGUEZ JOSE

ENRIQUE - 42821369

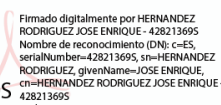

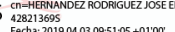

Codirector

Fernando Calvo

Francés

CALVO

FRANCES porCALVO FRANCES

FERNANDO $42792469 \mathrm{~A}$

Castellón de la Plana, abril de 2019 



\section{AGRADECIMIENTOS}

La elaboración de esta Tesis Doctoral, que ha sido como un viaje en barco que consigue llegar a buen puerto, no hubiese sido posible sin la ayuda, asesoramiento y apoyo de TODAS las personas que quisieron acompañarme en esta travesía y se convirtieron en una tripulación especial y fundamental para conseguir el objetivo planificado.

En primer lugar darle las GRACIAS a mi director de Tesis, el Dr. Jose Enrique Hernández, la ayuda prestada no solo desde el punto teórico, explicándome y enseñándome los mapas y rutas que debía usar para llegar a ese puerto soñado, sino además ofreciéndome su apoyo en los días de tormenta donde la navegación se tornaba complicada y se perdía el rumbo, para mí fue y es en la actualidad un referente profesional y personal como defensor de la enfermería y valor del arte de cuidar.

GRACIAS a mi codirector de tesis el Dr. Fernando Calvo que en los momentos que el "GPS del barco metodológico" se estropeaba conseguía con su manejo de la estadística y la metodología conseguir recobrar el rumbo deseado.

GRACIAS a la Dra. Loreto Maciá por transmitirme desde el primer momento el entusiasmo por la investigación enfermera, fundamental para crecer y avanzar como disciplina en una sociedad que necesita ser cuidada siempre en base a la evidencia científica.

GRACIAS al Dr. Juan Carlos Falcón, Dr. Ángel Ramos y a la Dra. Teresa Ramírez, que desde el comienzo de esta tesis antes de empezar con la construcción del barco que surcaría ese mar de conocimientos me dieron las directrices adecuadas que por su experiencia eran necesarias para conseguir los materiales y los permisos para que la travesía fuese lo más placentera posible.

GRACIAS a Sergio por su implicación tanto profesional como personal, dibujando y engalanando este barco para que no pasase desapercibido surcando los mares del saber. 
GRACIAS al personal de enfermería de las diferentes unidades de hospitalización, quirófano, despertar y reanimación, al servicio de anestesia y otorrinolaringología del Complejo Hospitalario Universitario Insular Materno Infantil de Gran Canaria, servicios y unidades que consiguieron con su apoyo que cada viajero que decidió participar en esta tesis doctoral tuviese lo mejores cuidados durante el proceso de investigación.

GRACIAS mis padres Beni y Pedro, mi hermana Jennifer, mi familia y amigos que durante el viaje supieron entender que en este tipo de travesías tan largas, era fundamental su apoyo y comprensión en los momentos en el que el barco necesitaba un empuje extra para sobrepasar las olas.

Por último y no menos importante GRACIAS a Carolina mi pareja el mástil donde me he apoyado desde el primer momento para conseguir llegar a puerto, sin tu apoyo incondicional no hubiese sido posible este viaje, deseo seguir compartiendo el rumbo de mi vida a tu lado.

Dedicarle esta tesis a mi hija Adriana que su nacimiento ha sido el mejor de los regalos que hemos tenidos en la vida, coincidiendo con la elaboración de esta tesis, perdona si en algún momento no he podido estar al cien por cien contigo en este tiempo, pero te lo recompensaré por el resto de mi vida. 


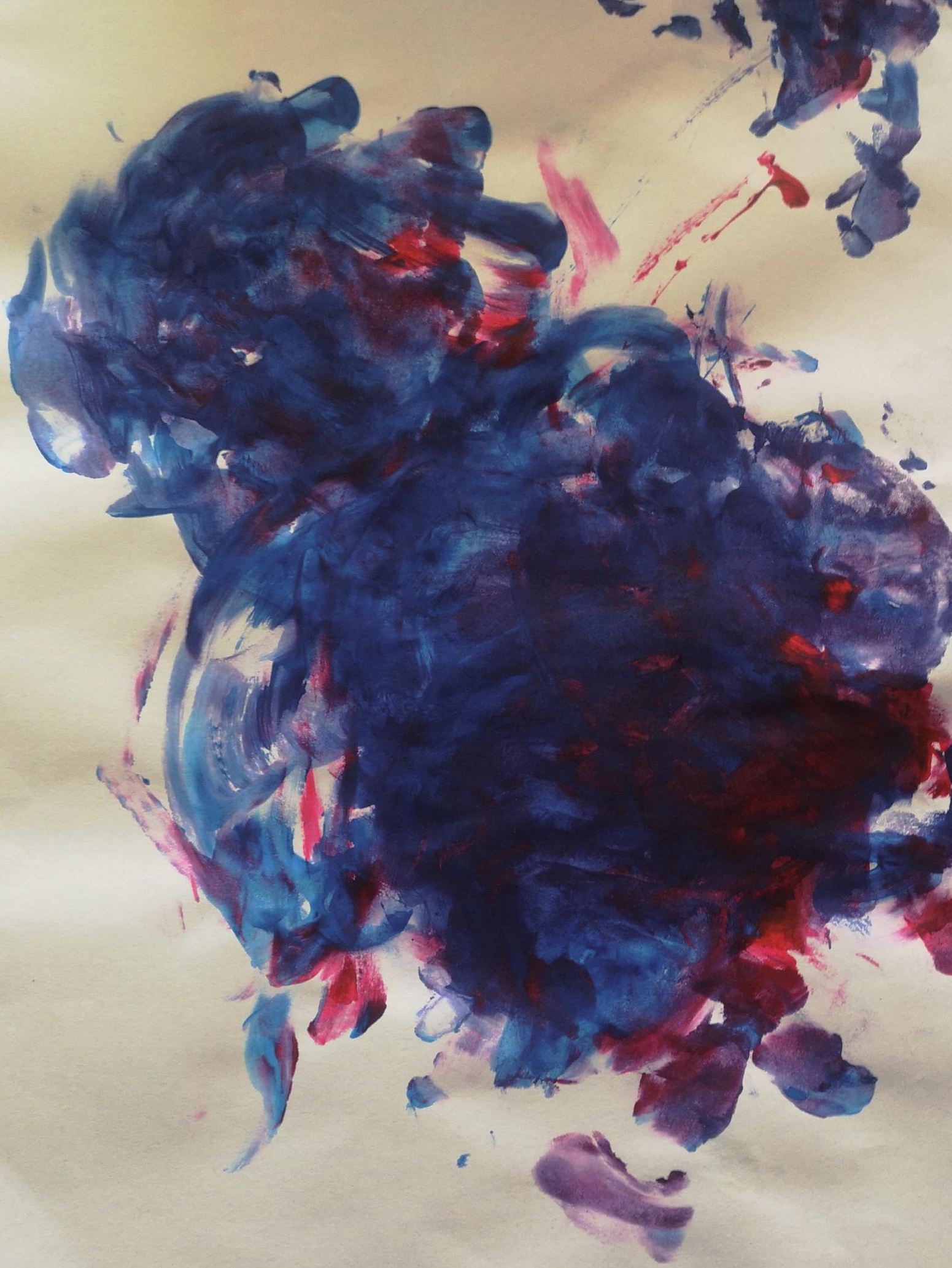

La meta de enfermería en sí es brindar cuidados; pero esto no tiene sentido si no se comprende en esencia el significado de Cuidar 



\section{ABREVIATURAS}

A

ACTH

$A E$

AR

AS

ASA

$B$

CASA

CENS

CHUIMI

CMA

CINAHL

CRF

DeCS

DxE

E

EBSCO

EFA

EISOP

EMBASE

ERAS

HOSP

HPA axis

IBECS

IC

IDDA-EA

JBI

KMO

LiLacs

Ansiedad

Hormona Adenocorticotropa

Ansiedad Estado

Ansiedad Rasgo

Apoyo social

American Society of Anaesthesiologists

Coeficiente de regresión parcial no estandarizado

Somatic Anxiety Scale

Cirugía endoscópica nasosinusal

Complejo Hospitalario Universitario Insular Materno Infantil

Cirugía mayor ambulatoria

Cumulative Index to Nursing and Allied Health Literature

Factor Liberador de Corticotropina

Descriptores de Ciencias de la Salud

Diagnóstico Enfermero

Estrés

Elton B. Stephens Company

Exploratorio de Factores

Emotional and Informational Support Scales-Operations

Excerpta Medica Database

Enhanced Recovery After Surgery

Hospitalización

Eje Hipotálamo-Pituitaria-Suprarrenal

Índice Bibliográfico Español en Ciencias de la Salud

Intervalo de confianza

Inventario Diferencial de Adjetivos para el estudio del estado de ánimo

The Joanna Briggs Institute

Kaiser-Meyer-Olkin

Literatura Latinoamericana de Información en Ciencias

de la Salud 
LOPD Ley Orgánica de Protección de Datos de Carácter Personal

MeSH Medical Subjects Headings

NANDA North American Nursing Diagnosis Association

NANDA-I NANDA Internacional, Inc.

NIC Nursing Interventions Classifications

NOC Nursing Outcomes Classification

OMS Organización Mundial de la Salud

OVID The Offshore Vessel Inspection Database

PAE

PR

Proceso de Atención de Enfermería

Scielo

Personas relevantes

SEA

Scientific Electronic Library Online

Sig

Sistema de Evaluación de la Amenaza

SNA

Significación

SPSS

Sistema nervioso autónomo

STAI

Statistical Package for the Social Sciences

$\mathrm{t}$ Cuestionario Ansiedad Estado-Rasgo

URPA

Estadístico de contraste

VIDA

Unidad de Reanimación Postanestésica

Escala de Vínculos Interpersonales de Apoyo 


\section{ÍNDICE GENERAL}

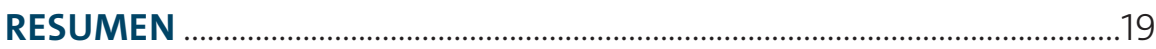

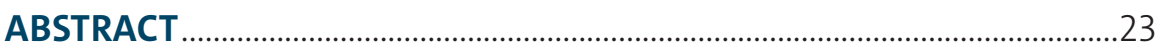

\section{INTRODUCCIÓN Y MARCO TEÓRICO}

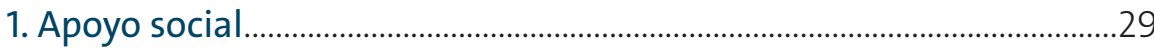

1.1. Aproximación histórica de la conceptualización del apoyo social ....29

1.1.1. Definición de apoyo social ......................................................................33

1.2. Dimensiones del apoyo social ....................................................................

1.2.1. Apoyo social estructural o cuantitativo ...........................................36

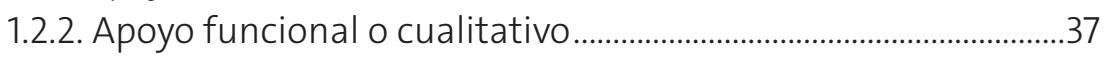

1.3. Apoyo social y salud ......................................................................................4

1.3.1. Evidencia científica actual sobre el apoyo social

y su relación con la salud

1.4. Los cuidados de enfermería relacionados con el apoyo social recibido/percibido …………………………………………………….........

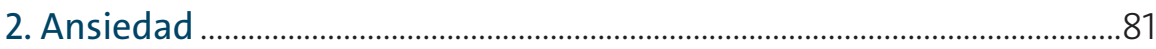

2.1. Aproximación histórica de la conceptualización de la ansiedad ......82

2.2. Aproximación del concepto de la ansiedad desde la perspectiva del cuidado enfermero

2.2.1. Los sesgos en el procesamiento de la información

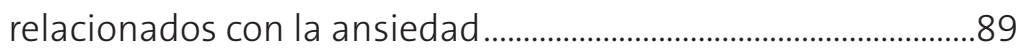

2.3. Ansiedad y salud ...............................................................................................97

2.3.1. Evidencia científica actual sobre la ansiedad y su relación con la salud ...................................................................98

2.4. Los cuidados de enfermería relacionado con la ansiedad del paciente

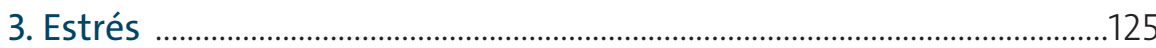

3.1. Aproximación histórica de la conceptualización del estrés .............125 
3.2. Definición de estrés......................................................................................127

3.2.1. Tipos de estrés en función del resultado .....................................128

3.2.2. Tipos de estrés en función de la duración ...................................128

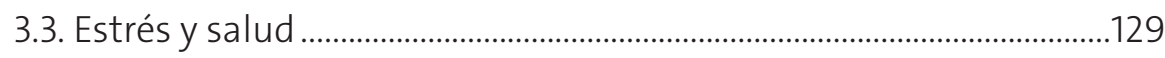

3.3.1. Evidencia científica actual sobre el estrés

y su relación con la salud

.144

3.4. Los cuidados de enfermería relacionado con el estrés

del paciente .148

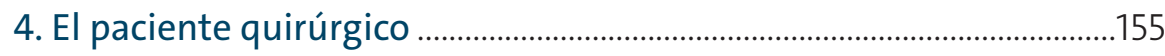

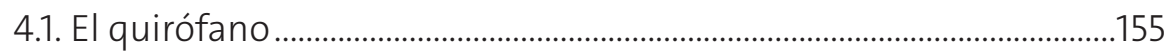

4.2. Etapas del acto quirúrgico ........................................................................

5. Cuidados enfermeros en la cirugía nasosinusal en el adulto.............159

5.1. Proceso de Atención de Enfermería en el paciente programado para ser intervenido de cirugía endoscópica nasosinusal .161

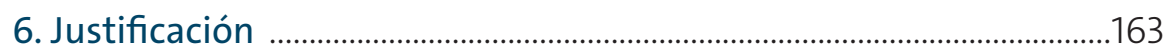

\section{ESTUDIO EMPÍRICO}

7. Hipótesis .171

8. Objetivos .173

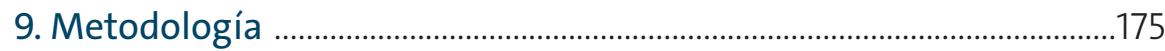

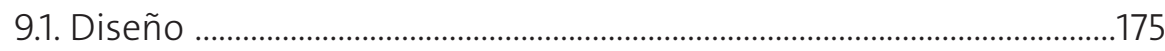

9.2. Población de estudio y muestra.............................................................175

9.3. Variables e instrumentación ..........................................................................176

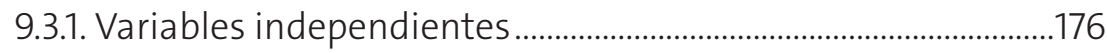

9.3.2. Variables dependientes ......................................................................176

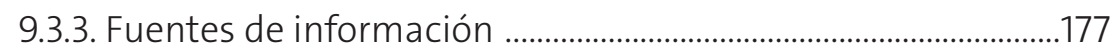

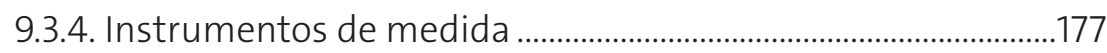

9.4. Procedimiento de recogida de datos........................................................... 
9.5. Análisis de datos 182

9.6. Consideraciones éticas .182

10. Resultados .185

10.1. Análisis descriptivo de las variables del estudio .185

10.1.1. Resultados variables sociodemográficas .185

10.1.2. Resultados de las variables relacionadas con el proceso quirúrgico .186

10.1.3. Resultados de las variables relacionadas con el apoyo social percibido .188

10.1.4. Resultados de las variables relacionadas con la ansiedad 188

10.1.5. Resultados de las variables relacionadas con el estrés .188

10.1.6. Resultados de las variables relacionadas con el estrés y la ansiedad previo a la intervención 190

10.2. Análisis de correlación de las variables del estudio 190

10.2.1. Variable apoyo social percibido sobre variables relacionadas con la ansiedad durante el proceso quirúrgico 190

10.2.2. Variable apoyo social percibido sobre las variables relacionadas con el estrés durante el proceso quirúrgico

10.2.3. Variables nivel de ansiedad y estrés escala numerada, apoyo social percibido y estrés

10.2.4. Variables analgesia extra administrada durante el ingreso, duración de la estancia hospitalaria, presencia de complicaciones durante el ingreso, el apoyo social percibido, ansiedad y estrés .195

10.2.5. Análisis estadístico mediante la prueba T de Student para muestras independientes .196

10.3. Análisis de regresión de las variables del estudio .198

10.3.1. Análisis de regresión del tiempo de ingreso en la unidad de hospitalización como criterio 198

11. Discusión .201 
12. Conclusiones

.217

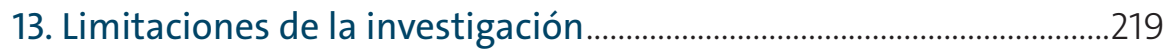

14. Futuras líneas de invetigación ...................................................................221

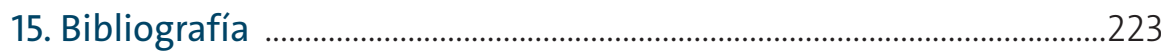

16. Anexos

Anexo I. Intrumentos de evaluación ..............................................................249

Anexo II. Formulario de recogida de datos ......................................................255

Anexo III. Hoja de información al paciente y consentimiento

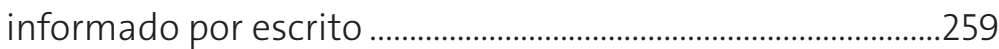

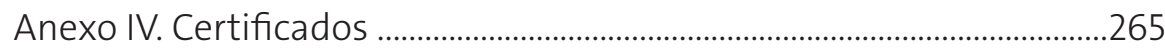




\section{ÍNDICE DE TABLAS Y FIGURAS}

\section{TABLAS}

Tabla 1. Descriptores controlados según nomenclatura

DeCS y MeSH

Tabla 2. Resumen de número artículos encontrados en la búsqueda bibliográfica con la palabra clave Social

Support como concepto principal.... .45

Tabla 3. Resumen de número artículos encontrados en la búsqueda bibliográfica con la palabra clave Social Support como concepto principal II (filtrado) .48

Tabla 4. Referencias analizadas según nivel de evidencia (Apoyo Social) .50

Tabla 5. Actividades relacionadas con la intervención enfermera "aumentar los sistemas de apoyo" .77

Tabla 6. Diagnósticos Enfermeros que pueden incluir la intervención "aumentar los sistemas de apoyo" .78

Tabla 7. Posibles criterios de resultado para la intervención "aumentar los sistemas de apoyo"

Tabla 8. Concepto de ansiedad según los enfoques psicológicos más relevantes

Tabla 9. Descriptores controlados según nomenclatura DeCS y MeSH

Tabla 10. Resumen de número de artículos encontrados en la búsqueda bibliográfica con la palabra clave Anxiety como concepto principal 99

Tabla 11. Referencias analizadas según nivel de evidencia (Ansiedad) .102

Tabla 12. Características definitorias del DxE Ansiedad .......................117

Tabla 13. Factores relacionados del DxE Ansiedad....................................118

Tabla 14. Indicadores de resultados para el NOC Nivel de Ansiedad (1211) . .119 
Tabla 15. Actividades para la intervención disminución de la ansiedad, código NIC 5820

Tabla 16. Actividades para la intervención disminución del estrés por traslado, código NIC 5350

Tabla 17. Actividades para la intervención aumentar los sistemas de apoyo, código NIC 5440

Tabla 18. Descriptores controlados según nomenclatura DeCS y MeSH

Tabla 19. Resumen de número artículos encontrados en la búsqueda bibliográfica con la palabra clave Stress como concepto principal .131

Tabla 20. Referencias analizadas según nivel de evidencia (Estrés)

Tabla 21. Factores de Riesgo del DxE riesgo de síndrome de estrés del traslado (00149) 148

Tabla 22. Características definitorias del DxE síndrome del estrés del traslado (00114)

Tabla 23. Factores relaciones del DxE síndrome del estrés del traslado (00114) .148

Tabla 24. Indicadores de resultado para el NOC conocimiento: manejo del estrés (1862) .150

Tabla 25. Indicadores de resultado para el NOC nivel de estrés (1862) 151

Tabla 26. Actividades para la intervención disminución del estrés por traslado (5350) .153

Tabla 27. Análisis descriptivo variables apoyo social percibido ........188

Tabla 28. Análisis descriptivo variables relacionadas con la ansiedad 189

Tabla 29. Análisis descriptivo variables relacionadas con la ansiedad por sexo y nivel de estudios.

Tabla 30. Análisis descriptivo variables relacionadas con el estrés

Tabla 31. Análisis descriptivo variables relacionadas con el estrés 
Tabla 32. Coeficiente de correlación de Pearson de las variables ansiedad y apoyo social percibido.

Tabla 33. Coeficiente de correlación de Pearson de las variables estrés y apoyo social percibido

Tabla 34. Coeficiente de correlación de Pearson de las variables estrés, ansiedad (escala numerada) y apoyo social percibido escala estrés

Tabla 35. Coeficiente de correlación de Pearson de las variables estrés, ansiedad (escala numerada) y apoyo social percibido .196

Tabla 36. Regresión Lineal múltiple con la variable tiempo de ingreso en la unidad de hospitalización como criterio y como variables predictora el apoyo social percibido

\section{FIGURAS}

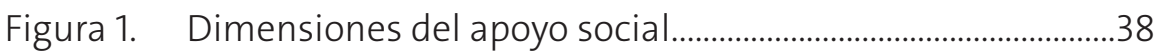

Figura 2. Evolución de los documentos encontrados en la base de datos Scopus, con la palabra "social support" en el título

Figura 3. Documentos encontrados en la base de datos Scopus con el título "social support" pertenecientes a la disciplina enfermera.

Figura 4. Documentos encontrados en la base de datos Scopus con el título "social support" pertenecientes a la disciplina enfermera, ordenados por países .48

Figura 5. Selección definitiva de referencias concepto principal apoyo social

Figura 6. Esquema de respuesta humana ante un estímulo percibido .94

Figura 7. Selección definitiva de referencias concepto principal ansiedad . .101 
Figura 8. Selección definitiva de referencias concepto principal estrés

Figura 9. Liberación de cortisol mediante el eje Hipotálamo-Hipófisis-Suprarrenal . .147

Figura 10. Porcentaje de participantes en el estudio por grupos de edad .185

Figura 11. Duración de la cirugía en minutos . .187 


\section{RESUMEN}

\section{Introducción}

El paciente programado para ser intervenido quirúrgicamente se enfrenta a una situación que le genera ansiedad y estrés. En concreto, el paciente intervenido de cirugía endoscópica nasosinusal deberá ingresar en una unidad de hospitalización o cirugía mayor ambulatoria, a continuación ser traslado al quirófano para ser intervenido, posteriormente recuperarse de la cirugía en el postoperatorio inmediato y finalmente ser dado de alta y volver a su entorno habitual. Es en este tipo de situaciones donde el apoyo social cobra vital importancia para enfrentarse a los cambios y experiencias relacionadas con la recuperación de la intervención quirúrgica. Por ello, desde una perspectiva enfermera, cuantificar el apoyo social percibido puede ser un herramienta importante en la planificación de los cuidados de enfermería del paciente intervenido quirúrgicamente, analizando las repercusiones que dicho apoyo social puede tener sobre la ansiedad y el estrés durante el proceso quirúrgico.

\section{Objetivo}

Describir y analizar las relaciones entre las variables sociodemográficas y variables sociales: apoyo social (AS), ansiedad (A) y estrés (E), del paciente adulto hospitalizado, programado para ser intervenido quirúrgicamente mediante cirugía endoscópica nasosinusal.

\section{Material y métodos}

Se realizó un estudio analítico observacional correlacional de asociación, prospectivo longitudinal con muestreo por conveniencia, en el Complejo Hospitalario Universitario Materno Insular de Gran Canaria, durante un 
año en pacientes programados para ser intervenidos mediante cirugía endoscópica nasosinusal, de edades comprendidas entre 18 y 100 años, que presentasen un riesgo anestésico tipo I o II según la American Society of Anesthesiologists. Se analizó como variable independiente al apoyo social percibido de amigos, familiares y personas relevantes y como variables dependientes la ansiedad estado, ansiedad rasgo, estrés, nivel de cortisol, variables sociodemográficas y las relacionadas con el proceso quirúrgico. El análisis estadístico se realizó con el paquete estadístico IBM ${ }^{\circledR}$ SPSS $^{\circledR}$ Statistics Versión 22.0. Se ha calculado la media, desviación típica y el intervalo de de confianza (IC) de 95\%. Se ha calculado la frecuencia y porcentaje en las variables cualitativas. Se ha utilizado el coeficiente de correlación de Pearson para comprobar la asociación entre las variables cuantitativas. Todas las pruebas estadísticas fueron bilaterales y se consideraron significativas con un valor $\alpha=0,05$. Un valor de $p<0,05$ se consideró estadísticamente significativo.

\section{Resultados}

Se incluyeron 61 paciente en el estudio, de los cuales 55 finalizaron la investigación correctamente, el 52,7\% eran varones y el 47,3\% eran mujeres, el 12,7\% estaban solteros, el 56,4\% estaban casados, el 16,4\% tenían una unión estable, el 9,1 \% estaban divorciados y el 5,5\% eran viudos, con respecto a la presencia de intervenciones previas que precisaron de anestesia general en los pacientes incluidos en el estudio, el 32,7\% no presentaban intervenciones previas respecto al $67,3 \%$ que habían no sido sometidos a ningún tipo de intervención quirúrgica que precisase anestesia general. El porcentaje de sujetos que dicen haber percibido apoyo social (AS) de familiares durante el proceso quirúrgico fue de $24,4 \%$ (SD 3,94), el de amigos fue de 47,35 (SD 8,815), y el de personas relevantes fue de 36,42\% (SD 5,603). Se obtuvo una correlación significativa inversa $(p<0,05)$ entre el AS percibido de familiares, amigos y personas relevantes en relación con la ansiedad estado al ingreso. Los pacientes incluidos en el estudio presentaron una correlación significativa positiva $(p<0,05)$ entre la duración del ingreso en la unidad de hospitalización y la ansiedad estado postquirúrgica. Por último, el AS percibido de personas relevantes 
destacó como variable predictora con efecto directo (Beta $=-0,530$ ), sobre el tiempo de ingreso en la unidad de hospitalización como criterio.

\section{Discusión y conclusiones}

La atención integral del paciente quirúrgico debe ser evaluada en todas sus dimensiones, incluida el apoyo social percibido, los resultados obtenidos en este estudio de investigación y los hallazgos encontrados por otros autores en líneas de investigación similares, revelan la importancia de dicho constructo y su influencia sobre la salud de las personas.

Un mayor apoyo social percibido, tanto de familiares y amigos como personas relevantes, se relaciona con una menor ansiedad estado en el momento del ingreso. Una mayor ansiedad estado postquirúrgica se relaciona con un mayor tiempo en la unidad de hospitalización. Un valor elevado de apoyo social percibido de personas relevantes se asocia con un menor tiempo de ingreso en la unidad de hospitalización.

\section{Palabras clave}

Apoyo social, ansiedad, estrés, cuidados de enfermería, práctica clínica basada en la evidencia, cirugía. 



\section{ABSTRACT}

\section{Introduction}

The patient, who has been programmed for surgery, faces an anxious, stressful situation for him. In particular, the patient has previously undergone an endoscopic sinus surgery and will be admitted in a hospitalisation or major outpatient surgery unit. After that, he will be moved to the operating theatre for being operated; then, he will recover from surgery in the immediate postoperative room; and, finally, he will be discharged and return to his regular environment. In this type of situations, social support becomes of great importance for facing changes and experiences related to the surgical intervention recovery. Therefore, from a nursing point of view, to quantify the social support the patient has perceived could be an important tool in the nursing care planning of the patient who underwent surgery, by analysing the effects that social support may cause on anxiety and stress during the surgical process.

\section{Objective}

To describe and analyse the relationships between socio-demographic variables and social variables: social support, anxiety and stress of the hospitalised adult patient who is programmed for undergoing an endoscopic sinus surgery.

\section{Matherial and methods}

An association correlational analytic observational, longitudinal prospective study was done with convenience sampling at the Complejo Hospitalario Universitario Materno Insular de Gran Canaria, during a year in patients who were programmed for undergoing an endoscopic sinus 
surgery, aged 18-100, with type I or II anaesthetic risk according to the American Society of Anesthesiologists. The independent variable was the social support of friends, relatives and relevant people, and the dependent variables were state anxiety, trait anxiety, stress, cortisol level, socio-demographic variables and those related to the surgical process. The statistical analysis was done with IBM ${ }^{\circledR}$ SPSS ${ }^{\circledR}$ Statistics Version 22.0. The median, standard deviation (DT) and 95\% confidence interval. Were calculated frequency and percentage were calculated in the qualitative variables. Pearson correlation coefficient was used for checking the association of the quantitative variables. All the statistical tests were bilateral and were considered as significant with an $\alpha=0.05$ value. $A p<0.05$ value was considered statistically significant.

\section{Results}

61 patients were included in the study. 55 of them appropriately concluded the research, $52.7 \%$ were men and $4.3 \%$ were women, $12.7 \%$ were single, $56.4 \%$ were married, $16.4 \%$ were in a stable relationship, $9.1 \%$ were divorced and $5.5 \%$ were widowed. Regarding previous interventions which needed general anaesthesia in the patients of our study, $32.7 \%$ had not had previous interventions against $67.3 \%$ who had undergone surgical interventions that required general anaesthesia. The percentage of subjects who have had social support of relatives during the surgical process was $24.4 \%$ (DT 3.94), $47.35 \%$ (DT 8.815) with friend's support and $36.42 \%$ (DT 5.603) with relevant people's support. We obtained an inverse significant correlation $(p<0.05)$ between the AS from relatives, friends and relevant people in relation with the state anxiety at admission. The patients included in the study showed a positive significant correlation $(p<0.05)$ between the hospitalisation unit admission duration and the postsurgical trait anxiety. Lastly, the social support perceived in relevant people stood out as a prognostic variable with direct effect (beta $=-0.530$ ) over the hospitalisation unit admission duration as a criterion. 


\section{Discussion and Conclusions}

The comprehensive care of the surgical patient should be assessed in every aspect, including the perceived social support. The results we have obtained in this research and the findings by other authors in similar lines of research show the importance of such construct and its influence over people's health.

A higher perceived social support - either from relatives, friends and relevant people - is related to a lower state anxiety at the admission. A higher postsurgical state anxiety is related with more time in the hospitalisation unit. A high value of perceived social support from relevant people is associated with a lower admission time in the hospitalisation unit.

\section{Keywords}

Social support, anxiety, stress, nursing care, evidence-based practice, surgery. 



\section{YMARCO TEORICO YM}

INTRODUCCIÓN
Y MARCO TEÓRICO

INTRODUCCIÓN
Y MARCO TEÓRICO 



\section{APOYO SOCIAL}

El apoyo social ha sido, a lo largo de la historia, investigado y citado en infinidad de ejemplos que ponen de manifiesto la necesidad que tienen las personas de una adecuada interacción social para lograr su crecimiento y el desarrollo de su personalidad.

Las diferentes disciplinas sanitarias: Medicina, Psicología y Enfermería han analizado las repercusiones sobre el desarrollo psicológico procedentes de una incorrecta integración social en el individuo (Landeta \& Breva, 2000).

La revisión de la literatura pone de manifiesto la falta de unanimidad y consenso a la hora de establecer y definir las características del apoyo social, se refieren tanto a aspectos objetivos del apoyo social (existencia y número de familiares, frecuencia de contactos y existencia o no de redes sociales de apoyo) como a aspectos subjetivos, relacionados con la percepción que tiene el individuo y la satisfacción por la dimensión social de su vida (Kervyn, Yzerbyt, Judd, \& Nunes, 2009).

\subsection{Aproximación histórica de la conceptualización del apoyo social}

A lo largo de la historia numerosos autores definen y experimentan cómo el concepto de "apoyo social" (AS), interfiere en los diferentes aspectos psicosociales del ser humano desde una perspectiva positiva y negativa.

En la antigua Grecia, alrededor del año 350 a.C., Aristóteles afirmaba que la amistad era una necesidad humana básica catalogando al hombre como un ser social por naturaleza (Samaranch, 1991). 
Hipócrates señala en el siglo Il a. C. la importancia de los procesos sociales y otros factores ambientales en el progreso de la enfermedad (Landeta \& Breva, 2000).

En 1536, el médico y científico Paracelso catalogaba y prescribía el amor como, posiblemente, la mejor medicina para un gran número de enfermedades.

Los primeros estudios sistemáticos y científicos que descubren los aspectos sociales como parte trascendental del bienestar del individuo, se publican a finales del siglo XIX y principios del siglo XX (Gracia, Herrero, \& Musitu, 1995).

Los primeros estudios epidemiológicos que tenían como objetivo relacionar el AS y la salud, planteando el comienzo de la evidencia científica sobre este tema, fueron elaborados por Émile Durkheim quien, en su obra El Suicidio (Durkheim, 1897), destacaba la relación existente entre el matrimonio y la pertinencia a grupos religiosos como fuente de AS y cómo estos elementos resultaban protectores frente la a parición de conductas autodestructivas. Émile Durkeheim investigó, a su vez, el concepto de integración social, matizando que la pérdida de integración social o anomia, potenciada por las nuevas sociedades industriales emergentes, era incompatible con el bienestar del individuo (Durkheim, 1897).

A comienzos del siglo XX se profundizó en el estudio científico del apoyo social, que anteriormente había iniciado Émile Durkeheim. La escuela de Chicago, fundada por Robert Park, Ernest Burguess y Roderick McKenzei, fue el lugar donde se agruparon esas primeras investigaciones. Estos autores enfatizaron el aspecto negativo de la falta de AS y su repercusión en el bienestar físico y/o psicológico de la persona, obviando el estudio de los posibles beneficios que pudieran resultar en el individuo el aumento del AS.

A finales de los setenta, las líneas de investigación se bifurcan en dos aspectos diferenciadores, aunque ambos tenían como objetivo averiguar el papel que desempeñaba el AS en la muerte de las personas.

La primera línea de investigación la formarían los autores que defienden la presencia de un efecto global del AS, basado en la existencia de una integración social de la persona dentro de su sistema. Autores como Berkman y Syme (1979) eran integrantes de esta línea de investigación, 
tenían como objetivo precisar el concepto de apoyo social, que hasta entonces no estaba del todo definido y, a su vez, relacionarlo con el fallecimiento de las personas. Los estudios de Berkman y Syme (1979) unidos al Índice de Red Social (Social Network Index) desarrollado por ellos, fueron referentes y punto de inicio para los estudios en años posteriores (Orth-Gomér, 1994; Schoenbach, Kaplan, Fredman, \& Kleinbaum, 1986).

Las investigaciones posteriores, con muestras de diferentes características, corroboraron los resultados obtenidos previamente por Berkman y Syme (Gottlieb, 1983). Estas investigaciones estipulan que las personas con poco apoyo social tienen mayor riesgo de experimentar estresores ambientales que aquellas que están socialmente integradas o que tienen acceso al a poyo en caso de necesitarlo. Según Vaux (1988), el mecanismo de actuación dependería de los efectos acumulativos de las interacciones sociales y de la simple existencia de esas relaciones.

La línea de investigación mencionada con anterioridad, definía la estructura social como "una serie de nodos o uniones que están relacionados por una o más formas de relaciones específicas entre ellos" (L. F. Berkman \& Syme, 1979). Según Ganster \& Victor (1988), la relación social en la que se encuentra involucrado el individuo (familia, trabajo, amistades...) serán elementos incluidos en los nodos o uniones.

Esta perspectiva estructural del concepto del apoyo social ha generado nuevos instrumentos de medida validados, que ofrecen mayor información sobre la estructura de ese sistema social, facilitando la cuantificación de la red social en cada persona. Autores como Cohen \& Wills (1985) exponen que hablar de los problemas propios con otras personas (apoyo evolutivo) o incrementar la autoestima mejoría la adaptación de la persona en cualquier situación estresante.

En definitiva, lo que intentan demostrar los investigadores que basan sus estudios en esta línea de investigación es determinar el efecto directo que el AS tiene sobre la salud física y mental de las personas, buscando como objetivo general, medir y cuantificar los efectos que las relaciones sociales tienen sobre la morbilidad y la mortalidad de los individuos.

Una segunda línea de investigación, que se desarrolló a partir de los años sesenta, fue la primera en considerar las relaciones interpersonales como modulador de la aparición de los eventos estresantes y sus conse- 
cuencias nocivas para la salud de las personas. Autores precursores de esta teoría fueron Cassel (1976) y Cobb (1976). Para estos autores, la presencia de una contribución social importante en el individuo reduce las consecuencias negativas derivadas de la experiencia de estrés. El efecto amortiguador del AS, según plantean los autores defensores de esta línea de investigación, se basa en la capacidad que tiene el AS para disminuir la evolución de una situación estresante mediante la provisión de soluciones al problema, disminuyendo la respuesta del sistema neuroendocrino, facilitando de esta manera que la gente sea menos reactiva al estrés percibido, o bien facilitando la realización de conductas saludables (House, 1981). Cassel, después de desarrollar sus investigaciones abordando el apoyo social desde esa línea de investigación, llega a la conclusión que si se produce un cambio en las condiciones ambientales cercanas al individuo, quizás se modifique la vulnerabilidad de los individuos a la enfermedad. El autor pone de manifiesto, por primera vez, la influencia del ambiente en los procesos metabólicos (Cassel, 1976). Otra de las conclusiones de los estudios de Cassel fue que las relaciones sociales afianzadas contribuyen a paliar los efectos negativos de los eventos estresantes. Cobb (1976) intenta perfeccionar la medición y cuantificación del AS en el individuo, desde una perspectiva clínica y teniendo como objetivo buscar la relación existente entre el AS y el estrés. Según define Cobb, el estudio del AS puede proporcionar información acerca de los sentimientos que tiene un individuo en su percepción de la valoración y estimación que le ofrecen sus seres queridos. Es lo que se ha denominado "La hipótesis del efecto amortiguador" ("The buffering hypothesis") (Cobb, 1976; S. Cohen \& Wills, 1985). Esta hipótesis afirma que el estrés psicosocial tendrá efectos negativos sobre la salud y el bienestar de aquellas personas que no tengan apoyo social, mientras que estos efectos negativos se reducirán en aquellas personas con fuertes apoyos sociales. En contraste, el AS no influirá en aquellas personas que no estén sometidas a estrés.

Los estudios dan a entender que las personas que han soportado períodos de estrés se recuperan antes y alcanzan un mejor estado de salud y bienestar si han recibido AS (Dura, 1991).

La hipótesis que defiende Cobb intenta explicar que el AS no influye directamente ni sobre la salud ni sobre los estresores, su efecto es amor- 
tiguar el impacto de los eventos estresores sobre la salud de las personas, y por lo tanto, de manera indirecta, influiría sobre la salud de los seres humanos. En revisiones realizadas previamente sobre la evidencia empírica del estudio del AS, como la realizada por Payne \& Jones (1987), catalogan los estudios de Cobb como una tercera línea de investigación.

Payne \& Jones (1987) concluyen en su revisión que, sin embargo, existen tanto estudios que afirman la hipótesis del efecto amortiguador como estudios que no logran verificarla; no obstante, la balanza parece inclinarse hacia los segundos. A pesar de ello, existen estudios que continúan sobreestimando la evidencia a favor de "The buffering hypothesis" (S. Cohen \& Wills, 1985; Thoits, 1982).

En resumen, estas investigaciones han sido los cimientos para ampliar el conocimiento, estudio e intervenciones del concepto de AS y su relación con la salud de las personas.

Siguiendo con el repaso histórico sobre la evolución y concepto del AS llegamos a la actualidad, donde se busca no solo relacionar el AS y la enfermedad, sino en otros ámbitos como el laboral, donde autores como Díaz (2014), destaca en sus investigaciones la importancia que posee el AS para disminuir determinadas características negativas del burnout en él, concluyendo que un menor AS percibido de familiares se asocia a un mayor cansancio emocional a lo largo de la vida laboral .

Se siguen manteniendo dos líneas de investigación que matizan dicho concepto desde dos perspectivas diferentes: Ia primera que establece el efecto directo del AS sobre la salud de las personas, y la segunda que defiende un efecto amortiguador del AS en la salud (Landeta \& Breva, 2000).

Evocando la idea de Aristóteles, anteriormente mencionada, se intenta con esas investigaciones prevenir el origen de la enfermedad realizando una intervención sobre el AS.

\subsubsection{Definición de apoyo social}

No existe en la actualidad una definición de AS aceptada por todos los autores, como se expuso en el apartado anterior. Las diferentes líneas 
de investigación han definido el concepto de AS desde una perspectiva diferente.

El AS es un concepto ambiguo desde su definición hasta el uso de la terminología para referirse a él, términos tales como "relaciones sociales", "redes sociales", "integración social”, "vínculos sociales” y otros son utilizados indistintamente, no refiriéndose esencialmente a los mismos (Castro, Campero, \& Hernández, 1997).

El AS es un concepto multidimensional y su realidad en sí misma es un proceso que se desarrolla y se transforma a través de las interacciones que se constituyen entre los sujetos y sus redes sociales (Alemán Ruiz, 2013).

Las definiciones acuñadas por los principales investigadores relacionados con el concepto de AS, se han centrado en describir y destacar aspectos positivos o negativos, subjetivos u objetivos en función de la línea de investigación a la que pertenece cada autor.

Las definiciones aportadas por los autores más relevantes son las siguientes:

Caplan (1974) define el AS como "la guía que unas personas proporcionan a otras y le permiten manejar emocionalmente un suceso estresante" (p. 139) (citado por Díaz, 2014). Caplan expone en su definición que existen cuatro tipos de AS: tangible objetivo, psicológico objetivo, tangible subjetivo y psicológico subjetivo. Matizando que lo tangible son los recursos, lo psicológico son cogniciones, lo objetivo son conductas y lo subjetivo percepciones (Caplan, 1974).

J. House, Wells, \& Landerman (1979) lo detalla como un intercambio entre dos o más individuos en el que se suministra una ayuda instrumental, un soporte informacional (información para solventar problemas), un alcance emocional o un soporte estimativo de la acción de las personas involucradas en la red.

Thoits (1982) lo define como el nivel en que las necesidades sociales básicas del sujeto son satisfechas mediante la interacción con otros, suministrando apoyo social emocional o instrumental.

Gottlieb detalla el AS como "una información verbal y no verbal, ayuda tangible o inferida y que tiene efectos conductuales y emocionales beneficiosos para el receptor" (citado por Barrón, Lozano, Chacón, \& Chacón, 1988, p. 209). 
Shumaker \& Brownell (1984) lo definen como "un intercambio, al menos, entre dos individuos, con el objetivo percibido por el receptor de incrementar su bienestar" (p. 11).

Según Sarason, Sarason, \& Hacker (1985) el AS "es un término referido a la existencia o disponibilidad de personas en las cuales se puede confiar o contar en períodos de necesidad, que proveen al individuo de amor, preocupación y valor personal" (p. 469).

Vaux (1988) establece que el AS presenta características de interacción y transición de recursos de la red de soporte, conductas de apoyo y estimaciones del apoyo.

Bowling (1991) define el AS como el proceso participativo en el que la persona alcanza apoyo emocional, instrumental o económico de la red social que integra.

Lin, Ye, \& Ensel (1999) definen el AS como "el conjunto de provisiones expresivas o instrumentales proporcionadas por la comunidad, las redes sociales y las personas de confianza. Estas provisiones se pueden producir tanto en situaciones cotidianas como de crisis, distingue niveles comunitarios, redes sociales o nivel íntimo" (p. 346).

Bellón Saameño, Delgado Sánchez, Luna del Castillo \& Lardelli Claret (1996) definen el AS como un grupo de aspectos cualitativos o funcionales de soporte, que son realizados por la red de apoyo o red social, que a su vez representan las características cuantitativas o estructurales del apoyo social, siendo dos elementos desiguales e independientes.

La proliferación de definiciones de AS, como se ha mencionado con anterioridad, comienza desde finales de los años setenta, se prolonga hasta mediados de los ochenta, y desde entonces parece haberse estancado. Es por ello que en la actualidad existen diferentes perspectivas para medir, intervenir y cuantificar cualitativamente o cuantitativamente el AS en el individuo, en función de la definición que usemos como base del estudio. Estableciendo como nexo de unión, entre todas las definiciones, la interrelación del individuo con las personas que le rodean, permitiendo de esta manera reforzar el sentido de valía y ser querido del individuo, al percibirse a sí mismo como miembro aceptado de un grupo social (Dura, 1991). 


\subsection{Dimensiones del apoyo social}

Respecto a las cualidades y características que posee el AS, para poder entender y contextualizar sus componentes, se deben definir las dimensiones del AS y sus componentes más importantes. En consonancia con la multitud de definiciones que los diferentes autores han hecho del constructor AS, también han creado diferentes teorías para definir las dimensiones del AS.

Caplan en 1974 ya acuñaba la característica multidimensional del AS, utilizando el concepto de AS objetivo y AS subjetivo.

En la investigación efectuada por King, Mattimore, King, \& Adams (1995) se destaca que los autores más relevantes que han investigado sobre el concepto de AS concuerdan en dos grandes segmentaciones, en relación con los tipos de apoyo, el emocional y el instrumental. El emocional o socioemocional contendría conductas de afecto y cuidado, y el instrumental o tangible relacionado con conductas de ayuda o tangible.

Se pueden exponer estas dos dimensiones, que clásicamente han definido el AS, como las describe Alonso Fachado (2009), basándose en las obras de Cobb (1976); S. Cohen \& Wills (1985); De la Revilla Ahumada, L., Luna del Castillo, J., Bailón Muñoz, E., Medina Moruno, (2005); Dolbier \& Steinhardt (2000); Livhits et al. (2011); Sherbourne \& Stewart (1991); Weiss (1974).

\subsubsection{Apoyo social estructural o cuantitativo}

También denominado red social, se refiere a la cuantía de vínculos sociales o número de individuos a los que consigue recurrir la persona para ayudarle a solucionar las dificultades planteadas (familia, amigos, situación marital o pertenencia al grupo de pares), y la interconexión entre estas redes. Esta red social poseerá unas tipologías en relación con el tamaño, periodicidad de contactos, composición, consistencia (grado en que los miembros de la red pertenecen simultáneamente a otras), parentesco, homogeneidad (semejanza o incongruencia entre los miembros de la red) y fuerza (grado de intimidad). En relación con estas cualidades, 
una red social consigue solucionar mejor unas necesidades que otras (Alonso Fachado, 2009).

\subsubsection{Apoyo funcional o cualitativo}

Posee un componente subjetivo y describe las percepciones de disponibilidad de soporte. Cobb (1976) la concibe como "la percepción que lleva el individuo a creer que lo cuidan, que es amado, estimado y valorado, que pertenece a una red de comunicaciones y obligaciones mutuas" (p. 300). Las funciones más significativas son emocional, informativa, instrumental afectivo e interacción social positiva (Alonso Fachado, 2009).

Pero la ambigüedad de investigaciones y definiciones hace que, por ejemplo, autores como Menéndez Villalva et al. (2003) hagan referencia a J. S. House (1981) definiendo cuatro tipologías de apoyo: instrumental, tangible o material (conductas claramente destinadas a enmendar el problema de la persona receptora o ayuda en las tareas); emocional (signos de empatía, amor y confianza, ayuda para enfrentarse las emociones negativas); informacional o informativo (recoger información ventajosa para afrontar el problema), y evaluativo o valorativo (información notable para la autoevaluación o las comparaciones sociales, descartando cualquier aspecto afectivo que lograra unirse a esta información, ya que siendo de ese modo se trataría de apoyo emocional) (Alemán Ruiz, 2013).

Las dimensiones del AS también resultan ambiguas a la hora de definir una sola teoría que sea aceptada por todos los investigadores, aunque cabe destacar la teoría de las dimensiones de Tardy (1985), que intenta resumir y representar las dimensiones del AS mediante un diagrama de árbol formado por cinco dimensiones, que establece las diferentes elecciones disponibles en la valoración del apoyo social, como se puede apreciar el Figura 1.

Esta figura, aunque no intenta ser exhaustiva, sirve como inicio para encuadrar los trabajos de investigación sobre apoyo social realizados desde diferentes aspectos de estudio y niveles de análisis (Terol M et al., 2004).

Tardy (1985) enumera las siguientes dimensiones:

- Primera dimensión (Dirección). Se refiere a la bidireccionalidad en el apoyo social, que puede ser provisto o recibido. En esta dimen- 


\section{Figura 1. Dimensiones del apoyo social}

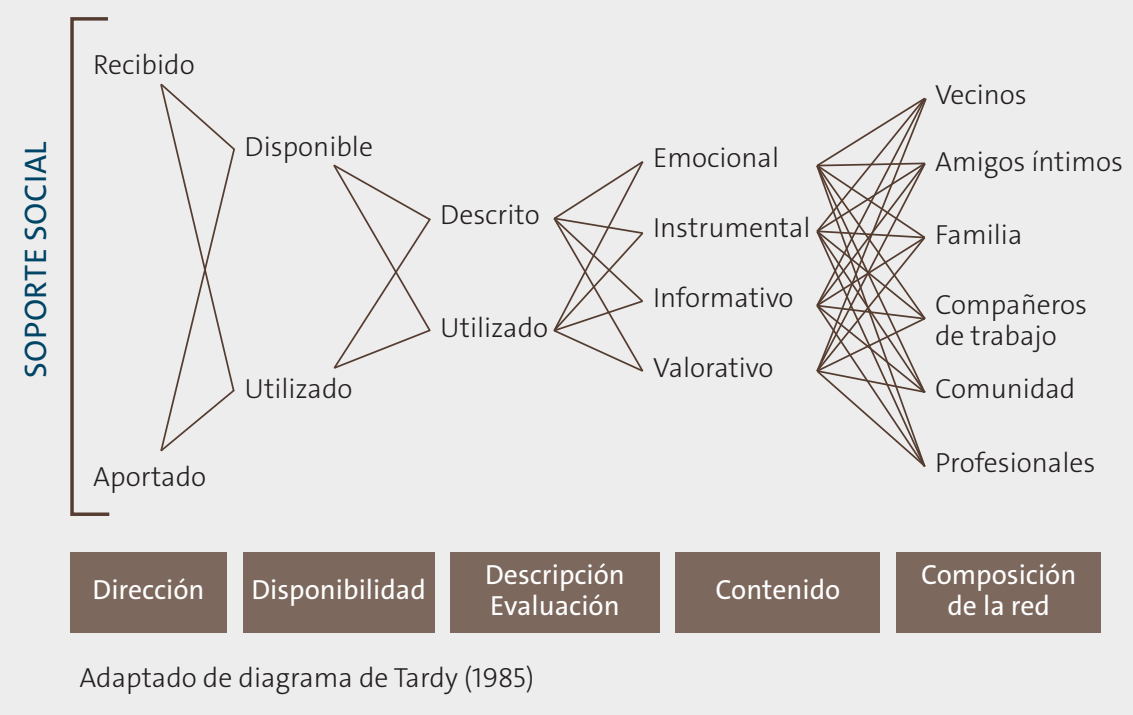

sión se establece desde dónde se valora el apoyo, bien desde quien lo provee o bien desde quien lo recibe. Los investigadores pueden disipar entre una, otra o ambas. Respecto al informe sobre apoyo desde el receptor, se refiere al apoyo recibido, en cambio cuando el informe se ejecuta desde el proveedor se hace referencia al apoyo provisto. Ambas situaciones admiten un informe subjetivo y, por consiguiente, es apoyo percibido por una u otra fuente (Winemiller, Mitchell, Sutliff, \& Cline, 1993). A pesar de que la mayoría de las investigaciones seleccionan quién adopta el apoyo como fuente de evaluación, contrastar la percepción de apoyo entre receptor y proveedor origina un gran interés en la actualidad (Terol M. et al., 2004).

- Segunda dimensión (Disposición). Por una parte se relaciona con la valoración del apoyo disponible o accesible frente a circunstancias hipotéticas determinadas; y por otro lado, está la estimación del apoyo real, el que se ha ofrecido o se está ofreciendo ante una entorno concreto, o en un determinado espacio de tiempo concerniente con la ocurrencia de un suceso estresante. Dichas evalua- 
ciones son factibles e incluso complementarias, dando lugar a la posibilidad de contrastar la disponibilidad del apoyo con la ocurrencia real del mismo. Así, podríamos aproximarnos a uno de los desafíos en el análisis y definición del apoyo social, la predictibilidad de la disponibilidad de apoyo sobre las valoraciones de apoyo real frente a sucesos trascendentales estresantes (Tardy, 1985).

- Tercera dimensión (Descripción o evaluación). El apoyo descrito detalla las tareas o clases de apoyo. El apoyo evaluado muestra el ajuste del mismo en términos de satisfacción, evaluado desde el receptor o desde quien lo provee. La información de los provisores acerca de que sus acciones o conductas de apoyo resulta, o no, que desempeñen la función esperada, o que realmente sean ventajosos para el receptor, conseguiría también informar de la falta de adecuación del apoyo percibido por el proveedor.

Ambos aspectos, evaluación y descripción, ultiman con mayor exactitud la estimación del AS (Tardy, 1985).

- Cuarta dimensión (Contenidos). Distingue cuatro categorías de AS: emocional (se traduce en términos de expresiones de afecto, empatía, etc.); instrumental (acciones o suministrar materiales o servicios que se utilicen para solucionar problemas prácticos: colaborar en tareas de casa, dar dinero, etc.); informacional (aconsejar, informar, guiar, etc.), y valorativo o evaluativo (se facilita información no afectiva, para que las personas se midan a sí mismas con los comportamientos sociales). Tardy (1985) cataloga esta dimensión como la menos exhaustiva y, por consiguiente, establece que pueden existir otras muchas.

- Quinta dimensión (Redes). Determina la particularidad transaccional e interpersonal del apoyo incluyendo términos más específicos que son señalados en la bibliografía sobre apoyo social, como proveedores, fuentes y relaciones íntimas. Tardy (1985) escoge la palabra "redes", porque en su opinión, simboliza mejor la dimensión social del apoyo y abarca las diferentes formas en que se ha calculado.

Autores como Sherbourne (1988) delimitan cuatro dimensiones distintas de apoyo social: emocional/informacional, instrumental, afectivo e 
interacción social positiva; cada una de ellas con tipologías diferentes entre sí. En cambio, Norbeck, Lindsey, \& Carrieri (1981) defienden que las cuatro dimensiones del AS están correlacionadas entre sí y son muy difíciles de separar y definir individualmente.

En relación con los niveles de conceptualización, Alemán Ruiz (2013) señala la diferencia entre cuatro niveles:

a) El primer nivel es la cota más elemental en la conceptualización, se ubica el AS provisto, que es objetivo y que relaciona el AS con la pertenencia a una estructura social más extensa, refiriéndose a todas las relaciones sociales, destacando la idea de integración social. Es el soporte que un individuo recoge en un periodo concreto. De la misma manera, se constituyen dos categoría, el cuantitativo que se relaciona exclusivamente en el número y fuerza de la correlación específica con los otros; y el cualitativo que se centra en definir la calidad de las relaciones.

b) El segundo nivel representa el AS como ayuda percibida, siendo subjetivo, concerniente a la apreciación y vivencia de la persona del acceso a los recursos disponibles de apoyo para un momento determinado. Esta apreciación por sí misma puede reducir la capacidad estresora de un evento.

c) El tercer nivel se relaciona como la idoneidad para lo que la persona precisa, el desarrollo efectivo y preciso de los apoyos. Se fundamenta en el reajuste de las conductas de apoyo.

d) El cuarto nivel se centra en la uniformidad, es decir, la variabilidad de las fuentes de apoyo.

En este sentido, el AS se logra idear y valorar desde diferentes representaciones. Una perspectiva cuantitativa-estructural (o de integración social) se concentra en la cuantía de vínculos en la red social de la persona (por ejemplo: el estatus marital, la cantidad de amigos, la participación comunitaria); en cambio, desde un aspecto cualitativo-funcional, se establece la presencia de relaciones próximas y relevantes, así como la valoración que concibe la persona del apoyo disponible (por ejemplo: la calidad marital, la intimidad de las relaciones, la complacencia de necesidades personales). En consonancia con la evidencia disponible, tanto 
la cantidad como la calidad de apoyo social podrían poseer efectos significativos en el bienestar y la salud (Dolbier \& Steinhardt, 2000).

La diferenciación mencionada anteriormente se corresponde con otra diferencia común entre el apoyo recibido y el apoyo percibido. El apoyo recibido se corresponde con las cualidades de la red social en términos de sus extensiones estructurales y funcionales; en cambio, el apoyo percibido se refiere a la evaluación subjetiva de la persona respecto de la adecuación del a poyo suministrado por la red social. Por lo que se refiere a la investigación epidemiológica, tiende a privilegiar el apoyo recibido (estatus marital, participación social, trabajo fuera del hogar); por otra parte, la investigación en Psicología se concentra preferiblemente en la apreciación que tiene el individuo de ser apoyado por otros, independientemente de la precisión de tal percepción (Dolbier \& Steinhardt, 2000). La evidencia científica señala que la adecuación percibida del apoyo disponible podría ser un mejor predictor de consecuencias en la salud que la disponibilidad de personas (Helgeson, 1993; Norris \& Kaniasty, 1996).

Dada la multidimensionalidad del constructo, se hace preciso diferenciarlo de conceptos más exactos y concretos (Sarason, Sarason, \& Pierce, 1990), distinguiendo los conceptos de red social de apoyo, soporte social recibido y soporte social percibido.

La red de AS de un individuo engloba a las personas con las que el individuo establece relaciones sociales directas o aquellas a través de las cuales este obtiene apoyo (Pierce, Sarason, \& Sarason, 1996).

El soporte social recibido hace referencia al apoyo que un individuo recibe de los demás cuando se enfrenta a una situación inductora de estrés (Helgeson \& Lopez, 2010; Sarason et al., 1990).

El soporte social percibido es la apreciación cognitiva que hace el individuo respecto a quiénes le pueden suministrar una determinada ayuda en periodos de necesidad (Vega Angarita \& González Escobar, 2009).

\subsection{Apoyo social y salud}

Se debe comenzar recordando el concepto de salud, acuñado por la Organización Mundial de la Salud, en su Constitución, aprobada en la Con- 
ferencia Sanitaria Internacional de Salud de 1946, y que entró en vigor el 7 de abril de 1948 (Moreno, 2008): "La salud es un completo estado de bienestar físico, mental y social y no la mera ausencia de afecciones o enfermedades". Esta definición ha sido objeto de multitud de críticas, basadas todas ellas en la utopía de considerar la salud como un estado completo de bienestar. En este sentido, algunos autores reconocen que la mencionada definición de la OMS presenta un problema epistemológico importante y señalan la falta de clarificación y matiz a la hora de delimitar y concretar los conceptos de salud y bienestar, dentro de la propia definición (Navarro, 1998). No obstante, la principal controversia que tal definición suscita viene dada por el carácter subjetivo, implícito en el concepto de bienestar, situación que cada individuo podrá describir de una manera o de otra. Partiendo de esta definición, la posibilidad de medir y la producir indicadores económico-sociales adecuados para su representación (San Martín \& Pastor, 1989). Como así lo manifiestan autoras como Madel Luz (1979) argumentando que "no es necesario ni posible adoptar la poética definición de la OMS porque no tendríamos forma de medir, por la subjetividad implícita en la definición, la extensión de la ausencia de salud en la población brasilera a lo largo de su historia" (citado en Caponi \& Canguilhem, 1997). En definitiva, un concepto que desde sus inicios ha tenido detractores y defensores, autores como Canguilhem (1997) delimitan la definición del concepto de salud, determinando que la normalidad en la salud de las personas viene establecida, en gran medida, por el contexto y la época en la que se encuentre el individuo, y va más allá, explicando que la aparición de anomalías insignificantes en la salud que pueden sufrir los seres humanos pueden ser percibidas como situaciones normales.

Canguilhem establece que un malestar social no podrá ser catalogado como una patología si la persona que lo experimenta no lo percibe como tal, en ese sentido y según explica dicho autor, un extranjero que llega a un nuevo lugar para trabajar puede padecer un malestar social como proceso de acomodación al nuevo entorno, pero no tiene porqué afectarle a su salud, es decir, lo normal y lo patológico relacionado con el concepto de salud de la OMS no pueden ser estudiados de manera independiente sino en una íntima relación de dependencia de uno y otro. 
Existen otras definiciones que, de alguna manera, matizan ese sentido de salud y sociedad como la siguiente: "el logro del más alto nivel de bienestar físico, mental y social, y de capacidad de funcionamiento, que permitan los factores sociales en los que viven inmersos el individuo y la colectividad" (Salleras Sanmartí, 1990, p. 17).

\section{Relación entre apoyo social y salud}

Como se explicó con anterioridad, existen dos grandes modelos que asocian salud y apoyo social (AS).

El primero de ellos es el del efecto directo, cuyos defensores afirman que el AS afecta directamente al nivel de salud de las personas independientemente del efecto que dicho AS tenga sobre otras variables, como el estrés. En este modelo, el AS aumentaría el bienestar emocional y físico de los individuos, y tendría efectos sobre los procesos fisiopatológicos y psicológicos (Sheldon Cohen \& Syme, 1985).

El segundo, el modelo del efecto indirecto, incide en el aspecto modulador del AS sobre la salud, es decir, el AS amortiguaría el efecto en el estrés de las personas, y este, a su vez, mejoraría o empeoraría el estado de salud.

Los autores que desarrollan esta línea de investigación postulan que no hay interacción alguna entre AS y estrés; por tanto, un AS tendrá un efecto determinado sobre el individuo independientemente del estrés percibido (Castro et al., 1997). En este mismo sentido, otros estudios indican que solo en los casos de muy baja presencia de apoyo social se observa un descenso en el nivel de bienestar físico y/o mental (House, 1981); por consiguiente, ya no existe un aumento considerable del nivel de bienestar después de alcanzar un determinado nivel de AS. Algunos modelos causales llegan a mencionar que el aislamiento social actúa como estresor y, de ese modo, sería la causa directa de enfermedad. Por su parte, el AS no constituiría una causa directa sino que produciría una mejor percepción de la salud (Lisa F. Berkman, 1985; Sheldon Cohen \& Syme, 1985).

Este segundo modelo de apoyo social es también denominado "modelo del efecto amortiguador" (S. Cohen \& Wills, 1985; Gore, 1981). Los autores que defienden este modelo establecen que el AS actúa como va- 
riable "mediadora" en la relación entre estrés y enfermedad (Wheaton, 1985). Como expresan Castro \& Campero (1997), existen dos posibilidades por las cuales el AS es capaz de modular la relación entre estrés y enfermedad y, por tanto, afectar a la salud:

1) El AS puede producir una reorientación de la situación estresante en los individuos, que afrontarán la situación con técnicas no estresantes que, a su vez, evitarán la aparición de procesos psicológicos patológicos.

2) El AS impide que los individuos perciban como estresante una determinada situación al ser conscientes de la disposición personal de recursos materiales y emocionales que les permitirán afrontar dicha situación con un nivel de estrés menor que en el caso de otras persona que no disponga de ese AS.

La revisión bibliográfica realizada hasta el momento lleva a la misma controversia mencionada antes, que radica básicamente en el modelo elegido por los investigadores. AS es un término cuya definición genera a mbigüedad y falta de limitaciones, aunque esto no ha supuesto un obstáculo en el proceso empírico de los estudios de investigación, dado que se han obtenido resultados parecidos empleando un modelo $u$ otro en relación con el AS y la salud de las personas (Sheldon Cohen, 2004).

\subsubsection{Evidencia científica actual sobre el apoyo social y su relación con la salud}

Se ha realizado una búsqueda bibliográfica preliminar sobre la evidencia existente en la actualidad de los conceptos de AS y salud, usando las palabras claves según la terminología de Descriptores de Ciencias de la Salud (DeCS) en español, y Medical Subjects Headings (MeSH) en inglés, utilizando como operador boleano "and", que se obervan en la Tabla 1; a su vez, dichos descriptores deben aparecer en el título o en el resumen, periodo comprendido entre 1969 y la actualidad, sin límite greográfico, con filtro de idioma: español, inglés y portugués, fecha de realización de la búsqueda 10 de enero de 2017. 


\begin{tabular}{ll}
\hline \multicolumn{2}{l}{ Tabla 1. Descriptores controlados según nomenclatura DeCS y MeSH } \\
\hline DeCS & MeSH \\
\hline Apoyo social & Social Support \\
\hline Salud & Health \\
\hline Enfemedad & Disease \\
\hline Salud mental & Mental Health \\
\hline Práctica clínica basada en la evidencia & Evidence-Based Practice \\
\hline Enfermería & Nursing \\
\hline
\end{tabular}

Se han consultado las bases de datos Elton B. Stephens Company (EBSCO), Cumulative Index to Nursing and Allied Health Literature (CINAHL), Science direct, PubMed, Cuiden, Excerpta Medica Database (EMBASE), The Offshore Vessel Inspection Database (OVID), The Joanna Briggs Institute (JBI), Literatura Latinoamericana de Información en Ciencias de la Salud (LiLacs), Cochrane, Scientific Electronic Library Online (Scielo), Google Scholar, Índice Bibliográfico Español en Ciencias de la Salud (IBECS) y ClinicalKey como se muestra en la Tabla 2.

Tabla 2. Resumen de número artículos encontrados en la búsqueda bibliográfica con la palabra clave Social Support como concepto principal

\begin{tabular}{lrrrrrr}
\hline Base de datos & $\begin{array}{r}\text { Social } \\
\text { Support } \\
\text { AND } \\
\text { Health }\end{array}$ & $\begin{array}{r}\text { Social } \\
\text { Support } \\
\text { AND } \\
\text { Mental } \\
\text { Health }\end{array}$ & $\begin{array}{r}\text { Social } \\
\text { Support } \\
\text { AND } \\
\text { Disease }\end{array}$ & $\begin{array}{r}\text { Social } \\
\text { Support } \\
\text { AND } \\
\text { Evidence } \\
\text { Based } \\
\text { Practice }\end{array}$ & $\begin{array}{r}\text { Social } \\
\text { Support } \\
\text { AND } \\
\text { Nursing }\end{array}$ & $\begin{array}{r}\text { Total } \\
\text { artículos }\end{array}$ \\
\hline EBSCO-CINAHL & 3098 & 774 & 590 & 3 & 305 & 4770 \\
\hline Science direct & 8475 & 2068 & 2779 & 379 & 1463 & 15164 \\
\hline PubMed & 13203 & 3145 & 3716 & 15 & 1037 & 21116 \\
\hline Cuiden & 918 & 328 & 285 & 4 & 465 & 2000 \\
\hline EMBASE & 323 & 92 & 23 & 0 & 3 & 441 \\
\hline OVID & 1522 & 1069 & 1506 & 12 & 605 & 4714 \\
\hline JBI & 1 & 1 & 0 & 0 & 0 & 2 \\
\hline LilacS & 611 & 78 & 24 & 0 & 14 & 727 \\
\hline Cochrane & 1840 & 441 & 517 & 29 & 161 & 2988 \\
\hline Scielo & 1827 & 368 & 409 & 18 & 192 & 2814 \\
\hline Google Scholar & 4050 & 1090 & 625 & 2 & 336 & 6103 \\
\hline IBECS & 557 & 63 & 192 & 2 & 10 & 824 \\
\hline ClinicalKey & 657 & 442 & 322 & 210 & 167 & 1798 \\
\hline & & & & & &
\end{tabular}


Esta primera búsqueda general tiene como objetivo valorar, desde un punto de vista cuantitativo, la cantidad de estudios que relacionan los conceptos de AS y salud con la práctica clínica. Aún obteniendo una cantidad considerable de estudios en las diferentes bases de datos, al profundizar en su lectura muchos se alejan del concepto de AS y su relación directa con la salud o la enfermedad en la práctica clínica.

Como resumen cuantitativo de la investigación realizada hasta 2017 sobre el AS en la base de datos Scopus se puede observar en la Figura 2, el aumento exponencial de los trabajos que han tenido como título la palabra social support.

Así mismo, si se filtra el total de documentos encontrados que estén catalogados como propios de la disciplina enfermera, se observa un descenso significativo en el total de documentos, como se observa en la Figura 3.

Por otro lado, si se ordenan los resultados expuestos en la Figura 3 según el país de origen de los documentos, se puede apreciar claramente como Estados Unidos abarcar la mayoría de los estudios de investigación publicados con esos criterios (Figura 4).

Finalmente, se realiza un segundo filtrado según los siguientes criterios de inclusión:

- Utilización específica de los descriptores "apoyo social”, "salud” y "enfermedad", según la nomenclatura MeSH para bases de datos en inglés y DeCS para bases de datos en español.

- La palabra clave "AS" se interrelacionó con el operador boleano "and" a la palabra clave "salud" y a la palabra clave "enfermedad".

- Se ha realizado una búsqueda donde se añade a las palabras claves anteriores la palabra clave "enfermería" o "nursing", unido por el operador boleano "and" con dos posibilidades: que aparezcan el como palabras claves en el estudio de investigación o que aparezcan en el resumen del artículo.

- Se seleccinaron a priori aquellos estudios que presentaron un mayor nivel de evidencia tales como, revisiones sistemáticas, metaanálisis, ensayos clínicos aleatorizados, estudios descriptivos y cualitativos bien diseñados. No obstante, debido a la falta de estudios de mayor evidencia encontrada durante la revisión bibliográfica, se han incluido en la búsqueda revisiones narrativas de autores relevantes de ámbito internacional. 
Figura 2. Evolución de los documentos encontrados en la base de datos Scopus, con la palabra "social support" en el título

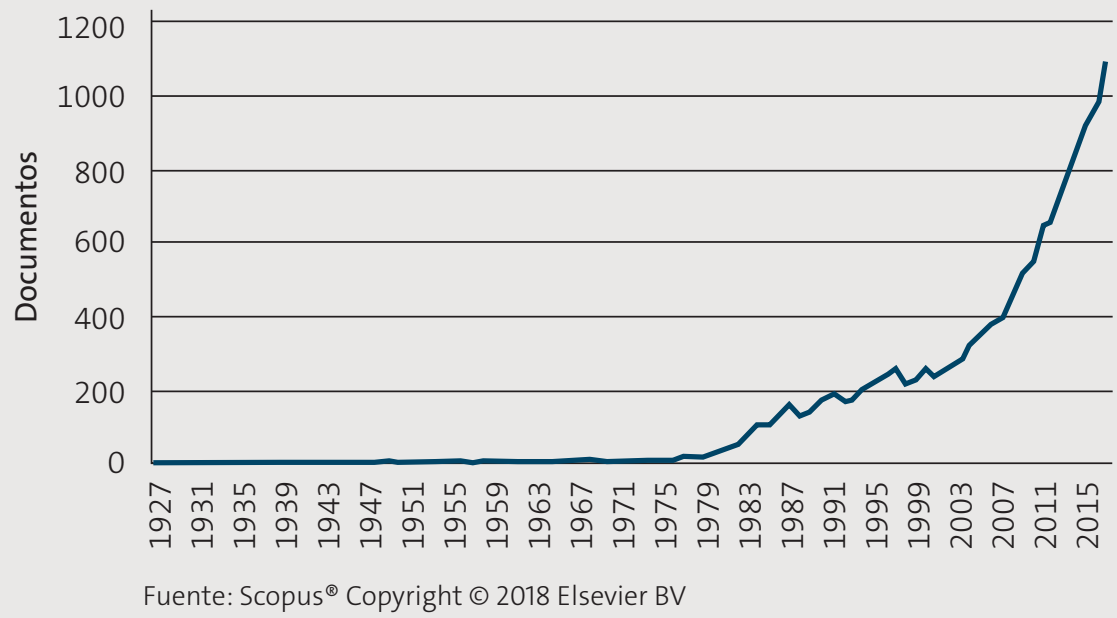

Figura 3. Documentos encontrados en la base de datos Scopus con el título "social support" pertenecientes a la disciplina enfermera

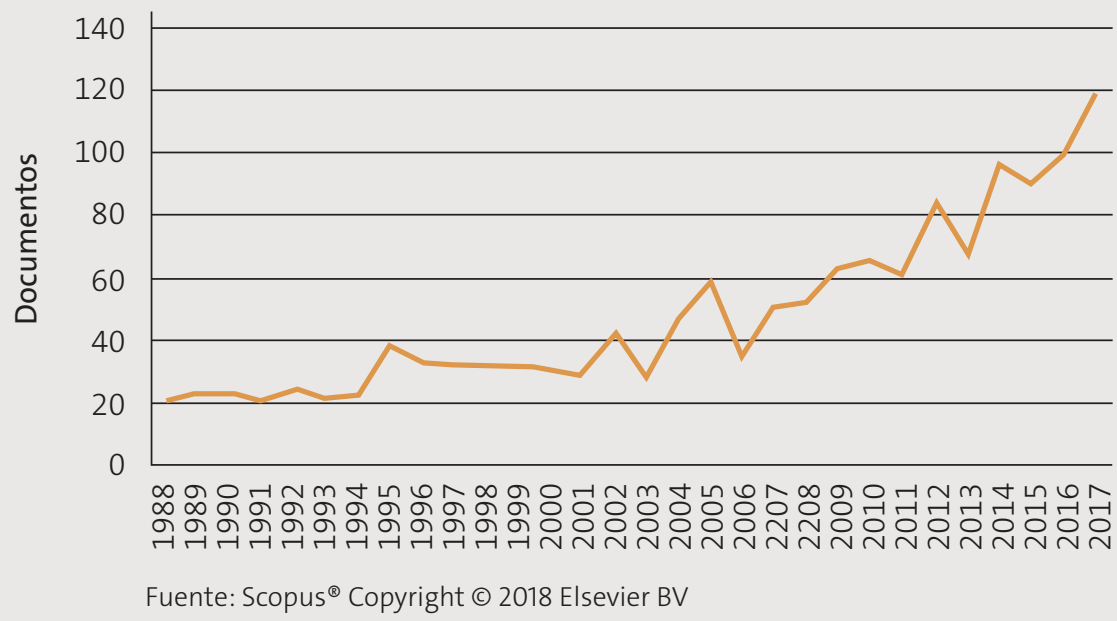

Con la filtros mencionados anteriormente activados se obtienen los resultados que se muestran en la Tabla 3. 
Figura 4. Documentos encontrados en la base de datos Scopus con el título "social support" pertenecientes a la disciplina enfermera, ordenados por países

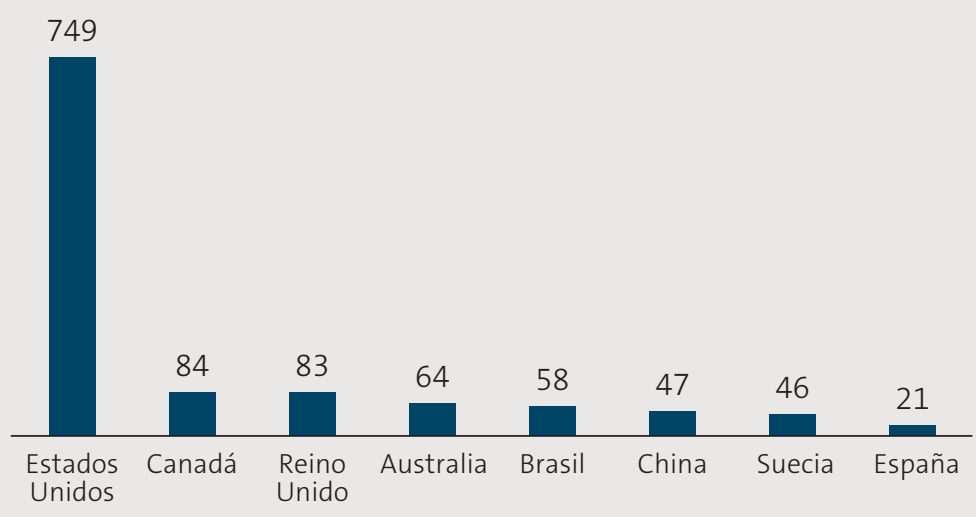

Fuente: Scopus ${ }^{\circledR}$ Copyright $\odot 2018$ Elsevier BV

Tabla 3. Resumen de número artículos encontrados en la búsqueda bibliográfica con la palabra clave Social Support como concepto principal II (filtrado)

\begin{tabular}{lrrr}
\hline Base de datos & $\begin{array}{r}\text { Social Support } \\
\text { AND Health and } \\
\text { Disease }\end{array}$ & $\begin{array}{r}\text { Social Support } \\
\text { AND Health and } \\
\text { Nursing }\end{array}$ & $\begin{array}{r}\text { Social Support } \\
\text { AND Health and } \\
\text { Nursing (abstract) }\end{array}$ \\
\hline EBSCO-CINAHL & 245 & 101 & 42 \\
\hline Science direct & 30 & 9 & 25 \\
\hline PubMed & 19 & 0 & 0 \\
\hline Cuiden & 0 & 0 & 0 \\
\hline EMBASE & 46 & 0 & 2 \\
\hline OVID & 40 & 0 & 0 \\
\hline JBI & 0 & 0 & 0 \\
\hline Lilacs & 0 & 0 & 0 \\
\hline Cochrane & 80 & 7 & 0 \\
\hline Scielo & 5 & 2 & 0 \\
\hline Google Scholar & 121 & 1 & 159 \\
\hline IBECS & 0 & 0 & 148 \\
\hline ClinicalKey & 102 & 0 & \\
\hline
\end{tabular}


Finalmente, se analizan con mayor detalle los resultados de la búsqueda en las distintas bases empleadas se exponen en la Tabla 3. Estrategia de búsqueda, según el flujograma reflejado en la Figura 5.

Figura 5. Selección definitiva de referencias concepto principal apoyo social

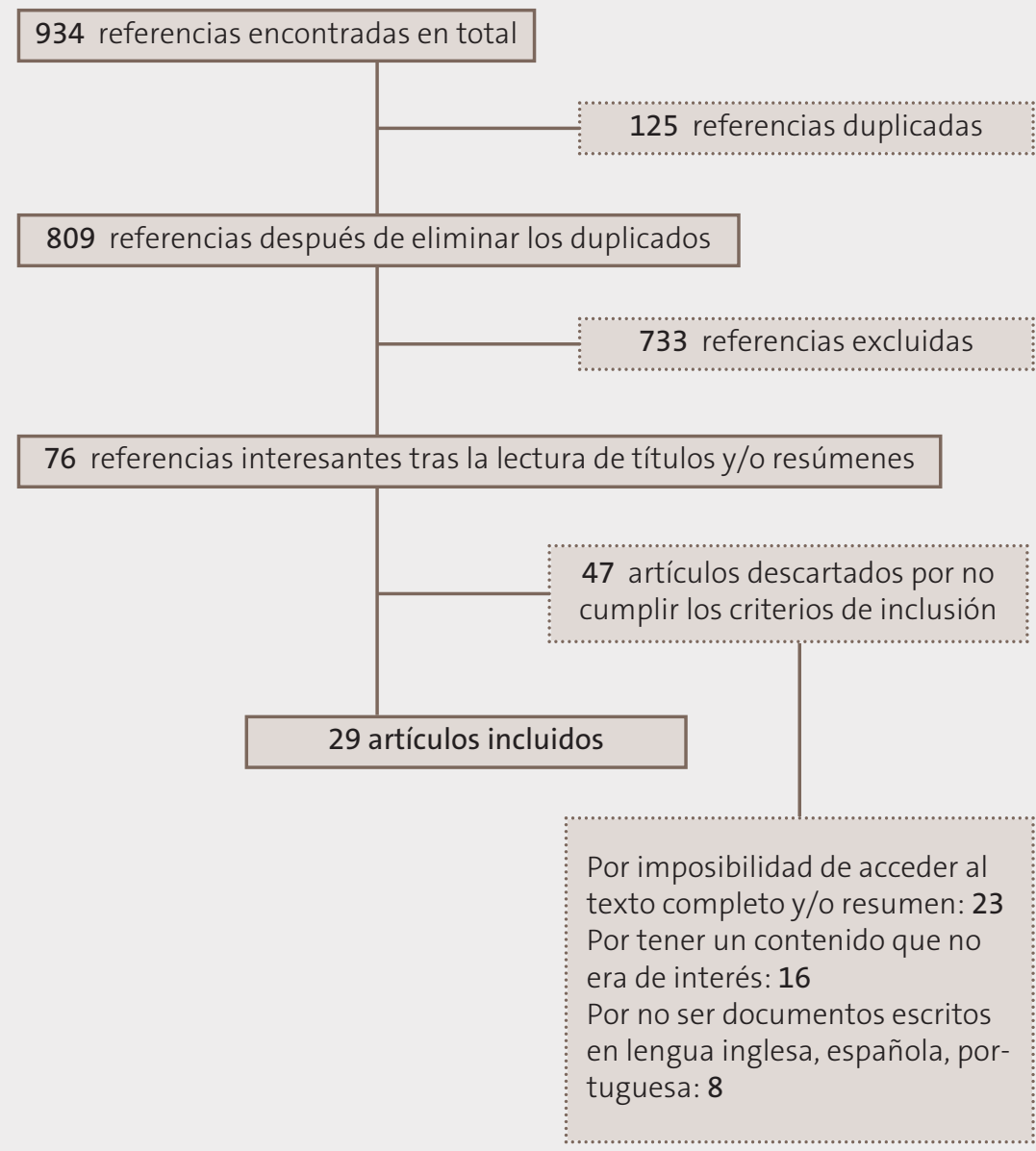

En la Tabla 4 se muestran los documentos seleccionados con su respectivo nivel de evidencia y recomendación según los criterios del epidemiólogo Sackett (Manterola, Asenjo-Lobos, \& Otzen, 2014). 


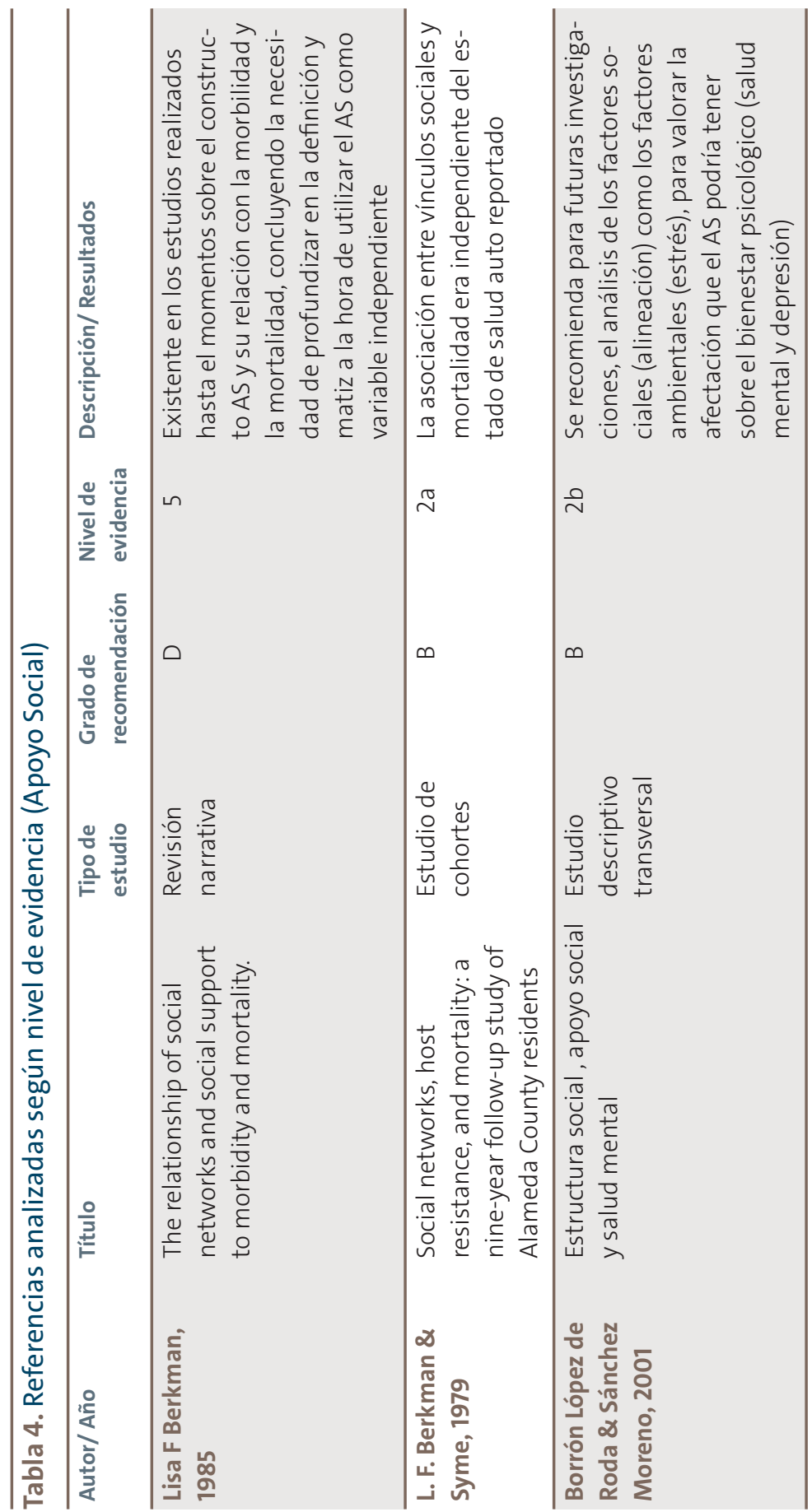




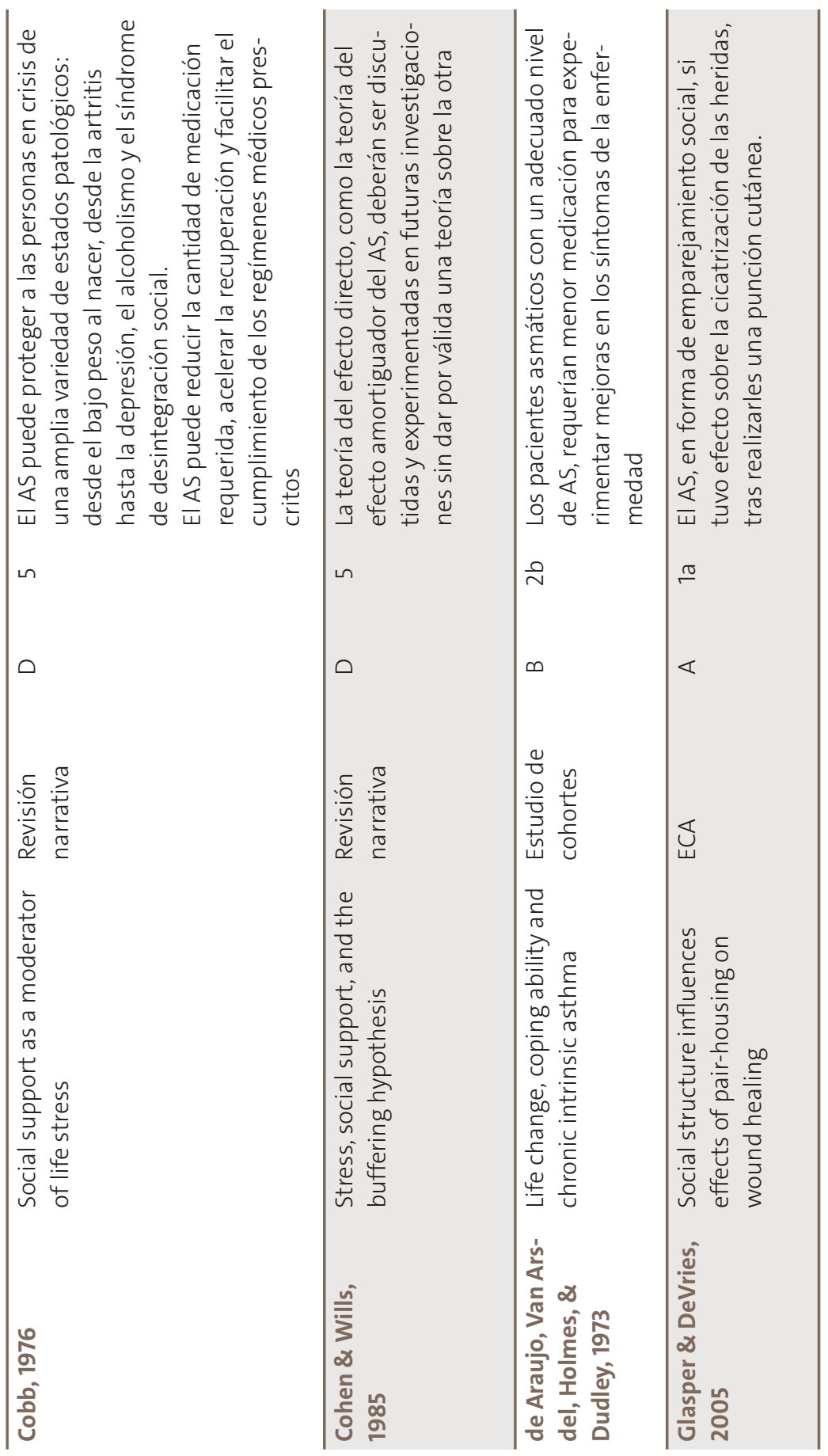




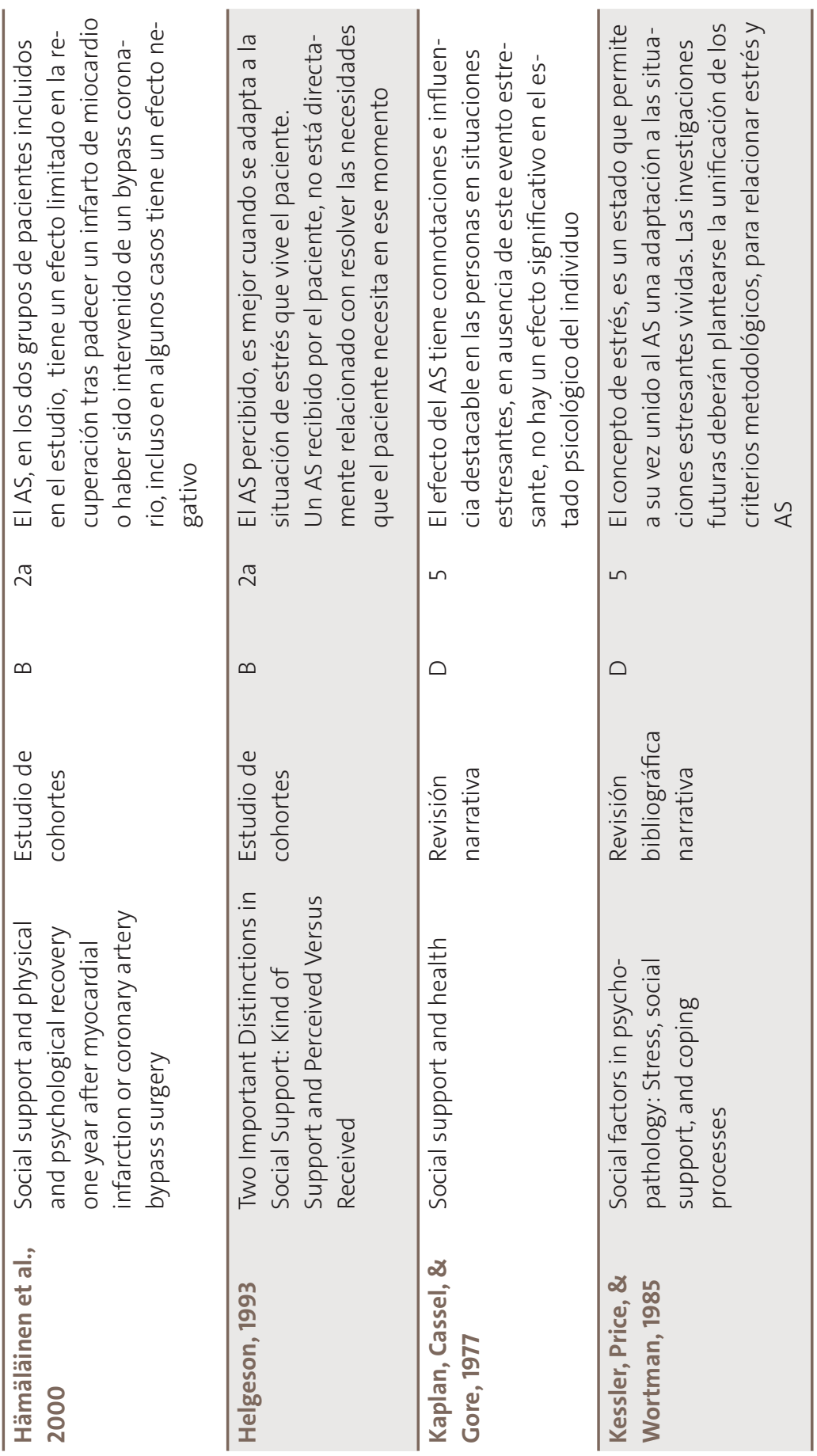




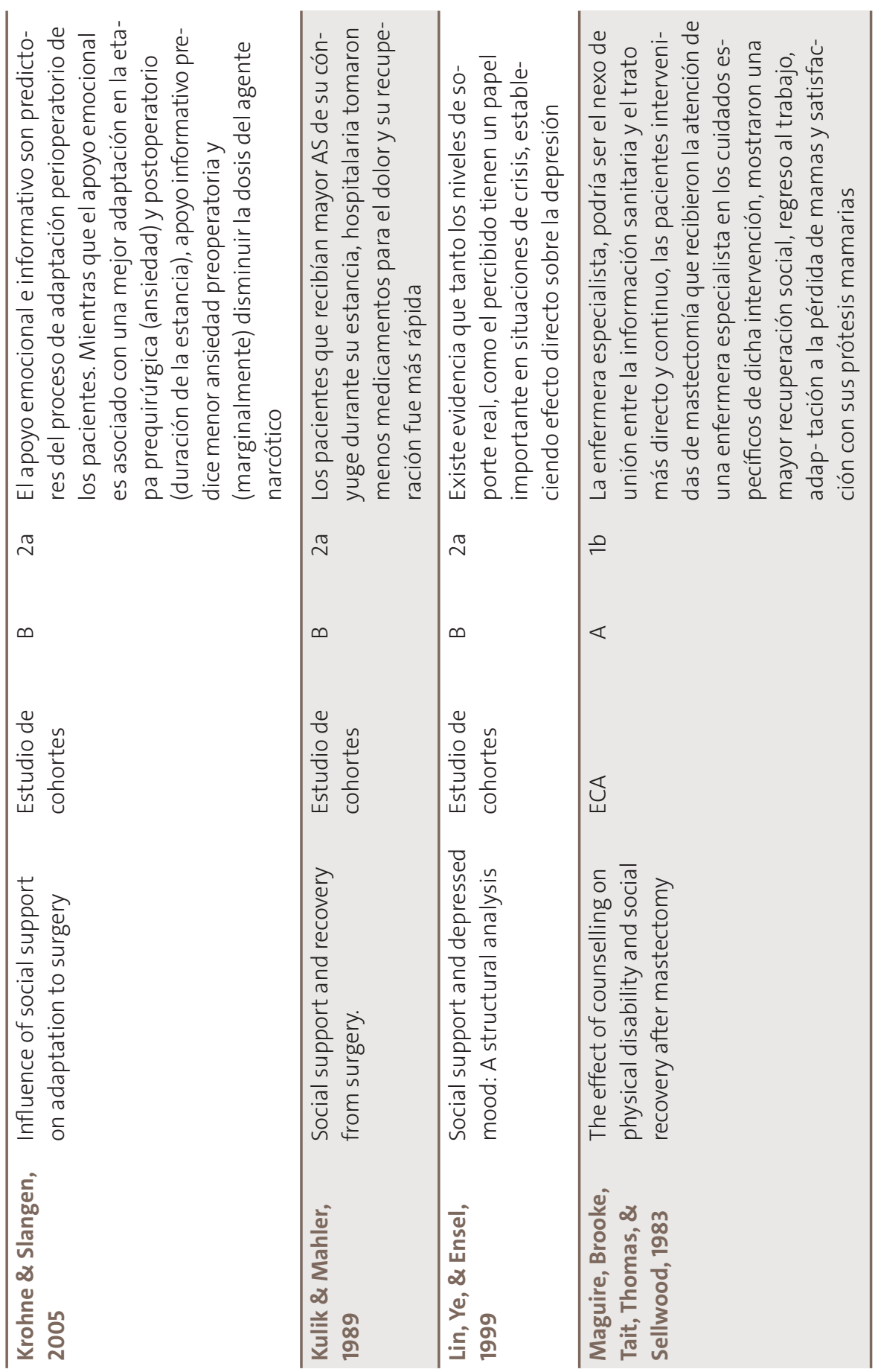




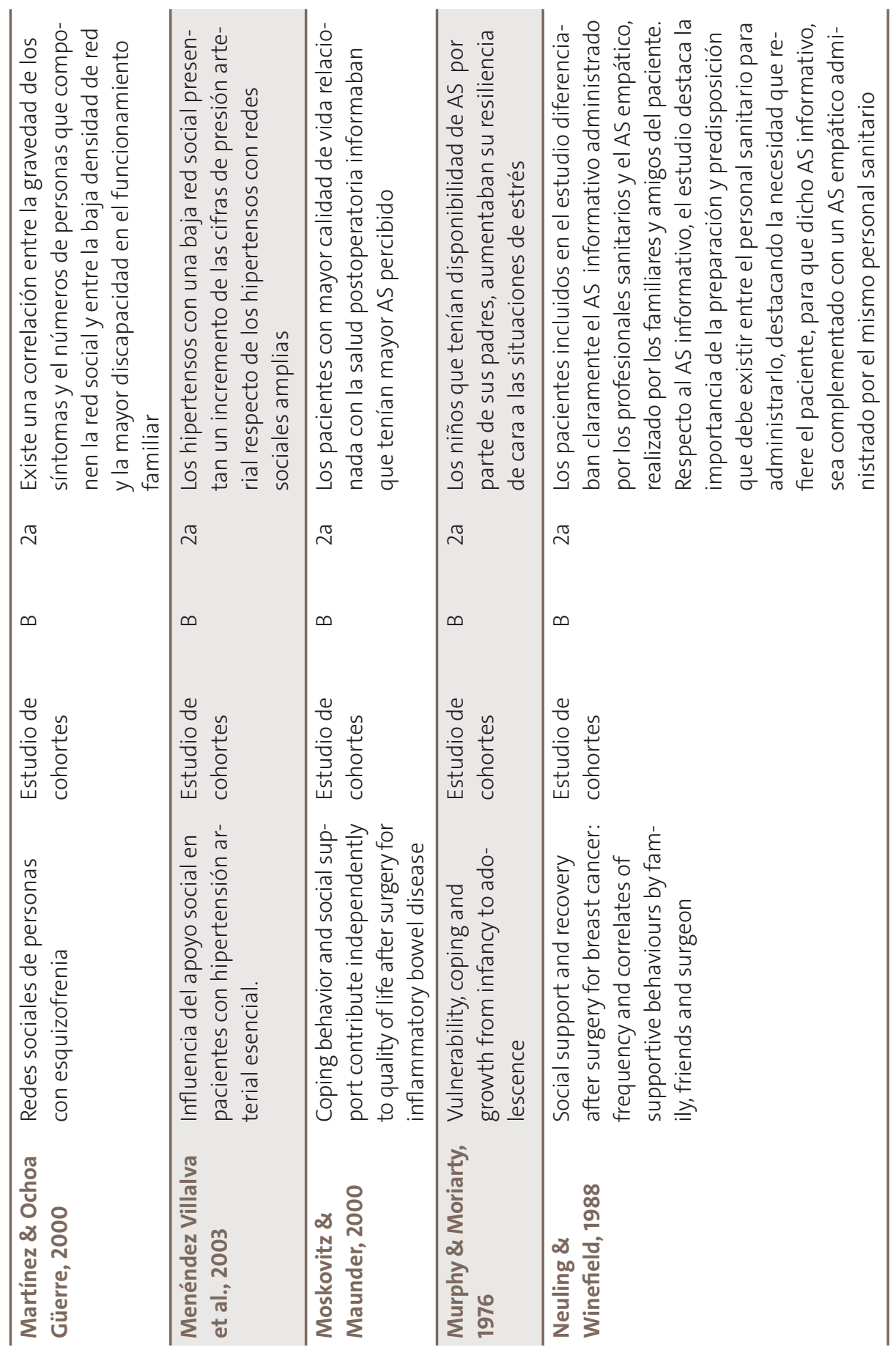




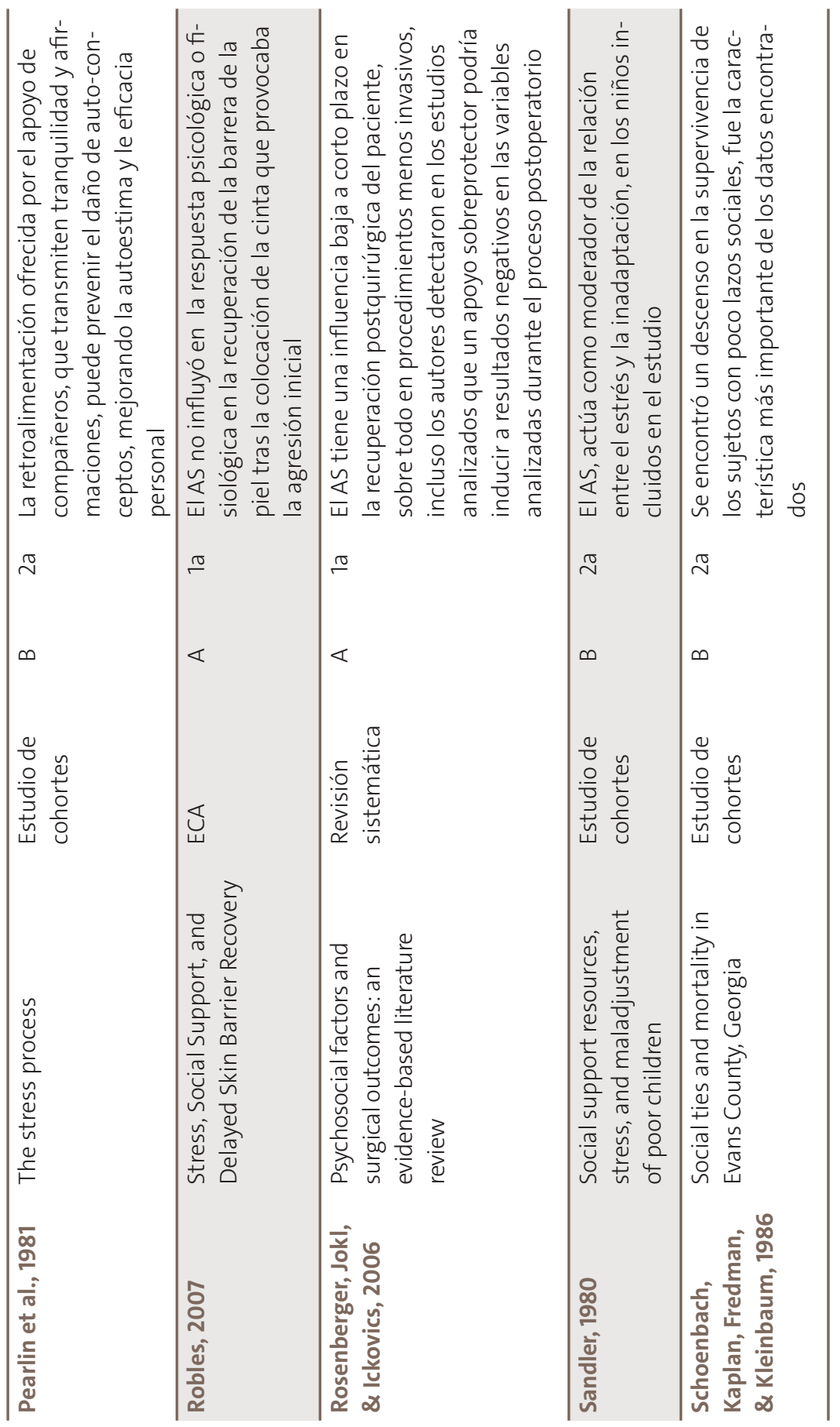




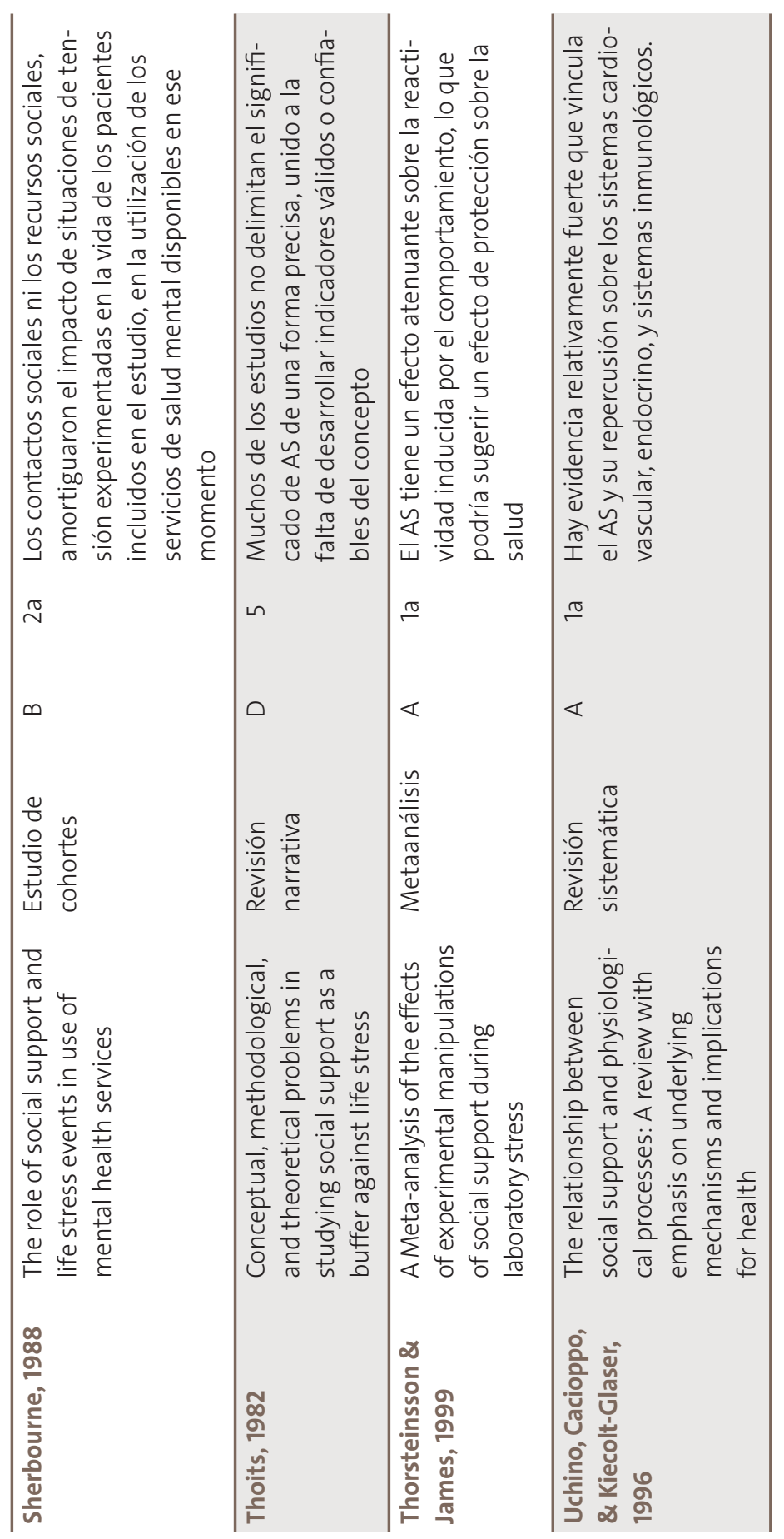


Seguidamente, se hace un análisis en orden cronológico de los estudios de investigación encontrados que cumplen los criterios de selección mencionados anteriormente, y que permiten el acceso a texto completo desde la biblioteca de la Universidad Jaume I y la biblioteca del Servicio Canario de Salud.

De esta manera, se expone la evolución del concepto de AS en relación con la salud desde una perspectiva empírica en orden cronológico.

El primero de los autores más influyentes sobre el estudio empírico del AS y su relación con la salud es John Bowlby (1969), que en años sucesivos publicaría varios trabajos que complementan su línea de investigación (Bowlby, 1969, 1973, 1982).

Este autor establece que la disponibilidad de otras personas y el apego, basadas en la presencia de un adecuado apoyo social en la niñez, capacitan para aceptar la ayuda de otros y llegar a ser autosuficientes. Defiende que si no está disponible este apoyo en la niñez, aumenta la probabilidad de tendencias psicopatológicas.

Cobb (1976) establecía como una posible hipótesis que

la evidencia de que las interacciones entre las personas de apoyo, tienen un efecto protector contra las consecuencias sanitarias del estrés de la vida. Parece que el soporte social puede proteger a las personas en crisis, a partir de una amplia variedad de estados patológicos: desde bajo peso al nacimiento hasta la muerte, en patologías como la tuberculosis, la artritis o la depresión. Por otra parte, el AS puede reducir la cantidad de medicación necesaria, acelerar la recuperación y facilitar el cumplimiento de los regímenes médicos prescritos (p. 300).

Estos serían los comienzos de los estudios empíricos que tenían como objetivo relacionar AS, salud y enfermedad.

Estudios en esta época con niños demostraron que aquellos que tenían disponibilidad de AS por parte de sus padres, aumentaban su resilieciencia de cara a las situaciones de estrés (Murphy \& Moriarty, 1976).

Un estudio realizado en Harvard a 268 estudiantes de género masculino descubrió que un entorno familiar de AS, en edades tempranas, se correlacionaba con adultos que presentan menos tasa de trastorno psiquiátrico (Vaillant, 1977). 
En 1979 se publica en el Condado de Alameda, California, un estudio que contó con una muestra de 6928 adultos con un seguimiento durante nueve años, que llegó a la conclusión que las personas que carecían de lazos sociales y comunitarios eran más propensas a morir que aquellos con más amplios contactos (L. F. Berkman \& Syme, 1979).

Sandler (1980) expone como resultados del experimento realizado con una muestra de 71 niños de una escuela infantil, que la presencia de los recursos de AS actuaban como moderador de la relación entre el estrés y la inadaptación. En ese mismo año y corroborando los hallazgos anteriores, Henderson (1980) llega a la conclusión de que una disminución en los lazos sociales podía, independientemente de otros factores, ser una causa de disfunción del comportamiento (Sarason \& Levine, 1983).

Pearlin, Menaghan, Lieberman, \& Mullan (1981) enuncian que en el ámbito psicológico, la retroalimentación ofrecida por el apoyo de compañeros que transmiten tranquilidad y afirmaciones podía prevenir el daño de auto-conceptos, mejorando la autoestima y le eficacia personal. Las posibles intervenciones de afrontamiento y AS podía tener un efecto indirecto disminuyendo, por ejemplo, la elevación de la depresión en los pacientes incluidos en el estudio.

En la década de los 70 y 80 no sólo existía evidencia sobre el efecto del AS en la niñez, también se crearon líneas de investigación que demostraban los efectos perjudiciales de la falta de AS en el adulto. Así, de Araujo, Van Arsdel, Holmes, \& Dudley (1973) evidenciaron que los pacientes asmáticos con un adecuado nivel de AS requerían menor medicación para experimentar mejoras en los síntomas de la enfermedad.

Es Thoits (1982), quien después de 20 años de investigaciones sobre el constructo AS, establece una serie de críticas a las diferentes investigaciones realizadas hasta la fecha.

Según Thoits, el intento de desarrollar el constructo AS, basado en la evidencia científica a través de las diferentes líneas de investigación existente, ha dado lugar a la aparición de una serie de limitaciones, que se exponen a continuación:

a) El AS no ha sido adecuadamente definido y contextualizado en los estudios realizados. 
b) La mayoría de las investigaciones han confundido efecto directo de acontecimientos de la vida del AS con el efecto interactivo (respaldo) de los eventos relacionados con el apoyo, dando lugar a posibles sesgos a favor de la hipótesis.

c) Las relaciones entre eventos, soporte y alteraciones psicológicas no han sido explicadas teóricamente.

Thoits explica e intenta matizar los problemas existentes en las investigaciones anteriores, y qué posibles soluciones se deben contemplar para sucesivos estudios.

Thoits enfatiza el hecho de que muchos de los estudios no delimitan el significado de AS de una forma precisa, unido a la falta de desarrollar indicadores válidos o confiables de este concepto.

Thoits destaca que las investigaciones anteriores también cometen un error al utilizar, en algunos casos, indicadores que no están relacionados directamente con el AS (por ejemplo, la falta de dinero para salir del paso, demasiadas responsabilidades o trabajo insatisfactorio); son, en todo caso, medidas de dificultades de la vida en lugar de indicadores de AS.

El autor matiza, y recomienda para futuras investigaciones, catalogar el constructo de AS como un concepto multidimensional.

Autores como Kaplan, Cassel, \& Gore (1977) van a destacar en la conceptualización multidisciplinar, definiendo el AS como "el grado de satisfacción de las necesidades sociales básicas (afecto, estima, pertenencia, etc.) a través de su interacción con otros individuos", esta definición amplía la visión multidimensional de AS, permitiendo al investigador poder abordar el concepto desde varios perspectivas, no solo el AS se basa en la ayuda socio-emocional sino también cabe investigar la prestación de ayuda instrumental.

Por último, la definición de Kaplan et al. (1977) establece que el AS no requiere de apoyo recíproco o simétrico; por consiguiente, maestros, consejeros, enfermeros, trabajadores sociales pueden ser miembros del sistema de AS de un individuo, además de su cónyuge, parientes o amigos, permitiendo al investigador medir propiedades estructurales del AS con respecto a la red social total, propiedades funcionales y estructurales percibidas por los individuos del estudio comparando las recibidas por 
sus familiares con las recibidas por sus amigos para satisfacer esa necesidad social básica, dimensiones que han sido obviadas por la mayoría de estudios anteriores.

\section{Confusión entre efecto directo del AS y efecto interactivo (respaldo)}

En este sentido, el estudio del AS, según Thoits debe diferenciar claramente el efecto directo que tiene en las vivencias de las personas y el efecto que las mismas vivencias pueden infundir en el AS. Por ello, las investigaciones que contemplan el estudio y cuantificación del AS, deben medirse antes del acontecimiento vital que precisa de AS o, en su defecto, valorar si ese acontecimiento ha sido vivido previamente y, por lo tanto, el AS percibido en sucesivas experiencias será diferente. Otra posible variable de confusión a tener en cuenta es la aparición de nuevas vivencias durante la duración del estudio, que alteren de manera indirecta el AS de la persona que, al no estar contempladas, pueden dar lugar a sesgos relacionados con la hipótesis del efecto directo del AS (Thoits, 1982).

\section{Alteraciones psicológicas y eventos estresante. Efecto en el AS}

En la selección de individuos para el estudio del AS, se debe tener en cuenta los aspectos relacionados con patologías psicológicas previas, los individuos con alteraciones psicológicas pueden percibir de manera errónea el AS obteniendo resultados que no representan fielmente la realidad (Thoits, 1982).

El efecto del AS tiene connotaciones e influencias destacables en las personas en situaciones estresantes. Sin embargo, en ausencia de este evento estresante no existe un efecto significativo en el estado psicológico del individuo (Kaplan et al., 1977).

Cassel (1976) defiende que es más factible corregir y fortalecer el AS en las personas que disminuir la exposición a factores de estrés. Thoits toma como base para las conclusiones de su estudio esta premisa, y añade que las relaciones sociales pueden ser más susceptibles de cambio durante las crisis vividas, que otros factores como rasgos de personalidad o habilidades de afrontamiento. 
Otra perspectiva que destaca la evidencia encontrada respecto al AS es la percepción que tiene el individuo de ese AS, que en muchos casos es rechazado porque la persona se siente en deuda con la recepción de esa ayuda y, por lo tanto, deberá ser correspondida. En este caso, los autores que han profundizado y teorizado sobre este hecho destacan el fomento de la reciprocidad en la planificación de estrategias para ofrecer AS y así conseguir que ambas partes pueden cumplir sus objetivos al máximo (Gottlieb, 1983; Walster, Walster, \& Berscheid, 1978).

En relación con la búsqueda de la evidencia científica sobre la relación del AS y otros conceptos como el estrés, cabe destacar la figura de Cohen \& Wills (1985), que concluyen en la revisión realizada a ambos términos, que tanto la teoría del efecto directo, como la teoría del efecto amortiguador del AS deberán ser discutidas y experimentadas en futuras investigaciones sin dar por válida una teoría sobre la otra.

Autores como Lisa F. Berkman (1985) destacan la discrepancia existente en los estudios realizados hasta el momento sobre el constructo apoyo social y su relación con la morbilidad y la mortalidad, concluyendo en la necesidad de profundizar en la definición, y a la hora de utilizar el AS como variable independiente.

Cabe destacar las aportación que realiza Kessler (1985), que se plantea como objetivo analizar la evidencia existente hasta ese momento que relacionaba el estrés, la psicopatología y el AS, concluyendo que las investigaciones hasta la fecha, teniendo como partida unos conceptos comunes, no habían utilizado el mismo método, las mismas definiciones de variables, lo que conlleva a una evidencia muy heterogénea y con una validez externa de poca fiabilidad; por ello, aconseja para los futuros investigadores confluir en el estudio longitudinal de la relación entre estrés, afrontamiento y AS, matizando que los individuos del estudio no tienen por qué presentar una patología psicológica para poder ser incluidos, ya que se ha demostrado qué niveles de estrés a lo largo del tiempo no están relacionados con la aparición de mayor morbilidad psicológica. Por ello, Kessler (1985) recomienda matizar el concepto de estrés como un estado que permite a su vez, unido al AS, una adaptación a las situaciones estresantes vividas, por lo que una vez dichas investigaciones contengan un método común, se podrán plantear intervenciones experimentales para 
analizar la relación directa entre los conceptos mencionados anteriormente.

Dentro de la revisión realizada por Kessler (1985) destaca la valoración que el autor realiza sobre el estudio del AS, destacando la importancia de dicho constructo a la hora de determinar su influencia sobre otros parámetros como el estrés, pero señalando que los estudios se centran en pacientes, en muchos casos, con patologías psiquiátricas que no son causa directa del nivel de AS percibido por el mismo y, por lo tanto, su validez interna es cuestionable. El autor profundiza en el análisis de los estudios que relacionan el AS percibido en una situación puntual de la vida, encontrando que los estudios precisan de un instrumento adecuado y válido para poder medir el AS percibido y recomienda para futuras investigaciones, plantear no sólo el efecto positivo del AS sobre la salud sino, en algunos casos, el efecto negativo en familias disfuncionales.

En definitiva, destacando dicha aportación en relación con el objetivo principal de esta tesis, Kessler (1985), basándose en los estudios de Price \& Thos (1980), concluye que en futuras investigaciones sobre el AS y su relación con el estrés debe desarrollarse sobre estudios prospectivos que complementen la evidencia científica actual, para de esta manera desarroIlar intervenciones preventivas y de apoyo en poblaciones de alto riesgo.

En 1986, en el condado de Evans, en Estados Unidos, se publica un estudio realizado con 2059 sujetos que fueron examinados entre 1969-1986, valorando la presencia de eventos cardiovasculares y su supervivencia relacionada con el efecto de las redes sociales de las que disponían. No se encontraron resultados significativamente estadísticos con respecto a las diferentes razas y sexos de los pacientes incluidos en el estudio. El descenso en la supervivencia de los sujetos con pocos lazos sociales fue la característica más importante de los datos encontrados (Schoenbach et al., 1986).

Continuando con la revisión sobre el concepto de AS se debe destacar el estudio realizado por Sherbourne (1988), con una muestra de 4580 pacientes totales analizados de forma longitudinal entre 3-5 años, en el que estudiaron el AP sobre las tensiones de la vida cotidiana y el uso de servicios de salud. La conclusiones relacionadas con el AS, señalaron los autores, fueron que ni los contactos sociales ni los recursos sociales amor- 
tiguaron el impacto de situaciones de tensión experimentadas en la vida de los pacientes incluidos en el estudio, ni en la utilización de los servicios de salud mental disponibles en ese momento (Sherbourne, 1988).

En 1988, por Neuling \& Winefield, se comienza a definir y cuantificar el AS en otros tipos de pacientes que presentan una situación de estrés concreta. Sobre un proceso que viven de manera puntual, en el caso de este estudio, los investigadores describen el AS percibido y su recuperación en el cáncer de mama, describiendo cómo los pacientes perciben ese AS, incluyendo el AS empático recibido por familiares y amigos, así como el AS profesional, la recogida de datos se realizó desde el mes antes de la cirugía hasta tres meses después de la intervención, no evaluando variables relacionadas con el periodo postoperatorio inmediato. Los autores concluyen que los pacientes incluidos en el estudio diferenciaban claramente esos dos tipos de AS, el informativo administrado por los profesionales sanitarios y el AS empático realizado por los familiares y amigos del paciente. Respecto al AS informativo, el estudio destaca la importancia de la preparación y predisposición que debe existir entre el personal sanitario para administrarlo, destacando la necesidad que refiere el paciente para que dicho AS informativo sea complementado con un AS empático administrado por el mismo personal sanitario. Este matiz de complementar el AS informativo con el empático por parte del personal sanitario, hace que muchos médicos y cirujanos refieren no poseer el tiempo ni las habilidades necesarias para dar un correcto AS empático y simplemente se limiten a relacionarse con el paciente para dar la información que ellos creen necesaria, esta carencia percibida por el paciente se podría resolver con la figura de la enfermera, que sería el nexo de unión entre la información sanitaria y el trato más directo y continuo con la paciente intervenida de mastectomía (Maguire et al., 1983).

En relación con el AS empático suministrado por familiares y amigos, el paciente lo percibe de suma importancia para su recuperación, pero no se establece una mayor eficacia si es dado por familiares o por amigos, ya que, probablemente, dependerá de las necesidades y características propias de cada paciente.

Continuando con los estudios que cuantifican el AS en los pacientes que van a ser sometidos a una intervención quirúrgica, Kulik \& Mahler 
(1989) publican un estudio realizado con los pacientes intervenidos de bypass coronario, en el que se intenta descubrir la relación existente entre el AS del cónyuge sobre la ansiedad preoperatoria y la recuperación postoperatoria, concluyendo, después de obtener y analizar una muestra de 56 pacientes, que los pacientes que recibían mayor AS durante su estancia hospitalaria necesitaron menos medicamentos para el dolor siendo su recuperación más rápida.

Dentro de las posibles limitaciones del estudio que los mismos autores mencionan, cabe la posibilidad de presentar variables de confusión que no han podido controlar debido al carácter multicéntrico del estudio, como puede ser el nivel de salud previo de los pacientes, la calidad y actividades recibidas en el preoperatorio o el postoperatorio inmediato.

Los autores concluyen que existen pocos o ningún estudio que haya examinado el AS en el contexto del paciente agudo y su fase de recuperación quirúrgica aguda en el hospital. Ellos consideran que puede existir una evidencia convincente de que el AS ofrecido por el cónyuge y medido mediante la monitorización de las visitas hospitalarias recibidas por el paciente, se asocia a una recuperación más rápida de los paciente casados, pero no se ha conseguido definir de manera precisa la relación cónyugepaciente.

Los autores recomiendan que debe fomentarse la investigación en estos conceptos de salud y vida social, para determinar cómo funciona ese soporte social y su repercusión en la salud de las personas.

Las líneas de investigación continúan intentando matizar y concretar un concepto tan ambiguo en su fase conceptual como es el AS y su relación con el proceso salud-enfermedad. Así, en 1993, un estudio realizado a 74 paciente que habían padecido un evento cardíaco adverso precisando la hospitalización y que, posteriormente, se les entrevistó mientras se encontraban hospitalizados y a los tres meses posteriores, concluyó que AS percibido es mejor cuando se adapta a la situación de estrés que vive el paciente, a sus necesidades individuales y a las de su cónyuge, destacando en los resultados obtenidos, que el AS percibido por el paciente tuvo mayor impacto en las variables de ajuste frente a la situación de estrés que el AS recibido, debido a que este último no se adaptaba a las necesidades específicas del paciente en ese momento (Helgeson, 1993). 
Se debe destacar, continuando con el análisis de los estudios de investigación que han tenido como objetivo relacionar los procesos sociales y la salud, la revisión exhaustiva que realizan Uchino, Cacioppo, \& Kiecolt-Glaser (1996), llegando a las siguientes conclusiones:

- Existe una gran heterogeneidad en la toma de medidas para valorar el AS, lo que dificulta el análisis en conjunto de los datos de diferentes estudios.

- El AS se ha relacionado con menores tasas de morbilidad y mortalidad en diferentes procesos y etapas de la enfermedad.

- La revisión indica que hay evidencia relativamente fuerte que vincula el AS y su repercusión sobre los sistemas cardiovascular, endocrino e inmunológicos.

- En la revisión, los autores detectan un déficit en la contextualización y decisión del constructo apoyo social y sus instrumentos de medida.

- Los autores de la revisión reportan que existen pocos estudios que midan las propiedades psicométricas relacionada con el sistema endocrino o inmune para la medida del AS.

- Recomiendan, para futuras investigaciones, debido a la heterogeneidad de la toma de datos relacionado con el AS, completar los resultados de dicha variable con datos analíticos de la repercusión que puede tener el AS sobre el sistema inmune o endocrino, ayudando a clarificar relaciones fiables entre las variables de estudio.

- La revisión sugiere que el apoyo familiar parece ser una fuente importante de AS y se debería considerar en el estudio de su relación con las repercusiones en el ámbito de la función fisiológica.

- La mayoría de los estudios revisados definen el AS como un concepto unidimensional, pero los autores recomiendan que las futuras investigaciones se centren en el enfoque multidimensional del AS y, por consiguiente, llegar a una definición y cuantificación más específica y real del concepto.

- Los autores recomiendan que en futuras investigación se complemente la correlación que podría existir entre AS y salud, relacionando los resultados con la posible influencia que podrían tener los factores personales y mecanismos psicológicos; por ejemplo, el estado de ánimo. 
- Por último, lo autores destacan, la falta de estudios prospectivos. Estos estudios serían un método útil para buscar la asociación entre AS, los procesos fisiológicos y los factores personales.

Posteriormente, Lin, Ye, \& Ensel (1999) publican una investigación que tuvo como objetivo especificar los posibles efectos que las diferentes dimensiones del AS tienen sobre la angustia y, por lo tanto, indirectamente sobre la salud de las personas. El estudio toma como fuente de datos la encuesta realizada entre 1993-1994, en un área metropolitana de New York, a 1261 individuos que respondieron a eventos vividos en los 12 meses anteriores. El estudio concluye en la evidencia de que tanto el nivel de soporte real como el percibido, tienen un papel importante en situaciones de crisis, estableciendo un efecto directo sobre la depresión.

El interés de los investigadores por buscar la causalidad entre el AS y el efecto que pudiese tener sobre variables hemodinámicas y fisiológicas, se puede resumir en el metaanálisis que realizan Thorsteinsson \& James (1999) de los estudios que han experimentado con el concepto de AS en situaciones de laboratorio y sus efectos sobre la hemodinámica del paciente. Los autores dedujeron que el AS tiene un efecto atenuante sobre la reactividad inducida por el comportamiento, lo que podría sugerir un efecto de protección sobre la salud. Esta afirmación es matizada por los autores con una serie de consideraciones que se deberían tener en cuenta para futuras investigaciones, tales como que convendría tratar de aumentar el poder estadístico mediante el aumento de tamaño de las muestras, mejorar la fiabilidad de las mediciones empleadas en estudios experimentales de la vida social, mejorando también la obtención de los datos relacionados con la reactividad fisiológica, ampliar la muestra a otros grupos poblacionales y no solo a estudiantes o profesionales. Así mismo, debido a la diferencia experimental que dio lugar a resultados inconsistentes, recomiendan la elaboración de un protocolo. Además, el control de las condiciones externas que compara la manipulación del AS ha sido descuidado en la metodología de la mayoría de los estudios, impidiendo aumentar la validez externa de los mismos. Y finalmente, entre las consideraciones destacan que se debería matizar si el AS es asociado en algunas personas al mero hecho de la presencia física de otra 
persona o si es debida a una interacción entre ambos (Thorsteinsson \& James, 1999).

En el año 2000, se realiza en Finlandia un estudio que tenía como objetivo evaluar cómo el AS podría afectar a la recuperación física y psicológica un año después de padecer un infarto de miocardio o haber sido intervenido de un bypass coronario. La muestra del estudio fue de 147 pacientes que padecieron un infarto de miocardio y 159 pacientes que se les realizó un bypass coronario. Los resultados fueron contradictorios con respecto a la bibliografía existente hasta ese momento, los autores concluyen que el AS, en los dos grupos de pacientes incluidos en el estudio, tiene un efecto limitado en la recuperación de la enfermedad, incluso en algunos casos tiene un efecto negativo. Los investigadores exponen como argumentos, para poder explicar estos hallazgos, las posibles características de la población y cultura finlandesa donde el AS no ocupa una parte tan importante como el resto del mundo, también matizan que los métodos utilizados para medir el AS no fueron del todo adecuados, valorando parámetros de tipo cuantitativo frente a la obtención de datos cualitativos. Incluso, los autores plantean como posible explicación para obtener esos resultados: los pacientes que tenían un AS elevado tenían a familiares demasiado preocupados que no permitían una rehabilitación cardíaca activa del paciente por miedo a volver a padecer un evento cardiaco adverso. Otra explicación que defiende los autores es que las relaciones sociales adversas puedan tener un efecto negativo en la recuperación de los pacientes. En definitiva, la investigación concluye con datos que no se correlacionan con la bibliografía anterior, pero que plantean nuevos puntos de vista y matices en un concepto tan ambiguo y difícil de cuantificar como es el AS (Hämäläinen et al., 2000).

Las investigaciones y revisiones sistemáticas como las expuestas previamente demuestran la importancia de los conceptos estudiados y sus posibles repercusiones en la salud, precisando la profundización y análisis de más estudios al respecto. Por lo tanto, en la valoración del paciente desde la perspectiva enfermera, en búsqueda de problemas de salud que pueden afectarle directa o indirectamente, el AS debe ser tenido en cuenta a la hora de realizar una valoración enfermera integral, previa a la obtención de los diagnósticos enfermeros. 
Cuando comenzaron las investigaciones relacionadas con el efecto que el AS podría tener sobre la salud de las personas, unas de las líneas de investigación más desarrollada fue aquella que tenía como objetivo buscar la relación entre AS y enfermedad mental. Así, autores como Martínez \& Ochoa Güerre (2000) se plantearon buscar la relación existente entre las redes sociales y las personas con esquizofrenia, realizando un estudio con 67 personas con esquizofrenia que siguen el tratamiento en centros de Salud Mental en Atención Primaria. Concluyeron que "existe una correlación entre la gravedad de los síntomas y el números de personas que componen la red social $(p=0,041)$ y entre la baja densidad de red y la mayor discapacidad en el funcionamiento familiar $(p=0,019)$ " (Martínez \& Ochoa Güerre, 2000).

Las investigaciones, en la mayor parte de los casos, relacionaban el AS con otras variables como el estrés, depresión y cómo a su vez podían afectar a la salud. En el año 2000 se publica una investigación que tiene como objetivo relacionar la asociación entre las características de afrontamiento y el AS percibido previas a la cirugía de los pacientes diagnosticados de enfermedad inflamatoria intestinal y su calidad de vida postquirúrgica (Moskovitz \& Maunder, 2000). La investigación se realizó en 86 pacientes que se sometieron cirugía para la enfermedad de Crohn o colitis ulcerosa en un hospital de Toronto durante un año (1996-1997). Los resultados del estudio indicaron que los pacientes con mayor calidad de vida relacionada con la salud postoperatoria informaban que tenían mayor AS percibido. Los autores destacan la utilidad de los estudios prospectivos para demostrar las validez de las variables de estudio en futuras investigaciones.

Durante la contextualización del AS a lo largo de la historia, muchos autores han encontrado deficiencias en el marco teórico de las investigaciones realizadas, que han dado lugar a posibles errores en los métodos elegidos para cuantificar el AS, esta debilidad encontrada en la bibliografía estudiada es detectada por Borrón \& Sánchez (2001), los cuales se plantean como objetivo principal del estudio crear un modelo teórico contrastado con una fase empírica formada por una muestra de 401 personas que eran entrevistadas para obtener las variables del estudio que fueron divididas en dos bloques, el primero relacionado con los aspectos sociodemográficos y el segundo relacionado con la información 
sobre eventos estresantes experimentados por el entrevistado, información en torno a su salud mental, medidas de alineación, apoyo comunitario y AS percibido. Los resultados empíricos confirmaron la estructura del modelo teórico, donde el concepto, posición social debe ser definido y cuantificado en dos grandes aspectos que influyen en su percepción por parte de las personas y a su vez mediados por aspectos psicológicos y psicosociales, que revierten en el bienestar psicológico. En definitiva, los autores pretendieron destacar y recomendar, para futuras investigaciones, no obviar tanto el análisis de los factores sociales (alineación) como los factores ambientales (estrés), para valorar la afectación que el AS podría tener sobre el bienestar psicológico (salud mental y depresión).

Las líneas de investigación enumeradas con anterioridad han conseguido delimitar la influencia que el AS tiene sobre la salud, la enfermedad, las enfermedades psiquiátricas y las enfermedades crónicas. En España, un ejemplo de este tipo de investigaciones, que tienen como objetivo determinar la influencia del AS en los pacientes diagnosticados de hipertensión arterial, fue el estudio publicado por Menéndez Villalva et al. (2003), donde se analizó el AS en una muestra de 236 pacientes diagnosticados de hipertensión arterial esencial, controladas en el centro de salud Centro Saúde Mariñamansa-A Cuña, Ourense (Galicia) durante un año de seguimiento donde, aparte de variables de tipo demográfico, se obtuvieron variables relacionadas con la patología diagnosticada, datos sociodemográficos y apoyo social percibido. Los autores concluyeron que los pacientes diagnosticados de hipertensión esencial con una baja red social mostraron un aumento de las cifras de presión arterial respecto de los hipertensos con redes sociales amplias. Estos resultados, según corroboran los autores en su revisión bibliográfica, coinciden con estudios similares realizados en otros lugares del mundo con muestras parecidas (Menéndez Villalva et al., 2003).

La revisión de las publicaciones referentes a la evidencia científica que intenta relacionar el AS con proceso salud-enfermedad nos lleva a 2005, donde destacamos un estudio realizado a 84 pacientes (42 mujeres y 42 hombres) sometidos a cirugía maxilofacial y cuyo objetivo del estudio fue determinar si el apoyo emocional e informativo influía sobre la ansiedad percibida por el paciente en el preoperatorio, intraoperatorio y 
postoperatorio. Los autores destacaron la falta de evidencia y estudios científicos que abordan la percepción y efecto del AS en el paciente hospitalizado durante su estancia hospitalaria. La hipótesis de partida de esta investigación fue la siguiente: "La accesibilidad de apoyo perioperatorio podría aliviar el estrés y mejorar la adaptación de los pacientes” (Krohne \& Slangen, 2005). A los 84 pacientes se les realizó la medición del apoyo emocional percibido y el apoyo informativo. Los datos obtenidos provenían de autoadministrar a los pacientes la escala Emotional and Informational Support Scales-Operations (EISOP), Cognitive, Affective, Somatic Anxiety scale (CASA), dosis de Tiopental intraoperatoria y días de estancia hospitalaria.

Los autores concluyeron que el apoyo informativo y emocional pudo afectar al proceso de adaptación perioperatorio de los pacientes. El apoyo informativo se correlacionó con menores valores de ansiedad preoperatoria y pudo influir marginalmente en la descenso del uso de agentes narcóticos. En el caso del apoyo emocional, se relacionó con una mejor adaptación en la etapa prequirúrgica, consiguiendo disminuir la ansiedad durante este proceso y acortando la estancia hospitalaria. Estas asociaciones entre las variables descritas son moderadas por género, apareciendo en mayor medida en el género femenino (Krohne and Slangen, 2005).

En definitiva, esta investigación demuestra la importancia que las variables AS y ansiedad tienen en el proceso quirúrgico sobre los pacientes. En este caso los autores enuncian que la hipótesis planteada solo se confirma en las mujeres. Dicho estudio plantea limitaciones tales como que el proceso de obtención de datos no está del todo aclarado respecto al tipo de AS que quieren medir, en este tipo de investigaciones en el que existe una ambiguedad del concepto AS, es complicado obtener un dato, lo más aproximado a la realidad de AS percibido del paciente, si a su vez se subdivide en dos escalas más, para poder medirlo.

Por otro lado, otra limitación del estudio fue utilizar la dosis de un fármaco de manera aislada, como variable dependiente sin matizar datos tan importantes como el peso que podría determinar el mayor o menor uso de tiopental en los pacientes seleccionados.

Como se menciona anteriormente, los autores detectan que existe una falta de estudios que cuantifiquen y relacionen el AS durante la estancia 
hospitalaria del paciente quirúrgico; por ello, se cree que elegir un abanico tan amplio de intervenciones como criterio de selección, incluso realizadas por varios cirujanos, no nos aporta connotaciones comunes y básicas para poder utilizar, por ejemplo, la estancia hospitalaria de todos los pacientes como variable dependiente.

Por último, cabe destacar que los autores recomiendan para futuras investigaciones estudiar el proceso de cicatrización y el AS percibido tanto por parte del paciente como por el personal médico que lo atiende (Krohne \& Slangen, 2005).

Como se ha podido observar a lo largo del desarrollo de este capítulo, desde el comienzo en el intento de contextualizar el concepto de AS y su relación con la salud han existido investigaciones con criterios de selección e instrumentos de toma de datos muy heterogéneos. Por ello, se han encontrado investigaciones que intentan aunar y unificar la bibliografía existen para poder llegar a conclusiones y relaciones de etiología entre ambos conceptos. Es el caso del estudio realizado por Rosenberger, Jokl \& Ickovics (2006), los investigadores tienen como objetivo principal determinar si los factores psicosociales pueden ser predictores en la recuperación quirúrgica de los pacientes, para ello se realizó un examen sistemático de los resultados de los estudios publicados desde 1990 hasta 2004 en las bases de datos MEDLINE y Psyc-INFO, donde se tomaron como criterios de inclusión aquellos estudios que tenían como variable independiente alguna característica psicosocial del paciente, por ejemplo, depresión o AS, y que tuviesen como criterio de resultado la recuperación quirúrgica; por último, los estudios seleccionados deberían tener un análisis estadístico multivariante de los datos obtenidos.

De los más de 1000 artículos encontrados por los autores, solo 29 tuvieron criterios para ser incluidos en el análisis exhaustivo, donde se dividieron las variables psicosociales en cinco categorías generales tales como humor, actitud, apoyo social, mecanismos de adaptación y factores de personalidad, que a su vez fueron analizados sobre cinco tipos de resultado quirúrgico (dolor y uso de analgésicos, procedimiento quirúrgico y complicaciones quirúrgicas, duración de la hospitalización, recuperación funcional, así como autopercepción de la salud). 
Este análisis arrojó las siguientes conclusiones:

- La variedad de disciplinas quirúrgicas y tipos de cirugía encontrados en los estudios analizados dan lugar a una falta de consistencia en los criterios de resultado de los estudios, que tienen como objetivo determinar las repercusiones que las variables independientes tienen sobre la recuperación quirúrgica de los pacientes.

- El estado emocional general no se ha demostrado como predictor de la evolución quirúrgica del paciente, ya que no se encontraron resultados significativos.

- El estado de ánimo no posee una relación clara y consistente como posible factor influenciador en la recuperación del paciente después de la intervención.

- El AS tiene una influencia baja a corto plazo en la recuperación postquirúrgica del paciente, sobre todo en procedimientos menos invasivos. Incluso los autores detectaron en los estudios analizados que un apoyo sobreprotector podría inducir a resultados negativos en las variables analizadas durante el proceso postoperatorio (Rosenberger et al., 2006).

En este sentido, la búsqueda del AS y su relación con la salud han encontrado controversia en los datos obtenidos en pruebas de laboratorio, como ocurrió con el estudio de Robles (2007), que tenía como objetivo analizar el efecto de un estresor en condiciones de laboratorio y la presencia de AS para cuantificar su efecto en la recuperación de la alteraciones en la barrera de la piel normal de los participantes en el estudio. Después de obtener los resultados de la muestra de 85 pacientes sanos incluidos en el estudio, Robles concluye que el AS no influyó en la respuesta psicológica o fisiológica en la recuperación de la barrera de la piel tras la colocación de la cinta que provocaba la agresión inicial. Estos resultados contrastan con los estudios previos como el realizado por Glasper \& DeVries (2005) que sí concluyen, en un experimento realizado en este caso con roedores, que el AS en forma de emparejamiento social tuvo efecto sobre la cicatrización de las heridas tras realizarles una biopsia cutánea. Por ello, el autor recomienda que se desarrollen más investigaciones en entornos reales para medir el AS, lo que contribuirá a delimitar exactamente el al- 
cance de dicho apoyo sobre la recuperación en este caso de la barrera de la piel (Robles, 2007).

Las autoras Sarason \& Sarason (1985) publican en su libro Social Support: Theory, Research and Applications cómo el concepto de AS debe ser cuantificado desde el punto de vista del AS percibido, recomendando a los futuros investigadores que complementen sus cualidades con datos objetivos y cuantificables, incluso con otros conceptos tan importantes para estas autoras como la soledad.

Cabe destacar el estudio publicado por Vinaccia \& Quiceno (2014), donde se seleccionaron a 29 pacientes diagnosticados de tumor pulmonar no terminal, a los que se les entregó para su cumplimentación una serie de cuestionarios tales como: cuestionario de calidad de vida, el módulo específico de cáncer de pulmón, el inventario de puntos de vista personales y la escala de apoyo social percibido, con el fin de relacionar dichas variables entre sí. Los autores concluyeron que el AS percibido por los pacientes provenía de su familia, percibiendo la calidad de dicho apoyo como baja, correlacionando estos valores con la calidad de vida percibida por los pacientes. Recomiendan seguir indagando, en futuras investigaciones, sobre las posibles relaciones entre las variables con muestras mayores.

Se debe destacar que la evidencia científica encontrada, y en concordancia con lo expuesto por otras autoras como Helgeson (1993), el apoyo social percibido sería un mejor predictor para cuantificar su consecuencia sobre la salud respecto a valorar simplemente la disponibilidad de personas en el entorno del individuo, es por ello que, para futuras investigaciones, se deben utilizar instrumentos de medida que cuantifiquen la percepción del apoyo social desde un punto de vista de percepción de dicho a poyo, ya sea como aspecto cuantitativo o cualitativo, sin limitarse simplemente a un análisis numérico de la cantidad de personas que forman el entorno social del individuo objeto de estudio.

La búsqueda de la relación entre la atención sanitaria y su efecto sobre el apoyo social percibido, comienza a cobrar importancia desde los primeros estudios científicos sobre este concepto, autores como Gurin, Veroff, \& Feld (1960) demostraron que las personas que percibían angustias en su vida, Ilegando al punto de producir trastornos mentales, 
acudían en busca de ayuda a miembros de la familia, amigos y vecinos, así como a los médicos y miembros del clero, cuyo papel como sanadores en cuestiones médicas y espirituales fueron percibidos como igualmente efectivas para hacer frente a los trastornos emocionales.

Caplan (1963) describe los primeros centros de salud destinados al asesoramiento, consulta y apoyo educativo a grupos de cuidadores informales.

En los años 70 y 80, los psicólogos comunitarios argumentaron que la el conocimiento generado por la interacción entre las personas y sus entornos podrían contribuir a la prevención primaria, en relación con la falta de apoyo social, de dos maneras. La primera como neutralizadora del factor de estrés (Goldenberg, 1971); la segunda identificando y, posteriormente, fortaleciendo las habilidades sociales de los agentes que actúan como cuidadores informales para adquirir competencias y habilidades de afrontamiento, con el fin de mejorar su resistencia frente a factores estrés inalterables (Cowen, 1977; Gottlieb, 1983).

Gottlieb (1983) en el desarrollo de su línea de investigación sobre las personas que prestan apoyo en el medio natural, describe cuatro tipos de grupos que van a sentar las redes de tratamiento que alinearán los problemas de salud mental de los ciudadanos, estos serían: grupos de autoayuda, cuidadores de la comunidad (médicos, abogados, miembros del clero), red básica de los barrios y red social primaria (familiares y amigos). Comienza a verse la importancia de los diferentes tipos de apoyo social que puede recibir una persona, en este caso con problemas de salud mental.

Cabe destacar las conclusiones de dos estudios de investigación que defienden el papel del apoyo social como refuerzo de las estrategias de preparación para afrontar acontecimientos de la vida predecibles como la entrada a la escuela o una operación quirúrgica, que disminuye el nivel de excitación emocional del individuo que recibe el evento (Langer, Janis, \& Wolfer, 1975; Meichenbaum, 1972). Estos dos estudios serían el comienzo sutil para conseguir delimitar y definir las características del AS, no solo en individuos con problemas mentales, como ha sido el objetivo en la mayoría de los estudios anteriores que se han basado en la enfermedad relacionada con el AS, sino tomar como muestra de estudios a paciente 
que al comienzo de la investigación no presentan ninguna patología o situación de estrés.

En la actualidad se está intentado instaurar en los hospitales los protocolos de Recuperación Acelerada después de la Cirugía, que no solo intentan mejorar la atención del paciente ofreciendo un tratamiento que permita un alta precoz, sino que además minimizan el tiempo de ingreso previo a la intervención, incluso ingresando el paciente el mismo día de la cirugía (Giulio et al., 2016; Gustafsson et al., 2011; Jakobsen et al., 2014; Scott, 2012).

En relación con la disponibilidad del AS durante el ingreso, disponer de un menor tiempo previo a la cirugía limita las posibilidades de estar acompañado durante la admisión y los momentos antes de la cirugía; en estos casos, la presencia de un profesional médico o enfermero momentos antes de la intervención quirúrgica que actúe como apoyo social puede ser beneficioso para el paciente (Krohne \& Slangen, 2005; Mitchell, 2007).

Desde la perspectiva propiamente enfermera, autoras como Norbeck, enfermera investigadora en la década de los 70, defiende que el AS es tanto acogido como brindado por los integrantes de la red social, de tal manera que se produzca un reparto equitativo, estableciendo a su vez que las necesidades de AS son específicas en cada individuo en función de las necesidades concretas que tenga en ese momento. En definitiva, el AS resulta ser una variable amortiguadora positiva en el cuidados de las personas (Norbeck, Lindsey, 1981; J. S. Norbeck, Tilden, J. S., \& V. P., 1988).

Hay que mencionar además, el estudio realizado por Norbeck \& Peterson (1983), que tenía como objetivo encontrar una posible relación entre el estrés, el apoyo social y las complicaciones durante el embarazo, en dicho estudio las autoras concluyen que aún con un resultado modesto significativamente, existe una posible relación amortiguadora del AS sobre el estrés durante el embarazo; por lo tanto, las pacientes se podrían beneficiar de posibles intervenciones destinadas a disminuir el estrés que fomenten el aumento del AS. Norbeck desarrolla esta línea de investigación en la que intenta diseñar una intervención que permita aumentar el apoyo social, en este caso durante el embarazo a mujeres afroamericanas para prevenir el bajo peso al nacer; tras realizar un ensayo clínico 
aleatorizado con ese objetivo, los autores concluyen que la intervención proporcionada para aumentar el apoyo social fue efectiva para reducir el bajo peso al nacer (Jane S. Norbeck, DeJoseph, \& Smith, 1996).

En definitiva, el estudio del AS debe ser una variable estudiada desde una perspectiva multidisciplinar, la enfermería debe ser parte de este equipo debido a los conocimientos no solo propios de la disciplina que servirán para intervenir sobre la mejora y valoración del AS de los paciente atendidos, sino debido al contacto directo y continuo que los profesionales enfermeros tienen con los pacientes, en especial con los pacientes hospitalizados, y en concreto, en este caso, con los paciente pendientes de intervención quirúrgica que estarán atendidos 24 horas por el personal de enfermería. Las enfermeras son el eje de los cuidados en los hospitales, realizando los cuidados de primera línea (Hendrich, Chow, Skierczynski, \& Lu, 2008).

La investigación sobre el concepto de AS se ha convertido en una de las variables a tener en cuenta a la hora de planificar e implantar estrategias de intervención enfermera para la solución de problemas de salud detectados

\subsection{Los cuidados de enfermería relacionados con el apoyo social recibido/percibido}

Según la sociedad científica NANDA Internacional, Inc. (NANDA-I), anteriormente llamada North American Nursing Diagnosis Asociación, acrónimo y nombre que es sustituido por NANDA-I a partir de 2002, en su Taxonomía II, el AS recibido o percibido no aparece como un posible diagnóstico enfermero, pero sí es importante tenerlo en cuenta como una posible intervención, denominada aumentar los sistemas de apoyo (NANDA Internacional, 2015).

La intervención enfermera aumentar los sistemas de apoyo (5440) según NANDA-I, en sus ediciones 1992 y 2013 corresponde con el campo tres, conductual, clase R, ayuda al afrontamiento y se define como "facilitar el apoyo del paciente por parte de la familia, los amigos y comunidad" (NANDA Internacional, 2015; Merino, 2013). 
Esta intervención puede realizarse mediante las siguientes actividades (Tabla 5).

\section{Tabla 5. Actividades relacionadas con la intervención enfermera "aumentar los sistemas de apoyo"}

\begin{tabular}{|c|c|}
\hline Código & Nombre de la actividad \\
\hline 544002 & Determinar la conveniencia de las redes sociales existentes \\
\hline 544003 & Determinar el grado de apoyo familiar y económico, así como otros recursos \\
\hline 544006 & $\begin{array}{l}\text { Determinar las barreras al uso de los sistemas de apoyo no utilizados o in- } \\
\text { frautilizados }\end{array}$ \\
\hline 544007 & Observar la situación familiar actual y la red de apoyo \\
\hline 544008 & Animar al paciente a participar en las actividades sociales y comunitarias \\
\hline 544009 & $\begin{array}{l}\text { Fomentar las relaciones con personas que tengan los mismos intereses y } \\
\text { metas }\end{array}$ \\
\hline 544010 & $\begin{array}{l}\text { Remitir a un grupo de autoayuda, o a un recurso basado en internet si se } \\
\text { considera oportuno }\end{array}$ \\
\hline 544011 & $\begin{array}{l}\text { Determinar los puntos fuertes y débiles de los recursos comunitarios y acon- } \\
\text { sejar los cambios cuando sean apropiados }\end{array}$ \\
\hline 544012 & $\begin{array}{l}\text { Remitir a programas comunitarios de prevención o tratamiento, según co- } \\
\text { rresponda }\end{array}$ \\
\hline 544013 & Proporcionar los servicios con una actitud de aprecio y de apoyo \\
\hline 544014 & Implicar a la familia/allegados/amigos en los cuidados y la planificación \\
\hline 544015 & Explicar a los demás implicados la manera en que pueden ayudar \\
\hline 5440 & 10 \\
\hline
\end{tabular}

La intervención aumentar los sistemas de apoyo, a su vez, puede realizarse dentro de la planificación de los siguientes diagnósticos enfermeros (Tabla 6).

Por otra parte, se puede cuantificar mediante los siguientes criterios de resultado Nursing Outcomes Classification (NOC) (Tabla 7). 


\section{Tabla 6. Diagnósticos enfermeros que pueden incluir la intervención} "aumentar los sistemas de apoyo"

\section{Código Diagnóstico enfermero}

\begin{tabular}{|c|c|}
\hline 71 & Afrontamiento defensivo \\
\hline 74 & Afrontamiento familiar comprometido \\
\hline 69 & Afrontamiento ineficaz \\
\hline 61 & Cansancio del rol de cuidador \\
\hline 83 & Conflicto de decisiones \\
\hline 51 & Deterioro de la comunicación verbal \\
\hline 214 & Disconfort \\
\hline 158 & Disposición para mejorar el afrontamiento \\
\hline 167 & Disposición para mejorar el autoconcepto \\
\hline 162 & Disposición para mejorar la gestión de la propia salud \\
\hline 184 & Disposición para mejorar la toma de decisiones \\
\hline 78 & Gestión ineficaz de la propia salud \\
\hline 80 & Gestión ineficaz del régimen terapéutico familiar \\
\hline 125 & Impotencia \\
\hline 79 & Incumplimiento \\
\hline 60 & Interrupción de los procesos familiares \\
\hline 99 & Mantenimiento ineficaz de la salud \\
\hline 199 & Planificación ineficaz de las actividades \\
\hline 209 & Riesgo de alteración de la díada materno/fetal \\
\hline 62 & Riesgo de cansancio del rol de cuidador \\
\hline 226 & Riesgo de planificación ineficaz de las actividades \\
\hline 114 & Síndrome de estrés del traslado \\
\hline 148 & Temor \\
\hline 118 & Trastorno de la imagen corporal \\
\hline
\end{tabular}




\section{Tabla 7. Posibles criterios de resultado para la intervención "aumentar} los sistemas de apoyo"

\begin{tabular}{|c|c|}
\hline Código & Nombre del criterio de resultado \\
\hline 1300 & Aceptación: estado de salud \\
\hline 2200 & Adaptación del cuidador principal al ingreso del paciente en un centro sanitario \\
\hline 2600 & Afrontamiento de los problemas de la familia \\
\hline 1302 & Afrontamiento de problemas \\
\hline 1402 & Autocontrol de la ansiedad \\
\hline 1405 & Autocontrol de los impulsos \\
\hline 1404 & Autocontrol del miedo \\
\hline 1205 & Autoestima \\
\hline 2508 & Bienestar del cuidador principal \\
\hline 2002 & Bienestar personal \\
\hline 2000 & Calidad de vida \\
\hline 1601 & Conducta de cumplimiento \\
\hline 1602 & Conducta de fomento de la salud \\
\hline 1605 & Control del dolor \\
\hline 1902 & Control del riesgo \\
\hline 1703 & Creencias sobre la salud: percepción de recursos \\
\hline 1306 & Dolor: respuesta psicológica adversa \\
\hline 1204 & Equilibrio emocional \\
\hline 2008 & Estado de comodidad \\
\hline 1305 & Modificación psicosocial: cambio de vida \\
\hline 1209 & Motivación \\
\hline 1211 & Nivel de ansiedad \\
\hline 1212 & Nivel de estrés \\
\hline 1504 & Soporte social \\
\hline 906 & Toma de decisiones \\
\hline
\end{tabular}


En resumen, la intervención enfermera aumentar los sistemas de apoyo, según la Taxonomía II de NANDA-I, en relación con el AS percibido/recibido, puede ser integrada en una amplia variedad de diagnósticos enfermeros durante el proceso de planificación de cuidados, lo cual demuestra la importancia de valorar el AS en los pacientes que son atendidos por el personal de enfermería; por ejemplo, en el caso de la valoración y planificación de los cuidados del paciente intervenido quirúrgicamente en el momento del ingreso hospitalario. 


\section{ANSIEDAD}

El concepto de ansiedad, desde el comienzo de su conceptualización científica, presenta cierta ambigüedad, incluso en las palabras usadas para mencionar el término en los diferentes idiomas.

La ansiedad, desde el punto de vista técnico, se menciona por primera vez en 1747 por el autor desconocido de la obra Exploración sobre el origen de los apetitos y afectos humanos, concluyendo que un estado de incertidumbre lleva a un periodo de ansiedad (De Ansorena, Cobo, \& Romero, 1983).

Posteriormente, en 1880 aproximadamente, aparece por primera vez la palabra "anxiety" en inglés, que deriva a su vez del verbo latino "ango" (estrechar, apretar), de donde a su vez también derivan los términos "angustias" y "anxietas".

No obstante, en español y francés los términos utilizados sí se diferencian "angustia" en español y "angoisse" en francés, provienen del término en latín "angustia", en cambio, "ansiedad" y "anxiété" derivan de la palabra latina "anxietas".

Por el contrario, en alemán sólo existe la palabra "angst", procedente de la raíz latina "angustia". Esta controversia, entre utilizar dos palabras o una para referirse a un término médico, ha generado diferentes discusiones al respecto, a pareciendo desiguales matices a lo largo de la historia para definir y delimitar ambos (Pichot, 1995).

En alemán "angst" significa miedo en sentido habitual y tiene como sinónimo la palabra "aurcht". Sin embargo, cuando se aisló por primera vez un trastorno relacionado con la ansiedad específicamente, la agora- 
fobia, se utilizó indistintamente "angst" y "furcht" para describir el síntoma central de este trastorno.

En la actualidad, pero sólo en el ámbito de la Psiquiatría, "angst" es semejante a "anxiety" en inglés.

En definitiva, el concepto de ansiedad desde sus inicios y contextualización formal, pone de manifiesto un término ambiguo que será motivo de controversias a lo largo de su desarrollo e investigación histórica.

\subsection{Aproximación histórica de la conceptualización de la ansiedad}

En la dos últimas década del siglo XIX, las hipótesis sobre los trastornos de ansiedad y del estado de ánimo sufren una transformación importante.

Un ejemplo de dicha transformación sería el postulado que el neurólogo americano Beard defiende en 1880, donde introduce en la nosología una neurosis, a la que el autor llama "estrés de la vida moderna", situando este nuevo término dentro de las neurastenias.

Este nuevo enfoque en el concepto de ansiedad fue tomado como base para los trabajos de otros autores como Sigmund Freud, quien incorpora el término de ansiedad en el ámbito de la Psicología. Freud descompone las neurastenias de Beard en dos neurosis distintas, la neurosis de angustia, donde el paciente presenta una angustia expresada de dos formas diferentes, pero que pueden coexistir en el enfermo; una forma leve que denomina Ängstlichkeit, que a su vez puede coexistir con crisis de angustia intensas, de duración limitada, quedando la angustia cubierta por síntomas físicos (sensación de ahogo, opresión torácica).

La otra vertiente de neurosis sería la neurosis propiamente dicha, a la que Freud denomina fatiga. Freud, durante el desarrollo de dicha línea de investigación, consideró que la ansiedad existe en todas las neurosis patentes o latentes (Pichot, 1995).

Abraham (1924), basándose en los estudios de Freud, contribuyó a entender los orígenes de la ansiedad y la culpa, siendo el primero en exponer la relación entre ansiedad, culpa y deseos canibalistas en la infancia.

Autoras como Melanie Klein (1948) corroboran los hallazgos de Abraham en años anteriores y matizan los conceptos de Freud, defendiendo 
la siguiente hipótesis: "la ansiedad es provocada por el peligro que amenaza el organismo proveniente del instinto de muerte; esta es la causa primaria de ansiedad" (M. Klein, Segal, \& Grinberg, 1987, p. 121). Según Klein, los instintos de vida y de muerte persisten a lo largo de la vida, nunca se eliminan, interviniendo como factor invariable en todas las circunstancias de ansiedad.

Para esquematizar y resumir la evolución del concepto ansiedad a lo largo de la historia se dividirá en cuatro grandes grupos, que se analizará a continuación (De Ansorena et al., 1983).

\section{Enfoque psicoanalítico-humanístico}

La ansiedad es un estado emocional que posee una dimensión motora, seguida de una sensación de malestar apreciada por el paciente, producida por el conflicto entre un impulso inaceptable del "yo" y la contrafuerza aplicada por el "ego". Freud, como principal precursor de esta teoría, defiende que la ansiedad es un estado afectivo desagradable en el que surgen fenómenos como la aprensión, pensamientos molestos y cambios fisiológicos que se asocian a la activación autonómica, siendo estos cambios dañinos para el organismo.

Las escuelas humanistas y existencialistas mantienen perspectivas que distan, en muchos casos, de la experimentación, y se acercan más a una visión filosófica del significado de ansiedad, estableciendo la ansiedad como el resultado de la percepción de peligro por parte del organismo.

Principales autores que continúan esta línea de investigación: Goldstein (1939), May (1950), Rogers (1951), Sullivan (1953), Lader y Marks Epstein (1972).

\section{Enfoque conductual}

Este enfoque tiene como objetivo el estudio experimental y operativo para resolver los problemas teóricos y conceptuales del método clínico de las escuelas psicoanalíticas. Desde el enfoque conductista, la ansiedad se concibe como un impulso motivacional (drive) que induce la con- 
ducta del organismo, siendo responsable de la capacidad del individuo para emitir respuestas ante un estímulo.

El periodo de 1950 a 1965 resulta clave en la generalización de la teoría conductual, autores como Dollard y Miller (1950) y Spence y Taylor (1953) representan los investigadores más relevantes que experimentan sobre este concepto.

Es, a partir de ese periodo, cuando se produce un progreso en la aclaración del constructo ansiedad, considerado como un estado o una respuesta emocional temporal conmensurable en función de sus antecedentes y consecuencias, así como su frecuencia y duración. Este hallazgo permite una mejora en la cuantificación y búsqueda de relaciones entre la ansiedad y otras variables, además ha permitido explicar la aparición o desaparición de la ansiedad en un sujeto por procedimientos de aprendizaje, siendo Mowrer (1950 y 1960) uno de los precursores de la visión de la ansiedad como una conducta aprendida por procedimientos de condicionamiento clásico (citado en De Ansorena et al., 1983).

Cabe destacar en este enfoque, que el estudio de los elementos cognitivos, que previsiblemente intervienen en la adquisición, mantenimiento y pérdida de la ansiedad, pasaría a un segundo plano en el proceso de investigación.

En líneas generales, el individuo hará frente a la situación que le provoca ansiedad mediante la reacción de lucha y huida, evitando el peligro percibido una vez que se propone iniciar la conducta (Sierra, Ortega, \& Zubeidat, 2003).

\section{Enfoque cognitivo}

A partir de la década de los años sesenta comienza el enfoque cognitivista, que tiene como objetivo establecer un nuevo modelo teórico general de la ansiedad apoyándose en las técnicas de análisis factorial, así como en la teoría de rasgos de personalidad. El proceso cognitivo del individuo intercepta y modula el reconocimiento de una señal hostil y la respuesta de ansiedad que expresa el sujeto. Desde esta orientación, la persona observa la situación, la evalúa y estima sus implicaciones. Si el resultado es percibido como una amenaza comenzará la reacción de an- 
siedad, modulada por el proceso cognitivo del individuo. Las situaciones que se aprecian con un mayor grado de ansiedad se evitan, incluso en ausencia de la amenaza real, la interpretación individual puede generar el comienzo de este proceso.

En resumen, los pensamientos, ideas y creencias de la persona inducen a la aparición de la ansiedad en una situación real o amenazante. Generalmente, este proceso funciona de manera automática, el individuo no se da cuenta del inicio y difícilmente puede controlarlo. La persona interpreta, en este caso, la realidad como amenazante, pudiendo ser una amenaza real o no; dicha percepción suele venir acompañada de sensaciones subjetivas, inquietud, nerviosismo, hipervigilancia, miedo, agobio (Akiskal S, 1985).

El primer intento sistemático de medir el constructo ansiedad se le debe al autor Raimond Cattell. En su obra El significado y medida de neuroticismo y ansiedad (citado en Maxwell, 1999) enfatiza en la existencia de dos factores relacionados con la ansiedad: ansiedad estado y ansiedad rasgo.

Posteriormente, Charles Spielberger acuña el segundo gran modelo conceptual. Se apoyó en la línea de investigación abierta por Cattell, tratando de ordenar las diferencias conceptuales existentes hasta 1966 del término ansiedad, enunciando la teoría del "estado-rasgo-proceso", unida a la creación del "Inventario de Ansiedad Estado Rasgo" (C. Spielberger, Gorsuch, Lushene, \& Vagg, 1983). Spielberger enfatiza en la idea de clarificar la relación existente entre los conceptos de ansiedad estado, ansiedad como un estado complejo que incluye el miedo y el estrés y la ansiedad rasgo de personalidad. Según Spielberger, el estrés se reduce a las condiciones estimulares que desencadenan la ansiedad.

Autores como Beck \& Clark (1997) detallan, en su teoría sobre la ansiedad y el pánico, cómo el procesamiento de la información se basa en percepciones cognitivas automáticas por un lado, y controladas por otro, considerando fundamental la anticipación como factor para modular la ansiedad percibida.

En conjunto, la escuela conductista, representada por los hallazgos de spielberger, concibe la ansiedad como un proceso formado por una sucesión compleja de hechos cognitivos, afectivos y comportamentales, evocada por algunas formas de estrés (De Ansorena et al., 1983). Los es- 
tímulos que activan el proceso son interpretados por el individuo, desde un punto de vista cognitivo, como potencialmente peligrosos, elevando por tanto el nivel de ansiedad-estado, acompañado de activación del sistema nervioso autónomo (SNA) y endocrino. La elevación de la ansiedad es contrarrestada con operaciones cognitivas y conductuales que tienen como objetivo disminuir la ansiedad-estado, pudiendo ser de tres tipos: reinterpretación del estímulo, evitación de la situación y emisión de conductas. Las experiencias anteriores, las características propias individuales del SNA y endocrino junto con las estrategias específicas, que se utilizan para interpretar el estímulo, formarían parte de la ansiedad-rasgo según (C. Spielberger et al., 1983).

\section{Enfoque cognitivo-conductual}

Esta línea de investigación tiene como objetivo principal establecer las relaciones entre los estímulos que desencadenan el inicio del proceso ansioso del individuo y su mantenimiento en el tiempo, aunando las aportaciones del enfoque cognitivo y el conductual.

La conducta vendría definida por las características individuales de la persona y las condiciones o contexto donde se desarrolle la actividad. Autores destacados que desarrollaron esta línea de investigación: Bowers (1973), Endler (1973).

Según expone en sus investigaciones, Bowers (1973) establece que las interacciones entre la persona y el contexto explican la mayor parte de las variaciones en la conducta de las personas.

Las investigaciones de Endler (1973) han permitido concluir, que en situaciones potencialmente ansiógenas, las variaciones en de la ansiedad percibida por el sujeto serán debidas en mayor medida por la interacción de la persona con la situación vivida, que las producidas directamente por la situación en sí misma o las diferencias individuales.

Finalmente, la conceptualización de la ansiedad a lo largo de la historia ha estado caracterizada por la influencia de diferentes enfoques, que han servido para complementarse mutuamente o, en algunos aspectos, crear controversia y discrepancia; por ello, para futuras investigaciones, se deberá definir previamente qué enfoque usará el investigador, de esta 
manera se podrán medir y definir las variables que influyen directamente en el nivel de ansiedad del individuo.

En último lugar, se puede puntualizar que la ansiedad ha sido estudiada desde dos perspectivas diferentes a lo largo de la historia, como respuesta emocional y como rasgo de personalidad. Las investigaciones han intentado definir y describir un concepto, que en la actualidad, es aceptado por la mayoría de los autores como un término multidimensional (Endler, 1973), por el cual, un mismo individuo puede reaccionar con diferentes niveles de ansiedad que otra persona que recibe el mismo estímulo, potencialmente amenazante; por ello, durante el desarrollo teórico de este término se deberá tener en cuenta todas sus manifestaciones: cognitiva, fisiológica y motora para delimitar y definir integralmente dicho constructo (Cano-Vindel, Antonio; Miguel-Tobal, 1999).

\begin{tabular}{|c|c|c|}
\hline $\begin{array}{l}\text { TIPO DE } \\
\text { ENFOQUE }\end{array}$ & CONCEPTO DE ANSIEDAD & $\begin{array}{l}\text { AUTORES } \\
\text { RELEVANTES }\end{array}$ \\
\hline $\begin{array}{l}\text { Psicoanalítico } \\
\text { Humanístico }\end{array}$ & $\begin{array}{l}\text { Estado afectivo desagradable en el que surgen } \\
\text { fenómenos como la aprensión, pensamientos } \\
\text { molestos y cambios fisiológicos que se asocian } \\
\text { a la activación autonómica, siendo estos cam- } \\
\text { bios dañinos para el organismo }\end{array}$ & $\begin{array}{l}\text { Freud (1936), Gold- } \\
\text { stein (1939), May } \\
\text { (1950), Rogers (1951), } \\
\text { Sullivan (1953), Lader } \\
\text { y Marks Epstein } \\
\text { (1972) }\end{array}$ \\
\hline Conductual & $\begin{array}{l}\text { Impulso motivacional (drive) que induce la con- } \\
\text { ducta del organismo, siendo responsable de la } \\
\text { capacidad del individuo para emitir respuestas } \\
\text { ante un estímulo }\end{array}$ & $\begin{array}{l}\text { Mowrer (1950 y } \\
\text { 1960), Dollard y } \\
\text { Miller (1950), Spence } \\
\text { y Taylor (1953) }\end{array}$ \\
\hline Cognitivo & $\begin{array}{l}\text { Proceso, formado por una sucesión compleja de } \\
\text { hechos cognitivos, afectivos y comportamenta- } \\
\text { les, evocada por algunas formas de estrés }\end{array}$ & $\begin{array}{l}\text { Charles Spielberger } \\
\text { (1966), Raimond } \\
\text { Cattell (1972), Beck y } \\
\text { Clark (1997) }\end{array}$ \\
\hline $\begin{array}{l}\text { Cognitivo } \\
\text { Conductual }\end{array}$ & $\begin{array}{l}\text { las variaciones en de la ansiedad percibida por el } \\
\text { sujeto, serán debidas en mayor medida por la in- } \\
\text { teracción de la persona con la situación vivida, } \\
\text { que las producidas directamente por la situación } \\
\text { en si misma o las diferencias individuales }\end{array}$ & $\begin{array}{l}\text { Bowers (1973), Endler } \\
(1973)\end{array}$ \\
\hline
\end{tabular}




\subsection{Aproximación del concepto de la ansiedad desde la perspectiva del cuidado enfermero}

Para poder definir el concepto de ansiedad desde el punto de vista enfermero y, para ello, poder planificar un plan de cuidados centrados en resolver posibles problemas independientes, se debe matizar y delimitar el constructor ansiedad (A).

En el apartado anterior se expone, de manera general, cómo ha sido la evolución de un concepto la A, que comienza con connotaciones unidimensionales hasta llegar a la actualidad, donde las teorías multidimensionales son las mayoritariamente aceptadas por los diferentes autores.

Por tanto, se debe diferenciar entre A expresada por una respuesta patológica o por una respuesta normal. Los criterios para diferenciar ambos niveles son los siguientes (Lindenfield, 2003):

- Intensidad, periodicidad y duración de la ansiedad.

- Nivel de sufrimiento que produce la persona.

- Proporción entre la gravedad objetiva del contexto y la intensidad de la respuesta de la ansiedad.

- Grado de interferencia negativa en la vida cotidiana del sujeto (relaciones sociales).

Se pueden destacar como aspectos principales para determinar el rango de respuesta patológica, el nivel de sufrimiento que percibe y experimenta la persona, y el grado de interferencia en las actividades de la vida cotidiana.

La ansiedad se puede manifestar de dos maneras, desde un punto de vista general o permanente a lo largo del tiempo, o desde una manifestación temporal:

a) Ansiedad rasgo: "predisposición a percibir un amplio rango de situaciones estimulares como peligrosas o amenazantes, y en la tendencia a responder tales amenazas con reacciones de estado de ansiedad" (C. D. Spielberger, 1972, p. 489).

b) Ansiedad estado: "un estado emocional transitorio o condición del organismo humano que varía en intensidad y fluctúa a lo largo del tiempo (...) se caracteriza por sentimientos subjetivos consciente- 
mente percibidos de tensión y miedo y activación del sistema nervioso autónomo (C. D. Spielberger, 1972, p. 483).

Desde el punto de vista práctico, las personas que posean niveles altos de "ansiedad rasgo" van a percibir las situaciones estresantes potencialmente más amenazantes que otras personas que tenga un nivel menor, presentando reacciones de ansiedad más frecuentes e intensas en dichos contextos.

En cambio, la "ansiedad estado" hace referencia a un proceso de carácter fisiológico. Se pone en funcionamiento en situaciones y momentos específicos, produciendo en el individuo sentimientos de inquietud, tensión, nerviosismo, manifestaciones conductuales y motoras; estas dos últimas expresiones debidas a la activación del sistema nervioso autónomo. La ansiedad estado se debe conceptualizar desde un punto de vista multidimensional (Bermúdez Moreno, Pérez García, Ruiz Caballero, SanJuán Suárez, \& Rueda Laffond, 2012).

En relación con el desarrollo del concepto de AS, se debe hacer referencia a la década de los setenta y principios de los ochenta, en la que se publicaron los modelos cognitivos de Beck (1976) y Bower (1981).

Beck (1979) basa su teoría en el concepto de esquemas, es decir, estructuras cognitivas constantes, que representan experiencias vividas anteriormente relacionadas con vivencias potencialmente amenazadoras vividas por el individuo, estos esquemas van a permitir codificar y almacenar los estímulos recibidos por la persona durante su vida; si el estímulo concuerda con el esquema previo será codificado y valorado por el individuo, si el estímulo no coincide, no será considerado para su codificación.

\subsubsection{Los sesgos en el procesamiento de la información relacionados con la ansiedad}

Desde la Psicología Cognitiva, se denominan sesgos a la predisposición o estilos cognitivos en el procesamiento de la información. La presencia de estos sesgos puede dar lugar la aparición de trastornos emocionales (Eysenck, MacLeod, \& Mathews, 1987). 
La atención, la interpretación y la memoria han sido de los conceptos con mayor base teórica dentro de las posibles funciones cognitivas del individuo. Se analizará cada concepto por separado y cómo diversos estudios han analizado la ansiedad como modulador de dichas funciones durante el procesamiento de la información percibida como amenazante; por ejemplo, durante el ingreso del paciente previo a una intervención quirúrgica.

\subsubsection{Modelos teóricos cognitivos sobre el procesamiento de la información asociado a la ansiedad}

Los siguientes modelos teóricos describen las diferentes líneas de investigación que explican cómo se producen sesgos cognitivos relacionados con la ansiedad.

El modelo de Beck \& Clark (1997) señala que el procedimiento para procesar la información recibida por las personas, en situaciones de vivencias potencialmente amenazantes, se establece de la siguiente manera:

1. Detección del estímulo (procesamiento automático).

2. Puesta en marcha de los esquemas relacionados con la percepción, vivida en ese momento por la persona.

3. Activación del proceso meta-cognitivo, en función de la información captada y los recursos de afrontamiento disponibles.

Esta teoría explicaría cómo las personas con un nivel de ansiedad estado/rasgo elevado son sensibles a las estímulos percibidos como peligrosos en mayor medida que otras personas con un nivel inferior, debido a que la activación de los esquemas previos dará lugar a un sesgo en puesta en marcha de los procesos cognitivos relacionados con los síntomas del proceso ansioso, aumentando la vulnerabilidad emocional de la persona. Así mismo, Bower (1981) relaciona el proceso de activación de los esquemas previos con la memoria humana. Plantea que la información y las emociones están organizadas en forma de redes "nodulares", interconectados entre sí mediante la información emocional y las experiencias vividas con anterioridad. Al activarse un esquema codificado anteriormente, después de recibir un estímulo, se activará también el "nodo" 
emocional, que repercutirá en la manera de obtener la información para comenzar el proceso cognitivo. En definitiva, el estado emocional en el momento de codificar el esquema o activarlo dependerá del estado de ánimo y la memoria de la persona (Bermúdez Moreno et al., 2012).

Cabe destacar, que el estudio de los sesgos cognitivos, relacionado con el procesamiento de la información en situaciones potencialmente amenazantes, adquiere una importancia relevante para descubrir la etiología, mantenimiento y debilidad a la hora de percibir trastornos emocionales como la ansiedad.

Es por ello que se han planteado diferentes modelos que tienen como objetivo determinar cuáles son los mecanismos cognitivos responsables de los sesgos de atención y el procesamiento de la información emocional.

Entre estos destaca el modelo de Williams, Watts, MacLeod, \& Mathews (1997), los autores describen el procesamiento de la información en dos etapas: una automática inicial y una posterior más procesada de vital importancia para delimitar la reacción frente a eventos potencialmente amenazantes; es en esta fase donde se establecen las relaciones respecto a la experiencia previa vivida y es codificada en la memoria por cada sujeto, dando lugar a la representación mental que se activará con la repetición de un posible evento estresante en el futuro.

En relación con la ansiedad rasgo, este modelo establece que los niveles individuales de dicha variable afectarán a los sesgos en la codificación y procesamiento de la información, debido a la activación, en primer lugar del Mecanismo de decisión afectiva, que tiene como función evaluar el estímulo amenazante, de tal manera que si el estímulo es considerado poco amenazante se continuará con la actividad realizada previamente a la aparición del estímulo, pero si el estímulo es interpretado como amenazante se activará el Mecanismo de localización de recursos, siendo su función la gestión de los nuevos recursos necesarios para afrontar dicha amenaza, lo que provocaría la interrupción de la actividad que se estaba realizando previamente (Williams et al., 1997).

Otro de los modelos propuestos es el de Mogg \& Bradley (1998), este modelo intenta mejorar la limitación que posee el modelo de Williams et al. (1997), que se centra en los diferentes niveles de ansiedad rasgo como concepto clave para los posibles sesgos de información ante eventos 
amenazantes. Sin embargo, para Mogg \& Bradley (1998) el entorno, la ansiedad estado y las experiencias previas van a influir en la evaluación de la amenaza. Según estos autores, el procesamiento de la información también estará formado por dos etapas: la primera, Sistema de Evaluación de la Amenaza (SEA), y la segunda, Sistema de Implicación en Metas, pero en este caso se activarán en función de los niveles de ansiedad estado del individuo, activando ambos sistemas si la acción es catalogada como altamente amenazante. La ansiedad rasgo influirá en los eventos ambiguos o de intensidad media, donde los individuos con alta ansiedad rasgo activarán el sistema completo.

El tercer modelo propuesto es del de Mathews \& Mackintosh (1998), al igual que los modelos anteriores, también explica los sesgos cognitivos asociados a la ansiedad. Dichos autores exponen que en las situaciones potencialmente amenazantes, el SEA tiene como objetivo producir una atención selectiva de los estímulos que son clasificados potencialmente amenazantes, acrecentando de esta menara el uso de recursos de procesamiento. Según Mathews \& Mackintosh (1998), el SEA almacenará las representaciones de esos estímulos amenazantes percibidos para luego acceder a ellos de forma automática, de esta forma, cuando se accede a dicha información es debido a una competitividad entre varios estímulos que compiten por esos recursos atencionales dando lugar a la aparición del sesgo atencional. Esta activación que, a priori parece automática, puede ser modulada y controlada hasta desaparecer mediante el esfuerzo controlado del individuo, basándose en las exigencias de la actividad que realiza o apoyándose en el contexto, evitando así la atención sobre los estímulos amenazantes mediante un sesgo de evitación. En este modelo, en contraposición con los postulados que defiende WiIliams et al. (1997), se propone la independencia en la activación del SEA sin relacionarse con los diferentes niveles de ansiedad rasgo, para Mathews \& Mackintosh (1998) los estímulos potencialmente amenazantes siempre activan el SEA.

El siguiente modelo más reciente es el que postula Bar-Haim, Lamy, Pergamin, Bakermans-Kranenburg, \& van IJzendoorn (2007), el cual se fundamenta en un metaanálisis inicial que realizan los autores sobre los estudios de investigación que analizaban los posibles sesgos atenciona- 
les en relación con la ansiedad. Como resultado del metaanálisis los autores exponen que los sesgos cognitivos relacionados con la amenaza percibida están relacionados con la aparición de ansiedad clínica o subclínica. Las personas con ansiedad estado rasgo elevada, estado de ansiedad o trastorno de ansiedad presentaban una mayor afinidad por los estímulos que percibían como amenazantes que los individuos que no presentaban ansiedad (Bar-Haim et al., 2007).

La revisión realizada por Bar-Haim et al. (2007) culmina estableciendo una teoría propia sobre el proceso de valoración y análisis de estímulos potencialmente amenazantes. Ellos dividen el proceso en cuatro fases: Sistema preatencional de evaluación de la amenaza, Sistema de distribución de recursos, Sistema de guiado de evaluación de la amenaza, Sistema de implicación en metas.

Los investigadores establecen la siguiente relación entre los distintos sistemas. Primero se evalúa el estímulo percibido con la activación del Sistema preatencional de evaluación de la amenaza, si en la evaluación previa el estímulo es catalogado como amenazante para el sujeto se activan el resto de sistemas. A continuación, el Sistema de distribución de recursos dispone los recursos cognitivos y fisiológicos para la resolución de la amenaza. En este sistema a parecen los sesgos atencionales que codifican la información. Posteriormente, se inicia el Sistema guiado de evaluación de la amenaza si el estímulo sigue siendo catalogado como amenazante. Este sistema aportará las estrategias necesarias para hacer frente a la amenaza detectada activando al Sistema de implicación en metas, que se encarga de actuar como defensa, utilizando más recursos de afrontamiento de la amenaza y aumentando la ansiedad estado para finalizar las tareas que se estaban realizando previamente (Figura 6).

\section{Sesgos atencionales asociados a la ansiedad}

La atención se puede definir como "un filtro selectivo que discrimina la información relevante de la irrelevante. La atención se ha descrito también como una capacidad mental limitada que puede centrar su foco sobre distintos aspectos de las situaciones para facilitar el procesamiento" (Eltiti, Wallace, \& Fox, 2005). 


\section{Figura 6. Esquema de respuesta humana ante un estímulo percibido}

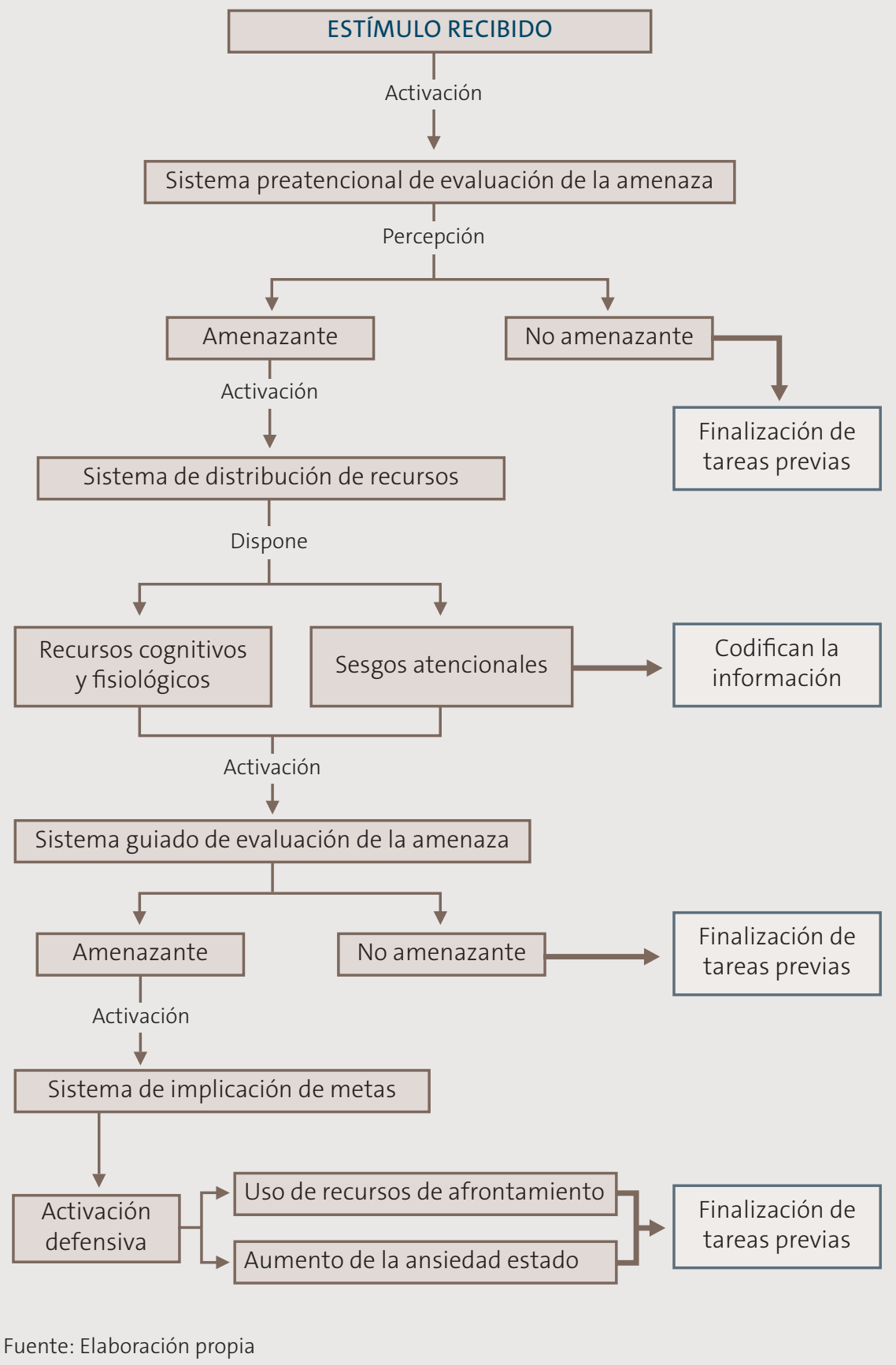


La atención es una condición previa a cualquier funcionamiento cognitivo, es por ello que los procesos atencionales han sido investigados por diversos autores. En líneas generales y basándose en los resultados del metaanálisis realizado por Bar-Haim et al. (2007), a través del análisis de 172 estudios publicados entre febrero de 1986 y mayo de 2005, con una muestra de 4031 sujetos (2273 participantes con ansiedad y 1768 individuos sin ansiedad); concluyen que, la aparición del sesgo atencional, durante el procesamiento de información potencialmente amenazante, se relaciona con los individuos ansiosos, tanto en situación clínica como subclínica, que presenten ansiedad rasgo elevado o tengan trastorno de ansiedad, sin que tal sesgo aparezca en las personas no ansiosas.

Cabe destacar que, en las personas que presentan niveles de ansiedad rasgo bajo, ocurre lo contrario que con las que experimentan ansiedad clínica o subclínica. Las personas con ansiedad rasgo baja tienden a evitar y, por lo tanto, a disminuir la atención de los estímulos que podrían ser potencialmente amenazantes (Mogg \& Bradley, 2005).

Desde la visión enfermera y la planificación de cuidados en pacientes que experimentan un proceso potencialmente amenazante; por ejemplo, las horas previas a una intervención quirúrgica, se debe tener en cuenta estos hallazgos en posibles intervenciones, como recomiendan los investigadores anteriormente mencionados. Por ello, sería beneficioso focalizar las posibles actuaciones del individuo sobre los aspectos conscientes del sesgo atencional.

\section{Sesgos de memoria asociados a la ansiedad}

El estudio de los posibles sesgos de memoria relacionados con la ansiedad ha originado un gran interés por parte de los diferentes equipos de investigación.

El metaanálisis realizado por Mitte (2008) pone de manifiesto la evidencia científica existente sobre la relación de ambos conceptos, analizando de manera cuantitativa 165 estudios, con una muestra total de 9046 personas, en la que compararon individuos no ansiosos con personas con ansiedad rasgo/estado elevada o trastorno de ansiedad, mientras ejecutaban diferentes pruebas de memoria. 
Mitte (2008) concluye que, en correlación a las pruebas de memoria implícita realizada en las investigaciones analizadas, no existe un sesgo de memoria implícita relacionado con niveles de ansiedad rasgo elevado. Respecto a la memoria explícita, en la actividad de reconocimiento de la información amenazante no se detectan diferencias significativas entre las personas con niveles altos y bajos en ansiedad, en cambio, sí a parece un mejor reconocimiento de estímulos pictóricos frente a estímulos verbales en los sujetos con mayor nivel de ansiedad. En relación con el recuerdo libre, existe un leve aumento de individuos ansiosos que recuerdan mejor la información potencialmente amenazante de carácter negativo, respecto a los no ansiosos que recuerdan mejor la información con carácter positivo.

En resumen, los sujetos con ansiedad clínica o subclínica no presentan grandes diferencias respecto al procesamiento de la información en relación con la memoria, la cual es modulada, no solo por el nivel de ansiedad, que tiene un efecto leve o el nivel de amenaza, sino por el tipo de estímulo negativo que puede experimentar el individuo.

Desde la perspectiva enfermera, durante la realización del proceso de enfermería y concretamente en la fase de valoración, se debe tener en cuenta que el sesgo de memoria, como se explicó anteriormente, dependerá en mayor medida del tipo de estímulo que esté recibiendo la persona. En este estudio los estímulos potencialmente amenazantes que percibirán los pacientes se basarán en las experiencias pre y postoperatorias que tengan con respecto al ingreso, intervención y evolución de la cirugía programada endoscópica nasosinusal.

\section{Sesgos de interpretación asociado a la ansiedad}

La evidencia científica existente sobre los posibles sesgos de interpretación relacionados con la ansiedad demuestra, que las personas con ansiedad, interpretan los estímulos que a priori resultan ambiguos como estímulos peligrosos (MacLeod \& Rutherford, 2004).

De este modo, el sesgo de interpretación se definió por una predisposición a procesar la información ambigua con un significado amenazante (Mathews, 2015). 
Así mismo, teniendo en cuenta las conclusiones de Bar-Haim (2010), tras su revisión de las investigaciones que tenían como objetivo manifestar los posibles sesgos cognitivos relacionados con la ansiedad, el autor explica que existe evidencia empírica que explica la correspondencia entre niveles altos de ansiedad rasgo y sesgos de interpretación.

En resumen, los sesgos de información intervienen como posible modulador sobre el nivel de ansiedad de las personas, aunque ningún modelo ha sido capaz de integrar totalmente los resultados obtenidos de forma empírica durante el procesamiento de la información, que es percibida como amenazante por el individuo (Cisler \& Koster, 2010).

Cabe mencionar, que los investigadores han planteado la ansiedad rasgo como un factor clave entre la vulnerabilidad a la ansiedad y la aparición de sesgos cognitivos. Las personas con niveles elevados de ansiedad rasgo podrían estar más predispuestas a desarrollar un trastorno de la ansiedad que las personas con niveles bajos de ansiedad rasgo (Cisler \& Koster, 2010).

En la actualidad, la investigación de la ansiedad rasgo se plantea desde una visión multidimensional, que supone establecer que la conducta ansiosa se define a partir de la interacción entre las características de personalidad y las condiciones del entorno.

Desde esta perspectiva, las personas pueden diferir en la preferencia a reaccionar con estado de ansiedad ante un extenso número de escenarios que pueden ser agrupados, como señalan Cano-Vindel y Miguel-Tobal (1999), en cuatro grandes áreas: ansiedad ante situaciones de evaluación, ansiedad interpersonal o social, ansiedad fóbica y ansiedad en la vida cotidiana.

\subsection{Ansiedad y salud}

A lo largo de la historia, en relación con los avances científicos en el estudio de la ansiedad y su repercusiones en la salud, se ha profundizado en este concepto desde diferente puntos de vista y perspectivas. Groso modo, si por ejemplo, se utilizan los conceptos de ansiedad (anxiety) y salud (health) como palabras claves y se buscan los posibles resultados 
uniendo ambos conceptos con el conector "and", sin restricción temporal en la base de datos MEDLINE, se encuentran 52861 estudios en humanos que cumplen esos criterios.

Por consiguiente, se limitará la revisión de la existencia de evidencia científica sobre ambos conceptos, a lo concerniente a los cuidados de enfermería; por lo tanto, en las búsquedas bibliográficas que se han hecho siempre se ha añadido la palabra clave: "cuidados de enfermería" (nursing care).

\subsubsection{Evidencia científica actual sobre la ansiedad y su relación con la salud}

En primer lugar, se planteó como objetivo inicial cuantificar desde una perspectiva real cuantos estudios de investigación obteníamos en las pricipales bases de datos sobre el concepto de ansiedad (A) y salud, pero siempre desde la perspectiva enfermera utilizando como palabra clave los "cuidados enfermeros".

Para ello, se usó como metodología de búsqueda la siguiente: estudios encontrados sin límite de fechas hasta la actualidad, con filtro de idioma, español, inglés y portugués, sin límite geográfico, usando las palabras claves según la terminología de Descriptores de Ciencias de la Salud (DeCS) en español, y Medical Subjects Headings (MeSH) en inglés, que se obervan en la Tabla 9, utilizando como operador boleano "and", las palabras clave elegidas deben a paracer en el título, o en el resumen, disponibilidad de texto completo, se filtraron los estudios con mayor nivel de evidencia tales como ensayos clínicos aleatorizados, estudios descriptivos y cualitativos bien diseñados, metaanálisis y revisiones sistemáticas, fecha de realización de la búsqueda 16 enero de 2017.

Se ha consultado las bases de datos Elton B. Stephens Company (EBSCO), Cumulative Index to Nursing and Allied Health Literature (CINAHL), Science direct, PubMed, Cuiden, Excerpta Medica Database (EMBASE), The Offshore Vessel Inspection Database (OVID), The Joanna Briggs Institute (JBI), Literatura Latinoamericana de Información en Ciencias de la Salud (LiLacs), Cochrane, Scientific Electronic Library Online(Scielo), Google Scholar, Îndice Bibliográfico Español en Ciencias de la Salud (IBECS) y ClinicalKey, como se muestra en la Tabla 9. 


\begin{tabular}{ll}
\hline Tabla 9. Descriptores controlados & \\
\hline DeCS & MeSH \\
\hline Ansiedad & Anxiety \\
\hline Salud & Health \\
\hline Atención de Enfermería & Nursing Care \\
\hline Práctica Clínica Basada en la Evidencia & Evidence-Based Practice \\
\hline Cirugía & Surgery \\
\hline Evaluación Preoperatoria & Surgical Clearance \\
\hline Enfermedad & Disease \\
\hline
\end{tabular}

Se debe destacar el descenso significativo de estudios con respecto a los resultados que encontramos en la Tabla 2, mencionada en el capítulo anterior cuando explícabamos la contextualicación del termino AS y salud (ver Tabla 10).

Tabla 10. Resumen de número de artículos encontrados en la búsqueda bibliográfica con la palabra clave Anxiety como concepto principal

\begin{tabular}{|c|c|c|c|c|c|}
\hline Base de datos & $\begin{array}{r}\text { Anxiety, } \\
\text { Nursing } \\
\text { Care } \\
\text { AND } \\
\text { Health }\end{array}$ & $\begin{array}{r}\text { Anxiety, } \\
\text { Nursing } \\
\text { Care } \\
\text { AND } \\
\text { Surgical } \\
\text { Clearance }\end{array}$ & $\begin{array}{r}\text { Anxiety, } \\
\text { Nursing } \\
\text { Care } \\
\text { AND } \\
\text { Disease }\end{array}$ & $\begin{array}{r}\text { Anxiety, } \\
\text { Nursing Care } \\
\text { AND } \\
\text { Evidence } \\
\text { Based } \\
\text { Practice }\end{array}$ & $\begin{array}{r}\text { Anxiety, } \\
\text { Nursing } \\
\text { Care } \\
\text { AND } \\
\text { Surgery }\end{array}$ \\
\hline EBSCO-CINAHL & 224 & 2 & 80 & 1 & 41 \\
\hline Science direct & 311 & - & 102 & 29 & 67 \\
\hline PubMed & 99 & 2 & 1147 & 213 & 66 \\
\hline Cuiden & 37 & 0 & 15 & 0 & 16 \\
\hline EMBASE & 746 & 2 & 321 & 21 & 90 \\
\hline OVID & 154 & - & 71 & & 3 \\
\hline$J \mathrm{BI}$ & - & - & - & - & - \\
\hline Lilacs & 20 & - & 8 & - & 8 \\
\hline Cochrane & - & - & - & - & - \\
\hline Scielo & 60 & - & - & 1 & 6 \\
\hline Google Scholar & 5 & - & 3 & - & 2 \\
\hline IBECS & 32 & - & 12 & - & 20 \\
\hline ClinicalKey & 104 & 1 & 69 & 38 & 46 \\
\hline
\end{tabular}


Al limitar la búsqueda usando como una de las palabras clave "cuidados de enfemería" ("nursing care"), se puede observar cómo se cuantifica a grandes rasgos un problema que ya han expuesto otros autores, respecto al escaso protagonismo de la enfermería en la investigación y las bases de datos internacionales (García, Gallegos, \& Ochoa, 2011; Morales Asencio, 2004; Triviño \& Sanhueza, 2005); por ejemplo, si en la base de datos PubMed se obvia la palabra clave "nursing care", y se buscan los estudios con los mismos criterios elegidos para elaborar la Tabla 10, se obtiene un total de 31568, frente a los 66 estudios encontrados si se añade como palabra clave "nursing care".

En relación con la lectura crítica de los resultados obtenidos, se han delimitado y filtrado los resultados y estudios analizados a aquellos que se relacionan, directamente o en su mayoría, con el objetivo principal de este estudio y el ámbito de aplicación, en este caso, la ansiedad estudiada desde la perspectiva de los cuidados enfermeros preoperatorios y su posterior planificación, para disminuir dicha ansiedad previa a una cirugía programada correspondiente a las referencias encontradas en la columna número seis de la Tabla 10, según el flujograma reflejado en la Figura 7.

La Tabla 11 muestra los documentos seleccionados con su respectivo nivel de evidencia y recomendación, según los criterios del epidemiólogo Sackett (Manterola, Asenjo-Lobos, \& Otzen, 2014). 
Figura 7. Selección definitiva de referencias

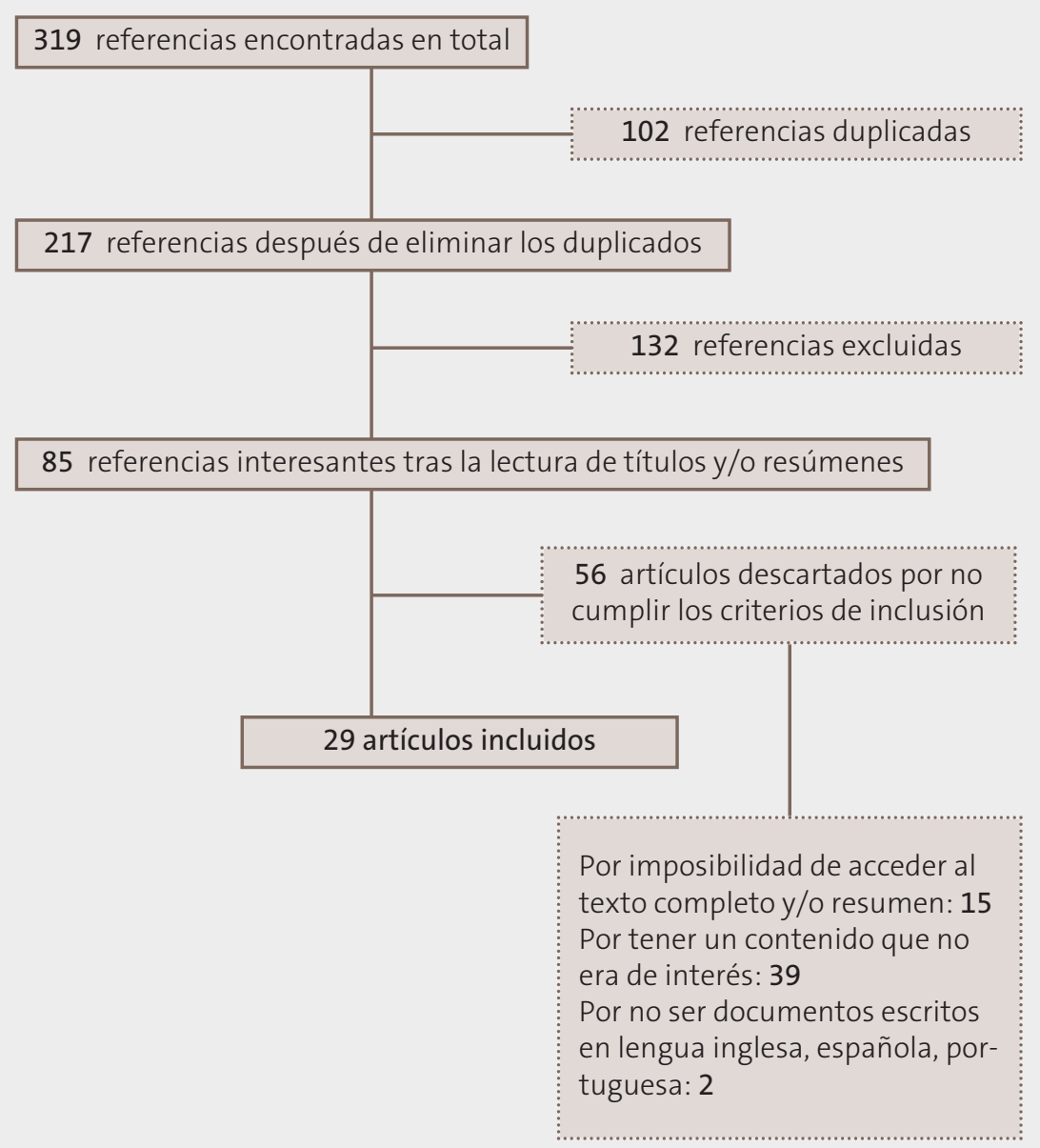




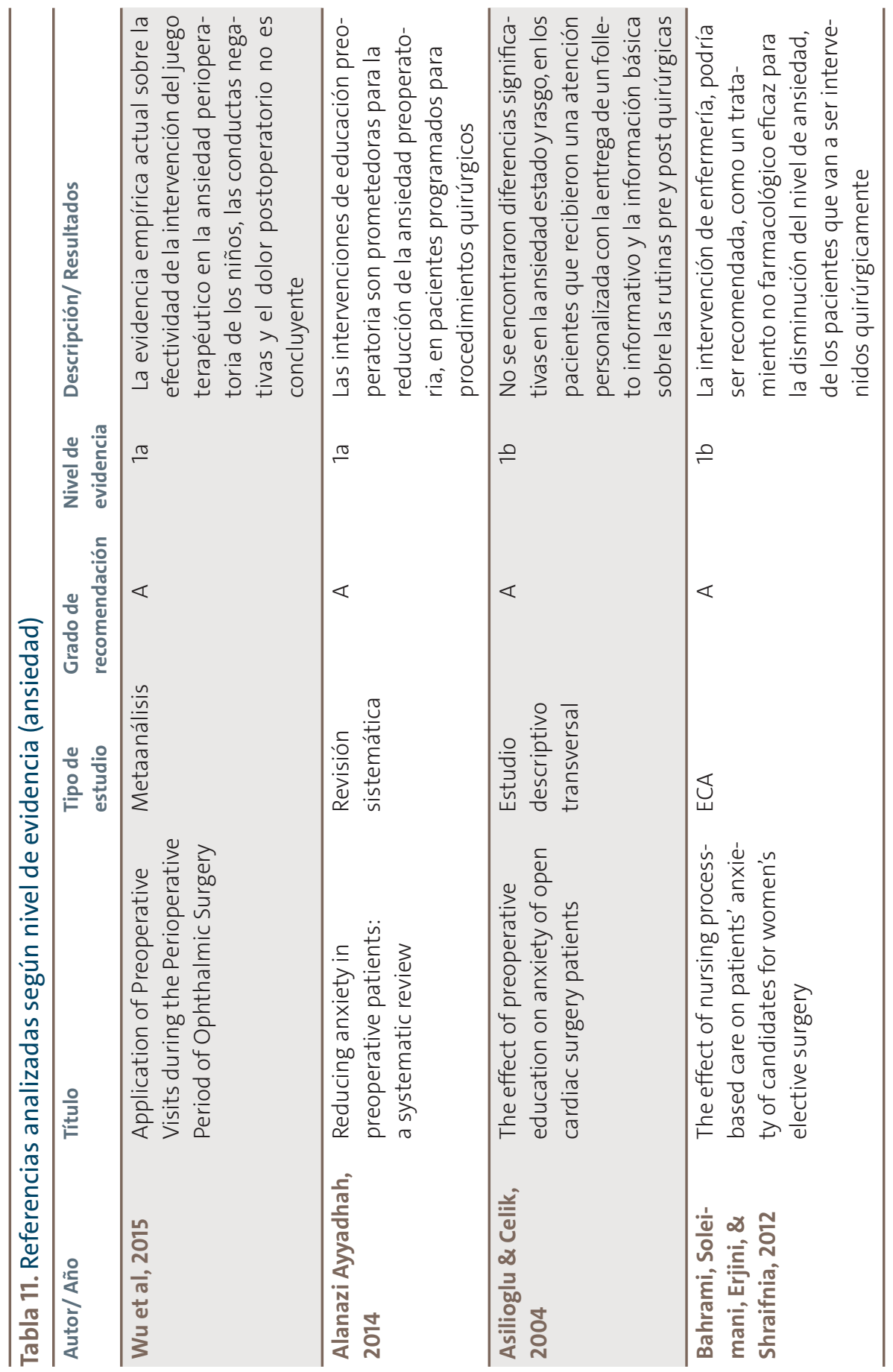




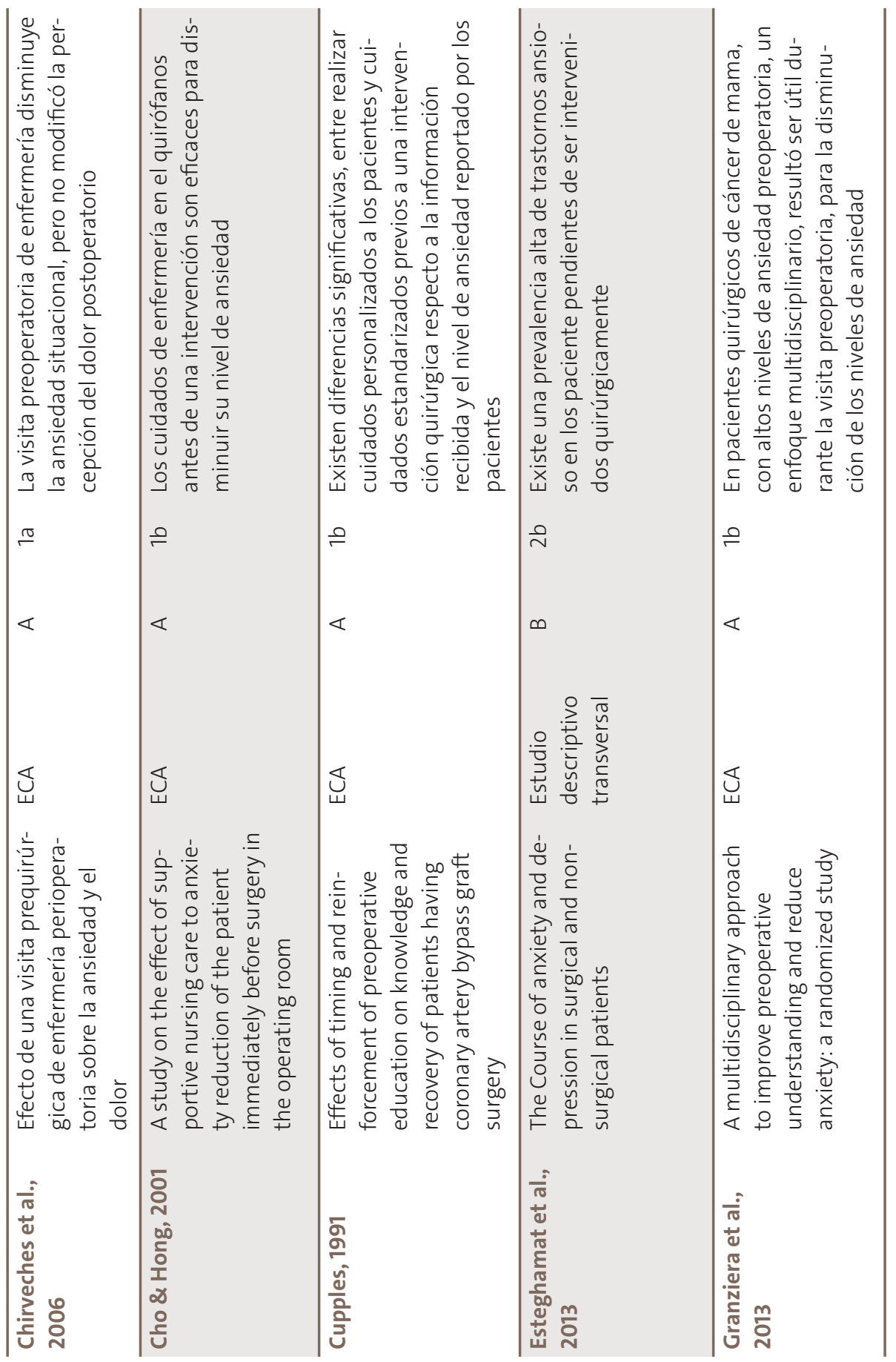




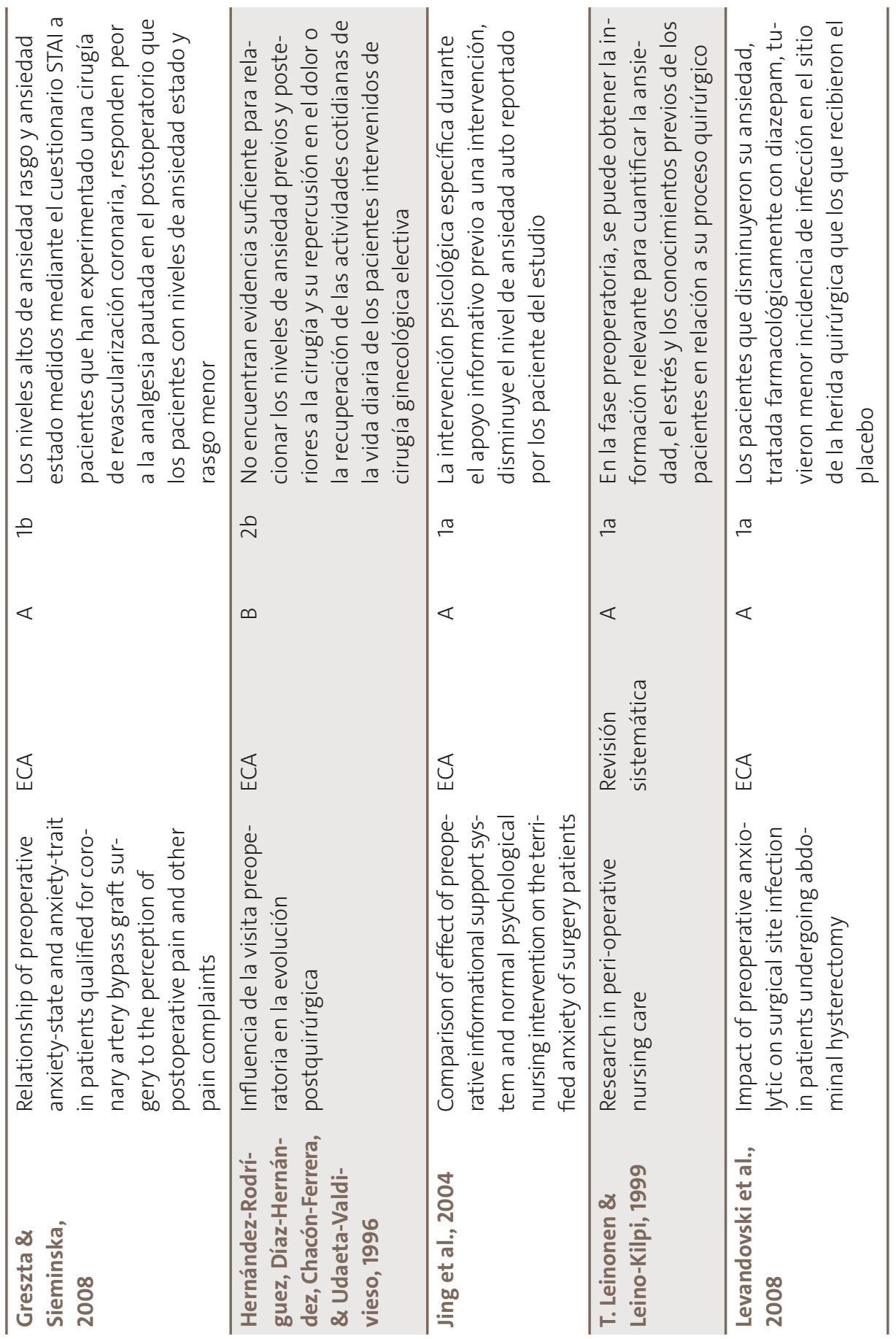




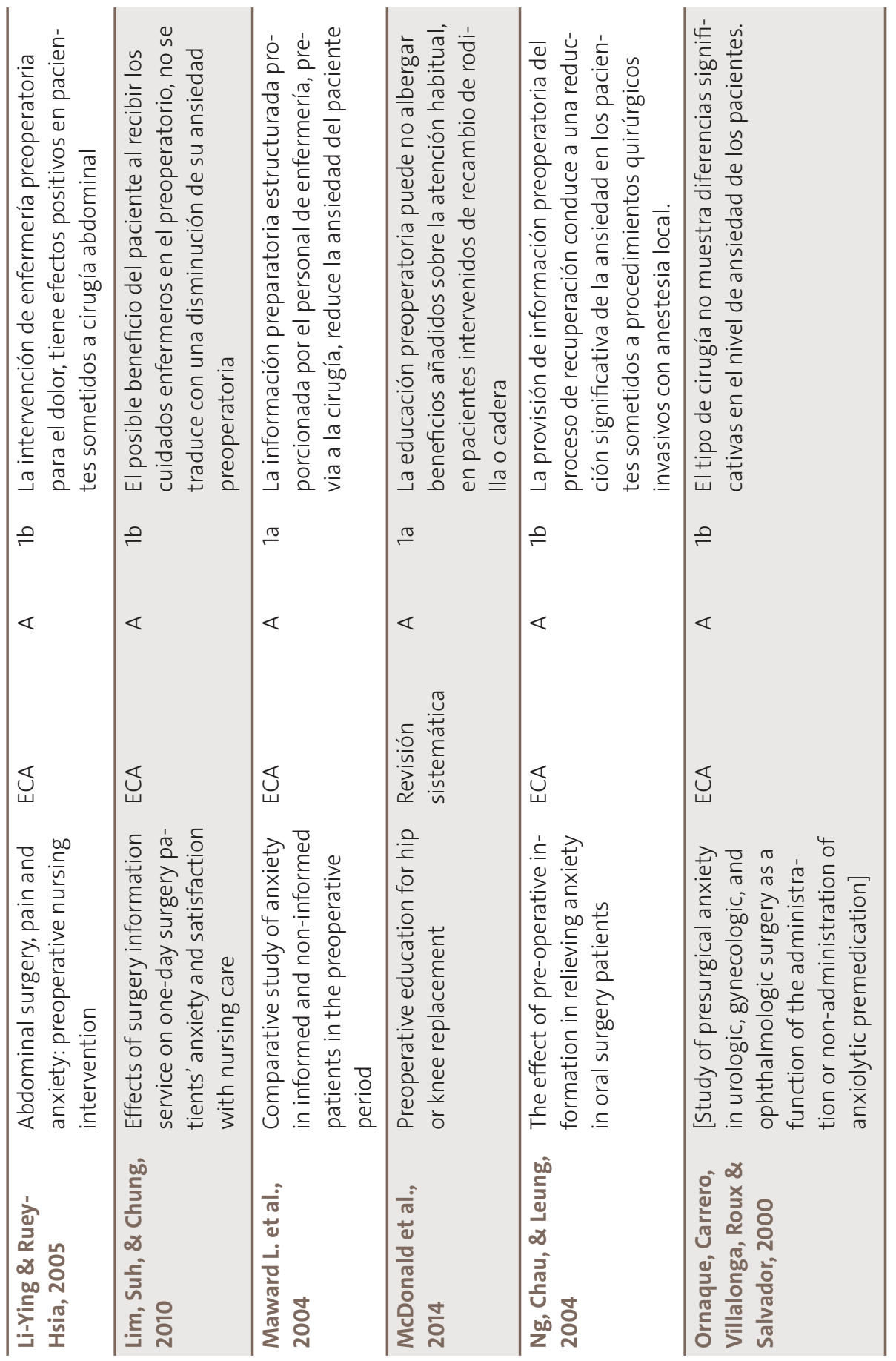




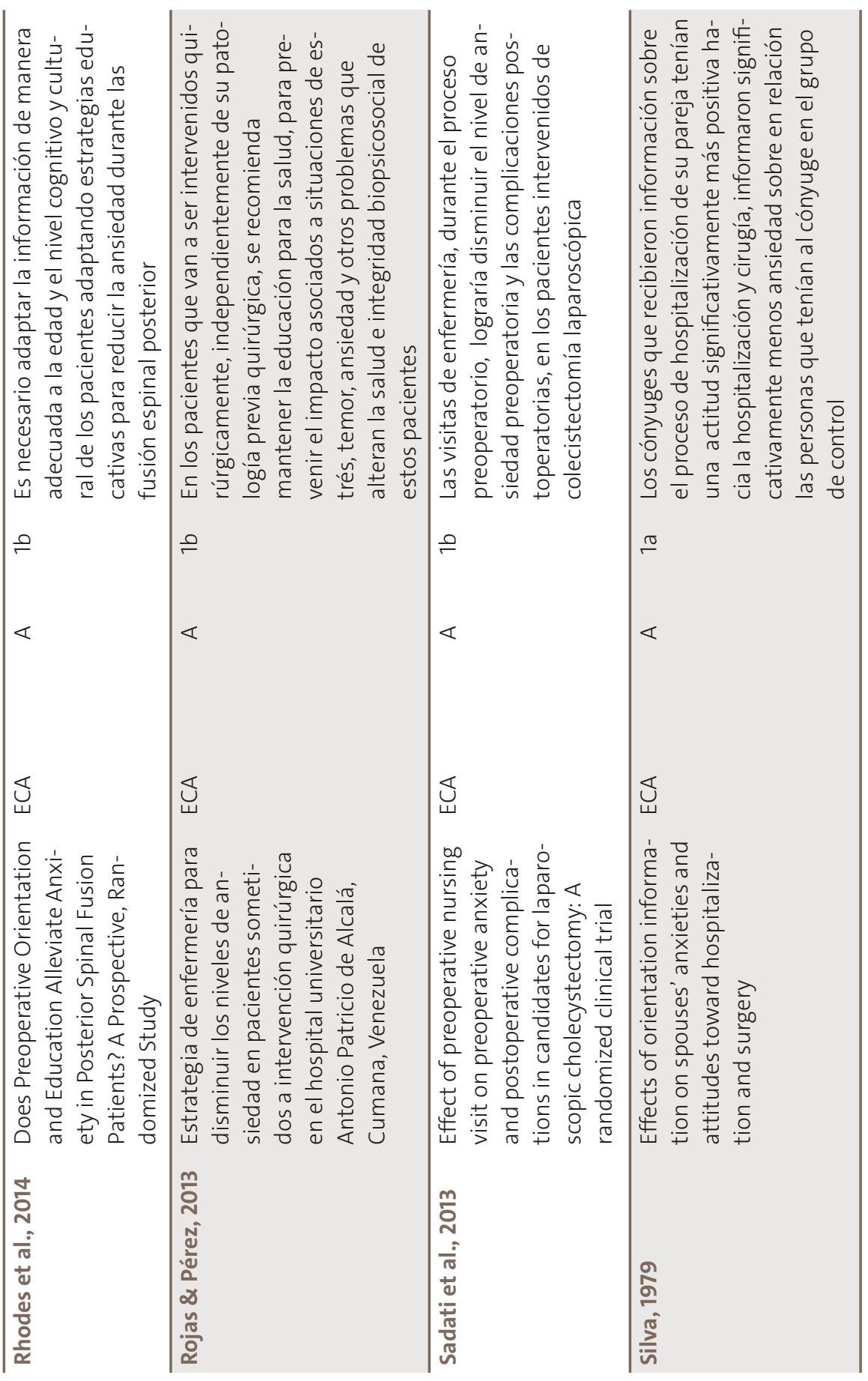




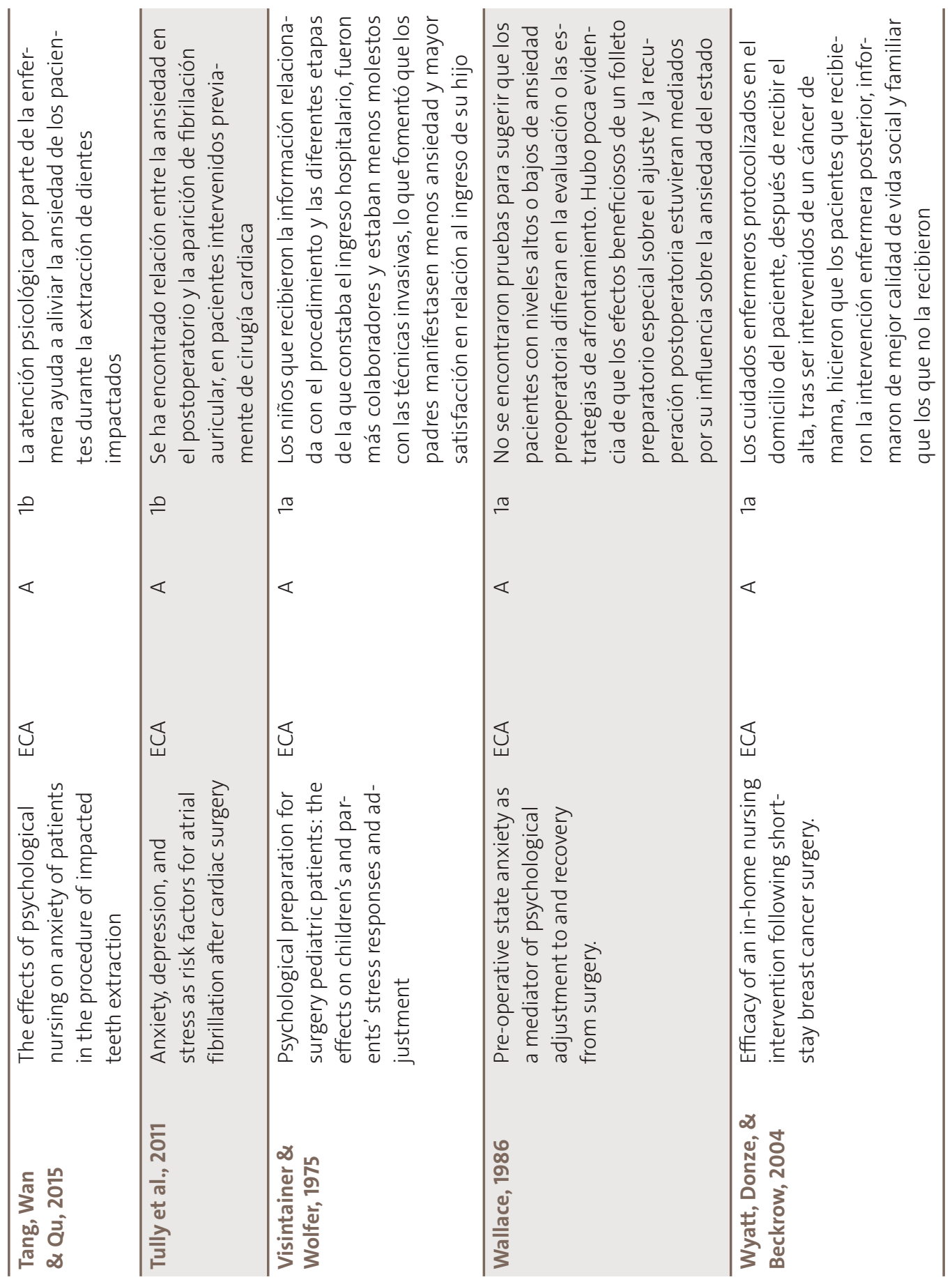


Prosigue el análisis en orden cronológico de los estudios de investigación encontrados que cumplen los criterios de selección mencionados anteriormente, y que permiten el acceso a texto completo desde la biblioteca de la Universidad Jaume I y la biblioteca del Servicio Canario de Salud.

En primer lugar, se debe mencionar el estudio realizado por Visintainer \& Wolfer (1975), este estudio tuvo como objetivo comprobar la hipótesis de que los niños programados para una cirugía menor, que reciben preparación psicológica de una manera protocolizada y un apoyo continuo en sus cuidados durante su estancia hospitalaria, serían más colaboradores y presentarían menos problemas postquirúrgicos que los que no la recibieran, a su vez se planeó, que estos niños que recibieron el apoyo, poseerían unos padres que se declararían menos ansiosos y más satisfechos de la información y cuidados recibidos.

El ensayo clínico aleatorizado se llevó a cabo con 80 niños programados para cirugía menor junto con sus padres, siendo asignados aleatoriamente a un grupo experimental y un grupo control. La intervención experimental radicó en brindar una información exacta sobre los distintos procesos por los que pasaría el niño junto con sus padres, se utilizaron técnicas basadas en juegos para los niños y apoyo directo sobre los padres. Como resultado, los autores obtuvieron diferencias significativamente estadísticas entre el grupo experimental y el grupo control, en parámetros como pulso antes y después del procedimientos doloroso, resistencia a la inducción, ansiedad de los padres, satisfacción de la información recibida, colaboración de los niños en los procedimientos. Los autores concluyeron que los niños que recibieron la información relacionada con el procedimiento y las diferentes etapas de la que constaba el ingreso hospitalario fueron más colaboradores y estaban menos molestos con las técnicas invasivas, lo que fomentó que los padres manifestasen menos ansiedad y mayor satisfacción en relación con el ingreso de su hijo.

Cabe destacar, que ya en los primeros estudios que relacionaban la ansiedad con el proceso quirúrgico y los cuidos enfermeros, se planteaba la importancia de valorar y cuantificar la ansiedad de las personas que serán el apoyo y que darán los cuidados después del alta hospitalaria del paciente, prueba de ello es el estudio de Silva (1979), que planteaba la hipótesis de que los cónyuges que recibían información orientativa sobre 
el proceso de hospitalización y quirúrgico de su pareja experimentarían menor ansiedad y actitud más favorable al ingreso hospitalario. Después de analizar los 48 cónyuges que fueron asignados de manera aleatoria al grupo experimental que recibió la información estructurada durante 20 minutos resolviendo posibles dudas, y al grupo control que no la recibió, inmediatamente después se evaluó su ansiedad y actitudes frente a la situación que estaban experimentando debido al ingreso de su pareja, mediante el Inventario de ansiedad estado y la Escala de percepción de los cónyuges. Los autores concluyen que los individuos concernientes al grupo experimental poseían una condición más positiva frente al ingreso hospitalario y la intervención quirúrgica. Dicho grupo experimental notificó significantemente menor ansiedad en relación con el grupo control (Silva, 1979).

En contraposición, como también ocurría en la evidencia científica analizada con respecto al constructo de AS, algunas líneas de investigación no encuentran la relación directa existente entre información y disminución de la ansiedad durante el proceso quirúrgico. Por ejemplo, Wallace (1986) defiende que hubo poca evidencia para sugerir que la información preoperatoria, por ejemplo, en forma de folleto explicativo para el paciente, influya directamente sobre su ansiedad estado previa a la cirugía.

Conviene subrayar que no es lo mismo un folleto que el contacto directo y personal del enfermero con el paciente, que se lleva a cabo en la unidad de hospitalización o durante la visita preoperatoria el día anterior, y el refuerzo el día de la intervención cuando es recibido en quirófano por el enfermero, resultando positivo durante las diferentes etapas de la recuperación del paciente intervenido quirúrgicamente (Hernández-Rodríguez et al., 1996).

Así mismo, en este mismo estudio, el autor no encuentra evidencia suficiente para relacionar los niveles de ansiedad previos y posteriores a la cirugía y su repercusión en el dolor o la recuperación de las actividades cotidianas de la vida diaria de los pacientes incluidos en el estudio, que en este caso fueron intervenidos de cirugía ginecológica electiva.

En relación con estas primeras décadas de estudios de investigación, centrados en el proceso quirúrgico y la cuantificación de los diferentes niveles de ansiedad y su relación otros factores quirúrgicos, destacamos 
la revisión realizada por Leinonen \& Leino-Kilpi (1999) sobre 97 estudios de investigación previos, que tenían como objetivo valorar la atención perioperatoria de los cuidados de enfermería desde el punto de vista de los pacientes. Los autores concluyeron que en la fase preoperatoria se puede obtener la información relevante para cuantificar la ansiedad, el estrés y los conocimientos previos de los pacientes en relación con su proceso quirúrgico. Leinon y Leino-Kilpi destacan los defectos mayoritarios encontrados en la revisión para que puedan ser subsanados en futuras investigaciones, como la falta de definición de términos, la ambigüedad teórica o el uso de fármacos o anestésicos no mencionados en el estudio y la utilización de herramientas construidas por los investigadores sin validar. Los autores finalizan recomendando, para futuras investigaciones, estudiar sobre la atención intraoperatorio y ahondar en el estudio de los cuidados de enfermería en el proceso quirúrgico, que hasta esa fecha todavía necesitaban más detalle y profundización conceptual y empírica.

Se debe destacar el estudio realizado por Ornaque, Carrero, Villalonga, Roux, \& Salvador (2000), que tuvo como objetivo medir el nivel de ansiedad en pacientes que iban a ser intervenidos quirúrgicamente, obteniendo una muestra de 87 pacientes, intervenidos de ginecología, oftalmología y urología, a los que se le administraba de manera aleatoria diazepam, placebo o nada, momentos antes de la cirugía, y revisa los valores en los niveles de ansiedad en ese momento con los valores que se obtuvieron durante la visita preoperatoria el día anterior. Los investigadores concluyen que el tipo de cirugía no muestra diferencias significativas en el nivel de ansiedad de los pacientes.

En relación con los cuidados enfermeros realizados justamente antes de la cirugía y su efecto con el nivel de ansiedad del paciente, encontramos evidencia científica que defiende la utilidad y eficacia de estos cuidados en el momento antes de la intervención, como se demuestra en el estudio realizado por Cho \& Hong (2001) a pacientes que fueron intervenidos de cirugía abdominal obteniendo una muestra de 48 pacientes, divididos en grupo control y grupo experimental, en el que se midió el nivel de ansiedad rasgo y estado mediante el cuestionario validado de Spielberger (1976). Un grupo recibió cuidados de enfermería en el quirófano previos a la cirugía y el otro grupo no, demostrando los resultados que 
los cuidados de enfermería en el quirófano antes de una intervención son significativamente eficaces para disminuir su nivel de ansiedad ( $p<0.01$ ).

Por otra parte, cabe señalar el estudio de investigación realizado por Jing et al. (2004) sobre un total de 296 pacientes que se asignaron al azar en dos grupos, uno recibió una intervención relacionada con el proceso informativo preoperatorio específico por parte de los autores del estudio, y el otro recibió un apoyo psicológico normal o estándar por parte del personal de enfermería. Los resultados concluyen que la intervención psicológica específica durante el apoyo informativo previo a una intervención disminuye el nivel de ansiedad auto reportado por los pacientes del estudio, siendo significativamente menor en el grupo que recibió la información de manera personalizada $(p<0,01)$.

De este modo, basándonos en los resultados mencionados anteriormente, los cuidados enfermeros pueden enriquecerse desde un punto de vista cualitativo si en la valoración se detectan datos sobre la personalidad del paciente o incluso posibles a poyos sociales que sean importantes para él. Así, de esta forma, se podrá planificar unos cuidados personalizados específicos durante el ingreso previo a una intervención quirúrgica. En este caso, el estudio intenta ser la base para que en futuras investigaciones se desarrolle un cuerpo de conocimientos en los que el enfermero o enfermera, no solo vea como parte importante la detección de parámetros objetivos y físicos, sino que valore al paciente desde un punto de vista integral usando herramientas que aporten datos de la personalidad del paciente y de su apoyo social percibido, en definitiva, realizar una valoración específica para que los cuidados sean individualizados y más completos.

De manera semejante, la evidencia científica avala el trabajo enfermero en el postoperatorio en el domicilio del paciente. Autores como Wyatt, Donze, \& Beckrow (2004) concluyen en su estudio controlado aleatorizado $(n=240)$, que los cuidados enfermeros protocolizados en el domicilio del paciente después de recibir el alta, tras ser intervenidos de un cáncer de mama, hicieron que los pacientes que recibieron la intervención enfermera posterior, informaron de mejor calidad de vida social y familiar que los que no la recibieron.

Por el contrario, existe otra corriente de investigadores que no han encontrado diferencias significativas entre realizar cuidados personalizados 
a los pacientes y cuidados estandarizados previos a una intervención quirúrgica respecto a la información recibida y el nivel de ansiedad reportado por los pacientes (Cupples, 1991). El estudio realizado por Asilioglu \& Celik (2004) tampoco encontró diferencias significativas en la ansiedad estado y rasgo en la muestra de 100 pacientes, 50 de los cuales recibieron una atención personalizada basada en la entrega de un folleto informativo, y los otros 50 pacientes solo recibieron la información básica sobre las rutinas pre y postquirúrgicas. Las conclusiones de los autores exponen como posibles causas de esa falta de significación estadística entre la intervención personalizada y la no personalizada: la falta de apoyo de las administraciones de los hospitales, la falta de habilidades de comunicación del personal de enfermería, la necesidad de mejora en el apoyo a la familia y, por último, ofrecer una educación multidisciplinar al paciente.

Es necesario recalcar que, debido al gran número de estudios disponibles y la variedad de los mismos, sobre todo a partir de 2004, se decidió sintetizar el gran número de estudios disponibles que tienen como objetivo relacionar el concepto de ansiedad durante el proceso quirúrgico y su correspondencia con los cuidados enfermeros. Además, a partir de 2004, dada la variedad de los mismos, se decidió sintetizarlos desde la perspectiva conceptual del objetivo que persigue cada estudio y de las conclusiones obtenidas, en lugar de ordenar la evidencia cronológicamente.

En primer lugar, se pueden destacar las investigaciones que intentan buscar la concordancia entre ansiedad y proceso quirúrgico unida a la posible relación con la presencia de otras patologías. Por ejemplo, el estudio descriptivo transversal realizado por Esteghamat et al. (2013) de manera transversal sobre 359 pacientes hospitalizados, concluye que existe una prevalencia alta de trastornos ansiosos en los pacientes pendientes de ser intervenidos quirúrgicamente. Dicho lo anterior, se ha encontrado relación entre la ansiedad en el postoperatorio y la aparición de fibrilación auricular en un estudio realizado a 222 pacientes que fueron intervenidos previamente de cirugía cardiaca (Tully et al., 2011).

Un dato interesante hallado en la búsqueda de Levandovski et al. (2008) es la relación encontrada entre la fase de cicatrización y la ansiedad desarrollada durante el proceso quirúrgico. Su ensayo clínico aleatorizado 
doble ciego controlado con placebo, que incluyó a 130 pacientes intervenidos de histerectomía, obtuvo como resultado que los pacientes que disminuyeron su ansiedad, en este caso tratados farmacológicamente con diazepam, tuvieron menor incidencia de infección en el sitio de la herida quirúrgica que los que recibieron el placebo.

En el caso de los cuidados preoperatorios y la información preoperatoria, existe una evidencia bastante sólida sobre su eficacia en la disminución de la ansiedad (Maward L. \& Azar, 2004; Ng et al., 2004). En el ensayo clínico prospectivo controlado con asignación aleatoria a dos grupos, que tenía como objetivo evaluar el efecto de la visita preoperatoria de enfermería, con una muestra final de 350 pacientes (183 grupo control y 167 en el grupo intervención), concluye que la visita preoperatoria de enfermería disminuye la ansiedad situacional, pero no modifica la percepción del dolor postoperatorio (Chirveches et al., 2006).

Hay que mencionar además, que conclusiones parecidas ya eran señaladas por estudios de investigación realizados por Hernández-Rodríguez, Díaz-Hernández, Chacón-Ferrera, \& Udaeta-Valdivieso (1996), los autores concluyen tras analizar los resultados de la muestra aleatoria de 80 pacientes, que fueron intervenidos quirúrgicamente recibiendo anestesia locorregional, concretamente raquianestesia; los pacientes recibieron la visita preoperatoria por parte del personal de enfermería, que basó sus recomendaciones en función de las necesidades de cada paciente, incluido las recomendaciones postquirúrgicas que debería seguir tras recibir la anestesia locorregional para evitar, entre otras cosas, las cefaleas asociadas a dicho procedimiento. Los investigadores concluyen, en función de los resultados encontrados, el efecto modulador que tiene la visita preoperatoria del paciente por parte del personal de enfermería sobre la cumplimentación de las recomendaciones dadas y la disminución de la incidencia de cefaleas postquirúrgicas asociada a la técnica anestésica realizada sobre los pacientes seleccionados. Por otro lado, el estudio concluye recomendando la realización de más investigaciones que tengan la visita preoperatoria como objetivo principal, como herramienta para demostrar la importancia de esta actividad que la enfermera puede realizar, sirviendo no solo como se demostró en el estudio de posible modulador en determinadas variables, como pueden ser el seguimiento de las 
indicaciones postquirúrgicas por parte de los pacientes, sino además puede ser útil como nexo de unión entre la enfermería de quirófano, hospitalización y atención primaria (Hernández-Rodríguez et al., 1996).

Por lo que se refiere a la correlación entre el dolor y la ansiedad percibida de los pacientes que van a ser intervenidos quirúrgicamente después de recibir los cuidados enfermeros preoperatorios, investigaciones como el estudio controlado aleatorizado desarrollado por Li-Ying \& RueyHsia (2005), sobre 62 pacientes que fueron intervenidos de cirugía abdominal, un grupo recibió atención específica diseñada para su proceso concreto y efectuada por la enfermera en el preoperatorio, y el otro grupo control solo atención única por parte del personal de enfermería que lo atendió en la planta de hospitalización, concluyen que "la intervención de enfermería preoperatoria para el dolor tiene efectos positivos en pacientes sometidos a cirugía abdominal. La intervención utilizada en este estudio podría servir de guía para que las enfermeras mejoren el cuidado del dolor de estos pacientes" (Li-Ying \& Ruey-Hsia, 2005).

De igual modo, se realizó un estudio sobre 60 pacientes que fueron intervenidos de artroplastia de rodilla, el objetivo del estudio fue buscar la relación entre la información específica antes de la intervención y el dolor postoperatorio, el resultado final del estudio sugirie que la información previa y factores psicológicos como la ansiedad influyen directamente sobre el dolor postoperatorio.

Así mismo, Greszta \& Sieminska (2008) observaron que los niveles altos de ansiedad rasgo y ansiedad estado, medidos mediante el cuestionario STAI a pacientes que han experimentado una cirugía de revascularización coronaria, responden peor a la analgesia pautada en el postoperatorio que los pacientes con niveles de ansiedad estado y rasgo menor, por lo que se recomienda planificar acciones para redudir la ansiedad en este tipo de pacientes.

Algo semejante ocurre con el uso de medicamentos ansiolíticos durante el preoperatorio, así un estudio realizado sobre 51 pacientes intervenidos de cirugía ortognática concluye que el consumo de ansiolíticos previos a dicha intervención redujo el consumo de morfina en el postoperatorio, administrada mediante una bomba de analgesia controlada por el paciente. 
Hay que mencionar además, los trabajos de los científicos que se han centrado en la intervención enfermera específica en el paciente quirúrgico.

Destacando y analizando, las principales investigaciones y ensayos clínicos aleatorizados realizados con pacientes que fueron sometidos a una intervención quirúrgica, con cálculo del nivel de ansiedad durante el proceso pre y postoperatorio, en relación con las intervenciones enfermeras específicas o intervenciones educativas, se obtuvo una serie de conclusiones en las que destacan que:

- La intervención de enfermería podría ser recomendada como un tratamiento no farmacológico eficaz para la disminución del nivel de ansiedad de los pacientes que van a ser intervenidos quirúrgicamente (Bahrami et al., 2012; Tang et al., 2015).

- Las visitas de enfermería durante el proceso preoperatorio lograrían disminuir el nivel de ansiedad preoperatoria y las complicaciones postoperatorias en los pacientes intervenidos de colecistectomía laparoscópica (Sadati et al., 2013).

- En los pacientes que van a ser intervenidos quirúrgicamente, independientemente de su patología previa quirúrgica, se recomienda mantener la educación para la salud, para prevenir el impacto asociado a situaciones de estrés, temor, ansiedad y otros problemas que alteran la salud e integridad biopsicosocial de estos pacientes (Rojas \& Pérez, 2013).

- En pacientes quirúrgicos de cáncer de mama con altos niveles de ansiedad preoperatoria, un enfoque multidisciplinario con intervención psico-oncológica resultó ser útil durante la visita preoperatoria para la disminución de los niveles de ansiedad (Granziera et al., 2013).

- Es necesario diseñar la información de manera adecuada a la edad y el nivel cognitivo y cultural de los pacientes adaptando estrategias educativas para reducir la ansiedad durante las fusión espinal posterior (Rhodes et al., 2014).

En contraposición, se encuentra, por ejemplo, el estudio de Lim, Suh, \& Chung (2010), aunque destaca como conclusión el posible beneficio del paciente al recibir los cuidados enfermeros en el preoperatorio, defiende que dichos cuidados no disminuyen su ansiedad preoperatoria. 
Como conclusión, se puede destacar la aportación de la revisión sistemática realizada por McDonald et al. (2014), que tuvo como objetivo valorar si la educación a los pacientes antes de ser intervenidos de reemplazo de rodilla o cadera tiene efecto positivo sobre el dolor, la función, calidad de vida, ansiedad, duración de la estancia hospitalaria y la incidencia de eventos adversos. Después de analizar los ensayos clínicos aleatorios y cuasialeatorios que cumplieron los criterios de inclusión de la revisión, se analizaron un total de 18 ensayos (1463 participantes), Ilegando a la conclusión de que la educación preoperatoria puede no albergar beneficios añadidos sobre la atención habitual en pacientes intervenidos de recambio de rodilla o cadera. Es por ello que los autores recomiendan para la práctica clínica no obviar una atención que es esencial en el cuidado del paciente, pero que debería ser administrada en función de las características individuales de cada persona, teniendo en cuenta aspectos físicos, psicológicos y sociales.

En conjunto, la búsqueda de la relación entre la intervención enfermera y la disminución de la ansiedad en los pacientes programados para ser intervenidos quirúrgicamente, ha sido un objetivo recurrente en infinidad de estudios de investigación, que en su mayoría destacan y concluyen el efecto positivo, que esta atención específica por el personal de enfermería tiene sobre la salud y satisfacción del paciente. Las intervenciones de educación preoperatoria son prometedoras para la reducción de la ansiedad preoperatoria en pacientes programados para procedimientos quirúrgicos (Alanazi, 2014), destacando la necesidad de un mayor número de ensayos experimentales que avalen los resultados positivos, que aparentemente demuestra la evidencia científica actual (Hines, Munday, \& Kynoch, 2015), sin olvidar que siempre deberá priorizarse en la atención individual basada en las necesidades físicas, psicológicas y sociales específicas del paciente en cada momento (McDonald et al., 2014).

\subsection{Los cuidados de enfermería relacionado con la ansiedad del paciente}

Según la sociedad científica NANDA-I, en su Taxonomía II, define el diagnóstico enfermero de "ansiedad" como 
sensación vaga e intranquilizadora de malestar o amenaza acompañada de una respuesta autónoma (el origen de la cual con frecuencia es inespecífico o desconocido para la persona); sentimiento de aprensión causado por la anticipación de un peligro. Es una señal de alerta que advierte de un peligro inminente y permite a la persona tomar medidas para afrontar la amenaza (NANDA Internacional, 2015, p. 45).

El diagnóstico enfermero (DxE) de "ansiedad" (00146) según NANDAI, corresponde con el dominio nueve, afrontamiento/tolerancia al estrés, clase dos, respuestas de afrontamiento. A su vez, en relación con los patrones funcionales de Marjory Gordon pertenece al patrón número siete Autopercepción-Autoconcepto y a la necesidad número nueve evitar peligros/seguridad según las catorce necesidades de Virginia Henderson.

\begin{tabular}{ll}
\hline \multicolumn{2}{l}{ Tabla 12. Características definitorias del DxE Ansiedad } \\
\hline a) Afectivas: & Conciencia de los síntomas fisiológicos \\
\hline Angustia & Confusión \\
\hline Aprensión & Deterioro de la atención \\
\hline Arrepentimiento & Dificultad para la concentración \\
\hline Atención centrada en el yo & Disminución del campo perceptivo \\
\hline Desquiciamiento & Olvido \\
\hline Distrés & Preocupación \\
\hline Impotencia creciente dolorosa & Temor a consecuencias inespecíficas \\
\hline Incertidumbre & Tendencia a culpar a otros \\
\hline Irritabilidad & Disminución de la habilidad para solucionar problemas \\
\hline Nerviosismo & Cognitivas \\
\hline Temor & Sentimientos de insuficiencia \\
\hline Preocupación creciente & Sobreexcitación \\
\hline Preocupación & Persistente aumento de la impotencia \\
\hline Bloqueo del pensamiento & Disminución de la habilidad para aprender \\
\hline Cavilación & \\
\hline b) Conductuales & Movimientos extraños \\
\hline Nerviosismo & Disminución de la productividad \\
\hline Vigilancia & Escaso contacto ocular \\
\hline Escrutinio & Expresa preocupaciones debidas a cambios en \\
\hline Inquietud & acontecimientos vitales \\
\hline Insomnio & Lanzar miradas alrededor \\
\hline & \\
\hline
\end{tabular}




\begin{tabular}{ll}
\hline c) Fisiológicas & \\
\hline Aumento de la sudoración & Disminución de la presión arterial \\
\hline Aumento de la tensión & Frecuencia urinaria \\
\hline Estremecimientos & Hormigueos en las extremidades \\
\hline Temblor de manos & Mareos \\
\hline Temblores & Náuseas \\
\hline Tensión facial & Trastornos del sueño \\
\hline Voz temblorosa & Urgencia urinaria \\
\hline Parasimpáticas & Dificultad para iniciar el chorro de orina. \\
\hline Diarrea & Disminución del pulso \\
\hline Fatiga & Dolor abdominal \\
\hline c) Simpáticas & \\
\hline Anorexia & Dilatación pupilar \\
\hline Aumento de la respiración & Excitación cardiovascular \\
\hline Aumento de la tensión arterial & Movimientos espasmódicos \\
\hline Aumento de los reflejos & Palpitaciones \\
\hline Aumento del pulso & Rubor facial \\
\hline Debilidad & Sequedad bucal \\
\hline Diarrea & Vasoconstricción capilar \\
\hline Dificultades respiratorias & \\
\hline
\end{tabular}

\begin{tabular}{ll}
\hline \multicolumn{2}{l}{ Tabla 13. Factores relacionados del DxE Ansiedad } \\
\hline Abuso de sustancias & Cambio en la situación económica \\
\hline Amenaza de muerte & Cambio en los patrones de interacción \\
\hline Amenaza para el autoconcepto & $\begin{array}{l}\text { Conflicto inconsciente sobre los objetivos vitales } \\
\text { esenciales }\end{array}$ \\
\hline Amenaza para el entorno & Contagio interpersonal \\
\hline Amenaza para el estado de salud & Crisis de maduración \\
\hline Amenaza para el estatus del rol & Crisis situacionales \\
\hline Amenaza para la función del rol & Estrés \\
\hline Exposición a toxinas & Amenaza para la situación económica \\
\hline Asociación familiar & Herencia \\
\hline Cambio en el entorno & Necesidades no satisfechas \\
\hline Cambio en el estado de salud & Transmisión interpersonal \\
\hline Cambio en el estatus del rol & Amenaza para los patrones de interacción \\
\hline Cambio en la función del rol & Conflicto inconsciente sobre los valores esenciales \\
\hline
\end{tabular}


El diagnóstico enfermero de "ansiedad" ha sido modificado en las diferentes ediciones de la taxonomía NANDA-I, 1973, 1982, 1998, 2006, 2008 y 2010. En la actualidad, y en relación con el paciente quirúrgico, estos son los posibles criterios de resultados (NOC) que se pueden elegir para elaborar el plan de cuidados

NOC: Nivel de ansiedad, código 1211, dominio tres, clase M, bienestar psicológico, patrón siete, autopercepción-autoconcepto.

Los siguientes indicadores pueden cuantificar el NOC, Nivel de ansiedad relacionados principalmente con el proceso quirúrgico:

\begin{tabular}{ll}
\hline \multicolumn{2}{l}{ Tabla 14. Indicadores de resultados para el NOC Nivel de Ansiedad (1211) } \\
\hline Código & Nombre del indicador \\
\hline 121101 & Desasosiego \\
\hline 121102 & Impaciencia \\
\hline 121104 & Distrés \\
\hline 121105 & Inquietud \\
\hline 121106 & Tensión muscular \\
\hline 121107 & Tensión facial \\
\hline 121108 & Irritabilidad \\
\hline 121109 & Indecisión \\
\hline 121112 & Dificultades para la concentración \\
\hline 121115 & Ataque de pánico \\
\hline 121116 & Aprensión verbalizada \\
\hline 121117 & Ansiedad verbalizada \\
\hline 121118 & Preocupación exagerada por eventos vitales \\
\hline 121119 & Aumento de la presión sanguínea \\
\hline 121120 & Aumento de la velocidad del pulso \\
\hline 121121 & Aumento de la frecuencia respiratoria \\
\hline 121122 & Pupilas dilatadas \\
\hline 121123 & Sudoración \\
\hline 121124 & Vértigo \\
\hline 121125 & Fatiga \\
\hline 121129 & Trastorno del sueño \\
\hline 121130 & Cambio en las pautas intestinales \\
\hline 121131 & Cambio en las pautas de alimentación \\
\hline
\end{tabular}




\begin{tabular}{ll}
\hline $\begin{array}{l}\text { Tabla 15. Actividades para la intervención disminución de la ansiedad, } \\
\text { código NIC } 5820\end{array}$ \\
\hline Código & Nombre de la actividad \\
\hline 582004 & $\begin{array}{l}\text { Tratar de comprender la perspectiva del paciente sobre una situación es- } \\
\text { tresante }\end{array}$ \\
\hline 582005 & $\begin{array}{l}\text { Proporcionar información objetiva respecto del diagnóstico, tratamiento } \\
\text { y pronóstico }\end{array}$ \\
\hline 582006 & $\begin{array}{l}\text { Permanecer con el paciente para promover la seguridad y reducir el } \\
\text { miedo }\end{array}$ \\
\hline 582007 & Animar a la familia a permanecer con el paciente, si es el caso \\
\hline 582012 & Escuchar con atención \\
\hline 582013 & Reforzar el comportamiento, según corresponda \\
\hline 582014 & Crear un ambiente que facilite la confianza \\
\hline 582015 & Animar la manifestación de sentimientos, percepciones y miedos \\
\hline 582016 & Identificar los cambios en el nivel de ansiedad \\
\hline 582018 & Ayudar al paciente a identificar las situaciones que precipitan la ansiedad \\
\hline 582019 & $\begin{array}{l}\text { Controlar los estímulos de las necesidades del paciente, según corres- } \\
\text { ponda }\end{array}$ \\
\hline 582020 & Apoyar el uso de mecanismos de defensa adecuados \\
\hline 582021 & $\begin{array}{l}\text { Ayudar al paciente a realizar una descripción realista del suceso que se } \\
\text { avecina }\end{array}$ \\
\hline 582022 & Determinar la capacidad de toma de decisiones del paciente \\
\hline Instruir al paciente sobre el uso de técnicas de relajación \\
\hline 52023 & Observar si hay signos verbales y no verbales de ansiedad \\
\hline 5
\end{tabular}

La cuantificación de los diferentes NOC se basarán en una Escala Tipo Likert de cinco puntos que va desde Grave hasta Ninguno.

Respecto a la planificación de las posibles intervenciones, Nursing Interventions Classifications (NIC) y sus actividades, destacamos las principales que están relacionadas con el paciente objeto de estudio.

Disminución de la ansiedad, código NIC 5820, se define como minimizar la aprensión, temor, presagios o inquietud relacionados con una fuente no identificada de peligro previsto, perteneciente al campo tres, conductual, clase T, fomento de la comodidad psicológica. 


\begin{tabular}{|c|c|}
\hline Código & Nombre de la actividad \\
\hline 535001 & Averiguar si el individuo ha tenido traslados previos \\
\hline 535002 & Incluir al individuo en el plan de traslados, según corresponda \\
\hline 535005 & Examinar con el individuo las estrategias de afrontamiento previas \\
\hline 535006 & Favorecer el uso de estrategias de afrontamiento \\
\hline 535007 & Valorar la necesidad/deseo del individuo de apoyo social \\
\hline 535008 & $\begin{array}{l}\text { Evaluar los sistemas de apoyo disponibles (p.ej., familia ampliada, implica- } \\
\text { ción de la comunidad, afiliaciones religiosas) }\end{array}$ \\
\hline 535009 & $\begin{array}{l}\text { Asignar un "compañero" que le ayude en la integración en el nuevo am- } \\
\text { biente }\end{array}$ \\
\hline 535010 & Fomentar que el individuo/familia busque asesoramiento, según corresponda \\
\hline 535011 & $\begin{array}{l}\text { Disponer que los objetos personales del individuo estén en su sitio antes } \\
\text { del traslado }\end{array}$ \\
\hline 535012 & $\begin{array}{l}\text { Controlar la presencia de signos y síntomas fisiológicos y psicológicos de es- } \\
\text { trés por traslado (p.ej., anorexia, ansiedad, depresión, aumento de exigen- } \\
\text { cias y desesperanza) }\end{array}$ \\
\hline 535013 & $\begin{array}{l}\text { Proporcionar actividades recreativas (p.ej., participación en aficiones, activi- } \\
\text { dades cotidianas) }\end{array}$ \\
\hline 535015 & $\begin{array}{l}\text { Evaluar el impacto de la alteración del estilo de vida, pérdida de hogar y } \\
\text { adaptación al nuevo entorno }\end{array}$ \\
\hline
\end{tabular}

Disminución del estrés por traslado, código NIC 5350, se define como ayudar al individuo a prepararse y a afrontar el traslado de un entorno a otro, perteneciente al campo tres, clase R, ayuda al afrontamiento.

Aumentar los sistemas de apoyo, código NIC 5440, se define como facilitar el apoyo del paciente por parte de la familia, los amigos y la comunidad, perteneciente al campo tres, conductual, clase R, ayuda para el afrontamiento.

Conviene subrayar que la hospitalización, incluso en las personas que no están programas para ser intervenidas quirúrgicamente, genera ansiedad. Esta ansiedad inducirá una respuesta fisiológica al estrés, que dificultará el proceso de recuperación (Grieve \& R.J., 2002; Koivula, PaunonenIlmonen, Tarkka, Tarkka, \& Laippala, 2001; Pritchard, 2009). 


\begin{tabular}{|c|c|}
\hline Código & Nombre de la actividad \\
\hline 544001 & $\begin{array}{l}\text { Calcular la respuesta psicológica a la situación y la disponibilidad del sis- } \\
\text { tema de apoyo }\end{array}$ \\
\hline 544002 & Determinar la conveniencia de las redes sociales existentes \\
\hline 544003 & Determinar el grado de apoyo familiar y económico, así como otros recursos \\
\hline 544006 & $\begin{array}{l}\text { Determinar las barreras al uso de los sistemas de apoyo no utilizados o in- } \\
\text { frautilizados }\end{array}$ \\
\hline 544007 & Observar la situación familiar actual y la red de apoyo \\
\hline 544008 & Animar al paciente a participar en las actividades sociales y comunitarias \\
\hline 544009 & Fomentar las relaciones con personas que tengan los mismos intereses y metas \\
\hline 544010 & $\begin{array}{l}\text { Remitir a un grupo de autoayuda, o a un recurso basado en internet si se } \\
\text { considera oportuno }\end{array}$ \\
\hline 544013 & Proporcionar los servicios con una actitud de aprecio y de apoyo \\
\hline 544014 & Implicar a la familia/allegados/amigos en los cuidados y la planificación \\
\hline 544015 & Explicar a los demás implicados la manera en que pueden ayudar \\
\hline 544016 & Identificar los recursos disponibles para el apoyo del cuidador \\
\hline
\end{tabular}

En concreto, en el paciente hospitalizado para ser intervenido quirúrgicamente, la disminución de la ansiedad como parte de los cuidados enfermeros forma parte de la rutina diaria de estos profesionales, pero la valoración de este diagnóstico y los estudios que relacionan su efecto perjudicial sobre la salud de las personas se basan en índices de recuperación ambiguos o pocos fiables (Salmon, 1993).

Según Luis Rodrigo (2008), se aconseja utilizar el diagnóstico enfermero de ansiedad cuando el paciente presenta ansiedad severa, haciendo referencia al tercer nivel de de los posibles cuatro niveles descritos clásicamente, como pueden ser ansiedad leve, moderada, severa y pánico.

Esta recomendación no corresponde con los datos encontrados en los diferentes estudios de investigación; por ejemplo, en algunos concluyen que el diagnóstico enfermero de ansiedad es el más común de los encontrados durante el preoperatorio en los pacientes programados para ser intervenidos de cirugía cardíaca, calificándolo como un fenómeno 
universal que experimentan casi todos los pacientes quirúrgicos (Vargas, Maia, \& Dantas, 2006).

Al mismo tiempo, se ha discutido, por parte de los diferentes investigadores que han estudiado la ansiedad en el contexto de la disciplina enfermera, la posibilidad que niveles de ansiedad leve y moderada ayuden al paciente a reducir el estrés y prepararse para la cirugía, no siendo necesario, en ese caso, planificar ninguna intervención para recudir dicho valor (Luis Rodrigo, 2008; Salmon, 1993). 



\section{ESTRÉS}

El concepto de estrés (E), al igual que ocurría en los conceptos anteriormente desarrollados, ha sufrido una evolución conceptual y de características definitorias a lo largo de la historia.

Hay que tener en cuenta que en algún momento de nuestra vida se experimenta el hecho de tener estrés por motivos diferentes. Dentro de las posibles diferenciaciones y tipos de estrés que puede percibir una persona, este estudio se centrará y destacará, primordialmente, el estrés relacionado con el proceso de salud y cómo las situaciones percibidas como amenazante, matizan o delimitan el estrés del individuo. Del mismo modo, se puede destacar el papel que tienen los factores sociales y cómo afectan al estrés.

\subsection{Aproximación histórica de la conceptualización del estrés}

El origen del término estrés comienza con los estudios realizados en el ámbito de la física en el siglo XVII, destacando la aportaciones que realiza Robert Hooke y Thomas Young, quien lo definió como "la respuesta intrínseca del objeto propia a su estructura, provocada por la fuerza concurrente" (citado en Roman \& Hernandez, 2011, p. 3), estableciendo con ello una característica interactiva del concepto.

Teniendo en cuenta los hallazgos científicos anteriores, se inicia la exportación del término estrés a diferentes ciencias afines como la medicina o la biología (Alvarez González, 1989). 
El concepto de estrés a lo largo de la historia ha experimentado diferentes características definitorias; a continuación comentamos brevemente aquellas realizadas por los autores más relevantes.

En primer lugar, es interesante destacar tres grandes corrientes teóricas que intentan definir el estrés. La primera corriente teórica, define estrés como un estímulo que provoca cambios en los procesos homeostáticos (Burchfield, 1979; Cannon, 1932). Esta línea de investigación recibe críticas porque esa visión del E no tiene en cuenta las diferencias individuales de cada sujeto y establece que la persona es pasiva (Sierra, Ortega, \& Zubeidat, 2003).

La segunda perspectiva cataloga este concepto como una reacción originada por el organismo, que se concreta en la definición de Selye (1973), que establece que "el estrés es una respuesta específica del organismo ante cualquier demanda que se le imponga"; corriente que también recibe críticas al no tener en cuenta que determinadas reacciones orgánicas, como la taquicardia o el aumento de la tensión arterial, no siempre se dan por una respuesta al estrés (Blanco et al., 1986).

Ambas ideas dan lugar a una visión general del término, perspectiva que se unifica en la tercera corriente conceptual donde el E se define como una interacción entre el organismo y el ambiente que le rodea.

En este sentido destacamos las aportaciones del modelo transaccional desarrollado por Lazarus, \& Folkman (1986), que describen el estrés psicológico como "una relación particular entre el individuo y el entorno que es evaluado por este como amenazante o desbordante de sus recursos y que pone en peligro su bienestar" (p. 43).

En la actualidad cobra gran interés el desarrollo conceptual del E desde una perspectiva social que afecta al ámbito físico, fisiológico y psicológico de la persona, que permite profundizar en el aspecto epidemiológico del mismo, delimitando y centrando las aportaciones científicas desde un aspecto social, diferente a la perspectiva puramente médica y biológica de los comienzos conceptuales anteriormente citado (Ferrero, Sandín, \& Ferrero, 2003). 


\subsection{Definición de estrés}

Por lo que se refiere a la definición de estrés, según se puede comprobar en el apartado anterior, a lo largo del recorrido histórico sobre su conceptualización parece que los diferentes autores aún no han logrado una definición unánime que permita definir el término en sí, para todas las líneas de investigación existentes.

En relación los instrumentos de medida elegidos para la obtención de los datos relacionados con la variable $\mathrm{E}$, se utilizará como referencia de partida la definición de E realizada por Tous-Ral \& Pueyo (1991), publicada durante la elaboración del test Inventario Diferencial de Adjetivos para el estudio del estado de ánimo (IDDA-EA). Tous-Ral \& Pueyo (1991) se refieren al E como una dimensión continua relajación-tensión, definiéndolo como "la tensión provocada por la interdependencia negativa entre las demandas de la situación y las expectativas del propio sujeto y le hacen experimentar el nivel de energía como desagradable" (Tous et al., 1991, p. 8).

No se debe obviar la definición realizada por la OMS: "el estrés es el conjunto de reacciones fisiológicas que prepara al organismo para la acción". Esta definición se basa en la evidencia científica existente que intenta definir el estrés desde una perspectiva puramente biológica, siendo el autor pionero y referente en investigar el E desde un punto de vista biológico Hans Selye (1956), dicho autor elabora la base empírica sobre el conocimiento del E, denominándolo como "síndrome de estar enfermo", después de observar que los pacientes, independientemente de su enfermedad de base, desarrollaron síntomas comunes y generales como: pérdida de peso, cansancio, astenia, etc. Para Selye, esos síntomas eran respuestas del organismo a una demanda externa.

Posteriormente, Selye define las tres fases por las que una persona experimenta el E:

- Primera fase de alarma: Ios individuos reacción mediante diversas respuestas vegetativas al componente causante del E.

- Segunda fase de resistencia: la persona trata de responder o abordar al elemento estresor. 
- Tercera fase de agotamiento: aparecen consecuencias en el organismo de ámbito físico, emocional o conductual, debido al efecto de la reacción al agente estresor (Hans Selye, 1965).

\subsubsection{Tipos de estrés en función del resultado}

- Eustrés: la reacción de afrontamiento permite al organismo adaptarse y resistir, siendo beneficioso para el individuo.

- Distrés: existe un deterioro en el bienestar individual relacionado una experiencia nociva en la reacción al estrés (Beck, Steer, \& Brown, 1996).

\subsubsection{Tipos de estrés en función de la duración}

- Estrés agudo: es la respuesta del individuo expuesto al componente promotor del estrés durante un corto periodo de tiempo.

- Estrés crónico: es la respuesta del individuo ante una situación estresante de una manera repetitiva o prolongada en el tiempo. Siendo este último tipo de E precursor de procesos patógenos en el paciente (Mitra, Jadhav, McEwen, Vyas, \& Chattarji, 2005).

En definitiva, en esta investigación se abordará el E desde una perspectiva psico-biológica aunando las dos principales corrientes conceptuales mencionadas, añadiendo como posible amenaza percibida por el individuo, el proceso quirúrgico que acontece a su intervención de cirugía endoscópica nasal.

Existen numerosos modelos conductuales que han intentado desarrollar la conceptualización del E. Un ejemplo de este modelo es el modelo Transaccional o de interactivo del estrés, desarrollado por Lazarus y Folkman (citado por Barraza Macías, 2006). En este modelo los autores establecen que para que aparezca una reacción de estrés, debe existir una correlación entre aspectos individuales y factores externos e internos. En este estudio se tomará como referencia de factor externo el AS percibido, que se ha relacionado con su efecto amortiguador sobre el estrés, 
que actúa reduciendo la percepción de un contexto vivenciado como estresante (Sheldon Cohen \& McKay, 1984; House, 1981). En los diversos estudios que se han llevado a cabo correlacionando la relación entre ambos factores, se concluye que el AS es una variable predictora del estrés (González \& Landero Hernández, 2004).

En conclusión, el objetivo en muchas líneas de investigación que han usado el estrés en el contexto del paciente quirúrgico es descubrir si las actividades psicológicas preparativas previas a una cirugía, disminuyen el estrés de los pacientes. Un ejemplo de ese tipo de líneas de investigación es la realizada por Broadbent, Kahokehr, Booth, \& Thomas (2012), el estudio realizado por este equipo de investigación tenía como objetivo descubrir si una breve intervención psicológica preoperatoria disminuiría el estrés percibido antes de la intervención. El ensayo clínico aleatorizado tenía como criterio de inclusión a pacientes mayores de 18 años, capaces de leer y escribir en inglés y someterse a colecistectomía laparoscópica electiva en el Centro Quirúrgico de Manukau, South Auckland, Nueva Zelanda, entre abril de 2008 y mayo de 2010, la muestra total de 60 pacientes se dividió al azar en dos grupos, uno de los cuales recibió una intervención de 45 minutos por parte de un psicólogo. El estudio obtiene como resultado, respecto a la valoración del estrés percibido, que hubo una mayor reducción del estrés en el grupo que recibió la atención psicológica respecto al grupo control $(p=0,048)$, la edad se relacionó con la reducción del estrés: a mayor edad mayor reducción del estrés percibido. No hubieron diferencias significativas por género. Los autores recomiendan para investigaciones futuras valorar el efecto de intervenciones similares en cirugía mayor como la resección intestina o el bypass coronario.

\subsection{Estrés y salud}

A continuación, se analizará la evidencia científica que existe entre el concepto de estrés y salud. Al igual que ocurría con el término ansiedad, el estrés se ha investigado en diferentes ámbitos sanitarios, como el médico, psicológico o enfermero. 
Las diferentes líneas de investigación han centrado sus objetivos en demostrar la relación del estrés con la enfermedad, el efecto negativo o el efecto positivo que puede tener sobre el individuo, incluso sus repercusiones en el ámbito fisiológico o biopsicosocial (Sierra et al., 2003).

En el caso de la ciencia enfermera, el estrés ha sido estudiado desde una perspectiva asistencial, en relación directa con el paciente, pero también se ha desarrollado una gran evidencia sobre su efecto en la práctica enfermera desde el ámbito laboral y las condiciones de trabajo (Cremades Puerto, 2011).

Por lo tanto, en la revisión de la bibliografía existente hasta la actualidad, este estudio se centra en la relación entre el estrés y la enfermería desde el punto de vista asistencial respecto a la valoración, planificación y realización de los cuidados enfermeros, utilizando como descriptor común en todas las búsquedas en bases de datos las palabras claves "estrés (stress)" y "cuidados de enfermería (nursing care)".

Los criterios de búsqueda utilizados fueron: estudios encontrados sin límite de fechas hasta la actualidad, con filtro de idioma, español, inglés y portugués, sin limitación geofráfica, usando las palabras claves según la terminología DeCS, en español y MeSH en inglés que se obervan en la Tabla 18, utilizando como operador boleano "and", las palabras claves elegidas deben formar parte de las palabras claves del autor del estudio, disponibilidad de texto completo, se filtraron los estudios con mayor nivel de evidencia tales como ensayos clínicos aleatorizados, estudios descriptivos y cualitativos bien diseñados, metaanálisis y revisiones sistemáticas, fecha de realización de la búsqueda 20 enero de 2017.

Se ha consultado las bases de datos Elton B. Stephens Company (EBSCO), Cumulative Index to Nursing and Allied Health Literature (CINAHL), Science direct, PubMed, Cuiden, Excerpta Medica Database (EMBASE), The Offshore Vessel Inspection Database (OVID), The Joanna Briggs Institute (JBI), Literatura Latinoamericana de Información en Ciencias de la Salud (LiLacs), Cochrane, Scientific Electronic Library Online(Scielo), Google Scholar, İndice Bibliográfico Español en Ciencias de la Salud (IBECS) y ClinicalKey, como se muestra en la Tabla 18.

Cabe destacar que la limitación de la búsqueda nos arroja una cantidad moderada de estudios de investigación que cumplen los criterios de se- 
Tabla 18. Descriptores controlados según nomenclatura DeCS y MeSH

\begin{tabular}{ll}
\hline DeCS & MeSH \\
\hline Ansiedad & Anxiety \\
\hline Salud & Health \\
\hline Atención de enfermería & Nursing Care \\
\hline Práctica clínica basada en la evidencia & Evidence-Based Practice \\
\hline Cirugía & Surgery \\
\hline Evaluación preoperatoria & Surgical Clearance \\
\hline Enfermedad & Disease \\
\hline
\end{tabular}

lección en la búsqueda bibliográfica, es por ello, que se han añadido al análisis las revisiones narrativas de autores relavantes que complementan desde el punto de vista teórico la falta de estudios de mayor evidencia existente en la actualidad, datos que se pueden observar en la Tabla 19.

Tabla 19. Resumen de número de artículos encontrados en la búsqueda bibliográfica con la palabra clave Stress como concepto principal

\begin{tabular}{|c|c|c|c|c|c|c|}
\hline Base de datos & $\begin{array}{r}\text { Stress, } \\
\text { Nursing } \\
\text { Care } \\
\text { and } \\
\text { health }\end{array}$ & $\begin{array}{r}\text { Stress, } \\
\text { Nursing } \\
\text { Care } \\
\text { And } \\
\text { Surgical } \\
\text { Clearance }\end{array}$ & $\begin{array}{r}\text { Stress, } \\
\text { Nursing } \\
\text { Care } \\
\text { and } \\
\text { Disease }\end{array}$ & $\begin{array}{r}\text { Stress, } \\
\text { Nursing } \\
\text { Care and } \\
\text { Evidence } \\
\text { Based } \\
\text { Practic }\end{array}$ & $\begin{array}{r}\text { Stress, } \\
\text { Nursing } \\
\text { Care } \\
\text { And } \\
\text { Surgery }\end{array}$ & $\begin{array}{r}\text { Stress, } \\
\text { Nursing } \\
\text { And } \\
\text { Surgery }\end{array}$ \\
\hline EBSCO - CINAHL & 230 & 0 & 35 & 18 & 36 & 169 \\
\hline Science direct & 13 & 0 & 3 & 0 & 1 & 2 \\
\hline PubMed & 0 & 0 & 0 & 0 & 0 & 0 \\
\hline Cuiden & 60 & 0 & 9 & 0 & 1 & 1 \\
\hline EMBASE & 1 & 0 & 0 & 0 & 0 & 5 \\
\hline OVID & 1 & 0 & 0 & 0 & 0 & 4 \\
\hline$J \mathrm{BI}$ & 0 & 0 & 0 & 0 & 0 & 0 \\
\hline Lilacs & 0 & 0 & 0 & 0 & 0 & 10 \\
\hline Cochrane & 61 & 0 & 18 & 1 & 13 & 22 \\
\hline Scielo & 49 & 0 & 7 & 0 & 1 & 3 \\
\hline Google Scholar & 20 & 0 & 2 & 1 & 1 & 1 \\
\hline IBECS & 0 & 0 & 0 & 0 & 0 & 0 \\
\hline ClinicalKey & 88 & 0 & 57 & 40 & 19 & 24 \\
\hline
\end{tabular}


Al igual que ocurría con búsqueda bibliográfica y los datos expuestos en la Tabla 11 del capítulo anterior, los estudios de investigación encontrados en la búsqueda bibliográfica que se observa en la Tabla 20 son de gran interés para comprender cómo ha evolucionado el concepto E desde un punto de vista específico y empírico respecto a la perspectiva enfermera, permitiendo un análisis directo y preciso sobre el estado actual de los hallazgos encontrados en relación con el trabajo propio enfermero, utilizando en algún caso otras disciplinas como anexo y complemento durante el desarrollo del estudio, pero centrando el resultado final en demostrar o refutar hipótesis que se postulan desde una perspectiva puramente enfermera.

Finalmente, tras la obtención de los resultados de la búsqueda bibliográfica mencionada con anterioridad, se han seleccionado los estudios que cumplen los criterios de inclusión mencionados anteriormente que se centran en aspectos relacionados con la atención de enfermería y el estrés del paciente que va ser intervenido quirúrgicamente, tal y como se observar en la Figura 8.

En la Tabla 20 se muestran los documentos seleccionados con su respectivo nivel de evidencia y recomendación según los criterios del epidemiólogo Sackett (Manterola, Asenjo-Lobos, \& Otzen, 2014). 
Figura 8. Selección definitiva de referencias concepto principal estrés

799 referencias encontradas en total

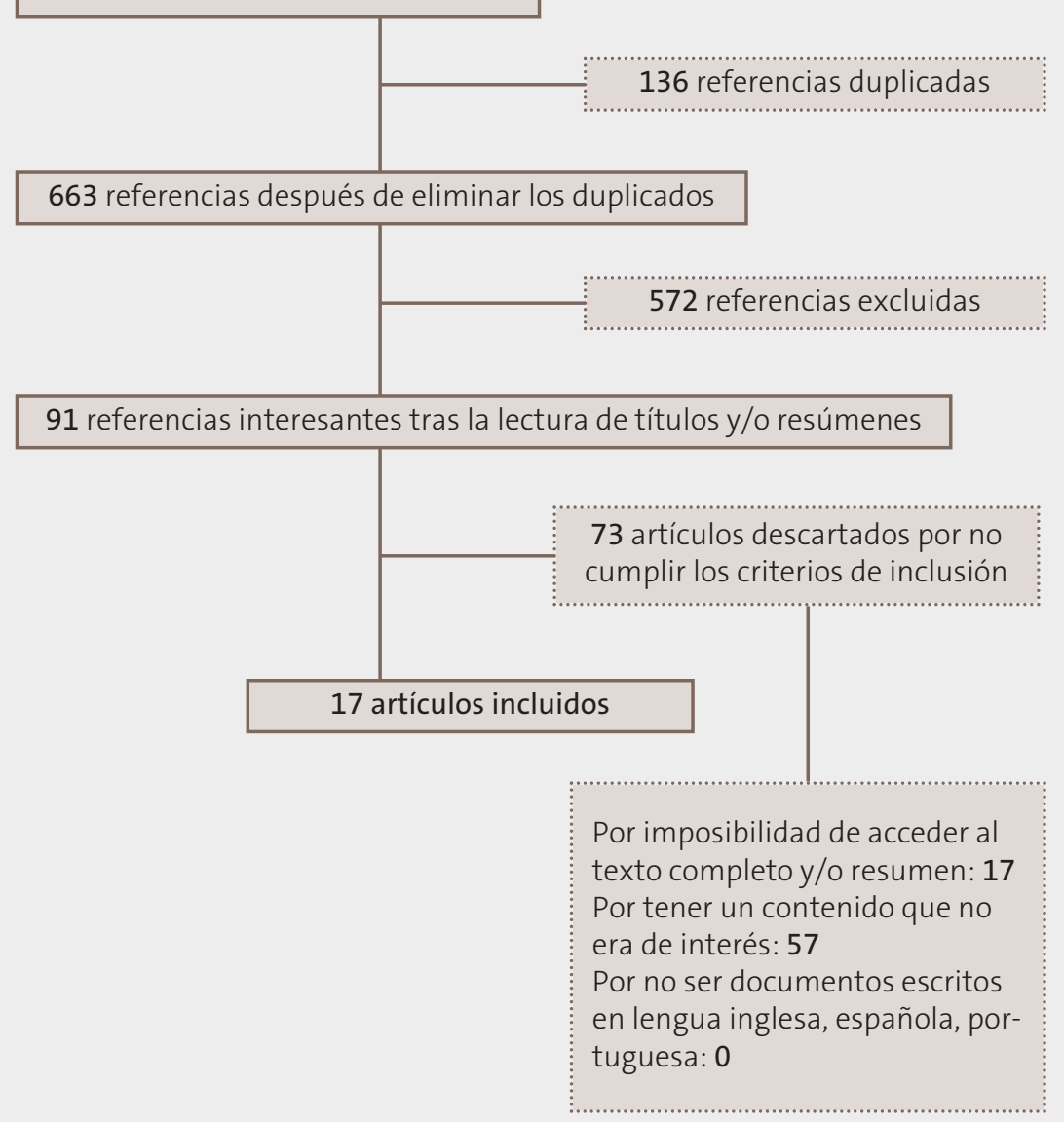




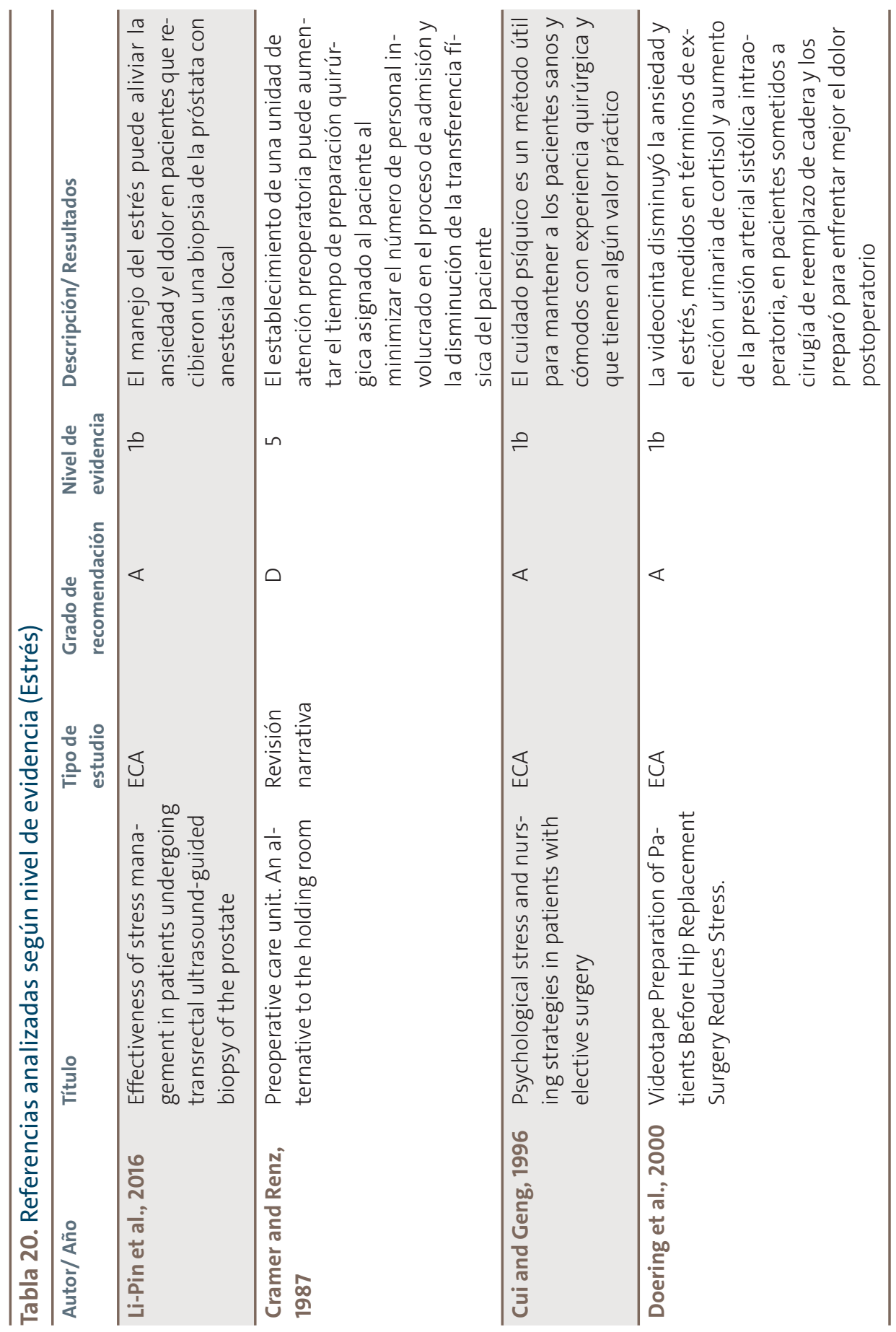




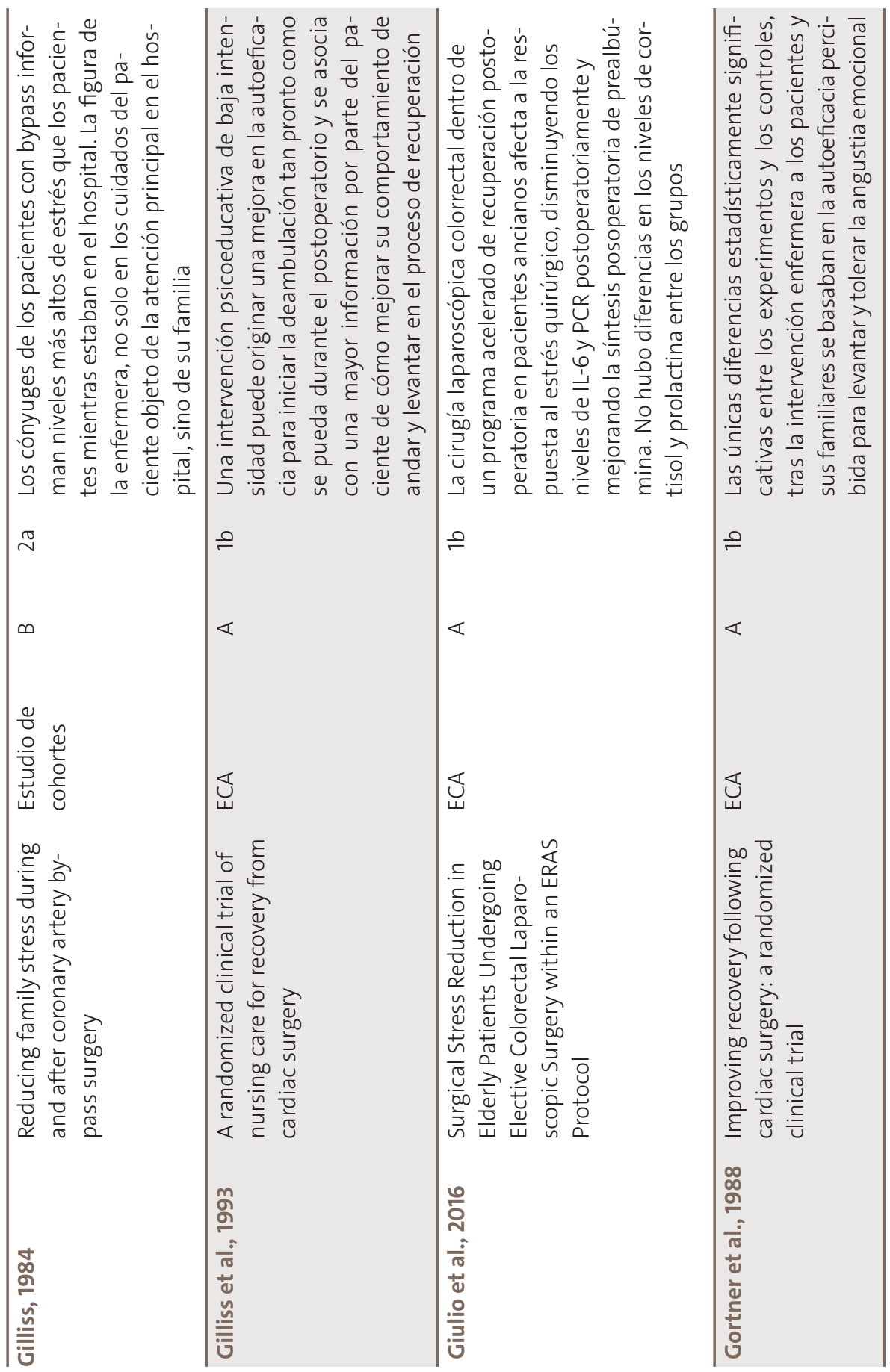




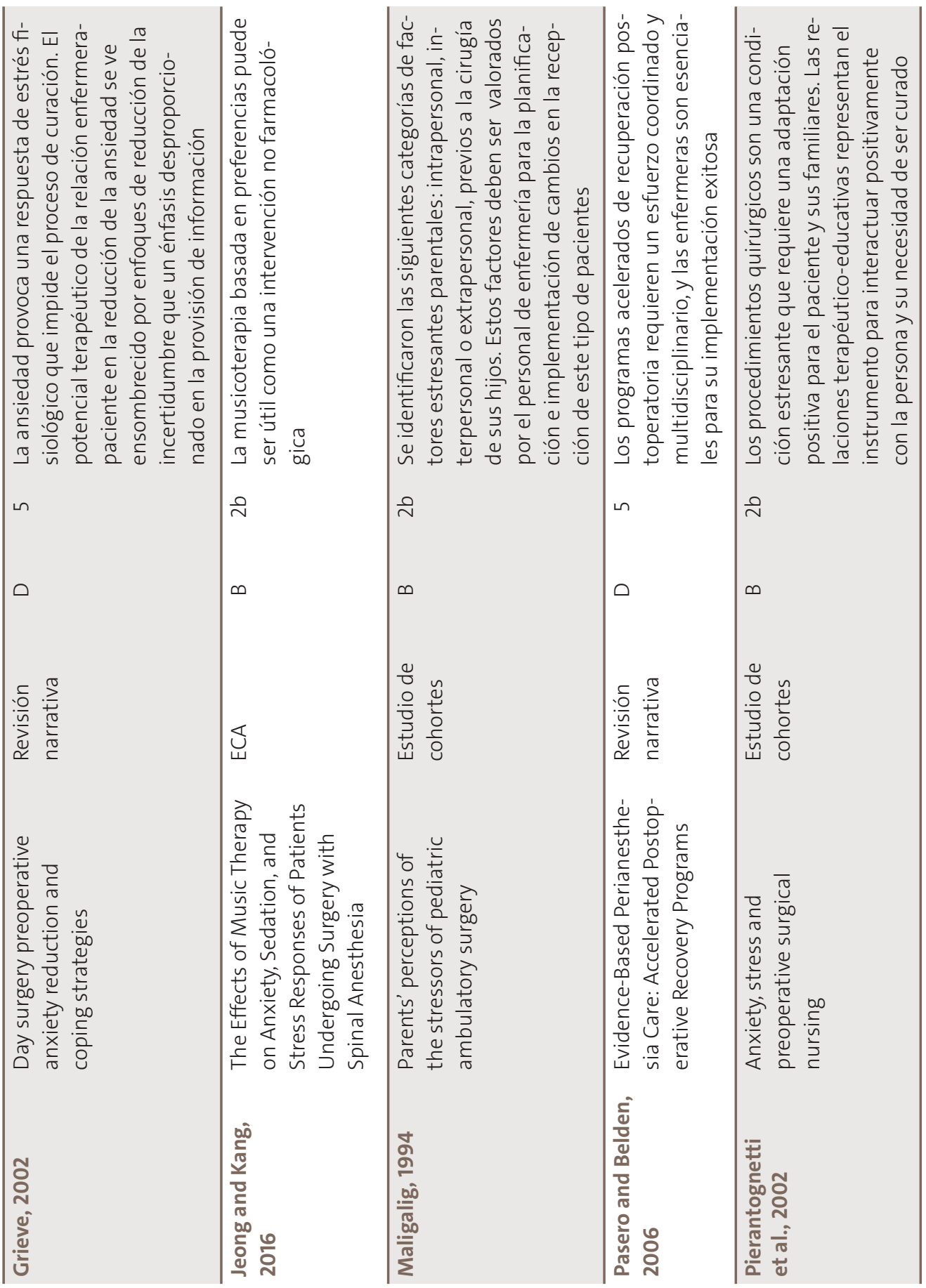




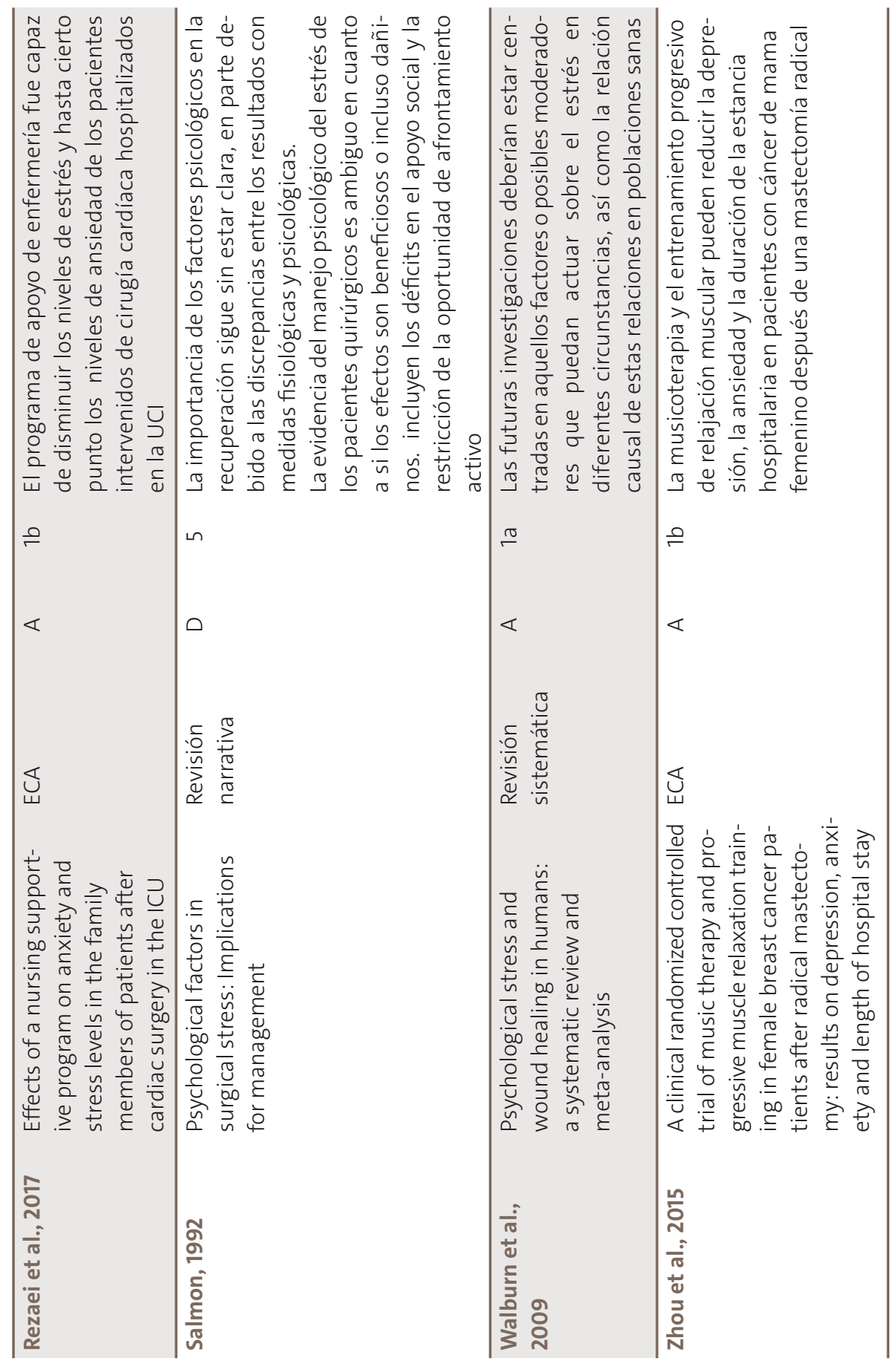


A continuación se analiza en orden cronológico los estudios de investigación encontrados que cumplen los criterios de selección mencionados anteriormente, y que permiten el acceso a texto completo desde la biblioteca de la Universidad Jaume I y la biblioteca del Servicio Canario de Salud.

Se inicia el análisis destacando el estudio realizado por Gilliss (1984), resulta interesante respecto al objetivo preliminar del estudio y las conclusiones del mismo. Gillis demostró en su estudio que las parejas de los pacientes que han sido intervenidos de bypass coronario presentaban mayores niveles de estrés que su cónyuge durante la estancia hospitalaria. Gillis propone la implementación de un programa de atención de enfermería que se concentre en la familia durante y después de la cirugía de bypass coronario. El programa que recomienda el autor debe desarrollarse en tres fases: una previa al ingreso, otra durante la estancia hospitalaria y otra después del alta, y tener como objetivo adaptar el contenido a cada paciente, pero siempre imprescindible actuar sobre la familia para disminuir el estrés durante el proceso hospitalario, en especial en enfermedades agudas. Los hallazgos encontrados son utilizados por el autor para recomendar y destacar la figura de la enfermera, no solo en los cuidados del paciente objeto de la atención principal en el hospital, sino de su familia.

En definitiva, ya desde comienzos de los años 80, resulta fundamental la figura de la enfermera y la planificación de los cuidados para abordar un proceso que engloba tanto al paciente como a sus familiares, ambos van a percibir la situación y cambio de entorno debido a la hospitalización como estresante (Artinian, 1989), pudiendo resultar perjudicial para su salud y la del familiar que es objeto de la atención hospitalaria.

En este sentido, Gortner et al. (1988) comenzó a evaluar la eficacia del programa de atención de enfermería que había desarrollado Gillis para los paciente intervenidos de bypass coronario, mediante un ensayo clínico aleatorizado prospectivo sobre una muestra inicial de 67 pacientes, después de 3 meses de la intervención programa específica frente a la atención habitual enfermera, la única diferencia estadísticamente significativa fue la autoeficacia percibida para tolerar la angustia emocional. La línea de investigación se complementa con los resultados obtenido posterior- 
mente por Gilliss et al. (1993) en el ensayo controlado aleatorizado por grupos con una muestra de 156 pacientes, que tenían como objetivo establecer la eficacia de una intervención psicoeducativa de enfermería en pacientes que han sido intervenidos de cirugía de revascularización coronaria y cirugía de reparación valvular. Los autores concluyen, que una intervención psicoeducativa de baja intensidad puede originar una mejora en la autoeficacia para iniciar la deambulación tan pronto como se pueda durante el postoperatorio y se asocia con una mayor información por parte del paciente de cómo mejorar su comportamiento de andary levantar en el proceso de recuperación (Gilliss et al., 1993).

En relación con los posibles agentes estresantes que el paciente pudiera experimentar, según Cramer \& Renz (1987), hay que añadir el ingreso apresurado del paciente quirúrgico programado, tanto adulto como pediátrico, que tiene como objetivo disminuir la estancia hospitalaria, obligando a la aceleración del proceso de admisión. El paciente es recibido en un periodo muy corto de tiempo por los profesionales que van a atenderle y entrevistarle, como son el personal de admisión, enfermera de hospitalización, anestesista, enfermera de quirófano y cirujano, generando un estrés añadido al hecho de ser intervenido quirúrgicamente en el hospital. Estos factores deben ser valorados por el personal de enfermería para la planificación e implementación de cambios en la recepción de este tipo de pacientes (Maligalig, 1994).

Hay que mencionar además, que el hecho de estar programado para ser intervenido quirúrgicamente y precisar una hospitalización, sí está ampliamente estudiado como factor estresante y productor de ansiedad, en especial para los sujetos que van a ser intervenidos quirúrgicamente. Las actividades enfermeras necesarias que el paciente recibe durante las diferentes etapas del proceso quirúrgico son estresantes también para él y su familia, unido al aumento de la ansiedad, que es común en el contexto del paciente quirúrgico, siendo mayor con personas de personalidad ansiosa previa o aquellas que presentan una enfermedad más grave. Hay que tener en cuenta la relación terapéutico-educativa como herramienta para obtener una adaptación positiva del paciente y su familia, al proceso estresante que están viviendo (Pierantognetti et al., 2002). 
Se debe agregar que el E debe ser estudiado, no solo desde una perspectiva puramente psicológica, sino añadir factores relacionados con los procesos fisiológicos que se pueden ver alterados por el E durante el proceso quirúrgico tanto antes como después de la intervención.

En síntesis, esta interrelación entre aspectos psicológicos, fisiológicos, sociales y variables relacionadas con la intervención quirúrgica, presentan resultados ambiguos, con efectos tanto beneficiosos como perjudiciales, que no demuestran una influencia clara entre el estrés y el resto de variables y que deben seguir siendo objeto de estudio para futuras investigaciones (Grieve \& R.J., 2002; Salmon, 1992).

Por lo que se refiere a la valoración, cuantificación e intento de encontrar la relación entre variables de tipo psicológico en el paciente quirúrgico, se puede destacar el estudio realizado por Cui \& Geng (1996) sobre un total de 600 pacientes, que fueron intervenidos de cirugía general, cirugía urinaria y cirugía ginecológica, dividiendo a los pacientes en dos grupos: experimental y control. En general, en ambos grupos se obtuvo un aumento de los niveles de estrés, ansiedad, miedo y presión arterial, la noche anterior de la intervención, frente al resto de etapas del proceso quirúrgico. Respecto al grupo experimental que recibió una atención psíquica específica en el momento del ingreso como preparación previa a la intervención, obtuvo menores niveles de estrés en la noche antes a la intervención $(p<0,05)$, durante la intervención ( $p<0,01)$ y después de la intervención $(p<0,001)$. En definitiva, estos resultados resumen el efecto que la atención psíquica específica sobre el paciente quirúrgico puede mejorar las variables de tipo psicológico en situaciones de estrés previas a una intervención quirúrgica.

En relación con los efectos adversos que pueden experimentar las personas que sufren estrés prolongado después de la cirugía, se pueden encontrar alteraciones gastrointestinales, atrofia muscular, deterioro cognitivo y complicaciones de tipo cardiológicas, pulmonares, infecciosas, o tromboembólicas, pudiendo en algunos casos posponer el alta hospitalaria y aumentar la convalecencia.

Cabe destacar la revisión sistemática realizada por Walburn, Vedhara, Hankins, Rixon, \& Weinman (2009) sobre estudios que tenían como objetivo evaluar el impacto del estrés en la cicatrización de diferentes tipos de heridas, después de analizar los veintidós artículos que cumplieron 
los criterios de inclusión para realizar la revisión sistemática, unido a una submuestra de once artículos en los que se realizó un metaanálisis, los autores obtuvieron como resultado de su análisis, que en diecisiete estudios existe una asociación entre el estrés y la aparición de deterioro en el proceso de cicatrización de las heridas. En el metaanálisis realizado por los autores, la relación entre el estrés y la cicatrización fue $r=-0,42$ (IC del $95 \%=-0,51$ a -0,32) $(p<0,01)$. Por último, se concluye en la revisión sistemática, que las futuras investigaciones deberían estar centradas en aquellos factores o posibles moderadores que puedan actuar sobre el estrés en diferentes circunstancias, así como la relación causal de estas relaciones en poblaciones sanas (Walburn et al., 2009).

El estudio del estrés y su relación con la salud ha llevado, en muchos casos, a la conclusión de la importancia del apoyo familiar como medida para disminuir el estrés y las intervenciones enfermeras destinadas específicamente a los familiares del paciente, con el objetivo de participar en la actividades relacionadas con su proceso de enfermedad. Teniendo en cuenta esos hallazgos, diferentes hospitales y asociaciones científicas han impulsado el desarrollo de programas específicos con el objetivo de disminuir el estrés familiar que, a su vez, repercutirá en el enfermo (Hanson-Heath, Muller, \& Cunningham, 2016).

Por ejemplo, el Exempla Good Samaritan Hospital, en Colorado, impulsó, en 2004, un programa de enfermeras de enlace quirúrgicas que realizarán las tareas de información, atención y, en definitiva, planificación de los cuidados a los familiares de los pacientes que van a ser intervenidos quirúrgicamente, apoyado por el director de los servicios perioperatorios del centro hospitalario, que desde el principio estimó a la enfermera como el profesional idóneo para dicho fin. Se han obtenido resultados positivos en las diferentes evaluaciones del programa de enfermera de enlace quirúrgica, en aspectos como la información a pacientes y familiares, los cuales han referido menos ansiedad y estrés durante los procedimientos que han experimentado durante el ingreso para ser intervenidos quirúrgicamente. Este centro es un ejemplo en el cuidado integral no solo del paciente sino de la unidad paciente-entorno social, eecomendando externalizar la figura de la enfermera de enlace quirúrgica a otros hospitales (Stefan, 2010). 
Estudios como el realizado por Tomlinson et al. (2012), tienen como objetivo el apoyo teórico y práctico al personal de enfermería, que deberá planificar las intervenciones necesarias para el entorno familiar del paciente, que a su vez repercutirán en sus niveles de estrés frente a la situación actual de su familiar, estas medidas solventan un déficits en la formación enfermera respecto al trato que deben dar a los familiares de los pacientes que atienden (Tomlinson et al., 2012).

Se debe agregar también la instauración progresiva que se está produciendo mundialmente de protocolos, que tienen como objetivo aumentar la eficiencia de las diferentes etapas que debe pasar el paciente que está programado para ser intervenido quirúrgicamente, mediante el ingreso previo a la cirugía lo más cerca del acto quirúrgico, la detección de complicaciones de manera precoz y el alta hospitalaria acelerada si se cumplen unos criterios mínimos después de ser intervenidos.

Esto protocolos reciben el nombre de recuperación acelerada después de la cirugía, en inglés Enhanced Recovery After Surgery (ERAS).

Pero se debe destacar que los resultados obtenido han sido dispares, la aplicación de los protocolos ERAS fomenta el ingreso el mismo día de la cirugía lo que puede originar un aumento en los niveles de estrés debido a que los pacientes no han podido adaptarse tan rápido al cambio de entorno habitual por el quirúrgico, la priorización del alta precoz de los pacientes quirúrgicos no debe ser una medida basada en aspectos puramente quirúrgicos o de gestión relacionados con la camas ocupadas o listas de espera del centro sanitario que ejecute el protocolo, sino de aspectos personales de los pacientes que son admitidos en el protocolo ERAS, todo ello justifica la necesitad de realizar más estudios que intenten relacionar el estrés y las diferentes maneras de implementación de los protocolos ERAS (Giulio et al., 2016).

Respecto a las técnicas e intervenciones individuales a los pacientes, destinadas a la reducción específicas estrés previo a la cirugía, se encuentran resultado ambiguos; autores como (Doering et al., 2000; Jeong \& Kang, 2016; Li-Pin et al., 2016) encontraron relación positiva significativamente estadística en la reducción del estrés percibido con el uso de videos para el visionado por parte del paciente o la combinación de intervención psicológica específica y la musicoterapia, ambos métodos re- 
dujeron los valores del estrés percibido de los pacientes previo a la cirugía, también se han encontrado diferencias significativamente estadísticas respecto al descenso del estrés tras realizar las técnicas e intervenciones psicológicas a los familiares de pacientes ingresados (Rezaei et al., 2017). En cambio, otros autores resaltan la falta de evidencia científica sólida que demuestre la existencia de una relación positiva entre intervención individual y descenso del estrés, unido a la necesidad de realizar más estudios que valoren dicho término desde un punto de vista fisiológico en relación con los niveles hormonales de los pacientes (Johansson, Nuutila, Virtanen, Katajisto, \& Salanterä, 2005; Liu, Xu, \& Zang, 2014).

Como se ha mencionada anteriormente, la figura de la enfermera es una pieza clave en la realización de estas actividades encaminadas a reducir el estrés previo a una intervención quirúrgica, así lo demuestra, por ejemplo, el estudio realizado por Gürsoy et al. (2016) después de obtener los datos de los 182 pacientes que cumplieron los criterios de inclusión, entre ellos: mayor de 18 años y estar programado para cirugía con un día previo de hospitalización; los pacientes se dividieron en dos grupos: uno de 93 perteneciente al grupo control y otro de 86 pacientes, pertenecientes al grupo experimental, que recibió la visita de la enfermera que les iba a atender al día siguiente en quirófano, para realizarle una actividad educativa de 20 minutos que contenía información breve sobre la cirugía, los procedimientos quirúrgicos y la anestesia antes de la cirugía. Los resultados concluyeron, que los pacientes que recibieron la visita específica de la enfermera manifestaron que dicha visita minimizó sus niveles de estrés, que se tradujo en una diferencia significativa en el periodo postoperatorio, durante el periodo preoperatorio los niveles de estrés de ambos grupos no resultaron estadísticamente significativos, destacando que más del $90 \%$ de los pacientes de ambos grupos estaban estresados antes de la cirugía, siendo el principal factor manifestado desencadenante de estrés, el miedo a lo desconocido.

En conclusión, la revisión de la evidencia científica encontrada y disponible sobre el estudio del concepto E en relación con el proceso quirúrgico desde un perspectiva enfermera, ha intentado aunar, en la mayoría de investigaciones, ambos conceptos con las actividades e intervenciones enfermeras que, como pieza clave del equipo multidisciplinar en la recep- 
ción, acogida y atención del paciente quirúrgico, van a permitir, en muchos casos, disminuir no solo el estrés al propio paciente objeto de la atención recibida sino a su entorno social; las futuras investigaciones deberán concretar cuáles son las mejores intervenciones y el momento y lugar idóneos para administrarlas.

Como método para disminuir las situaciones de estrés que viven los pacientes, los hospitales deben priorizar la creación de programas de atención específicos, estos programas deben de ser de tipo multidisciplinar, donde el trabajo de la enfermería es esencial para obtener una implementación exitosa (Pasero \& Belden, 2006).

Para finalizar, se debe destacar el efecto modulador que puede tener la información previa a la cirugía sobre el paciente programado para ser intervenido quirúrgicamente mediante la visita preoperatoria de enfermería. En el Complejo Hospitalario Universitario Insular de Gran Canaria, se ha intentado instaurar programas de apoyo a los pacientes previo a la cirugía, pero por motivos relacionados con falta de estrategias para completar y mantener el seguimiento de estas actividades, no se han podido llevar a la práctica (Hernández-Rodríguez et al., 1996).

Es por ello, que la búsqueda de la evidencia científica que demuestre la necesidad de administrar ese apoyo hacia los pacientes y familiares previo a una intervención quirúrgica, debe usarse con rigor para influir en la toma de decisiones de cara implementar actividades como la visita preoperatoria de enfermería al paciente quirúrgico, que debe ser, no solo apoyada con metodología y planificación científica, sino con los recursos humanos necesarios para que sea factible su funcionamiento.

\subsubsection{Evidencia científica actual sobre el estrés y su relación con la salud}

El concepto en sí de estrés, por lo analizado en distintos apartados de esta investigación, parece denotar cierta ambigüedad en relación con su procesamiento en el ser humano. En la actualidad, no se ha conseguido encuadrar específicamente ni desde la perspectiva ambiental ni desde la perspectiva de la adaptación puramente psicológica o, incluso, desde el aspecto puramente fisiológico en relación con el sistema inmune y endocrino (Duval, González, \& Rabia, 2010). Quizás, y aunando ambos as- 
pecto, podría ser enmarcado en mayor medida en la psiconeuroendocrinología, término que comenzó inicialmente con las aportaciones de SoIomon \& Moos en 1964 y de Ader \& Cohen en 1975, entre otros. En la actualidad ya es catalogado como un nuevo ámbito de las Ciencias de la Salud, comenzando a cobrar mayor importancia con estudios como los realizados por Rabin (1999), Glaser \& Kietcolt-Glaser (2005), en definitiva, un nuevo paradigma que debe ser investigado sin duda, desde una perspectiva multidisciplinar (Citado en S. Moscoso, 2009).

Por lo tanto, parece más oportuno explicar el proceso fisiológico del estrés en relación con las interacciones entre cuatro sistemas que se comunican recíprocamente: el sistema nervioso, el sistema endocrino, el sistema inmune y la mente (S. Moscoso, 2009).

En este sentido, es factible establecer la relación de estos cuatro sistemas respecto al estrés agudo en los pacientes que han cumplido los criterios de inclusión del estudio de investigación, objeto de estudio de esta tesis doctoral.

Es necesario recalcar, que esta relación entre los sistemas mencionados con anterioridad, se basó inicialmente en el concepto de homeostasis, descrito por Cannon (1932) junto a las teorías de Hans Selye (1965) sobre el proceso de adaptación frente al estrés, investigaciones realizadas en ratas.

En la actualidad, las investigaciones centradas en la respuesta humana y el avance tecnológico para la medición de las hormonas implicadas en el estrés, permiten obtener una definición más detallada de la relación de los cuatro sistemas implicados, que se explica a continuación:

La respuesta fisiológica del estrés que se comenta se centrará en un proceso que se activa de forma aguda por un estresor principal que, en este caso, serán los diferentes estadios por el que pasará el paciente que va a ser intervenido quirúrgicamente de CENS y precisa un ingreso en hospitalización para, posteriormente, entrar en la sala de operaciones y, por último, tras recuperarse del postoperatorio inmediato, volver a su entorno después de recibir el alta médica.

Es conocido que esta repuesta fisiológica tiene un objetivo claro en el individuo, la protección frente al agente estresor, que debe ser puesta en marcha de forma inmediata. 
La activación del proceso comienza en el hipotálamo, donde se genera el Factor Liberador de Corticotropina (CRF), que al pasar por el sistema circulatorio de la glándula pituitaria, activa la hipófisis anterior para segregar la hormona Adenocorticotropa (ACTH), todo ello a través del eje Hipotálamo-Pituitaria-Suprarrenal (HPA axis), produciendo hormonas glucocorticoides en la capa reticular y fascicular de la corteza suprarrenal, que son liberadas al torrente sanguíneo, principalmente cortisol, el más activo, como se explica en la Figura 9, que se unirá a la globulina fijadora de cortisol o transcortina y en menor valor a la albúmina. El 94\% del cortisol se transporta en forma fija y el resto en forma libre, liberándose además otras hormonas como adrenalina y noradrenalina principalmente (Cruz, 2015).

Hay que mencionar además, que la secreción de cortisol no solo se regula por el efecto de un agente estresor específicamente con su posterior activación del Eje Hipotálamo-Hipófisis-Suprarrenal, sino que es controlada por la secreción episódica relacionada con el ritmo circadiano de ACTH y la retroalimentación que los niveles de cortisol plasmático ejercen sobre la hormona ACTH inhibiendo su producción (Greenspan et al., 2003).

El cortisol, como principales efectos en el organismo, dará lugar a un aumento de la glucemia al activar la glucogenólisis y la gluconeogénesis, intensificando la acción del glucagón, pero al existir una modificación en la acción de la insulina generada induciendo a una resistencia a la insulina en músculos y tejidos adiposos, el organismo no podrá hacer uso de la glucosa como sustrato energético, obteniendo en su lugar la energía del catabolismo de los lípidos principalmente (Weissman, 1990).

Entre los desencadenantes más relevantes para producir una reacción neuroendocrina, de liberación de cortisol se encuentran el dolor y los estados de estrés (Deak et al., 1999; McEwen, 2007; Weissman, 1990).

Las investigaciones relacionadas con la respuesta al estrés por los seres humanos en algunos casos ha demostrado la existencia de factores ambientales, culturales, estrato social, rasgos de personalidad, género y actitudinales que actúan como mediadores o moduladores de la respuesta fisiológica al estrés mencionada anteriormente (Goldstein \& Eisenhofer, 2010). Por el contrario, otras líneas de investigación no han obtenido resultados concluyentes para poder afirmar las relaciones men- 
Figura 9. Liberación de cortisol mediante el eje Hipotálamo-Hipófisis-Suprarrenal

\section{Evento estresor}

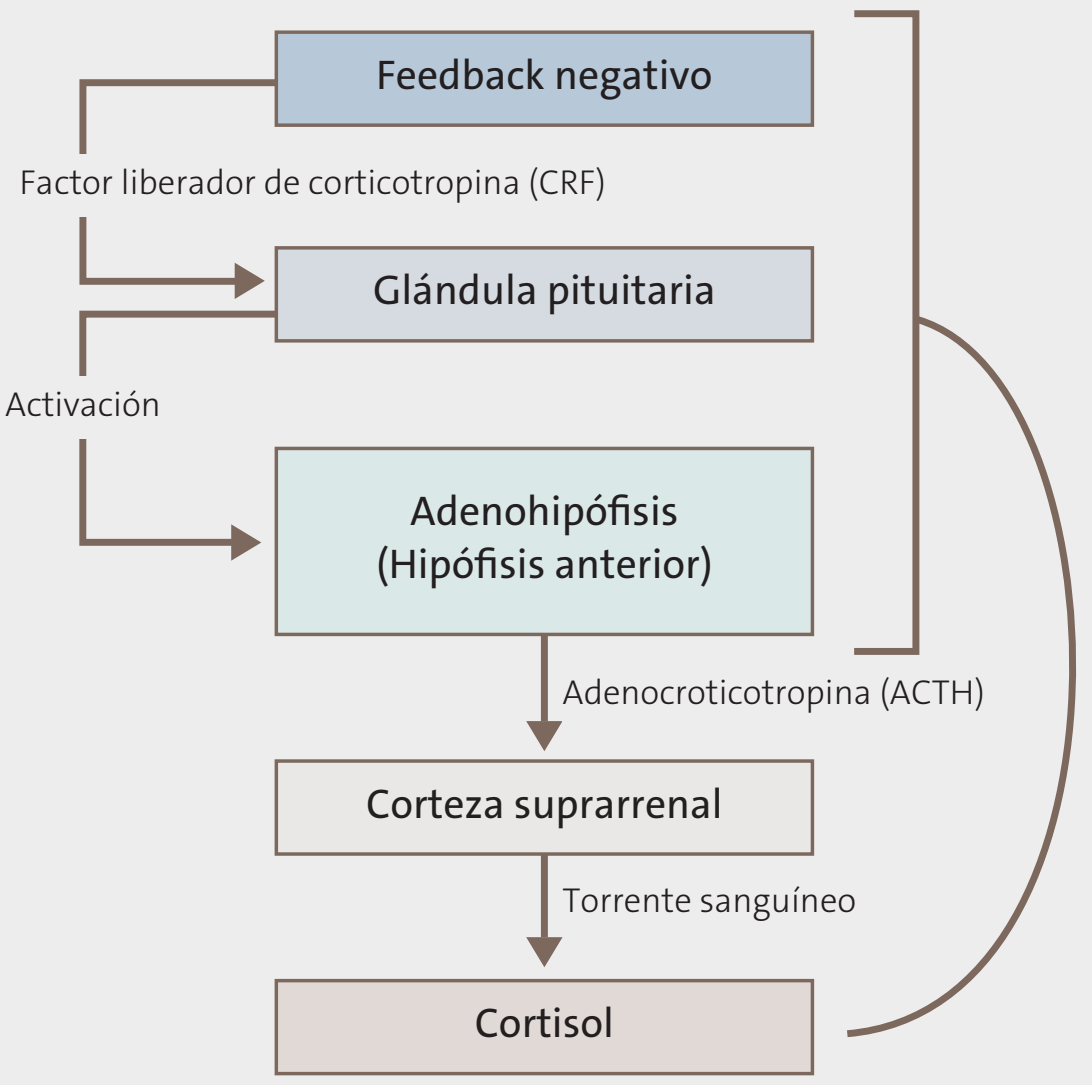

Fuente: Elaboración propia

cionadas con anterioridad, por ejemplo, la relación entre los niveles de cortisol y el género (Aguilar Cordero et al., 2014)

Por lo que se refiere a la cuantificación de los niveles de cortisol, los estudios han definido la manera de obtener ese valor en función de los objetivos del estudio, pudiendo obtener las muestras a través de los niveles séricos del individuo mediante la extracción de una muestra de sangre, saliva, orina o incluso en el cortisol depositado en el pelo o uñas, pudiéndose calcular en función del método elegido la cantidad de cortisol basal en 
un momento determinado, su variación circadiana o su producción durante un periodo más prolongado (Maidana, Bruno, \& Mesch, 2013). Se han establecido una relación directa entre estos valores y los datos obtenidos de pruebas psicológicas, siendo la mejor opción combinar ambos métodos el subjetivo y el fisiológico (Aguilar Cordero et al., 2014).

\subsection{Los cuidados de enfermería relacionado con el estrés del paciente}

En primer lugar, se debe aclarar que según la Taxonomía II, creada por la NANDA-I, el estrés no aparece como diagnóstico enfermero propiamente dicho, en su caso aparece graduado por otras características que lo matizan, por ejemplo, existe el diagnóstico enfermero estrés por sobrecarga, riesgo de síndrome de estrés del traslado o síndrome de estrés del traslado.

El diagnóstico enfermero riesgo de síndrome de estrés del traslado, código 00149, en su ediciones 2000, 2006, 2008, 2010, es definido por la NANDA-I como "riesgo de sufrir un trastorno fisiológico y/o psicológico como después del traslado de un entorno a otro" (NANDA International, 2015).

Pertenece a la necesidad número nueve, evitar peligros/seguridad, según las catorce necesidades de Virginia Henderson y al patrón funcional número ocho, rol/relaciones, según los once patrones funciones de Marjory Gordon.

Dentro de la Taxonomía II, pertenece al dominio nueve, afrontamiento/tolerancia al estrés y a la clase uno, respuestas postraumáticas.

Tabla 21. Factores de riesgo del DxE Riesgo de síndrome de estrés del traslado (00149)

\begin{tabular}{l}
\hline Afrontamiento pasivo \\
\hline Cambio ambiental de moderado a importante \\
\hline Competencia mental moderada \\
\hline Deterioro del estado de salud \\
\hline Expresa impotencia \\
\hline Falta de asesoría previa al traslado \\
\hline Falta de un sistema de apoyo adecuado \\
\hline Imprevisibilidad de la experiencia \\
\hline Pérdidas \\
\hline Trasladarse de un entorno a otro \\
\hline
\end{tabular}


El diagnóstico enfermero síndrome de estrés del traslado, código 00114, en sus ediciones 1992, 2000, 2006, 2008 y 2010 es definido por la NANDA-I como "trastorno fisiológico y/o psicológico tras el traslado de un entorno a otro".

Pertenece a la necesidad número nueve, según Virginia Henderson, evitar peligros/seguridad y al patrón funcional de Marjory Gordon número ocho rol/relaciones

Dentro de la Taxonomía II, pertenece al dominio nueve, afrontamiento/tolerancia al estrés, clase uno, respuestas postraumáticas.

\begin{tabular}{ll}
\hline \multicolumn{2}{l}{ Tabla 22. Características definitorias } \\
\hline Abandono & Expresa no tener deseos de trasladarse \\
\hline Alienación & Aumento de síntomas físicos \\
\hline Ansiedad (p.ej: separación) & Baja autoestima crónica \\
\hline Ira. & Aumento de enfermedades \\
\hline Inseguridad & Manifestación creciente de necesidades \\
\hline Frustración & Pérdida de la autoestima \\
\hline Pesimismo & Pérdida de la identidad \\
\hline Dependencia & Trastornos del patrón del sueño \\
\hline Depresión & Preocupación por el traslado \\
\hline Soledad & Preocupación \\
\hline
\end{tabular}

Tabla 23. Factores relacionados del DxE síndrome del estrés del traslado (00114) Afrontamiento pasivo

Aislamiento

Barreras lingüísticas

Deterioro del estado de salud

Expresa sentimientos de impotencia

Falta de orientación antes del traslado

Falta de un sistema de apoyo adecuado

Imprevisibilidad de la experiencia

Pérdidas

Trasladarse de un entorno a otro

Conviene subrayar que tanto el diagnóstico enfermero síndrome de estrés por traslado, como el riesgo de padecer dicho diagnóstico debe ser contextualizado en relación con el cambio de entorno que se produce cuando 
el paciente ingresa en hospitalización para ser intervenido quirúrgicamente, en el que se produce un cambio de entorno habitual por un ambiente en muchos casos desconocido y que precisa un proceso de aceptación y afrontamiento.

En relación con el proceso enfermero, durante la elección de posibles objetivos e intervenciones en el paciente que estamos valorando, si se pueden encontrar los siguientes NOC relacionados con el estrés del paciente:

Conocimiento: manejo del estrés, código NOC 1862, en su edición 2013 de la Taxonomía II se define como: "Grado de conocimiento transmitido sobre el proceso de estrés y las estrategias para reducir o afrontar el estrés", perteneciente al dominio cuatro, conocimiento y conducta de salud, clase $\mathrm{S}$, conocimientos sobre salud, patrón seis, cognitivo-perceptivo (Merino, 2013).

\begin{tabular}{|c|c|}
\hline Código & Nombre del indicador \\
\hline 186206 & Respuesta conductual al estrés \\
\hline 186207 & Respuesta espiritual al estrés \\
\hline 186208 & Papel del estrés en la enfermedad \\
\hline 186209 & Beneficios del manejo del estrés \\
\hline 186210 & Técnicas de terapia cognitiva \\
\hline 186211 & Técnicas de inoculación del estrés \\
\hline 186212 & Enfoques de resolución de problemas \\
\hline 186213 & Técnicas de meditación efectivas \\
\hline 186214 & Técnicas de relajación efectivas \\
\hline 186215 & Técnicas efectivas de disminución del estrés \\
\hline 186216 & Técnicas de comunicación efectivas \\
\hline 186217 & Importancia de mantener un sueño adecuado \\
\hline 186218 & Beneficios de la dieta saludable \\
\hline 186219 & Beneficios del ejercicio regular \\
\hline 186220 & Beneficios del masaje \\
\hline 186221 & Beneficios de la oración \\
\hline 186222 & Beneficios de la hipnosis \\
\hline 186223 & Beneficios de la música \\
\hline 186224 & Efectos sobre el estilo de vida \\
\hline
\end{tabular}




\section{Tabla 25. Indicadores de resultado del NOC nivel de estrés}

\begin{tabular}{|c|c|}
\hline Código & Nombre del indicador \\
\hline 121201 & Aumento de la presión arterial \\
\hline 121202 & Aumento de la frecuencia del pulso radial \\
\hline 121203 & Aumento de la frecuencia respiratoria \\
\hline 121204 & Pupilas dilatadas \\
\hline 121205 & Aumento de la tensión muscular en el cuello, hombros y espalda \\
\hline 121206 & Cefalea tensional \\
\hline 121207 & Palmas de las manos sudorosas \\
\hline 121208 & Boca y garganta secas \\
\hline 121209 & Diarrea \\
\hline 121210 & Micción frecuente \\
\hline 121211 & Cambio en la ingesta de alimentos \\
\hline 121212 & Malestar estomacal \\
\hline 121213 & Inquietud \\
\hline 121214 & Trastornos del sueño \\
\hline 121215 & Falta de memoria \\
\hline 121216 & Errores cognitivos frecuentes \\
\hline 121217 & Disminución de la atención a detalles \\
\hline 121218 & Incapacidad para concentrarse en las tareas \\
\hline 121219 & Arrebatos emocionales \\
\hline 121220 & Irritabilidad \\
\hline 121221 & Depresión \\
\hline 121222 & Ansiedad \\
\hline 121223 & Desconfianza \\
\hline 121224 & Pensamientos opresivos \\
\hline 121225 & Episodios de flashback \\
\hline 121226 & Disociación \\
\hline 121227 & Conducta compulsiva \\
\hline 121228 & Aumento del consumo de alcohol \\
\hline 121229 & Aumento del consumo de fármacos psicotrópicos \\
\hline 121230 & Aumento del consumo de tabaco \\
\hline 121231 & Absentismo \\
\hline 121232 & Disminución de la productividad \\
\hline 121233 & Aumento de la frecuencia de accidentes \\
\hline 121234 & Cambios en la libido \\
\hline 121235 & Interrupción del proceso de pensamiento \\
\hline
\end{tabular}


Todas las escalas de los indicadores se pueden cuantificar desde ningún conocimiento hasta conocimiento extenso.

Nivel de estrés, código NOC 1212, en su edición 2004, 2008, 2013 de la Taxonomía II, se define como: "Gravedad de la tensión física o mental manifestada como consecuencia de factores que alteran un equilibrio existente", perteneciente al dominio tres, salud psicosocial, clase $M$, bienestar psicológico, patrón diez, afrontamiento tolerancia al estrés.

Todas las escalas de los indicadores se pueden cuantificar desde ningún conocimiento hasta conocimiento extenso.

Por último, respecto a las posibles intervenciones relacionadas con el estrés, según la Taxonomía II, se obtiene:

Disminución del estrés por traslado, código 5350, en su edición 2004, 2013 se define como "ayudar al individuo a prepararse y a afrontar el traslado de un entorno a otro" (Merino, 2013), perteneciente al campo tres, conductual, clase $\mathrm{R}$, ayuda para el afrontamiento.

Dicha intervención puede ser planificada eligiendo las actividades descritas en la Tabla 26.

Cabe mencionar que, en el ámbito de los estudios científicos que han intentado desarrollar tanto el concepto de estrés como el de ansiedad desde un punto de vista empírico, y al contrario de lo que ocurre con la planificación de los cuidados en enfermeros, encontramos evidencias científicas que demuestran la existencia de una conceptualización errónea de ambos términos a lo largo de la historia, dichas investigaciones desde sus comienzos refieren la dificultad que existe en distinguir la ansiedad del estrés, debido al gran número de elementos comunes entre ambos (Endler, 1997).

Es necesario recalcar que, desde la disciplina enfermera unida al uso de la nomenclatura propia NANDA-I, el nivel estrés y ansiedad en ocasiones proceden de un diagnóstico enfermero común, es por ello que durante la realización del proceso de atención de enfermería se debería valorar la percepción tanto del nivel de estrés o ansiedad que el paciente manifieste en cada momento, tomando como base teórica la diferencia principal entre el concepto de estrés como la imposibilidad del individuo de hacer frente a las demandas del ambiente, es este caso, al enfrentarse a una intervención quirúrgica, en contraposición a la características de 
Tabla 26. Actividades para la intervención disminución del estrés por traslado (5350)

\begin{tabular}{|c|c|}
\hline Código & Actividad \\
\hline 535001 & Averiguar si el individuo ha tenido traslados previos. \\
\hline 535002 & Incluir al individuo en el plan de traslados, según corresponda. \\
\hline 535003 & $\begin{array}{l}\text { Averiguar qué es lo más importante en la vida del individuo (familia, } \\
\text { amigos, objetos personales). }\end{array}$ \\
\hline 535004 & $\begin{array}{l}\text { Animar al individuo y a la familia a comentar las preocupaciones res- } \\
\text { pecto al traslado. }\end{array}$ \\
\hline 535005 & Examinar con el individuo las estrategias de afrontamiento previas. \\
\hline 535006 & Favorecer el uso de estrategias de afrontamiento. \\
\hline 535007 & Valorar la necesidad/deseo del individuo de apoyo social. \\
\hline 535008 & $\begin{array}{l}\text { Evaluar los sistemas de apoyo disponibles (p.ej., familia ampliada, impli- } \\
\text { cación de la comunidad, afiliaciones religiosas). }\end{array}$ \\
\hline 535009 & $\begin{array}{l}\text { Asignar un "compañero" que le ayude en la integración en el nuevo am- } \\
\text { biente. }\end{array}$ \\
\hline 535010 & $\begin{array}{l}\text { Fomentar que el individuo/familia busque asesoramiento, según co- } \\
\text { rresponda. }\end{array}$ \\
\hline 535011 & $\begin{array}{l}\text { Disponer que los objetos personales del individuo estén en su sitio } \\
\text { antes del traslado. }\end{array}$ \\
\hline 535012 & $\begin{array}{l}\text { Controlar la presencia de signos y síntomas fisiológicos y psicológicos } \\
\text { de estrés por traslado (p.ej., anorexia, ansiedad, depresión, aumento de } \\
\text { exigencias y desesperanza). }\end{array}$ \\
\hline 535013 & $\begin{array}{l}\text { Proporcionar actividades recreativas (p.ej., participación en aficiones, } \\
\text { actividades cotidianas). }\end{array}$ \\
\hline 535014 & $\begin{array}{l}\text { Ayudar al individuo en su período de duelo y a superar la pérdida del } \\
\text { hogar, amigos e independencia. }\end{array}$ \\
\hline 535015 & $\begin{array}{l}\text { Evaluar el impacto de la alteración del estilo de vida, pérdida de hogar y } \\
\text { adaptación al nuevo entorno. }\end{array}$ \\
\hline
\end{tabular}

la ansiedad en la que el individuo refiere un estado de reacción emocional, como pueden ser la agitación o inquietud, producida por la anticipación a un posible peligro. Se deberá evitar la disyuntiva entre ambos conceptos desde un punto de vista teórico, y centrarnos en resolver los diagnósticos enfermeros encontrados mediante la planificación de los objetivos (NOC) y la realización de las intervenciones (NIC), que serán comunes en la realización del proceso de atención de enfermería catalogán- 
dolos preferiblemente como posibles objetivos de mejora, en lugar de centrarnos en diagnosticarlos como aspectos independientes. Con ello, simplificaría la actuación enfermera, alejándonos de aspectos más concretos y propios de otras disciplinas como la Psicología o la Psiquiatría. Por ejemplo, un paciente que está programado para ser intervenido quirúrgicamente puede presentar como posible diagnóstico enfermero el temor, código 00148, que en sus ediciones 1980, 1996, 2000, 2006, 2008 y 2010 es definido por la NANDA-I como "respuesta a la percepción de una amenaza que se reconoce conscientemente como un peligro" (NANDA Internacional, 2015), en la planificación de los objetivos y las intervenciones para este diagnóstico se podrá cuantificar el nivel de ansiedad para poder medir las características definitorias o el nivel de estrés y así medir los posibles factores relacionados con el diagnóstico principal del paciente, en este caso el temor.

En definitiva, los cuidados enfermeros relacionados con el estrés del paciente,deberán ser valorados en el contexto individual de cada persona, evitando la obcecación por diagnosticar un concepto que puede ser compartido por otras disciplinas afines y que, en el caso del proceso de atención de enfermería, debería centrarse en mayor medida en detectar las repercusiones que ese estrés puede tener en otros diagnósticos enfermeros como posible factor relacionado, y actuar sobre él planificando las actividades necesarias para disminuirlo, como por ejemplo aumentar los sistemas de apoyo. 


\section{EL PACIENTE QUIRÚRGIGO}

En la actualidad, el personal de enfermería se plantea como objetivo en planificación de los cuidados, la humanización de la atención del paciente quirúrgico, sobre todo en el momento de entrar en el quirófano. En numerosas ocasiones la atención en el quirófano, servicio de los más técnicos del hospital, pierde su carácter humanizado y se convierte en impersonal siendo el paciente tratado como un caso más de esa jornada, unido al aislamiento que sufren también sus familiares (Heluy de Castro et al., 2004).

\subsection{El quirófano}

El quirófano es un lugar donde cotidianamente se pueden generar situaciones elevadas de estrés, no solo para el personal que trabaja en él sino para los pacientes que llegan a una infraestructura, que en muchos casos van a conocer por primera vez en su vida (Cho \& Hong, 2001; Ortiz, 2006).

El quirófano está compuesto por tres zonas diferenciadas (Badani Lenz, 2011):

- Zona negra: primera zona de acceso restringido, se refiere al área de vestidores, baños y labores administrativas del quirófano.

- Zona gris: denominada también zona limpia, todo el personal que se encuentre en esta zona debe llevar la vestimenta específica del quirófano. El paciente en esta área entra generalmente desnudo, cubierto con bata, gorro y calzas, acostado sobre una camilla que 
se utilizará para entrarlo al quirófano y trasladarlo después a la unidad de recuperación de la anestesia (URPA), sala que compartirá con el resto de pacientes que están realizando la recuperación postquirúrgica inmediata, para una vez dado de alta, volver a la habitación de hospitalización.

- Zona blanca: es donde se encuentra la sala de operaciones propiamente dicha, en dicho habitáculo se encontrará todo el material necesario para la realización de la intervención, como puede ser el aparato de anestesia, la mesa de cirugía, el instrumental quirúrgico, la torre de endoscopia, la lámpara de iluminación, así como las diferentes mesas auxiliares que se precisarán para la intervención propiamente dicha..

La labor de enfermería, en concreto la del enfermero que realiza los cuidados perioperatorios, es fundamental para la satisfacción y la seguridad del paciente quirúrgico, con la administración de cuidados enfermeros en el quirófano y favoreciendo la interacción y transición adecuada y favorable entre las fases preoperatoria, intraoperatoria y postoperatoria (Possari, 2004).

\subsection{Etapas del acto quirúrgico}

El acto quirúrgico consta de tres periodos principales (Colomer Mascaró et al., 2009; Martín Abreu \& Pérez Vela, 2004):

- Preoperatorio: es el periodo que comienza con el ingreso del paciente en el hospital hasta el comienzo de la anestesia en el quirófano. En este periodo, el paciente comienza su incursión en el hospital esperando la recepción por parte del servicio de admisión, dicho personal de admisión identifica al paciente y lo acompaña a su habitación de hospitalización, en estos momentos sí puede estar acompañado de su entorno socio-familiar. En la unidad de hospitalización es recibido por el personal de enfermería que comienza los preparativos para su intervención, entrevista personal, verificación de pruebas preoperatorias, ayuno, resolución de posibles 
dudas previas a la intervención, entrega de bata para la bajada al quirófano.

Finalmente, el paciente es bajado en su cama junto a los posibles acompañantes que tenga hasta la entrada de la unidad de quirófano, en ese momento sus acompañantes irán a la sala de espera y el paciente entrará, junto al celador, en la unidad, hacia el antequirófano.

- Intraoperatorio: etapa comprendida entre el ingreso del paciente en el quirófano hasta la salida del paciente a la unidad de URPA, entregado por la enfermera de anestesia responsable de ese proceso. Esta etapa comienza con la presentación del equipo quirúrgico al paciente, confirmación de la correcta preparación preoperatoria, canalización de una vía venosa periférica para la administración de la medicación parenteral, realizándose todas estas actividades en la sala contigua al quirófano, denominada antequirófano. Posteriormente, el paciente es trasladado por el celador a la sala de operaciones para comenzar con la anestesia general previa a la cirugía endoscópica nasal. Finalizada la intervención, se realiza la educción anestésica y se traslada al paciente a la URPA, acompañado por el celador, el anestesista y la enfermera de anestesia. En estos momentos el paciente no tiene contacto con su entorno socio-familiar.

- Postoperatorio: periodo que comienza con la recuperación inmediatamente después de su salida de la sala de operaciones (postoperatorio inmediato), recuperación que será controlada en la URPA, seguida de su alta en la unidad para el posterior traslado a su habitación de hospitalización. Es en este momento cuando el paciente vuelva a estar en contacto con su entorno social. Por último, si la evolución del paciente es la adecuada, es dado de alta entre las 24 y 48 horas para un control postoperatorio en consultas externas hasta el alta definitiva por el proceso que motivó su ingreso hospitalario, en este caso la cirugía endoscópica nasal. 



\section{CUIDADOS ENFERMEROS EN LA CIRUGÍA NASOSINUSAL EN EL ADULTO}

La cirugía endoscópica nasosinusal (CENS) es una procedimiento quirúrgico mínimamente invasivo que consigue mejorar y restaurar la ventilación y función sinusal (Lobo et al., 2003).

La obstrucción nasal puede ser debida a causas de tipo mecánico o funcionales. Entre las causas de tipo mecánico se pueden encontrar (Nazar, Cabrera, \& Naser, 2013):

- Congénitas: encefalocele, teratoma, glioma, atresia coanal.

- Anatómicas: septodesviación, colapso válvula nasal, sinequias, hipertrofia cornetes.

- Tumorales: pólipos nasales, neoplasias benignas y malignas.

- Traumáticas: cuerpo extraño, perforación septal.

- latrogénicas: rinitis atrófica, resección excesiva en osteotomías.

Entre las causas de tipo funcional se pueden encontrar:

- Alérgicas: rinitis alérgica.

- Endocrinas: embarazo, hipotiroidismo, insuficiencia adrenal, menstruación.

- Infecciones: rinosinusitis aguda y crónica, absceso septal.

- Fármacos: rinitis medicamentosa, reacción adversa a fármacos.

- Reumatológicas: granulomatosis de Wegene.

La cirugía endoscópica nasosinusal ha sido el procedimiento quirúrgico más utilizado para solucionar los estados inflamatorios nasosinusales, crónicos y recurrentes que no han podido ser resueltos por el tratamien- 
to médico convencional, siendo una técnica tanto diagnóstica como terapéutica muy frecuente dentro de la especialidad de otorrinolaringología.

La cirugía endoscópica nasal ha ido evolucionando como procedimiento quirúrgico desde su implantación en España, siendo una técnica que se ha ido posicionando poco a poco como una cirugía mayor ambulatoria (CMA) en función de los antecedentes del paciente y las indicaciones quirúrgicas, variables que deben ser detectadas previamente para poder derivar correctamente al paciente a una CMA con garantías de una correcta recuperación sin complicaciones (Eisenberg et al., 2008).

Los pacientes intervenidos de CENS se pueden clasificar según la patología intervenida (Lobo et al., 2003):

- Pólipo nasal CIE J33.

- Sinusitis crónica CIE J32.9.

- Hipertrofia Cornetes Nasales CIE J34.2.

- Dacriocistitis CIE H04.30.

- Mucocele CIE J34.1.

- Papiloma invertido CIE J35.8.

Las complicaciones que pueden aparecer relacionadas con la CENS pueden clasificarse en mayores corregibles con tratamiento, mayores no corregibles con tratamiento, menores temporales que no requieren tratamiento, menores temporales que requieren tratamiento y menores permanentes no corregibles con tratamiento (Bross et al., 1999).

\section{Complicaciones mayores}

Corregibles con tratamiento

Pérdida de visión

Diplopía

Epifora (que requiere dacriocistorrinostomía)

Lesión a la carótida

Hematoma orbital (postseptal)

Hemorragia que requiere transfusión

Meningitis

Fístula de líquido cefalorraquídeo

Enfermedad vascular cerebral 
Absceso cerebral

Permanente a pesar del tratamiento

Déficit de sistema nervioso central

Ceguera

Diplopía

Enfermedad vascular cerebral

Muerte

\section{Complicaciones menores}

Temporales que no requieren tratamiento

Dolor o adormecimiento dental o labial

Equimosis periorbitaria (preseptal)

Enfisema periorbitario subcutáneo

Temporales corregibles con tratamiento

Asma bronquial (relativa)

Infecciones

Sinequias (sintomáticas)

Permanentes y no corregibles

Anosmia

Dolor o adormecimiento dental

\subsection{Proceso de Atención de Enfermería en el paciente programado para ser intervenido de cirugía endoscópica nasosinusal}

La propuesta de Proceso de Atención de Enfermería (PAE) tiene como objetivo ejemplarizar las relaciones que existen entre los tres conceptos principales de esta tesis doctoral, como son el apoyo social, la ansiedad y el estrés en el paciente programado para ser intervenido de cirugía endoscópica nasosinusal, dentro de la planificación de los DxE y los posibles objetivos y actividades, necesarias para ejecutar el PAE.

Se puede definir el proceso enfermero como "un método sistematizado de brindar cuidados humanistas centrados en el logro de objetivos (resultados esperados) de forma eficiente" (Alfaro-LeFevre, 1998, p. 4).

Se distinguen cinco etapas durante el proceso de atención de enfermería (PAE), valoración, diagnóstico, planificación, ejecución y evaluación. 
EI PAE debe tener una visión holística debido a que, durante las diferentes fases del proceso, se deben tener en cuenta y respetar los intereses, creencias y deseos de la persona, su familia o la comunidad, analizando su efecto sobre el paciente y su familia (Alfaro-LeFevre, 1998).

Así mismo, utilizando la visión holística de los cuidados enfermeros junto a la planificación de los objetivos centrados en la seguridad del paciente, se generará un PAE para un perfil específico de paciente, teniendo en cuenta que cada persona es diferente y sus respuestas humanas son individuales, es decir, que la intención no es generalizar, sino de lo que se trata es de ofrecer una aproximación a modo de guía, de aquellos aspectos a tener en cuenta en la realización de un PAE centrado en las variables objeto de estudio de esta tesis doctoral, como son el apoyo social, la ansiedad y el estrés, dicha propuesta de PAE se desarrollará después de la obtención de los resultados del estudio de investigación. 


\section{JUSTIFICACIÓN}

La figura del enfermero de quirófano, en la actualidad, incluye los cuidados al paciente en su etapa preoperatoria, intraoperatoria y postoperatorio, por lo que se ha generalizado el uso del término "enfermero perioperatorio" para referirse al personal que planificará y realizará las actividades en las diferentes etapas del proceso quirúrgico (Chirveches et al., 2006).

En mi práctica profesional diaria como enfermero perioperatorio en el servicio de quirófano del Complejo Universitario Hospitalario Materno Insular de Gran Canaria (C.H.U.I.M.I), he experimentado cómo los pacientes al Ilegar a la sala de operaciones, previo a la inducción anestésica, refieren estar preocupados no solo por los factores relacionados directamente con la cirugía o la anestesia que van a recibir, sino por las posibles repercusiones de su situación en su entorno social e inquietud y preocupación por los familiares que esperan durante su cirugía, solicitándome en su mayoría, contactar con ellos durante la cirugía para tranquilizarles, no siendo una actividad que esté protocolizada en el C.H.U.I.M.I.

Asimismo, al salir a informar a los familiares del paciente sobre el estado del mismo durante la cirugía, percibía la importancia de la relación que en muchos casos tenía el entorno social y el paciente, más allá de las dudas puramente relacionadas con el proceso quirúrgico que se estaba realizando.

Es decir, la realización de este acto sencillo y que puede planificarse como una actividad enfermera, me hizo plantearme la importancia que el apoyo social como valor intangible puede tener para el paciente qui- 
rúrgico, al cual no se puede ver simplemente como una persona con un problema puramente quirúrgico sin un entorno social que es necesario para su recuperación. En países como Estados Unidos está aumentando el número de hospitales que valoran e involucran al entorno social del paciente como valor intangible importante para la realización de los cuidados (Andrews, 2009; Lpez-Navas et al., 2011).

Los cuidados de enfermería deben ser suministrados de manera integral y desde una perspectiva holística (Chirveches et al., 2006; Cristina Martín-Crespo Blanco, Isabel Caravantes Marín, Maria García Mas, \& Gómez González, 2006; Fern, 2015; Fernández Sánchez, Gonzales, \& Ordoqui, 2009; Paiva, Rossi, Costa, \& Dantas, 2010; Pritchard, 2009; RiveraRomero, Pastoriza-Galán, Díaz-Perianez, \& Hilario-Huapaya, 2013), es por ello que se debe ir más allá de los problemas de colaboración que pueda presentar el paciente quirúrgico, involucrando en los cuidados a todo el entorno social, lo que mejorará los resultados, siendo la enfermera el catalizador del cambio, presentado opciones de cuidados enfermeros basados en la evidencia científica que no se concentran solo en aspectos meramente médicos sino que además se ajustan a las necesidades del paciente (Hendrich et al., 2008; Pasero \& Belden, 2006).

El paciente quirúrgico, durante su proceso previo a la intervención, va a enfrentarse a una serie de retos y cambios en su entorno habitual que puede generar un aumento de su ansiedad y estrés (Díez-álvarez et al., 2012a). El ingreso en el hospital y el contacto con el personal de enfermería debe ser protocolizado para servir como base en la planificación de los cuidados a los diferentes profesionales que atienden al paciente, pero siempre teniendo en cuenta las características individuales.

La investigación enfermera debe girar en torno a los cuidados, en ocasiones los investigadores han desarrollado un cuerpo de conocimientos que se centra más en aspectos internos de la profesión o su estado actual que en las necesidades del paciente. Por ello, los estudios que han evaluado la contribución científica de la disciplina enfermera abogan por la combinación de metodología enfermera, en términos de resultados de salud unido al desarrollo de líneas de investigación afines a los cuidados, por ejemplo, las recomendadas por el Instituto Carlos III en su conferencia titulada "Building a European Nursing Research Strategy" celebrada 
en Salamanca en 1999; en ella se estableció como una de las prioridades en investigación enfermera, la "valoración de necesidades de la persona y sus cuidadores"(Morales Asencio, 2004).

Si se escoge esa prioridad en relación con los cuidados del paciente quirúrgico podríamos descubrir cuáles son los posibles factores que pueden perjudicar o favorecer la experiencia personal del paciente durante las distintas etapas del proceso operatorio, lo que va a permitir prever posibles complicaciones si son detectadas esas debilidades o fortalezas durante la valoración del paciente para poder, de esta manera, planificar los cuidados adaptados específicamente a esas necesidades, permitiendo un enfoque holístico en la investigación, el cual no es sencillo conseguir en determinados procesos biomédicos donde se ha priorizado la resolución de la patología frente al enfoque integral de atención sanitaria (Burnside \& Snowden, 2017; Delgado Hito et al., 2001).

Se debe destacar la existencia de una fuerte evidencia que demuestra la presencia de sentimientos de ansiedad y estrés en el paciente quirúrgico, que comienza con el cambio del entorno al producirse el ingreso en la unidad de hospitalización y el paso por el resto de etapas del proceso quirúrgico hasta el alta definitiva a su domicilio (Grieve \& R.J., 2002; Herdman et al., 2015; Koivula et al., 2001; Lazarus \& Folkman, 1986; Mogg \& Bradley, 1998; Pritchard, 2009).

Por otra parte, cada vez existen más estudios que intentan definir la importancia que el apoyo social tiene sobre los pacientes en situaciones de estrés. Desde la perspectiva enfermera existe una abundante corriente teórica que justifica la importancia de cuantificar cualitativa y cuantitativamente la necesidad de apoyo social (AS) en el paciente crítico, pero no se ha correspondido con un aumento de la evidencia empírica de gran calidad metodológica en este ámbito o del uso práctico de instrumentos para evaluar el AS en los pacientes durante la valoración enfermera (Neabel, Fothergill-Bourbonnais, \& Dunning, 2000; O’Reilly, 1988).

Es por ello, que el enfermero no solo debe valorar aspectos relacionados directamente con características personales del paciente, sino que debe, a su vez, detectar posibles carencias en el apoyos social percibidos por los pacientes que atiende para poder actuar en consecuencia (Artinian, 1989; Torres \& Morales, 2004). 
Los estudios que han intentando relacionar las variables de ansiedad, estrés y apoyo social en el entorno hospitalario en el paciente quirúrgico desde una perspectiva enfermera son escasos, es por ello que se debe profundizar en investigaciones que comiencen a desvelar cómo se interrelacionan entre sí estas variables (Neuling \& Winefield, 1988).

La cirugía endoscópica nasosinusal puede ser integrada dentro de las posibles intervenciones que son candidatas para ser incluidas dentro del protocolo de Recuperación Acelerada después de la cirugía, que entre otras condiciones para aplicarse, el paciente debe disponer de un entorno social capaz de atender sus necesidades al alta, es por ello que es de vital importancia la cuantificación del apoyo social percibido para planificar el alta precoz en este tipo de pacientes, cobrando cada vez mayor importancia el análisis de dicha variable en la disciplina enfermera (Vega Angarita \& González Escobar, 2009).

El objetivo de esta tesis es describir y analizar las relaciones entre las variables sociodemográficas y variables sociales: apoyo social (AS), ansiedad (A) y estrés (E) del paciente adulto hospitalizado en el C.H.U.I.M.I., programado para ser intervenido quirúrgicamente mediante cirugía endoscópica nasosinusal. Los resultados de la investigación deberán ser la base para generary desarrollar un conocimiento que en la actualidad precisa de nuevas investigaciones y permitirá, en un futuro, realizar intervenciones para mejorar el AS en los pacientes quirúrgicos. Para ello, se usarán cuestionarios validados y pruebas séricas hormonales, evitando de esta manera resultados basados en medidas a mbiguas o conceptos poco definidos, situación ya señalada y descrita como un déficit en investigaciones previas que han intentando relacionar las variables objeto de estudio (Salmon, 1992; Sierra et al., 2003), siendo, por tanto, la fase preoperatoria el momento ideal para comenzar las mediciones de las variables seleccionadas (Leinonen \& Leino-Kilpi, 1999).

Se parte de la hipótesis inicial de que el apoyo social percibido influye en los niveles de estrés y ansiedad prequirúrgica y postquirúrgica en los pacientes adultos hospitalizados en el C.H.U.I.M.I., programados para ser intervenidos de cirugía endoscópica nasosinusal.

La confirmación o no de la hipótesis permitirá sentar las bases para futuras investigaciones que pueden evaluar la eficacia de posibles inter- 
venciones enfermeras que tengan como objetivo aumentar el AS percibido del paciente quirúrgico.

La labor de la enfermera en la sociedad debe ser cuidar al paciente en su conjunto desde una perspectiva holística, lo que implica no solo actuar para prevenir la enfermedad o fomentar conductas saludables, sino conseguir un entorno social adecuado que sirve como apoyo para el paciente en su proceso de recuperación, actividades que el profesional enfermero está cualificado para realizar y es la figura idónea dentro del equipo multidisciplinar para hacerlo (Ang, Chen, Siah, He, \& Klainin-Yobas, 2013; Cochran \& Ganong, 1989; Fernández Sánchez et al., 2009; Martín Díaz, Hidalgo Gutiérrez, Cerezo Solana, Casas Carriazo \& Martín Morcillo, 2012).

Los resultados de este trabajo de investigación, permitirán tener una visión inicial de la relación de las variables ansiedad, estrés y apoyo social en el paciente intervenido quirúrgicamente de endoscopia nasosinusal, que dará las pautas para extrapolarlo a otros pacientes, aumentando la potencia de la evidencia existente para conseguir desarrollar futuras intervenciones en relación con los resultados obtenidos, mejorando y actuando sobre las fortalezas detectadas.

A su vez, se debe destacar la importancia del uso de la metodología enfermera y la taxonomía NANDA, para la adecuada valoración, planificación, ejecución y evaluación de los cuidados enfermeros; en este caso, los cuidados enfermeros a los pacientes que van a ser intervenidos quirúrgicamente, concretamente los pacientes programados para realizarles una cirugía endoscópica nasosinusal (Luis Rodrigo, 2008).

Con esta investigación se pretende conseguir una base científica y metodológica para medir la relación entre las tres variables objeto de estudio en los pacientes incluidos en el estudio, permitiendo posteriormente abordar las necesidades de información e implicar en el proceso quirúrgico al entorno social del paciente que permitirán una mejor recuperación (Krohne \& Slangen, 2005). Por último, se debe matizar que no existe, en la actualidad, la figura de una enfermera de enlace en el período perioperatorio en el hospital elegido para la investigación, como sí ocurre en otro hospitales donde se realiza una atención centrada en la familia con resultados positivos no solo para el paciente sino para su entorno social, motivo por el cual estos resultados podrán justificar la creación de ese 
rol profesional (Deselms, Duvall, \& Ruyle, 2016; Freeman \& Denham, 2008; Leske, 1993). 
ESTUDIO EMPÍRICO 



\section{HIPÓTESIS}

1. Los participantes en el presente estudio que refieren un mayor apoyo social percibido muestran menores niveles de estrés prequirúrgico y postquirúrgico.

2. Los participantes en el presente estudio que refieren un mayor apoyo social percibido muestran menores niveles de ansiedad prequirúrgica y postquirúrgica. 



\section{OBJETIVOS}

\section{Objetivo general:}

1. Describir y analizar la relación existente entre el grado de apoyo social (AS) percibido y los niveles de ansiedad (A) y estrés (E) del paciente adulto hospitalizado programado para ser intervenido quirúrgicamente mediante cirugía endoscópica nasosinusal.

\section{Objetivos específicos:}

1. Determinar el grado de apoyo social percibido de los pacientes adultos hospitalizados programados para ser intervenidos quirúrgicamente mediante cirugía endoscópica nasosinusal.

2. Determinar el nivel de ansiedad de los pacientes adultos hospitalizados programados para ser intervenidos quirúrgicamente mediante cirugía endoscópica nasosinusal.

3. Determinar el nivel de estrés de los pacientes adultos hospitalizados programados para ser intervenidos quirúrgicamente mediante cirugía endoscópica nasosinusal.

4. Analizar las relaciones existentes entre las variables sociodemográficas y variables sociales: apoyo social percibido, ansiedad y estrés, de los pacientes adultos hospitalizados programados para ser intervenidos quirúrgicamente mediante cirugía endoscópica nasosinusal. 
5. Analizar la relación existente entre el grado de apoyo social percibido, el nivel de ansiedad y estrés de los pacientes adultos hospitalizados programados para ser intervenidos quirúrgicamente mediante cirugía endoscópica nasosinusal y la variables relacionadas con el proceso quirúrgico. 


\section{METODOLOGÍA}

\subsection{Diseño}

Estudio analítico observacional correlacional de asociación prospectivo longitudinal con muestreo por conveniencia.

\subsection{Población de estudio y muestra}

La muestra del estudio estaba formada por pacientes hospitalizados en el Hospital Universitario Insular de Gran Canaria que fueron programados para ser intervenidos por el servicio de otorrinolaringología y se les realizó la intervención quirúrgica mediante cirugía endoscópica nasosinusal desde el 1 de septiembre de 2016 hasta el 31 de agosto de 2017.

Los criterios de inclusión en el estudio fueron los siguientes:

- Pacientes de 18-100 años con escala GCS de 15 pts.

- Hospitalizados para ser intervenidos por cirugía endoscópica nasosinusal en el Hospital Universitario Insular de Gran Canaria.

- Han sido informados sobre la participación en el estudio de investigación y han firmado el consentimiento informado.

- Idioma oral y escrito español.

- No presentan comorbilidad excepto la que precisa ser tratada quirúrgicamente

- Paciente sin ninguna alteración diferente del proceso localizado que precisa la intervención. Paciente sano. ASA I según la American Society of Anesthesiologists (Flores-Rivera, 1996). 
- Paciente con alguna alteración o enfermedad sistémica leve o moderada, que no produce incapacidad o limitación funcional. ASA II según la American Society of Anesthesiologists (Flores-Rivera, 1996).

Los criterios de exclusión en el estudio fueron los siguientes:

- Los participantes seleccionados no podrán padecer de ningún tipo de comorbilidad, ni física (problemas cardiovasculares, respiratorios metabólicos-endocrinos, neurológicos), ni psíquica que pudieran alterar los resultados, eliminado los casos excepcionales.

- Los paciente con riesgo anestésico ASA III, IV, V, VI, VII, E según la American Society of Anesthesiologists (Flores-Rivera, 1996).

El proceso de selección de muestra se realizó un muestreo no probabilístico consecutivo por conveniencia desde el 1 de septiembre de 2016 hasta el 31 de agosto de 2017.

\subsection{Variables e instrumentación}

\subsubsection{Variables Independientes}

Apoyo social percibido de amigos, familiares y personas relevantes.

\subsubsection{Variables dependientes}

- Ansiedad estado y ansiedad rasgo.

- Estrés.

- Nivel de cortisol sérico prequirúrgico.

- Analgesia extra solicitado después de la intervención.

- Tiempo en la unidad de recuperación postanestésica (URPA) en minutos.

- Duración de la cirugía en minutos.

- Tiempo de estancia hospitalaria en horas. 
- Presencia de complicaciones durante la intervención, la estancia en URPA, la estancia en hospitalización y a la semana de la intervención.

\subsubsection{Fuentes de información}

Las fuentes de información que se utilizaron en el estudio fueron los cuestionarios entregados a los pacientes en el momento del ingreso hospitalario previo a la cirugía, los cuestionarios después de la realización de la intervención quirúrgica y el resultado del análisis del nivel de cortisol, extraído en la sala contigua al quirófano justo antes de entrar para comenzar la intervención quirúrgica.

\subsubsection{Instrumentos de medida}

Las variables sociodemográficas fueron obtenidas mediante un cuestionario ad hoc en el que se recogían edad, sexo, estado civil, ocupación y nivel de estudios.

Las variables del paciente fueron obtenidas mediante un cuestionario ad hoc en el que se recogían presencia o no de consumo de tabaco, tipo de cirugía, tiempo de duración de la cirugía, complicaciones durante la cirugía, tiempo de ingreso en la unidad de recuperación postanestésica (URPA) en minutos, complicaciones durante el ingreso en URPA, tipo de complicación durante el ingreso en URPA, tiempo de ingreso en hospitalización (horas), complicaciones durante la hospitalización, tipo de complicación durante la hospitalización, analgesia extra recibida en URPA y hospitalización, intervenciones previas con anestesia general y complicaciones durante la primera semana.

El apoyo social percibido fue medido mediante la cumplimentación del cuestionario autocumplimentado Escala de Vínculos Interpersonales de Apoyo (VIDA) (Alemán Ruiz, 2013a; Calvo-Francés \& Alemán-Ruiz, 2016).

La escala VIDA ha sido validada con una muestra de 1080 participantes (48,2\% mujeres, edad media 33,51), la varianza en el proceso de validación del $73 \%$, con una consistencia interna de 0,94 o más. El proceso de validación tenía como objetivo crear una escala en español para propósitos generales que supere las limitaciones de los cuestionarios ante- 
riores, entre ellas, las muestras muy específicas y pequeñas (Alemán Ruiz, 2013b; Calvo-Francés \& Alemán-Ruiz, 2016).

Durante el desarrollo y validación del cuestionario VIDA, se crearon tres factores medibles que son los que se han utilizado para cuantificar el AS percibido: apoyo de amigos, familiar y personas relevantes.

En definitiva, el cuestionario VIDA es una herramienta eficaz para la medición del AS en los pacientes objeto de estudio, pacientes adultos intervenidos de CENS, debida a su excelente consistencia interna (,94 o superior), fiabilidad y validez convergente que permiten medir de una manera óptima esta variable en los pacientes seleccionados.

La ansiedad se evaluó mediante el Cuestionario de Ansiedad EstadoRasgo (Buela-Casal, Guillén-Riquelme, \& Seisdedos, 2011). Esta escala es autoevaluativa y mide la ansiedad desde dos conceptos diferentes: la es la ansiedad estado (AE) y la ansiedad rasgo (AR).

La creación del cuestionario de ansiedad Estado-Rasgo STAI empieza en 1964 con el objetivo de desarrollar una escala que permitiera medir de manera objetiva la AE y la AR (Charles Donald Spielberger, Gorsuch, \& Lushene, 1970). Este caso se centra en el desarrollo y justificación de la adaptación española de dicho cuestionario.

En primer lugar, cabe destacar que desde el comienzo del uso de la versión española del STAI, en el año 1982, el STAl se ha convertido en uno de los cuestionarios más utilizados por los profesionales sanitarios en nuestro país. Así lo demuestra el estudio realizado por Muñiz y Fernández-Hermida (2010), que lo situó como el séptimo cuestionario más utilizado en España tanto por psicólogos como dentro de la Psicología Clínica (citado en Buela-Casal, Guillén-Riquelme, \& Seisdedos, 2011).

En relación con la edición de la escala elegida para obtener los resultados en los pacientes intervenidos de CENS en el adulto, se usa la adaptación española actualizada y revisada por Buela-Casal, Guillén-Riquelme, \& Seisdedos (2011).

La diferentes ítems del cuestionario STAl fueron bastante discriminadores y diferenciadores en las diferentes muestras analizadas durante el proceso de validación del cuestionario, por lo que la consistencia interna de la versión española y su fiabilidad se asemeja a los estudios originales en la validación inicial del STAI, por lo que dicha versión es 
adecuada para su uso en los pacientes que cumplen los criterios de inclusión de este estudio (Buela-Casal et al., 2011).

El estado de ánimo relacionado con el estrés se cuantificará en relación con las exigencias de la situación que está experimentando el paciente y que generan una tensión producida por las demandas del contexto, en este caso, el ingreso hospitalario y la programación para ser intervenido quirúrgicamente, que da lugar a sentimientos desagradables o de excitación corporal negativa o de respuesta emocional negativa, midiendo su valor mediante el uso del inventario diferencial de adjetivos para el estudio del estado de ánimo (IDDA-EA) mediante la autoaplicación por el paciente (Tous-Ral \& Pueyo, 1991).

El IDDA-EA evalúa tres factores: activación, estrés y arousal. Se analizarán los resultados obtenidos en el factor estrés. Dicho factor presenta una fiabilidad en relación con el coeficiente omega 0,87 en mujeres de y 0,81 en hombres. La validez e interrelación con el STAI obtuvieron unos resultados de 0,376 en mujeres (resultado estadísticamente significativo p > 0,001) y 0,340 en hombres, no alcanzando significación estadística. Finalmente, la validez concurrente obtuvo un resultado de coeficiente de Kaiser-Meyer-Olkin (KMO) de 0,8322 y una prueba de significación de Bartlett $p>0,0001$.

En definitiva, el cuestionario IDDA-EA, por su fiabilidad y validez es adecuado para la detección del estrés relacionado con el estado de ánimo en los pacientes seleccionados en el estudio de investigación.

El cortisol en todos los pacientes incluidos en el estudio se ha medido mediante la extracción de una muestra de sangre que, posteriormente, ha sido procesada con el aparato Unice ${ }^{\circledR}$ Dxl 800 Inmunoassay System, siendo evaluado su rendimiento analítico en adultos con un resultado positivo y adecuado para el cortisol sérico respecto a la veracidad, precisión, límites de detección, linealidad y consistencia (Akbas et al., 2014).

\subsection{Procedimiento de recogida de datos}

Verificados los criterios de selección, se solicitó el consentimiento informado a cada paciente participante en el estudio. La recogida de datos 
se realizó a través del formulario de recogida de datos (Anexo II), tras la aprobación del protocolo del estudio por el Comité de Ética e Investigación del Complejo Hospitalario Universitario Materno Insular de Gran Canaria, y respetando los principios éticos de la declaración de Helsinki, certificado número EIC-CHUIMI-2015/833 (Anexo IV).

En primer lugar, se confirmó el ingreso del paciente para ser intervenido de CENS, a través de la consulta del programa de gestión de historias clínicas electrónicas del complejo Hospitalario denominado DRAGO-AE.

Los pacientes llegaron a admisión central del complejo hospitalario y estos fueron acompañados a su habitación en la unidad de hospitalización correspondiente.

Después de tener el primer contacto con la enfermera responsable de sus cuidados en hospitalización, recibieron la visita del investigador principal. En ese primer contacto se les explicó las características del estudio de investigación, la voluntariedad de su participación, la entrega y correspondiente firma del consentimiento informado para la inclusión en el estudio y la autorización para el trato de los datos de carácter personal (ANEXO III).

Seguidamente, el investigador principal comenzó a exponer cómo deben cumplimentarse los diferentes cuestionarios entregados, explicando cada apartado y resolviendo las dudas en todo momento. Además, se informó al paciente que en esa documentación escrita hay un número de teléfono al que podrá llamar en caso de tener dudas de cara a la cumplimentación de los cuestionarios.

Se le explicó al paciente que habrá cinco cuestionarios que hay que rellenar antes de la intervención, y dos cuestionarios después de la intervención.

Posteriormente, el paciente continuó con su protocolo estándar de actividades de enfermería previas a la intervención quirúrgica, en la que estaba programado actividades realizadas por el personal de hospitalización, como el aseo previo a la intervención quirúrgica, así como el control del ayuno de sólidos y líquidos.

Momentos antes de comenzar la cirugía, el celador trasladó al sujeto desde su habitación hasta quirófano en su propia cama, junto a su fa- 
milia y amigos que pudieron acompañarlo hasta la sala de espera de familiares, en ese momento el paciente entró solo con el celador a la zona contigua al quirófano (antequirófano) para ser recibido por el personal quirúrgico.

La enfermera de anestesia que recibió al paciente, previamente ha asimilado las indicaciones oportunas por parte del investigador principal para la cumplimentación de la hoja de recogida de datos del quirófano (ANEXO II). Dicha enfermera realizó las dos preguntas que aparecen en la hoja y cuantificó en la escala del uno al diez las respuestas del paciente.

Después de la presentación de la enfermera que estuvo a cargo del paciente y la cumplimentación de la hoja de recogida de datos de quirófano (Anexo II), la enfermera procedió a la canalización de una vía venosa periférica necesaria para administrar la anestesia general en la intervención y posibles fármacos necesarios durante el proceso intraoperatorio. Justo en ese momento, y aprovechando la punción venosa, antes de administrar ningún tipo de fármaco o sueroterapia, la enfermera obtuvo una muestra sanguínea del paciente para analizarla y obtener los niveles de cortisol sérico, en la sala contigua al quirófano minutos antes de entrar a la sala de operaciones y ser anestesiado.

A continuación, el paciente fue llevado a la sala de operaciones para comenzar a administrarle los fármacos anestésicos para la anestesia general y empezar la intervención. Así mismo, terminada la intervención, el paciente fue despertado y extubado en el quirófano para posteriormente ser trasladado a la unidad de recuperación postanestésica (URPA).

En la sala de recuperación de anestesia fue atendido a cargo de una enfermera, la cual anotó en la historia electrónica del paciente las incidencias durante su postoperatorio inmediato, como la aparición de posibles complicaciones, uso de analgésicos o nivel de dolor durante su estancia en URPA. Después de recibir el alta en la unidad de URPA por parte del anestesista responsable en ese momento, tras desaparecer los efectos de la medicación anestésica y la presencia de dolor postquirúrgico el paciente fue trasladado a su habitación, donde rellenó los cuestionarios postquirúrgicos que fueron entregados en el ingreso.

Por último, todos los cuestionarios cumplimentados por el paciente fueron introducidos en una funda con su nombre y entregados al perso- 
nal de enfermería de la unidad de hospitalización para ser guardados y recogidos al día siguiente por el investigador principal.

\subsection{Análisis de datos}

El análisis estadístico se realizó con el paquete estadístico IBM ${ }^{\circledR}$ SPSS $^{\circledR}$ Statistics Versión 22.0. Se ha calculado la media, desviación típica y el intervalo de de confianza (IC) de 95\%. Se ha calculado la frecuencia y porcentaje en las variables cualitativas. Se ha utilizado el coeficiente de correlación de Pearson para comprobar la asociación entre las variables cuantitativas.

Todas las pruebas estadísticas fueron bilaterales y se consideraron significativas con un valor $a=0,05$. Un valor de $p<0,05$ se consideró estadísticamente significativo.

\subsection{Consideraciones éticas}

La información a todos los pacientes de los objetivos e implicaciones del estudio se realizará mediante la entrega de una hoja de información y de consentimiento informado. Adicionalmente, se les indicará la confidencialidad de sus datos de acuerdo a la Ley Orgánica 15/99 del 13 de diciembre de Protección de Datos de Carácter Personal (LOPD). Para lo cual, se ha seguido la declaración de Helsinki.

El consentimiento contendrá la información detallada en lenguaje comprensivo de la intervención a realizar, se indicará que no existen consecuencias directas de la intervención enfermera, ni complicaciones derivadas del estudio, y la posibilidad de renunciar en cualquier momento al tratamiento quirúrgico.

Los sujetos fueron identificados y codificados con un número para garantizar el anonimato, datos conocidos unicamente por el investigador principal. Los datos fueron registrados y guardados de forma confidencial no estando accesible dicha información a personas ajenas al estudio. Para lo cual se ha seguido los principios de la declaración de Helsinki, los prin- 
cipios éticos básicos de la investigación clínica, de acuerdo con la Ley 14/2007, de 3 de julio de Investigación Biomédica, la Ley orgánica de Protección de Datos de Carácter Personal 15/1999 de 13 de diciembre y la Ley 41/2002 de 14 de noviembre, básica reguladora de la autonomía del paciente y de derechos y obligaciones en materia de información y documentación clínica.

El protocolo del estudio fue aprobado por el comité de Ética e Investigación del Complejo Hospitalario Universitario Insular de Gran Canaria con fecha de aprobación 14 de enero de 2016, certificado número EICCHUIMI-2015/833.

No existe conflicto de intereses por parte del investigador en la realización de este estudio. 



\section{RESULTADOS}

\subsection{Análisis descriptivo de las variables del estudio}

\subsubsection{Resultados variables sociodemográficas}

El número de personas participantes en la investigación fue de 61 descartándose 5 individuos por no cumplimentar adecuadamente el cuestionario y uno por desistir su participación en el estudio durante el proceso quirúrgico, por lo que finalmente se obtienen un total de 55 personas participantes ( $n=55)$, de los cuales el 52,7\% (29) eran varones y el 47,3\% (26) eran mujeres. La edad mínima es de 20 años y la máxima de 70 (rango 50), siendo la media de 47,73 años (IC 95\%: 44,01-51,44) y la desviación típica 13,75 (ver Figura 10).

Figura 10. Porcentaje de participantes en el estudio por grupos de edad

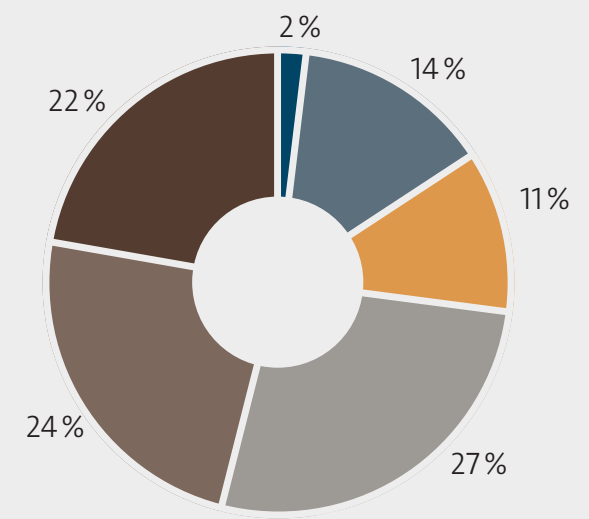

- $18-20$

- 21-30

- $31-40$

- $41-50$

- $51-60$

- $61-70$

Fuente: Elaboración propia 
En relación con el estado civil, el 12,7\% (7) estaban solteros, el 56,4\% (3) estaban casados, el 16,4 (9) tenían una unión estable, el 9,1\% (5) estaban divorciados y el 5,5\% (3) eran viudos.

Con respecto al nivel máximo de estudios alcanzados, el 3,6\% (2) no tenían estudios, el 25,5\% (14) poseían estudios primarios, el 9,1\% (5) tenían educación secundaria, el 27,3\% (15) tenían formación profesional de grado medio, el 9,1\% (5) poseían formación profesional de grado superior y, por último, el 25,5\% (14) habían realizado estudios universitarios.

En relación con la ocupación actual, el 21,8\% (12) estaban desempleados, el 58,2\% (32) estaban empleados y el $20 \%$ (11) eran jubilados.

Con respecto al consumo de tabaco, el 78,2\% (43) eran no fumadores, el $12,7 \%$ (7) eran fumadores que presentaban un consumo mínimo de cigarrillos diario de 2 y máximo de 20 (rango 18), siendo la media de 14,57 cigarrillos consumidos al día (IC 95\%: 8,39-20.75) y la desviación típica 6,68. Los cuartiles tomaron los valores: 10, 15 y 20.

\subsubsection{Resultados de las variables relacionadas con el proceso quirúrgico}

En relación con el proceso quirúrgico, el 38,1\% (21) de los pacientes fueron intervenidos con un diagnóstico previo de pólipos nasales, el 9,1\% (5) presentaban un diagnóstico previo de hipertrofia de cornetes, el 18,2\% (10) presentaron un diagnóstico de sinusitis crónica y el 34,5\% (19) presentaron tabique nasal desviado con pólipos nasales.

Con respecto a la presencia de intervenciones previas que precisaron de anestesia general en los pacientes incluidos en el estudio, el 32,7\% (18) no presentaban intervenciones previas respecto al 67,3\% (37) que sí habían recibido anestesia general en alguna intervención previa.

Por lo que se refiere a la clasificación del riesgo anestésico de los pacientes según la American Society of Anaesthesiologists (ASA), el 60\% (33) presentaban un ASA I y el $40 \%$ (22) presentaban un ASA II.

En cuanto a la duración de la cirugía en minutos, el proceso quirúrgico duró un mínimo de 60 minutos y un máximo de 120 minutos (rango 60), siendo la media de 75,73 minutos (IC 95\%: 72.88-78.57) y la desviación típica 10,515 (ver Figura 11). Se debe destacar que no se presentaron com- 
plicaciones durante el acto quirúrgico en los pacientes seleccionados para el estudio.

Figura 11. Duración de la cirugía en minutos

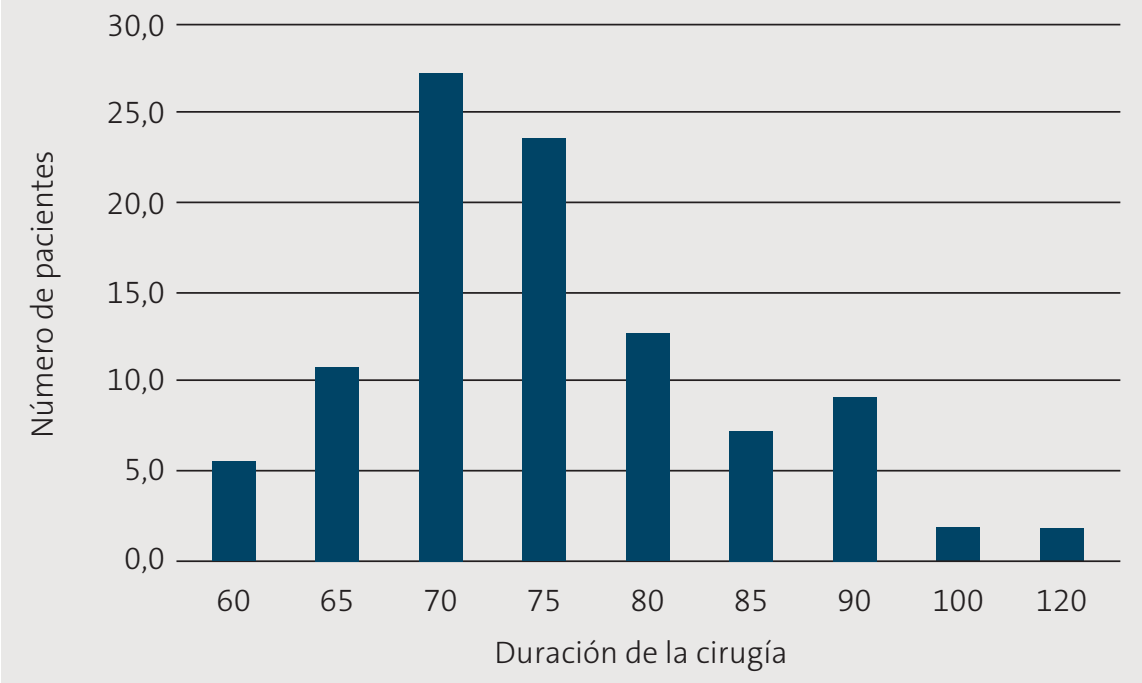

Con respecto al tiempo de ingreso en la Unidad URPA, los pacientes estuvieron un mínimo de 40 minutos ingresados en la URPA y un máximo de 130 minutos (rango 90), siendo la media de 63.47 minutos (IC 95\%: $58,89-68,05)$ y la desviación típica 16,95. El 80\% (44) de los pacientes no presentaron complicaciones en URPA, el 16,4\% (9) presentaron sangrados que se resolvieron en la misma unidad con cambio de apósito, el 1.,8\% (1) presentó globo vesical como complicación que se resolvió con un sondaje vesical y el 1,8 \% (1) manifestó desorientación durante su ingreso en URPA, que se resolvió espontáneamente antes del alta en la unidad.

En relación con el ingreso del paciente en hospitalización los pacientes estuvieron un mínimo de 12 horas ingresados en hospitalización y un máximo de 72 horas (rango 60), siendo la media de 29,24 horas (IC 95\%: 25,50 - 32.97) y la desviación típica 13,81. El 74,5\% (41) de los pacientes no presentaron complicaciones durante su estancia en hospitalización, el 23,6 \% (13) presentaron sangrados que se resolvieron en la misma unidad 
con cambio de apósito, el 1,8 \% (1) presentó una parada cardiorrespiratoria como complicación que se resolvió favorablemente con reanimación cardiopulmonar instrumentalizada sin secuelas posteriores. Se debe destacar que de los pacientes incluidos en el estudio $(n=55)$, solamente un paciente $(1,8 \%)$ presentó complicación postoperatoria durante la primera semana después del alta del hospital, presentando sangrado que precisó el ingreso en urgencias para su valoración, siendo resuelto en el mismo momento del ingreso.

10.1.3. Resultados de las variables relacionadas con el apoyo social percibido

En la Tabla 27 se muestran los estadísticos descriptivos del apoyo social percibido.

\begin{tabular}{lrrrrrr}
\hline \multicolumn{7}{l}{ Tabla 27. Análisis descriptivo variables apoyo social percibido } \\
\hline Estadísticos & Media & \multicolumn{2}{l}{ IC 95\% para la media } & DE & Mínimo & Máximo \\
& \multicolumn{2}{c}{ Inferior } & Superior & & & \\
\hline Familia & 24,4 & 23,34 & 25,46 & 3,937 & 12 & 28 \\
\hline Amigos & 47,35 & 44,96 & 49,73 & 8,815 & 21 & 60 \\
\hline Personas relevantes & 36,42 & 34,9 & 37,93 & 5,603 & 16 & 40 \\
\hline
\end{tabular}

\subsubsection{Resultados de las variables relacionadas con la ansiedad}

En la Tabla 28 se exponen el análisis descriptivo de la ansiedad, datos obtenidos del Cuestionario STAI para la AE (sumatorio, centiles y decatipo). Posteriormente, se tomó otra medida de la AE (sumatorio, centiles y decatipo) a su regreso a hospitalización después de ser intervenido y dado de alta en URPA.

\subsubsection{Resultados de las variables relacionadas con el estrés}

En la Tabla 30 se muestran los estadísticos descriptivos de la variable estrés, relacionada con el estado de ánimo medido durante el ingreso del mismo en la unidad de hospitalización y después de su regreso tras la intervención quirúrgica. 


\begin{tabular}{lrrrrrr}
\hline \multicolumn{6}{l}{ Tabla 28. Análisis descriptivo variables relacionadas con la ansiedad } \\
\hline Estadísticos & Media & \multicolumn{2}{l}{ IC 95\% para la media } & DE & Mínimo & Máximo \\
& & Inferior & Superior & & & \\
\hline AR & 24,56 & 23,51 & 25,62 & 3,891 & 6 & 33 \\
\hline Decatipo AR & 6,34 & 6,19 & 6,48 & 0,528 & 5 & 7 \\
\hline Centil AR & 64,96 & 62,6 & 67,32 & 8,735 & 43 & 79 \\
\hline AE ingreso & 16,62 & 14,33 & 18,91 & 8,48 & 0 & 47 \\
\hline Decatipo AE al ingreso & 4,56 & 4,1 & 5,02 & 1,703 & 1 & 9 \\
\hline Centil AE al ingreso & 34,2 & 27,29 & 41,11 & 25,563 & 0 & 95 \\
\hline AE postquirúrgico & 16,82 & 14,64 & 19 & 8,056 & 0 & 48 \\
\hline Decatipo AE postquirúrgico & 4,72 & 4,26 & 5,18 & 1,71 & 1 & 9 \\
\hline Centil AE postquirúrgico & 37,45 & 31,05 & 43,86 & 23,692 & 1 & 96 \\
\hline
\end{tabular}

Nota: $\mathrm{AE}=$ Ansiedad Estado; $\mathrm{AR}=$ Ansiedad Rasgo

Tabla 29. Análisis descriptivo variables relacionadas con la ansiedad por sexo y nivel de estudios

\begin{tabular}{|c|c|c|c|c|c|c|c|}
\hline \multirow[t]{2}{*}{ Estadísticos } & & \multicolumn{2}{|c|}{ AE ingreso } & \multicolumn{2}{|c|}{ AE post } & \multirow{2}{*}{\multicolumn{2}{|c|}{$\frac{\overline{A R}}{\mathrm{DE}}$}} \\
\hline & & Media & $\overline{\mathrm{DE}}$ & Media & $\overline{\mathrm{DE}}$ & & \\
\hline \multirow[t]{2}{*}{ Universitarios } & Hombres & 10,75 & 6,84 & 12,38 & 8,017 & 26,38 & 1,847 \\
\hline & Mujeres & 18,5 & 8,385 & 17,17 & 8,183 & 24 & 2,828 \\
\hline \multirow[t]{2}{*}{ No universitarios } & Hombres & 17 & 7,389 & 15,48 & 6,585 & 23,76 & 5,039 \\
\hline & Mujeres & 18 & 9,663 & 19,9 & 8,783 & 24,85 & 3,265 \\
\hline
\end{tabular}

Nota: $\mathrm{AE}=$ Ansiedad Estado; $\mathrm{AE}$ post = Ansiedad Estado postquirúrgica; $\mathrm{AR}=$ Ansiedad Rasgo

\begin{tabular}{lrrrrrrr}
\hline Tabla 30. Análisis descriptivo variables relacionadas con el estrés \\
\hline Estadísticos & Media & \multicolumn{2}{l}{$\begin{array}{l}\text { IC 95\% para la media } \\
\text { Inferior }\end{array}$} & Superior & DE & Mínimo & Máximo \\
& & 853,77 & 917,98 & 118,768 & 684 & 1078 \\
\hline $\begin{array}{l}\text { IDDA-EA estrés ingreso } \\
885,87\end{array}$ & 3,69 & 3,27 & 4,11 & 1,562 & 1 & 8 \\
\hline $\begin{array}{l}\text { Eneatipo IDDA-EA } \\
\text { ingreso }\end{array}$ & 858,11 & 816,72 & 899,5 & 153,101 & 644 & 1560 \\
\hline $\begin{array}{l}\text { IDDA-EA estrés } \\
\text { postquirúrgico }\end{array}$ & 3,09 & 2,71 & 3,47 & 1,418 & 1 & 7 \\
\hline $\begin{array}{l}\text { Eneatipo IDDA-EA } \\
\text { postquirúrgico }\end{array}$ & 11,4473 & 7,3361 & 15,5585 & 15,2076 & 1,4 & 118,02 \\
\hline $\begin{array}{l}\text { Córtisol sérico } \\
\text { prequirúrgico }\end{array}$ & & & & & & \\
\hline
\end{tabular}


A los resultados de este cuestionario se le añadió la realización de un análisis sérico de cortisol justo antes de la cirugía (ver Tabla 30).

10.1.6. Resultados de las variables relacionadas con el estrés y la ansiedad previo a la intervención

A continuación, se exponen los resultados de las variables ansiedad y estrés medidas justo antes de ser intervenido el paciente (ver Tabla 31).

\begin{tabular}{lrrrrrr}
\hline \multicolumn{6}{l}{ Tabla 31. Análisis descriptivo variables relacionadas con el estrés } \\
\hline Estadísticos & Media & \multicolumn{2}{l}{ IC 95\% para la media } & DE & Mínimo & Máximo \\
& & Inferior & Superior & & & \\
\hline Escala numerada estrés & 4,44 & 3,72 & 5,16 & 2,665 & 0 & 10 \\
\hline Escala numerada ansiedad & 4,29 & 3,6 & 4,98 & 2,565 & 0 & 10 \\
\hline
\end{tabular}

\subsection{Análisis de correlación de las variables del estudio}

A partir de los objetivos planificados en este estudio, se realizó un análisis de correlaciones para comprobar la asociación lineal entre las variables seleccionadas. Se calculó el coeficiente de correlación lineal de Pearson, para comprobar la asociación entre las variables cuantitativas y se consideró como significativas las pruebas estadísticas con un valor $p<0,05$.

10.2.1. Variable apoyo social percibido sobre variables relacionadas con la ansiedad durante el proceso quirúrgico

Se obtuvieron las correlaciones entre el AS con la AE (sumatorio y centil) en el momento del ingreso en hospitalización y después de la intervención quirúrgica a su regreso a la unidad de hospitalización, y con la AR (sumatorio y centil), en el momento del ingreso en hospitalización, con los siguientes resultados.

Con respecto al AS percibido de familiares y la $A E$ (sumatorio) al ingreso, se obtuvo una correlación significativa e inversa $(p<0,05)$, por consiguiente, valores elevados de AS percibido de familiares se correlacionan 
con una menor $\mathrm{AE}$ al ingreso con una fuerza de relación moderada en los pacientes seleccionados en el estudio. En relación con el AS percibido de familiares y AE (centil) al ingreso, se obtuvo una correlación significativa e inversa, por lo que en los datos obtenidos en la muestra seleccionada, el aumento del AS percibido de familiares se correlaciona con una disminución del centil de la AE $(p<0,05)$ (ver Tabla 32) .

En relación con el AS percibido de amigos y AE (sumatorio) al ingreso, se obtuvo una correlación significativa e inversa $(p<0,05)$, es decir, un mayor valor en la variable AS percibido de amigos se correlaciona con un menor valor en la $\mathrm{AE}$ al ingreso en la muestra selecciona en el estudio (ver Tabla 32).

Con respecto al AS percibido de personas relevantes y el sumatorio de la AE al ingreso, se obtuvo una correlación significativa e inversa $(p<0,05)$, es decir, los pacientes del estudio que presentaron valores elevados en el AS percibido de personas relevantes se correlacionan significativamente con un menor valor en la AE al ingreso, con una fuerza de relación moderada entre las variables.

En relación con el AS percibido de personas relevantes y el centil de la $A E$ al ingreso, se obtuvo una correlación significativa e inversa $(p<0,05)$. En consonancia con los resultados anteriormente expuestos, el aumento del AS percibido de personas relevantes en los sujetos seleccionados en el estudio se correlaciona con una disminución del centil de la $A E$ al ingreso, con una fuerza de relación moderada.

En relación con el AS percibido de personas relevantes y el sumatorio de la AE después de la cirugía a su regreso a la unidad de hospitalización, se alcanzó una correlación significativa e inversa $(p<0,05)$, por consiguiente, valores altos de AS percibido en personas relevantes se correlacionan con valores bajos de AE después de la cirugía en la muestra seleccionada (ver Tabla 32).

10.2.2. Variable apoyo social percibido sobre las variables relacionadas con el estrés durante el proceso quirúrgico

A continuación, se exponen las correlaciones entre el AS percibido con el factor estrés medido mediante el cuestionario IDDA-EA en el momento 


\begin{tabular}{|c|c|c|c|c|}
\hline & & Familia & Amigos & PR \\
\hline \multirow{2}{*}{$\begin{array}{l}\text { Ansiedad estado } \\
\text { al ingreso }\end{array}$} & Correlación de Pearson &,$- 331^{*}$ &,$- 285^{*}$ &,$- 300^{*}$ \\
\hline & Sig. (bilateral) & ,014 & ,035 & ,026 \\
\hline \multirow{2}{*}{$\begin{array}{l}\text { Centil ansiedad estado } \\
\text { al Ingreso }\end{array}$} & Correlación de Pearson &,$- 325^{*}$ &,- 227 &,$- 311^{*}$ \\
\hline & Sig. (bilateral) & 015 & ,096 & 021 \\
\hline \multirow{2}{*}{$\begin{array}{l}\text { Ansiedad estado } \\
\text { postquirúrgica }\end{array}$} & Correlación de Pearson &,- 157 &,- 209 &,$- 288^{*}$ \\
\hline & Sig. (bilateral) & 252 & 125 & ,033 \\
\hline \multirow{2}{*}{$\begin{array}{l}\text { Centil ansiedad estado } \\
\text { postquirúrgica }\end{array}$} & Correlación de Pearson &,- 070 &,- 112 &,- 251 \\
\hline & Sig. (bilateral) & ,613 & ,415 & ,065 \\
\hline \multirow[t]{2}{*}{ Ansiedad rasgo } & Correlación de Pearson &,- 252 &,- 030 &,- 173 \\
\hline & Sig. (bilateral) & ,064 & 827 & ,206 \\
\hline \multirow[t]{2}{*}{ Centil ansiedad rasgo } & Correlación de Pearson &,- 242 &,- 006 &,- 185 \\
\hline & Sig. (bilateral) & ,075 & 968 & , 175 \\
\hline
\end{tabular}

Nota: $P R=$ Personas Relevantes

*. La correlación es significativa en el nivel 0,05 (2 colas).

del ingreso en hospitalización y después de la intervención quirúrgica a su regreso a la unidad de hospitalización, y con los niveles de cortisol sérico justo antes de ser intervenido quirúrgicamente.

En relación con el AS percibido de familiares y el nivel de cortisol sérico minutos antes de ser intervenido quirúrgicamente, se obtuvo una correlación significativa e inversa ( $p<0,05)$, por lo tanto, valores elevados de AS percibido de familiares se correlacionan con menores niveles de cortisol sérico en los sujetos seleccionados en el estudio (ver Tabla 33).

Con respecto al AS percibido de amigos y el nivel de cortisol sérico minutos antes de ser intervenido quirúrgicamente, se obtuvo una correlación significativa e inversa $(p<0,05)$, por consiguiente, un mayor valor en la variable AS percibido de amigos se correlaciona con menor nivel de cortisol sérico en los sujetos seleccionados en el estudio (ver Tabla 33).

En cambio, la correlación entre el AS percibido de familiares, amigos y personas relevantes y los valores del factor estrés antes y después de la intervención quirúrgica de los pacientes seleccionados en el estudio no presentaron correlación significativa. 
Tabla 33. Coeficiente de correlación de Pearson de las variables estrés y apoyo social percibido

\begin{tabular}{llrrr}
\hline & & Familia & Amigos & PR \\
\hline $\begin{array}{llrr}\text { Estrés sumatorio IDDA-EA } \\
\text { en el ingreso }\end{array}$ & Correlación de Pearson & 0,059 & $-0,002$ & $-0,059$ \\
\cline { 2 - 5 } & Sig. (bilateral) & 0,669 & 0,991 & 0,668 \\
\hline $\begin{array}{l}\text { Estrés sumatorio IDDA-EA } \\
\text { postquirúrgico }\end{array}$ & Correlación de Pearson & $-0,006$ & $-0,102$ & $-0,149$ \\
\cline { 2 - 5 } & Sig. (bilateral) & 0,966 & 0,457 & 0,279 \\
\hline Cortisol sérico & Correlación de Pearson &,$- 293^{*}$ &,$- 278^{*}$ & $-0,115$ \\
\cline { 2 - 5 } & Sig. (bilateral) & 0,030 & 0,040 & 0,403 \\
\hline
\end{tabular}

*. La correlación es significativa en el nivel 0,05 (2 colas).

10.2.3. Variables nivel de ansiedad y estrés escala numerada, apoyo social percibido y estrés

A continuación, se exponen los resultados de las correlaciones entre las escalas numeradas del 0-10 que cuantifican la percepción del nivel de estrés y ansiedad de los pacientes minutos antes de la intervención quirúrgica, las variables AS percibido, el estrés relacionado con el estado de ánimo en el ingreso y posquirúrgico, el cortisol sérico medido minutos antes del inicio de la intervención quirúrgica, la AE (sumatorio y centil) antes y después de la intervención quirúrgica y, por último, la AR.

Respecto al valor de la escala numerada del estrés y su correlación con el resto de variables mencionadas con anterioridad, se ha obtenido una correlación significativa y positiva entre el valor de la escala numerada del estrés y la AE al ingreso ( $p<0,01)$, al igual que ocurre con la correlación entre el centil de la AE al ingreso y la escala numerada del estrés $(p<0,01)$ (ver Tabla 34). Por lo tanto, un mayor valor en la escala numerada del estrés se corresponde con una mayor AE y un aumento del centil de la AE al ingreso en los pacientes seleccionados en el estudio.

Algo semejante ocurre con la escala numerada de la ansiedad y su correlación con las variables $A E$ al ingreso y el centil de la AE al ingreso, las cuales presentan una correlación significativa y positiva $(p<0,01)$. Por consiguiente, en los pacientes analizados, un aumento de los valores en la escala numerada de la ansiedad se correlacionada con una mayor $\mathrm{AE}$ y un mayor centil de la AE al ingreso. 
Se debe mencionar además, la correlación significativa y positiva entre la escala numerada de la ansiedad y la AE postquirúrgica $(p<0,05)$, que muestra que un mayor nivel de ansiedad expresado en la escala numerada cumplimentada en el antequirófano se correlaciona significativamente con un mayor valor de la AE postquirúrgica en los sujetos participantes en el estudio (ver Tabla 34).

Tabla 34. Coeficiente de correlación de Pearson de las variables estrés, ansiedad (escala numerada) y apoyo social percibido

\begin{tabular}{|c|c|c|c|}
\hline & & Escala estrés & Escala ansiedad \\
\hline \multirow[t]{2}{*}{ Familia } & Correlación de Pearson &,- 248 &,- 235 \\
\hline & Sig. (bilateral) & ,068 & ,084 \\
\hline \multirow[t]{2}{*}{ Amigos } & Correlación de Pearson & ,007 & ,021 \\
\hline & Sig. (bilateral) & 960 &, 880 \\
\hline \multirow[t]{2}{*}{ Personas Relevantes } & Correlación de Pearson &,- 130 &,- 123 \\
\hline & Sig. (bilateral) & ,343 & 370 \\
\hline \multirow{2}{*}{$\begin{array}{l}\text { Ansiedad estado } \\
\text { al ingreso }\end{array}$} & Correlación de Pearson & ,419** &, $454^{* *}$ \\
\hline & Sig. (bilateral) & ,001 &, 001 \\
\hline \multirow{2}{*}{$\begin{array}{l}\text { Centil ansiedad } \\
\text { estado al ingreso }\end{array}$} & Correlación de Pearson & ,414** &, $444^{* *}$ \\
\hline & Sig. (bilateral) & ,002 & ,001 \\
\hline \multirow{2}{*}{$\begin{array}{l}\text { Ansiedad estado } \\
\text { postquirúrgica }\end{array}$} & Correlación de Pearson & 179 & ,291* \\
\hline & Sig. (bilateral) & ,191 &, 031 \\
\hline \multirow{2}{*}{$\begin{array}{l}\text { Centil ansiedad } \\
\text { estado postquirúrgica }\end{array}$} & Correlación de Pearson & , 104 & 207 \\
\hline & Sig. (bilateral) & ,448 & 129 \\
\hline \multirow[t]{2}{*}{ Ansiedad rasgo } & Correlación de Pearson & 151 & ,132 \\
\hline & Sig. (bilateral) & ,272 &, 338 \\
\hline \multirow{2}{*}{$\begin{array}{l}\text { Centil ansiedad } \\
\text { rasgo }\end{array}$} & Correlación de Pearson & ,118 &, 000 \\
\hline & Sig. (bilateral) & ,389 & 997 \\
\hline \multirow{2}{*}{$\begin{array}{l}\text { Estrés sumatorio } \\
\text { IDDA-EA en el ingreso }\end{array}$} & Correlación de Pearson & ,079 &,- 062 \\
\hline & Sig. (bilateral) & ,565 &, 653 \\
\hline \multirow{2}{*}{$\begin{array}{l}\text { Estrés sumatorio } \\
\text { IDDA-EA postquirúrgico }\end{array}$} & Correlación de Pearson &,- 033 &,- 009 \\
\hline & Sig. (bilateral) & ,809 & 950 \\
\hline \multirow[t]{3}{*}{ Cortisol sérico } & Correlación de Pearson & , 127 &, 005 \\
\hline & Sig. (bilateral) & ,357 & 970 \\
\hline & Sig. (bilateral) & ,366 & ,203 \\
\hline
\end{tabular}

*. La correlación es significativa en el nivel 0,05 (2 colas).

**. La correlación es significativa en el nivel 0,01 (2 colas). 
10.2.4. Variables analgesia extra administrada durante el ingreso, duración de la estancia hospitalaria, presencia de complicaciones durante el ingreso, el apoyo social percibido, ansiedad y estrés

Por lo que se refiere a las correlaciones que se obtuvieron entre la variables relacionadas con la evolución quirúrgica, como fueron analgesia extra administrada durante el ingreso, duración de la estancia hospitalaria, presencia de complicaciones durante el ingreso en relación con el apoyo social percibido (AS), la AE (sumatorio y centil) en el momento del ingreso en hospitalización, la AR (sumatorio y centil) en el ingreso en hospitalización, la AE (sumatorio y centil) después de la intervención quirúrgica, el estrés como estado de ánimo en el ingreso y posquirúrgico y, finalmente, el cortisol sérico minutos antes del inicio de la intervención quirúrgica, presentaron los siguientes resultados:

En el caso de la duración del ingreso en la unidad de hospitalización calculado en horas y el centil de la AE postquirúrgica, existe una correlación significativa y positiva $(p<0,05)$, por lo tanto, valores elevados de AE postquirúrgica se correlacionan con mayor tiempo de ingreso en hospitalización en la muestra seleccionada (ver Tabla 35).

Se debe destacar la correlación significativa e inversa $(p<0,05)$ existente entre el AS percibido en personas relevantes y el tiempo de ingreso en la unidad de hospitalización, es decir, que los participantes en el estudio que tuvieron un mayor AS percibido de personas relevantes tuvieron un menor tiempo de ingreso en la unidad de hospitalización.

En relación con la analgesia extra administrada a demanda en la URPA y el AS percibido de personas relevantes, se obtuvo una correlación significativa y positiva, por lo que en los datos obtenidos en el estudio, un AS percibido de personas relevantes elevado se correlaciona con aumento en la demanda de analgesia extra en la URPA con una fuerza de relación moderada $(p<0,05)$ (ver Tabla 35).

Con respecto a la aparición de complicaciones quirúrgicas durante la estancia en hospitalización, se observó una correlación significativa y positiva ( $p<005)$ en relación con el centil de la AE postquirúrgico, por consiguiente, los pacientes que tuvieron una mayor AE postquirúrgica presentaron mayores complicaciones durante su estancia hospitalaria. 
Tabla 35. Coeficiente de correlación de Pearson de las variables estrés, ansiedad (escala numerada) y apoyo social percibido

\begin{tabular}{|c|c|c|c|c|c|}
\hline & & $\begin{array}{r}\text { Tiempo } \\
\text { HOSP }\end{array}$ & $\begin{array}{r}\text { Analgesia } \\
\text { URPA }\end{array}$ & $\begin{array}{r}\text { Complica- } \\
\text { ciones } \\
\text { HOSP }\end{array}$ & $\begin{array}{r}\text { Complica- } \\
\text { ciones al } \\
\text { ALTA }\end{array}$ \\
\hline \multirow{2}{*}{$\begin{array}{l}\text { Centil ansiedad } \\
\text { estado postqui- } \\
\text { rúrgico }\end{array}$} & Correlación de Pearson & ,289* & ,065 & ,289* & 032 \\
\hline & Sig. (bilateral) & ,033 & ,639 & ,032 & ,816 \\
\hline \multirow{2}{*}{$\begin{array}{l}\text { Centil ansiedad } \\
\text { rasgo }\end{array}$} & Correlación de Pearson & ,160 & ,115 & ,097 &,$- 345^{* *}$ \\
\hline & Sig. (bilateral) & ,243 & ,403 & ,482 & 010 \\
\hline \multirow{2}{*}{$\begin{array}{l}\text { Apoyo social perci- } \\
\text { bido de persona } \\
\text { relevantes }\end{array}$} & Correlación de Pearson &,$- 284^{*}$ & $322^{*}$ & ,013 &,- 037 \\
\hline & Sig. (bilateral) & ,035 & ,016 & ,924 & ,791 \\
\hline
\end{tabular}

Nota: Tiempo HOSP: Tiempo de ingreso en hospitalización, Analgesia URPA: analgesia administrada en URPA a demanda, Complicaciones HOSP: Complicaciones durante la estancia en hospitalización, Complicaciones al ALTA: Complicaciones al alta del paciente de la unidad de hospitalización

*. La correlación es significativa en el nivel 0,05 (2 colas).

**. La correlación es significativa en el nivel 0,01 (2 colas).

Por último, la correlación existente entre la aparición de complicaciones en el domicilio después de recibir el alta de los pacientes de la unidad de hospitalización, se correlacionó de manera significativa y negativa $(p<0,01)$ con una fuerza de relación moderada con el centil de la AR, así pues, una mayor AR dio lugar en los pacientes seleccionados a una menor frecuencia de complicaciones al alta en hospitalización (ver Tabla 35).

\subsubsection{Análisis estadistico mediante la prueba T de Student para muestras independientes}

Tras realizar el análisis estadístico mediante la prueba T de Student para muestras independientes de las variables presencia de complicaciones en URPA, analgesia extra administrada a demanda en hospitalización, aparición de complicaciones en hospitalización, analgesia extra a demanda administrada en URPA e intervenciones previas bajo anestesia general, se obtuvieron los siguientes resultados: 
La comparación entre las medias de la AE después de la intervención quirúrgica en los pacientes que presentaron complicaciones durante su estancia en hospitalización $(\bar{x}=48,53)$ y las medias de la AE después de la intervención en los individuos que no presentaron complicaciones durante su estancia en hospitalización $(\bar{x}=33,30)$, obtuvo como resultado $(t(53)=-2,198, p=0,032)$. Es decir, que los pacientes que presentaron complicaciones durante la hospitalización tuvieron significativamente mayor AE después de ser intervenidos que los pacientes que no sufrieron complicaciones durante la hospitalización.

La comparación entre las medias del factor estrés después de la intervención quirúrgica en los pacientes que presentaron complicaciones durante su estancia en hospitalización $(\bar{x}=3,73)$ y las medias del factor estrés después de la intervención en los individuos que no presentaron complicaciones durante su estancia en hospitalización $(\bar{x}=2,85)$, obtuvo como resultado $(t(53)=-2,124, p=0,038)$. Por lo tanto, los pacientes que presentaron complicaciones durante la hospitalización tuvieron significativamente mayor estrés después de ser intervenido que los pacientes que no presentaron complicaciones durante la hospitalización.

La comparación entre las medias del AS percibido de amigos de las personas que precisaron analgesia extra a demanda durante su estancia en URPA $(\bar{x}=46,27)$ y las medias del AS percibido de amigos de las personas que no precisaron analgesia extra a demanda durante su estancia en URPA $(\bar{x}=54,71)$, obtuvo como resultado $(t(53)=-2,477, p=0,16)$. Por lo tanto, los pacientes que precisaron analgesia extra a demanda durante su estancia en URPA tuvieron significativamente mayor AS percibido de amigos que los pacientes que no precisaron analgesia extra.

Se debe destacar que la comparación entre las medias del AS percibido de personas relevantes de los pacientes que precisaron analgesia extra a demanda durante su estancia en URPA $(\bar{x}=39,25)$ y las medias del AS percibido de personas relevantes de los pacientes que no precisaron analgesia extra a demanda durante su estancia en URPA ( $\bar{x}=36)$, obtuvo como resultado $(t(38,39)=-3,228, p=0,003)$. Es decir, que los pacientes que precisaron analgesia extra a demanda durante su estancia en URPA tuvieron significativamente mayor AS percibido de personas relevantes que los pacientes que no precisaron analgesia extra. 
Por último, la comparación entre las medias del tiempo de estancia hospitalaria de los participantes en el estudio que habían experimentado intervenciones previas bajo anestesia general $(\bar{x}=31,78)$ y las medias del tiempo de estancia hospitalaria de los participantes en el estudio que no habían experimentado intervenciones previas bajo anestesia general $(\bar{x}=24)$ se obtuvo como resultado $(t(53)=-2,54, p=0,014)$. Es decir, que los pacientes que no habían sido intervenidos nunca bajo anestesia general permanecieron significativamente menos tiempo ingresados en el hospital que los pacientes que sí habían recibido anteriormente anestesia general.

El resto de comparaciones de medias mencionadas al inicio del capítulo no presentaron resultados estadísticamente significativos.

\subsection{Análisis de regresión de las variables del estudio}

Se realizaron diversos análisis de regresión con las variables criterio objeto de estudio, se exponen a continuación aquel análisis que resultó significativamente estadísticos.

10.3.1. Análisis de regresión del tiempo de ingreso en la unidad de hospitalización como criterio

Destacó como variable predictora con efecto directo el AS percibido de personas relevantes (Beta $=-0,530)$ (ver Tabla 36). Este resultado podría indicar que un aumento en el AS percibido de personas relevantes provocaría una disminución del tiempo de ingreso en la unidad de hospitalización de los pacientes objeto de estudio. El modelo explicó el 15,7\% $\left(R^{2}\right.$ ajustado $\left.=0,107\right)$ de la variabilidad o varianza del tiempo de ingreso en la unidad de hospitalización. 
Tabla 36. Regresión Lineal múltiple con la variable tiempo de ingreso en la unidad de hospitalización como criterio y como variable predictora el apoyo social percibido

\begin{tabular}{|c|c|c|c|c|c|c|c|c|c|}
\hline \multirow[t]{2}{*}{$\begin{array}{l}\text { Variables } \\
\text { independientes }\end{array}$} & \multicolumn{3}{|c|}{$\begin{array}{l}\text { Coeficientes de } \\
\text { regresión }\end{array}$} & \multirow[b]{2}{*}{$\mathrm{t}$} & \multicolumn{3}{|c|}{$\begin{array}{l}95,0 \% \text { IC para } \\
\text { la media }\end{array}$} & \multicolumn{2}{|l|}{ Correlaciones } \\
\hline & $B$ & $\begin{array}{r}\text { Error } \\
\text { estándar }\end{array}$ & Beta & & Sig. & $\begin{array}{l}\text { Límite } \\
\text { inferior }\end{array}$ & $\begin{array}{r}\text { Límite } \\
\text { superior }\end{array}$ & $\begin{array}{l}\text { Orden Parcial } \\
\text { cero }\end{array}$ & Parte \\
\hline Familiares & 0,222 & 0,58169 & 0,063 & 0,381 & 0,7 & $-0,946$ & 1,38938 & $-0,05 \quad 0,0533$ & 0,05 \\
\hline Amigos & 0,517 & 0,27626 & 0,33 & 1,87 & 0,1 & $-0,038$ & 1,07113 & $0,0290,2533$ & $\overline{0,24}$ \\
\hline PR & $-1,31$ & 0,43477 & $-0,53$ & $-3,01$ & 0,04 & $-2,18$ & $-0,4339$ & $-0,28 \quad-0,388$ & $-0,39$ \\
\hline
\end{tabular}

Nota: Familiares: Apoyo Social percibido de Familiares, Amigos: Apoyo Social percibido de Amigos, PR: Apoyo Social percibido de Personas Relevantes, B: Coeficiente de regresión parcial no estandarizado, t: estadístico de contraste, Sig: significación 



\section{DISCUSIÓN}

El presente trabajo de investigación se ha centrado en describir la posible relación del apoyo social (AS) percibido sobre el estrés (E) y la ansiedad (A) en los pacientes intervenidos de cirugía endoscópica nasosinusal (CENS).

Desde una perspectiva enfermera, como se explica en el marco teórico de esta tesis doctoral y haciendo uso del proceso de atención de enfermería, el AS, en concreto la intervención "aumentar los sistemas de apoyo", perteneciente a la Clasificación de Intervenciones de Enfermería recogida en la Taxonomía II según la NANDA-I (NANDA Internacional, 2015; Merino, 2013), resulta fundamental para abordar, tratar y solucionar diferentes problemas en el ámbito psicoemocional y social que se les plantean a estos pacientes a la hora de ser intervenidos, y que podría ser extensivo a otros pacientes quirúrgicos. Es por ello que en los resultados de este estudio, y después de confirmar la falta de evidencia científica relacionada con la disciplina enfermera, sobre este concepto en la bibliografía consultada (Lisa F Berkman, 1985; Borrón López de Roda \& Sánchez Moreno, 2001; S Cohen \& Wills, 1985; Hernández-Rodríguez et al., 1996; Kaplan et al., 1977; Thoits, 1982), se corrobora la necesidad se sentar una base teórica y metodológica para el análisis del constructo AS por parte de la enfermera, que es responsable, en este caso, del paciente quirúrgico, variable que sí ha sido investigada principalmente en pacientes con enfermedades crónicas o en la edad infantil (de Araujo et al., 1973; Lin et al., 1999; Martínez \& Ochoa Güerre, 2000; Menéndez Villalva et al., 2003; Moskovitz \& Maunder, 2000; Murphy \& Moriarty, 1976; Schoenbach et al., 1986; Visintainer \& Wolfer, 1975). 
Por lo tanto, los resultados encontrados que se discuten a continuación y el perfil del paciente seleccionado han permitido describir una posible influencia entre las variables objeto de estudio y, por consiguiente, justificar para futuras investigaciones, el uso de metodología de carácter experimental que tenga como objetivo valorar posibles intervenciones o validar herramientas para conseguir ahondar sobre un constructo tan importante desde el punto de vista teórico para la disciplina enfermera como es el AS (J. Norbeck, 1981; J S Norbeck et al., 1988; Jane S Norbeck et al., 1996), permitiendo, de esa manera, el crecimiento en la ejecución y publicación de trabajos de investigación que intenten demostrar la relación que puede tener el AS con otros factores o variables en el paciente quirúrgico.

El paciente programado para ser intervenido quirúrgicamente se enfrenta, desde que espera para ser ingresado en la unidad de hospitalización hasta que es intervenido y dado de alta, a diferentes procedimientos y etapas que pueden variar en función de la patología a tratar, la comorbilidad asociada o la aparición de complicaciones (Colomer Mascaró et al., 2009; Martín Abreu \& Pérez Vela, 2004); esta experiencia vivida por la persona, unida al cambio en su entorno habitual puede generar estrés y ansiedad que, a su vez, puede afectar a la evolución quirúrgica, además de poder estar modulada por el entorno social de cada individuo (Barrera Ortiz et al., 2006; Cho \& Hong, 2001; Cobb, 1976; Díez-álvarez et al., 2012a; Esteghamat et al., 2013; Glasper \& DeVries, 2005; Grieve \& R.J., 2002; Heluy de Castro et al., 2004; NANDA Internacional, 2015; Koivula et al., 2001; Kulik \& Mahler, 1989; Lazarus \& Folkman, 1986; Mogg \& Bradley, 1998; Pritchard, 2009; Sandler, 1980).

Los pacientes seleccionados en el estudio de investigación estaban programados para ser intervenidos quirúrgicamente de CENS, siendo el procedimiento quirúrgico más utilizado para solucionar los estados inflamatorios nasosinusales (Lobo et al., 2003). En el hospital objeto del estudio, la CENS se realiza de forma estandarizada y similar por los diferentes cirujanos.

La muestra final de pacientes que cumplieron los criterios de inclusión en el estudio fue de 55 personas, procedentes del reclutamiento de un año de duración realizado en el Complejo Hospitalario Universitario In- 
sular de Gran Canaria, desde el 1 de septiembre de 2016 hasta el 31 de agosto de 2017.

Los resultados obtenidos en las variables analizadas que podrían afectar a la evolución quirúrgica deberían ser valorados por la enfermera responsable del cuidado del paciente para poder evaluar y planificar un proceso de atención de enfermería desde un punto de vista holístico, más allá de la cuantificación de signos y síntomas relacionados solamente con la cirugía. Las variables y resultados analizados en la investigación de esta tesis doctoral complementan la visión integral que la valoración enfermera debe poseer, consiguiendo, de esa manera, no obviar la percepción personal que el paciente está viviendo de su proceso quirúrgico, centrándose, por error, en una visión enfermera puramente fisiopatológica priorizando la resolución de la patología frente al enfoque integral de la atención sanitaria (Burnside \& Snowden, 2017; Delgado Hito et al., 2001; Grieve \& R.J., 2002; Hendrich et al., 2008; Pasero \& Belden, 2006; Possari, 2004).

En este sentido, al analizar los resultados obtenidos en la variable AS percibido de familiares, amigos y personas relevantes en la muestra seleccionada, se aprecia que el AS percibido se corresponde con valores similares a estudios previos, entre ellos, el realizado para el procedimiento de validación del instrumento de medida de dicha variable (Alemán Ruiz, 2013; Calvo-Francés \& Alemán-Ruiz, 2016).

Los resultados alcanzados del análisis del AS percibido muestran que los pacientes que presentaron un AS percibido de familiares, amigos y personas relevantes mayor, a su vez también mostraron una menor $A E$ durante el ingreso hospitalario $(p<0,05)$, este hecho coincide con estudios realizados por Silva (1979) y Krohne \& Slangen (2005). En este sentido, es de destacar que los pacientes que presentaron un mayor AS percibido de personas relevantes en el momento del ingreso, refirieron una menor AE después de la cirugía $(p<0,05)$. Se debe mencionar que la muestra de pacientes seleccionados presenta una media ligeramente inferior respecto a la obtenida en la adaptación española del cuestionario STAI, que obtuvo para adultos universitarios una AE de media de 18,44 para varones y 20,01 para mujeres $(n=610)$, y en no universitarios una media de 16,25 para los varones y 18,32 para las mujeres $(n=1157)$. Res- 
pecto a la AR la media en estudiantes universitarios fue de 19,02 en varones y 22,45 en mujeres, y en estudiantes no universitarios fue de 18,98 en hombres y 23,37 en mujeres (Buela-Casal, Guillén-Riquelme, \& Seisdedos, 2011).

Como ya se comentó en el marco teórico, la AE influye en aspectos como la cicatrización de heridas, dolor, incidencia de infecciones de la herida quirúrgica o la aparición de complicaciones relacionadas con la cirugía (Greszta \& Sieminska, 2008; Grieve \& R.J., 2002; Levandovski et al., 2008; Thorsteinsson \& James, 1999; Tully et al., 2011; Uchino et al., 1996; Visintainer \& Wolfer, 1975), es por ello que resultados como los expuestos anteriormente reconocen la posible relación existente entre ambas variables. Dicha relación no ha sido estudiada en profundidad en investigaciones anteriores en pacientes quirúrgicos, incluso algunos autores han descrito un posible efecto negativo o nulo del AS (Asilioglu \& Celik, 2004; Hämäläinen et al., 2000; Robles, 2007; Rosenberger et al., 2006; Sherbourne, 1988).

Por todo esto, los resultados mencionados con anterioridad servirían como base para desarrollar una evidencia científica que, desde una metodología experimental, tenga como objetivo la búsqueda de la relación causal entre las variables AS y A en el paciente quirúrgico, por lo tanto, se abre una nueva visión holística del paciente quirúrgico, donde el AS podría ser una variable a tener en cuenta en la valoración inicial del paciente por parte de la enfermera, que en la actualidad y, concretamente, en el hospital objeto de estudio no se valora ni cuantifica de una manera sistemática, obviando una posible relación que podría afectar a la evolución del paciente quirúrgico.

Por lo que se refiere al análisis de la relación existente entre el E y el AS en el paciente quirúrgico, se debe tener en cuenta que una intervención quirúrgica, independientemente del tipo de cirugía realizada, podría ser por sí misma un condicionante para aumentar su estrés (Díez-álvarez et al., 2012b; Ornaque et al., 2000; Pierantognetti et al., 2002). A su vez, la investigación previa realizada por otros autores en diferentes ensayos clínicos aleatorizados demostró que la intervención de enfermería por si sola (Alanazi , 2014; Gilliss et al., 1993) o unida al uso de métodos como la musicoterapia (Jeong \& Kang, 2016; K Zhou et al., 2015) o la visualiza- 
ción de un video explicativo (Doering et al., 2000) podría disminuir el estrés y la ansiedad en el paciente quirúrgico. En cuanto a la relación que el estrés puede tener sobre la evolución del paciente quirúrgico, la bibliografía encontrada destaca que la reducción del estrés se traduce, por ejemplo, en una disminución en la percepción del dolor del paciente (Xie et al., 2016). Aún así, autores como Walburn, Vedhara, Hankins, Rixon, \& Weinman (2009), en la revisión sistemática y metaanálisis realizado sobre este constructo, recomiendan en futuras investigaciones la búsqueda de nuevos factores o moderadores del estrés.

Es por ello que se planteó como uno de los objetivo de esta tesis doctoral, describir la posible influencia entre el estrés (E) y el apoyo social percibido como posible nuevo moderador que no había sido evidenciado de manera exhaustiva en la bibliografía consultada desde una perspectiva enfermera. Así pues, en este estudio de investigación, se debe distinguir dos resultados diferentes respecto a esa posible relación entre el E y el AS.

En primer lugar, el AS percibido de familiares y amigos se correlacionó con menor nivel de cortisol sérico, hormona secretada como respuesta al estrés. Respecto a los estudios de investigación previos, se han centrado, pero sin obtener resultados concluyentes, en la relación directa de aspectos psicológicos, ambientales o de género sobre los niveles de cortisol sérico en situaciones de estrés en el ámbito sanitario (Aguilar Cordero et al., 2014; Goldstein \& Eisenhofer, 2010; Salmon, 1992), sin profundizar en el estudio de la influencia de aspectos sociales, como el apoyo social percibido.

En segundo lugar, al comparar el resultado del E, medido mediante el cuestionario IDDE-EA antes y después de ser intervenido quirúrgicamente, no se obtienen resultados significativos en su relación con el AS. En relación con los resultados obtenidos en la validación y tipificación del cuestionario IDDA-EA y los resultados obtenidos en el estudios, se puede apreciar un aumento de los valores de la dimensión estrés respecto a la muestra utilizada para la tipificación, que obtuvo una media de 800,27 en mujeres, desviación típica 79,74 y 699,09 en varones, desviacióntípica 83,76 ( $n=771$ ) (Tous-Ral \& Pueyo, 1991).

Teniendo en cuenta el resultado significativo entre AS y cortisol sérico, frente al resultado no significativo entre AS y E, en un primer análisis po- 
drían parecen contradictorios, pero deben ser analizados con detalle y desde una perspectiva holística.

Hay que tener en cuenta que la muestra seleccionada presentó un 67,3\% de pacientes que habían recibido anestesia general en alguna intervención previa, por lo tanto, en estos pacientes se podría prever cierto nivel de condicionamiento respecto a una experiencia anterior, haciendo que el estrés percibido sea menor. Por consiguiente, se decide realizar un análisis de las medias en función de la presencia o no de intervenciones previas en las que se administró anestesia general sin hallarse resultados significativos, por lo que habría que plantearse dos posibles causas de la aparición de estos resultados.

Una primera causa, se centraría en el momento de medición del cortisol sérico y el estrés psicológico. El estrés psicológico se midió justo en el momento del ingreso, en cambio el cortisol sérico se medió justo antes de entrar en el quirófano, situación que podría ser percibida por el paciente como más estresante que el momento del ingreso en el hospital.

La otra causa que explicaría esos resultados es la posibilidad de que el estrés, previo a una intervención quirúrgica, al presentar otras variables moduladoras como podrían ser aspectos ambientales, psicológicos o de género, precisen un análisis cualitativo para concretar la percepción individual e importancia que esas variables moduladoras tienen en cada paciente. Por ejemplo, para una persona la intervención previa con anestesia general puede ser un factor que disminuya su estrés, siempre y cuando la experiencia anterior haya sido vivida positivamente, ya que en caso contrario, la intervención quirúrgica previa podría aumentar ese estrés.

Desde mi perspectiva como enfermero en relación con los resultados analizados anteriormente, la visión integral del paciente conlleva un análisis en profundidad de las variables que puedan influir, en este caso, sobre el estrés del paciente quirúrgico. En este estudio se planteó describir la influencia que el AS podría tener sobre las variables E y A, es por ello, que la aparición de relaciones significativas y no significativas en el análisis de dichas relaciones coincide con los resultados encontrados en la bibliografía consultada que resaltan la necesidad de analizar en profundidad las definiciones y relaciones de dichas variables (L. F. Berkman \& Syme, 1979; Lisa F Berkman, 1985; S Cohen \& Wills, 1985; Kessler et al., 1985). 
Por lo tanto, este estudio permite sentar las bases de una evidencia que, siendo observacional, permite demostrar la aparición de resultados que resultan significativos en algunos aspectos sobre la influencia del AS sobre el paciente quirúrgico, permitiendo justificar una continuidad en la búsqueda de posibles relaciones de un constructor tan importante desde la perspectiva enfermera, que podría ser objeto de intervenciones independientes, pero que obviamente debe estar basado en una evidencia científica que sea originaria desde la propia disciplina y adaptado a las necesidades de apoyo específico de cada paciente (Helgeson, 1993).

Es necesario recalcar que el profesional de enfermería en su práctica diaria se enfrenta a una carga laboral que, en muchos casos, sobrepasa sus posibilidades y capacidades individuales para poder realizar un proceso de atención de enfermería exhaustivo, riguroso y de calidad a los pacientes que tienen a su cargo, este hecho se une al síndrome de Burnout que sufre el personal de enfermería que ha alcanzado, en los últimos años, cifras alarmantes en Europa, las condiciones descritas con anterioridad se han relacionado con un descenso en la calidad de los cuidados, el aumento de las infecciones nosocomiales o el aumento de la estancia hospitalaria (Aiken et al., 2012; Aiken, Clarke, Sloane, Sochalski, \& Silber, 2002; Escobar-Aguilar et al., 2013; Fuentelsaz-Gallego et al., 2012; Machado-Alba et al., 2013; Manzano-García \& Ayala-Calvo, 2014).

Por lo tanto, el diseño de herramientas que minimizan y simplifican la medición de los diferentes estados del paciente permitirían que la labor enfermera se pueda realizar con mayor eficiencia.

En este estudio de investigación planteamos, desde un punto de vista empírico, la posibilidad de cuantificar la Ay el E, mediante una escala numerada del 1-10 aplicada minutos antes de ser intervenido el paciente, destacando los valores obtenidos con esta escala y los resultados de la AE medidos mediante el cuestionario STAI, que se comenta a continuación.

Los pacientes que informaron de un mayor valor en la escala numerada del estrés y de ansiedad se correspondieron con una mayor AE y un aumento del centil de la $A E$ al ingreso $(p<0,01)$. Además, respecto a la escala numerada de ansiedad, un valor elevado en dicha escala se correlacionó también con un mayor valor de la AE postquirúrgica en los sujetos participantes en el estudio $(p<0,05)$. 
Se deberá tener en cuenta para futuras investigaciones la posibilidad de reducir a unas escalas más sencillas y operativas, variables que desde una perspectiva enfermera resulten interesantes para la valoración del paciente quirúrgico, proponiéndose, en virtud de lo comentado anteriormente, escalas numeradas o de tipo likert, que la NANDA-I, ya recomienda, por ejemplo, para la medición resultados de enfermería (Merino, 2013).

En relación con las variables relacionadas con el proceso quirúrgico, se debe destacar que los pacientes seleccionados en el estudio con una mayor AE postquirúrgica se correlacionan con mayor tiempo de ingreso en hospitalización. Este dato no se ha conseguido relacionar con estudios previos con una evidencia científica alta que tuviesen como objetivo buscar la relación entre ambas variables. A su vez, los individuos que refirieron un mayor AS percibido de personas relevantes tuvieron un menor tiempo de ingreso en la unidad de hospitalización, resultado importante a tener en cuenta sobre las repercusiones que se comentaban al principio de este constructo respecto a su análisis empírico.

Se debe destacar que las personas que refirieron en el estudio de investigación un AS percibido de personas relevantes elevado se correlacionó con aumento en la demanda de analgesia extra en la URPA, con una fuerza de relación moderada $(p<0,05)$. Este hecho, que parecería contradictorio en un primer momento, se podría justificar contextualizando la situación del paciente en URPA en el hospital donde se realizó la investigación, dichos pacientes se encuentran en el postoperatorio inmediato en un ambiente hostil y desconocido para ellos (Barrera Ortiz et al., 2006; Cho \& Hong, 2001; Heluy de Castro et al., 2004; Lenz Oscar, 2011), separados de otro paciente en las mismas condiciones, mediante un biombo, que no limita la percepción de ruidos o quejas, por ejemplo, de otro paciente que esté padeciendo dolor, unido a la imposibilidad de recibir visitas durante este periodo debido a la dinámicas de este tipo de unidades. Es por ello, que si el paciente previamente ha referido que percibe un AS de personas relevantes elevado, en el contexto mencionado anteriormente durante su estancia en la URPA y la restricción de visitas por parte de familiares y amigos, le genere mayor incomodidad e incluso dolor, si no puede apoyarse de su entorno social, en ese momento. 
La aparición de complicaciones quirúrgicas, siendo una técnica en principio sin una tasa de complicaciones mayores elevada (Bross et al., 1999), tuvo una correlación positiva $(p<0,05)$ en relación con el centil de la $A E$ postquirúrgico, es decir, los pacientes que tuvieron una mayor AE postquirúrgica presentaron mayores complicaciones durante su estancia hospitalaria, dato que coincide con la bibliografía encontrada sobre la relación de la AE y la aparición de complicaciones durante el proceso quirúrgico (Levandovski et al., 2008; Sadati et al., 2013). Este hallazgo se une a la comparación de medias para muestras independientes que se realizó con el factor estrés, en el que se concluyó que los pacientes que presentaron complicaciones durante la hospitalización tuvieron significativamente mayor nivel de estrés después de ser intervenidos que los pacientes que no presentaron complicaciones durante la hospitalización. Autores como Sadati et al. (2013) obtuvieron resultados parecidos, pero relacionando la disminución de la ansiedad mediante una intervención enfermera con la disminución de las complicaciones quirúrgicas.

Por otra parte, se debe señalar que una mayor AR dio lugar, en los pacientes seleccionados, a una menor frecuencia de complicaciones al alta en hospitalización, resultado interesante desde el punto de vista sanitario, lo cual podría permitir al personal de enfermería cuantificar esa AR, plasmando ese dato en el informe al alta del paciente que será evaluado por la enfermera de Atención Primaria, para prever la posible aparición de complicaciones al alta de hospitalización en función de dicha variable.

Así mismo, también se puede valorar este resultado desde una perspectiva de gestión sanitaria donde la enfermera responsable del paciente, junto con el equipo multidisciplinar de cirujanos que han realizado la intervención quirúrgica, podrían valorar un alta precoz para pacientes que previamente presenten una AR menor. Además, y basándonos en los resultados alcanzados, unir la variable experiencia previa en intervenciones con anestesia general para planificar ese alta precoz, ya que como corroboraron los resultados obtenidos, los pacientes que no habían sido intervenidos nunca bajo anestesia general permanecieron significativamente menos tiempo ingresados en el hospital que los pacientes que sí habían recibido anteriormente anestesia general. 
A continuación, se debe matizar la labor que la enfermera asistencial realiza en las diferentes etapas del proceso quirúrgico, como se ha mencionado en diferentes apartados de la tesis doctoral, la visión holística e integral del paciente debe ser el objetivo principal en la valoración y a plicación del proceso de atención de enfermería. Es obvio que las actividades de colaboración relacionadas con el acto quirúrgico son de vital importancia para el tratamiento y atención del paciente intervenido quirúrgicamente, pero sin obviar la valoración e intervención sobre aspectos psicoemocionales como el estrés o la ansiedad, y sociales como el apoyo social percibido, que podrían mejorar la experiencia del paciente y su entorno social (Cui \& Geng, 1996; Gilliss, 1984; Leinonen \& Leino-Kilpi, 1999; Maligalig, 1994; Neuling \& Winefield, 1988; Pierantognetti et al., 2002).

Como se afirma en el párrafo anterior, la atención integral podría ser realizada por una enfermera específicamente destinada para ese fin, en forma de intervención enfermera prequirúrgica, que se desarrollaría en una visita preoperatoria a los pacientes programados, lo que permitiría la valoración integral e individual del paciente y su entorno social, sin afectar a la carga laboral de la enfermera asistencial encargada del paciente en hospitalización, y permitiendo disminuir aspectos como la ansiedad prequirúrgica del paciente (Wu et al., 2015; Alanazi, 2014; Bahrami et al., 2012; Chirveches et al., 2006; Cupples, 1991; Granziera et al., 2013; Jing et al., 2004; Li-Ying \& Ruey-Hsia, 2005; Maguire et al., 1983; Maward L. et al., 2004; Ng et al., 2004; Rhodes et al., 2014; Rojas \& Pérez, 2013; Silva, 1979; Tang et al., 2015).

Por último, se debe destacar el desarrollo e implementación de los nuevos programas acelerados de recuperación que se están instaurando en los hospitales para mejorar le eficiencia en la recepción, atención y alta del paciente quirúrgico, actividades que deben ser realizadas sin disminuir la calidad en la atención sanitaria. La disciplina enfermera debe tener un papel importante en la gestión, planificación y ejecución de dichos programas (Pasero \& Belden, 2006), aportando la visión integral del paciente que solo la valoración enfermera permite obtener en la actualidad, y priorizando o aconsejando la idoneidad de este programa para determinados pacientes, por ejemplo, en función del apoyo social percibido y evaluado durante el ingreso en hospitalización. En un futuro, y 
basándose en resultados de estudios como este, el personal de enfermería podría plantear a la dirección de los hospitales normalizar las visitas temporales y controladas de personas relevantes en unidades que, en la actualidad, son de acceso restringido, como puede ser la Unidad de Recuperación Postanestésica.

El perfil del paciente presentaría las siguientes características basadas en la mediana para variables cuantitativas y la moda para las variables cualitativas de los datos obtenidos de la muestra seleccionada en el estudio de investigación:

El perfil de esta persona sería un varón de 49 años de edad que ingresa en el Complejo Hospitalario Universitario Materno Insular de Gran Canaria programado para ser intervenido a través de la técnica de cirugía endoscópica nasosinusal, casado, no fumador, que ha alcanzado estudios primarios, actualmente empleado, que ha recibido anestesia general en alguna intervención previa, con una ASA I, que no ha presentado complicaciones durante el ingreso, que presenta una ansiedad estado al ingreso de 15, una ansiedad estado después de la cirugía de 18, una ansiedad rasgo de 25 , una ansiedad estado después de la cirugía de 21, IDDA-EA al ingreso de 891 puntos y 832 puntos al regresar a la unidad hospitalización, presenta un cortisol sérico de $8,52 \mu \mathrm{g} / \mathrm{dl}$, presenta un apoyo social percibido de familiares de 25 puntos, de amigos 46 puntos y de personas relevantes 39 puntos. La duración de la cirugía sería de 75 minutos, sin presentar complicaciones durante la misma. El tiempo de estancia en la unidad de recuperación postanestésica ha sido de 60 minutos, sin presentar complicaciones ni demandas de analgesia extra en ese periodo. Su estancia en hospitalización ha sido de 24 horas, que tampoco ha presentado complicaciones, ni solicitado analgesia extra. El nivel de estrés y ansiedad en quirófano según la escala numerada del 1-10 ha sido de 4 puntos tanto para el estrés como para la ansiedad, no ha presentado complicaciones durante la primera semana después del alta en hospitalización.

A partir de este perfil de paciente se puede sugerir o aventurar una seria de DxE, que servirán como ejemplo de la relación que existe entre los términos apoyo social, ansiedad y estrés durante la valoración, planificación, ejecución y evaluación de los cuidados enfermeros, en este caso 
en el paciente programado para ser intervenido quirúrgicamente de cirugía endoscópica nasosinusal.

Los posibles diagnósticos que relacionan los conceptos anteriormente mencionados se basarán en la taxonomía NANDA II, organizándose la planificación de los cuidados siguiendo criterios de resultados NOC (Nursing Outcomes Classification), estableciendo las actividades enfermeras que se plantean para conseguir dicho objetivo, según la NIC (Nursing Interventions Classification) (Cereto, Rico, Heras, \& Palop, 2005; Johnson et al., 2006; Luis Rodrigo, 2008; Merino, 2013).

El primer diagnóstico posible sería: 00146 Ansiedad, relacionado con cambios en el estado de salud y el entorno manifestado por ansiedad verbalizada e inquietud.

Los resultados esperados NOC y su respectivas intervenciones NIC podrían ser:

\section{NOC: 1302 Afrontamiento de los problemas}

NIC: 5820 Disminución de la ansiedad

\begin{tabular}{ll}
\hline Código & Actividades \\
\hline 582004 & $\begin{array}{l}\text { Tratar de comprender la perspectiva del paciente sobre una situación } \\
\text { estresante. }\end{array}$ \\
\hline 582006 & $\begin{array}{l}\text { Permanecer con el paciente para promover la seguridad y reducir el } \\
\text { miedo. }\end{array}$ \\
\hline 582007 & Animar a la familia a permanecer con el paciente, si es el caso. \\
\hline 582012 & Escuchar con atención. \\
\hline 582014 & Crear un ambiente que facilite la confianza. \\
\hline 582016 & Identificar los cambios en el nivel de ansiedad. \\
\hline 582025 & Observar si hay signos verbales y no verbales de ansiedad \\
\hline NIC: 5350 Disminución del estrés por traslado \\
\hline Código & Actividades \\
\hline 535007 & Valorar la necesidad/deseo del individuo de apoyo social \\
\hline 535008 & $\begin{array}{l}\text { Evaluar los sistemas de apoyo disponibles (p.ej., familia ampliada, im- } \\
\text { plicación de la comunidad, afiliaciones religiosas) }\end{array}$ \\
\hline 535010 & $\begin{array}{l}\text { Fomentar que el individuo/familia busque asesoramiento, según co- } \\
\text { rresponda. }\end{array}$ \\
\hline
\end{tabular}


NIC: 5440 Aumentar los sistemas de apoyo

\begin{tabular}{ll}
\hline Código & Actividades \\
\hline 544001 & $\begin{array}{l}\text { Calcular la respuesta psicológica a la situación y la disponibilidad del } \\
\text { sistema de apoyo. }\end{array}$ \\
\hline 544002 & Determinar la conveniencia de las redes sociales existentes. \\
\hline 544003 & $\begin{array}{l}\text { Determinar el grado de apoyo familiar y económico, así como otros } \\
\text { recursos. }\end{array}$ \\
\hline 544006 & $\begin{array}{l}\text { Determinar las barreras al uso de los sistemas de apoyo no utilizados } \\
\text { o infrautilizados. }\end{array}$ \\
\hline 544007 & Observar la situación familiar actual y la red de apoyo. \\
\hline 544014 & Implicar a la familia/allegados/amigos en los cuidados y la planificación. \\
\hline
\end{tabular}

El segundo diagnóstico posible: 00114 Riesgo de estrés por traslado, relacionado con trasladarse de su entorno habitual al entorno hospitalario.

Los resultados esperados NOC y su respectivas intervenciones NIC podrían ser:

NOC: 1212 Nivel de estrés

NIC: 5350 Disminución del estrés por traslado

\begin{tabular}{ll}
\hline Código & Actividades \\
\hline 535007 & Valorar la necesidad/deseo del individuo de apoyo social. \\
\hline 535008 & $\begin{array}{l}\text { Evaluar los sistemas de apoyo disponibles (p.ej., familia ampliada, im- } \\
\text { plicación de la comunidad, afiliaciones religiosas). }\end{array}$ \\
\hline 535010 & $\begin{array}{l}\text { Fomentar que el individuo/familia busque asesoramiento, según co- } \\
\text { rresponda. }\end{array}$
\end{tabular}

NOC: 1504 Soporte social

NIC: 5440 Aumentar los sistemas de apoyo

\begin{tabular}{ll}
\hline Código & Actividades \\
\hline 544001 & $\begin{array}{l}\text { Calcular la respuesta psicológica a la situación y la disponibilidad del } \\
\text { sistema de apoyo. }\end{array}$ \\
\hline 544002 & Determinar la conveniencia de las redes sociales existentes. \\
\hline 544003 & $\begin{array}{l}\text { Determinar el grado de apoyo familiar y económico, así como otros } \\
\text { recursos. }\end{array}$ \\
\hline 544006 & $\begin{array}{l}\text { Determinar las barreras al uso de los sistemas de apoyo no utilizados } \\
\text { o infrautilizados. }\end{array}$ \\
\hline 544007 & Observar la situación familiar actual y la red de apoyo. \\
\hline 544014 & Implicar a la familia/allegados/amigos en los cuidados y la planificación. \\
\hline
\end{tabular}




\section{NIC: Fomentar la implicación familiar}

\section{Código Actividades}

711001 Establecer una relación personal con el paciente y los miembros de la familia que estarán implicados en el cuidado.

711002 Identificar la capacidad de los miembros de la familia para implicarse en el cuidado del paciente.

711005 Identificar las preferencias de los miembros de la familia para implicarse con el paciente.

711006 Identificar las expectativas de los miembros de la familia respecto del paciente.

711007 Animar a los miembros de la familia y al paciente a ayudar a desarrollar un plan de cuidados, incluidos los resultados esperados y la implantación del plan de cuidados.

711009 Observar la estructura familiar y sus roles.

711010 Observar la implicación de los miembros de la familia en el cuidado del paciente.

711011 Favorecer los cuidados por parte de los miembros de la familia durante la hospitalización.

711012 Proporcionar información crucial a los miembros de la familia sobre el paciente de acuerdo con los deseos de este último.

711017 Determinar el nivel de dependencia respecto de la familia que tiene el paciente, según corresponda por la edad o la enfermedad.

711023 Animar a los miembros de la familia a mantener relaciones familiares, según cada caso.

711027 Anticipar e identificar las necesidades de la familia.

NIC: Apoyo a la familia

\section{Código Actividades}

714001 Asegurar a la familia que al paciente se le brindan los mejores cuidados posibles.

714002 Valorar la reacción emocional de la familia frente a la enfermedad del paciente.

714005 Escuchar las inquietudes, sentimientos y preguntas de la familia.

714010 Orientar a la familia sobre el ambiente de cuidados sanitarios, como un centro hospitalario o una clínica.

714013 Identificar el grado de coherencia entre las expectativas del paciente, de la familia y de los profesionales sanitarios. 
714014 Reducir las discrepancias entre las expectativas del paciente, de la familia y de los profesionales sanitarios mediante el uso de técnicas de comunicación.

714020 Proporcionar información frecuente a la familia acerca de los progresos del paciente, de acuerdo con los deseos de éste.

714023 Incluir a los miembros de la familia junto con el paciente en la toma de decisiones acerca de los cuidados, cuando resulte apropiado.

714025 Reconocer la comprensión de la decisión familiar acerca de los cuidados posteriores al alta.

El tercer diagnóstico que el paciente podría presentar sería el de 00148 Temor, relacionado con ser intervenido quirúrgicamente manifestado por expresiones verbales y gestuales.

Los resultados esperados NOC y su respectivas intervenciones NIC podrían ser:

NOC: 1210 Nivel de miedo

NIC: 5820 Disminución de la ansiedad

\begin{tabular}{ll}
\hline Código & Actividades \\
\hline 582004 & $\begin{array}{l}\text { Tratar de comprender la perspectiva del paciente sobre una situación } \\
\text { estresante. }\end{array}$ \\
\hline 582006 & $\begin{array}{l}\text { Permanecer con el paciente para promover la seguridad y reducir el } \\
\text { miedo. }\end{array}$ \\
\hline 582007 & Animar a la familia a permanecer con el paciente, si es el caso. \\
\hline 582012 & Escuchar con atención. \\
\hline 582014 & Crear un ambiente que facilite la confianza. \\
\hline 582016 & Identificar los cambios en el nivel de ansiedad. \\
\hline 582025 & Observar si hay signos verbales y no verbales de ansiedad. \\
\hline NIC: 5350 Disminución del estrés por traslado \\
\hline Código & Actividades \\
\hline 535007 & Valorar la necesidad/deseo del individuo de apoyo social. \\
\hline 535008 & $\begin{array}{l}\text { Evaluar los sistemas de apoyo disponibles (p.ej., familia ampliada, im- } \\
\text { plicación de la comunidad, afiliaciones religiosas). }\end{array}$ \\
\hline 535010 & $\begin{array}{l}\text { Fomentar que el individuo/familia busque asesoramiento, según co- } \\
\text { rresponda. }\end{array}$ \\
\hline
\end{tabular}


En conclusión, el perfil de paciente utilizado como ejemplo presentaría una serie de diagnósticos enfermeros, unos posibles NOC y sus respectivas NIC que expondrían la interrelación existente entre los conceptos de ansiedad y estrés, que mayoritariamente son usados en la práctica clínica diaria, pero que a su vez, en este desarrollo del plan de cuidados, se puede detectar cómo el a poyo social debe ser también valorado para resolución de los diagnósticos reales o para la prevención de los posibles diagnósticos de riesgo, siendo la familia o las personas relevantes para el individuo, una pieza clave en la recuperación y adaptación del paciente durante todo el proceso quirúrgico.

Se debe mencionar que, en este proceso de atención de enfermería, se han obviado los diagnósticos habituales relacionados con el periodo perioperatorio y los problemas de colaboración relacionados con la intervención quirúrgica que, siendo fundamental detectarlos y actuar sobre ellos para favorecer la recuperación y fomentar la seguridad del paciente quirúrgico, no ejemplarizan la interrelación de los conceptos anteriormente citados. 


\section{CONCLUSIONES}

Las conclusiones que se describen a continuación se basan en los objetivos planteados inicialmente en la tesis doctoral, y derivan de los resultados obtenidos de los pacientes adultos hospitalizados para ser intervenidos quirúrgicamente mediante cirugía endoscópica nasosinusal en el Complejo Hospitalario Universitario Insular de Gran Canaria, y que cumplieron los criterios de inclusión en el estudio de investigación:

1. Los pacientes incluidos en la investigación refieren un apoyo social similar a los estudios previos realizados durante el proceso de validación de la Escala de Vínculos Interpersonales de Apoyo (VIDA).

2. Los pacientes seleccionados en el estudio presentan un nivel de ansiedad estado ligeramente menor y una ansiedad rasgo ligeramente mayor, respecto a la media de los estudios de validación de la adaptación española de Buela-Casal et al. (2011) del cuestionario STAI.

3. Los pacientes elegidos en el estudio refieren unos niveles de estrés superiores en relación con la muestra utilizada para la tipificación y validación del cuestionario IDDA-EA utilizado.

4. Un mayor apoyo social percibido, tanto de familiares y amigos como personas relevantes, se relaciona con una menor ansiedad estado en el momento del ingreso

5. Un incremento del apoyo social percibido de familiares, amigos y personas relevantes no se correlaciona con un menor valor en el factor estrés antes y después de la intervención quirúrgica en la muestra escogida. 
6. Los pacientes refieren un mayor apoyo social percibido de amigos y familiares presentan un menor nivel cortisol sérico minutos antes de ser intervenidos.

7. Una mayor ansiedad estado postquirúrgica se relaciona con un mayor tiempo en la unidad de hospitalización.

8. Un valor elevado de apoyo social percibido de personas relevantes se asocia con un menor tiempo de ingreso en la unidad de hospitalización.

9. El aumento de la ansiedad estado postquirúrgica y los niveles elevados de factor estrés se correlacionan con una mayor aparición de complicaciones durante la estancia hospitalaria.

10. Una ansiedad rasgo menor se correlaciona con una disminución en el número de complicaciones después del alta hospitalaria.

11. Los pacientes que presentan una aumento en la demanda de analgesia extra en la Unidad de Recuperación Postanestésica refieren un apoyo social percibido de personas relevantes mayor que los pacientes que solicitan menos analgesia extra durante dicha estancia. 


\section{LIMITACIONES DE LA INVESTIGACIÓN}

La limitación inicial del estudio se centran en los aspectos relacionados con los recursos materiales disponibles, después de recibir la aceptación por parte de la gerencia del hospital objeto de estudio, solamente se autoriza realizar una única muestra de cortisol sérico, es por ello que se decide extraer esta única muestra de cortisol sérico minutos antes del comienzo de la intervención quirúrgica.

Otra posible limitación se produce durante la entrega del consentimiento informado y la explicación a los pacientes de las normas para cumplimentar los diferentes cuestionarios. Dicha entrega se realiza por el investigador principal y, aunque se mantuvo la premisa de actuar de la misma forma en todos los casos, fue inevitable desde el punto de vista asistencial y debido a la relación del investigador principal con el servicio de quirófano, responder a alguna duda que el paciente plantease durante la entrega del consentimiento informado, aún siendo muchas estas cuestiones derivadas y comentadas tanto a la enfermera responsable del paciente en ese momento como al cirujano que iba a realizar la intervención. Por consiguiente, la instauración de una intervención estructurada que podría ser catalogada como una intervención enfermera y, por lo tanto, medir su efecto directo sobre las variables ansiedad y estrés, o delegar la entrega de la documentación a una persona ajena al proyecto de investigación. Por último, este estudio debería ser replicado con muestras mayores y diferentes tipos de intervenciones quirúrgicas donde la posibilidad de aumentar su validez externa. 



\section{FUTURAS LÍNEAS DE INVETIGACIÓN}

Concluido el estudio, se plantea la posibilidad de desarrollar las siguientes líneas de investigación en función de los hallazgos descubiertos.

Se debería continuar con la búsqueda de posibles relaciones entre el apoyo social y las diferentes variables, tanto psicológicas, como pueden ser la ansiedad o el estrés, como variables relacionadas con el proceso quirúrgico, en otro tipo de intervenciones quirúrgicas más complejas; a su vez, se recomienda para futuras investigaciones complementar los datos obtenidos en estas investigaciones con un análisis cualitativo de la percepción del apoyo social percibido en el paciente quirúrgico.

Por otra parte, sería oportuno el estudio experimental centrado en aspectos sociales como, por ejemplo, el apoyo social percibido y su posible relación con el cortisol sérico. Con el objetivo de obtener y comparar los niveles basales de cortisol con los niveles en el momento de iniciarse el evento desencadenante del estrés.

Así mismo, se podrían utilizar los hallazgos obtenidos en este estudio para plantear una posible línea de investigación en la se intente diseñar e implementar, para su posterior análisis, una intervención enfermera que tenga como objetivo actuar sobre el apoyo social del paciente y, por lo tanto, mejorar los cuidados integrales de la unidad paciente-familiaentorno social.

En un futuro, el personal de enfermería podría plantear y normalizar las visitas temporales y controladas de personas relevantes en unidades que, en la actualidad, son de acceso restringido, como puede ser la Unidad de Recuperación Postanestésica. Es por ello que se recomienda, para 
futuras investigaciones, profundizar en los aspectos sociales y psicológicos que los pacientes experimentan en las unidades que restringen el acceso libre de familiares y amigos.

Finalmente, se deben desarrollar estudios de investigación que diseñen y validen herramientas que permitan la medición de aspectos psicológicos que relacionen el apoyo social con aspectos psicoemocionales derivados de las respuestas humanas ante este tipo de situaciones que puedan ser aplicadas e interpretadas por la enfermera, de manera que puedan ser integradas en el cuidado diario, por ejemplo, en el paciente quirúrgico, pero desde una perspectiva enfermera, con escalas más sencillas que puedan ser integradas de manera realista en la práctica asistencial con las cargas laborales actuales. 


\section{BIBLIOGRAFÍA}

Abraham, K. K. (1924). Un Breve estudio de la evolución del libido, considerada a la luz de los trastornos mentales. Psicoanálisis clínico, 319-381. Aguilar Cordero, M. J., Sánchez López, A. M., Mur Villar, N., García García, I., Rodríguez López, M. A., Ortegón Piñero, A., Cortés Castell, E. (2014). Cortisol salival como indicador de estrés fisiológico en niños y adultos: revisión sistemática. Nutrición Hospitalaria, 29(5), 960-968. http:// doi.org/ 10.3305/nh.2014.29.5.7273

Aiken, L. H., Clarke, S. P., Sloane, D. M., Sochalski, J., Silber, J. H. \& Cortés Castell, E. (2002). Hospital nurse staffing and patient mortality, nurse burnout, and job dissatisfaction. JAMA, 288(16), 1987-93.

Aiken, L. H., Sermeus, W., Van den Heede, K., Sloane, D. M., Busse, R., McKee, M., et al. (2012). Patient safety, satisfaction, and quality of hospital care: cross sectional surveys of nurses and patients in 12 countries in Europe and the United States. BMJ (Clinical Research Ed.), 344(March), e1717. http://doi.org/10.1136/bmj.e1717

Akiskal S, H. (1985). Anxiety: Definition, relationship to depression, and proposal for an integrative model. Anxiety and the Anxiety Disorders. Hillsdale, NJ, EE. UU. Lawrence Erlbaum Associates, Inc.

Alanazi, A. A. (2014). Reducing anxiety in preoperative patients: a systematic review. British Journal of Nursing, 23(7), 387-393. http://doi.org/ 10.12968/bjon.2014.23.7.387

Alemán Ruiz, I. L. (2013). Desarrollo y validación del cuestionario de apoyo social V.I.D.A. (Vínculos Interpersonales de Apoyo) (tesis doctoral). ULPGC, Las Palmas de Gran Canaria. España. 
Alfaro-LeFevre, R. (1998). Aplicación del proceso enfermero: guía paso a paso. Springer Science \& Business Media.

Alonso Fachado, A. (2009). Influencia del apoyo social en el control metabólico de la Diabetes Mellitus tipo 2 (tesis doctoral). Universidad de Santiago de Compostela. Santiago de Compostela. España.

Alvarez González, M. A. (1989). Estrés: un enfoque neuroendocrino (pp. 5270). Ciudad de La Habana: Editorial Científico-Técnica.

Andrews, S. M. (2009). Patient Family-Centered Care in the Ambulatory Surgery Setting. Journal of Perianesthesia Nursing, 24(4), 244-246. http://doi.org/10.1016/j.jopan.2009.05.100

Ang, S. G. M., Chen, H.-C., Siah, R. J. C., He, H.-G., \& Klainin-Yobas, P. (2013). Stressors relating to patient psychological health following stoma surgery: An integrated literature review. Oncology Nursing Forum, 40(6), 587-594. http://doi.org/10.1188/13.ONF.587-594

Artinian, N. T. (1989). Family member perceptions of a cardiac surgery event. Focus on Critical Care / American Association of Critical-Care Nurses, 16(4), 301-8.

Asilioglu, K., \& Celik, S. S. (2004). The effect of preoperative education on anxiety of open cardiac surgery patients. Patient Education and Counseling, 53(1), 65-70. http://doi.org/10.1016/S0738-3991(03)00117-4

Badani Lenz, O. (2011). Bioseguridad en Quirófano Procedimientos. Revista de Actualización Clínica Investiga. 15, 880-885.

Bahrami, N., Soleimani, M., Erjini, Z., \& Shraifnia, H. (2012). The effect of nursing process-based care on patients' anxiety of candidates for women's elective surgery. Iran Journal of Nursing, 25 (77).

Bar-Haim, Y. (2010). Research Review: Attention bias modification (ABM): A novel treatment for anxiety disorders. Journal of Child Psychology and Psychiatry and Allied Disciplines, 57(8), 859-870. http://doi.org/ JCPP2251 [pii] \r10.1111/j.1469-7610.2010.02251.x

Bar-Haim, Y., Lamy, D., Pergamin, L., Bakermans-Kranenburg, M. J., \& van IJzendoorn, M. H. (2007). Threat-related attentional bias in anxious and nonanxious individuals: a meta-analytic study. Psychological BuIletin, 133(1), 1-24. http://doi.org/10.1037/0033-2909.133.1.1

Barraza Macías, A. (2006). Un modelo conceptual para el estudio del estrés académico. Revista Electrónica de Psicología Iztacala, 9(3). 
Barrera Ortiz, L., Galvis López, C. R., Moreno Fergusson, M. E., Pinto Afanador, N., Pinzón Rocha, M. L., Romero González, E. \& Herrera, B.S. (2006). Caring ability of family caregivers of chronically diseased people. Investigación y Educación En Enfermería, 24(1), 36-46.

Barrón, A., Lozano, P., Chacón, F., \& Chacón, E. (1988). Autoayuda y apoyo social. Psicología comunitaria. Madrid: Visor.

Beck, A. T. (1979). Cognitive therapy and the emotional disorders. New York: The New American Library.

Beck, A. T., \& Clark, D. A. (1997). An information processing model of anxiety: Automatic and strategic processes. Behaviour Research and Therapy, 35(1), 49-58. http://doi.org/10.1016/S0005-7967(96)00069-1

Beck, A. T., Steer, R. A., \& Brown, G. K. (1996). Beck depression inventory. San Antonio, 78(2), 490-498.

Bellón Saameño, J., Delgado Sánchez, A., Luna del Castillo, J. de D., \& Lardelli Claret, P. (1996). Validez y fiabilidad del cuestionario de apoyo social funcional Duke-UNC-11. Atención Primaria, 18(4), 153-163.

Berkman, L. F. (1985). The relationship of social networks and social support to morbidity and mortality. Social Support and Health, 241-262.

Berkman, L. F., \& Syme, S. L. (1979). Social networks, host resistance, and mortality: a nine-year follow-up study of Alameda County residents. American Journal of Epidemiology, 109(2), 186-204. http://doi.org/ 10.16953/deusbed.74839

Bermúdez, J., Pérez-García, A. M. y Sanjuán, P. (2003). Psicología de la Personalidad: Teoría e Investigación. Volúmenes 1 y 2. Madrid: UNED

Blanco, A., F. Jimenez Burillo \& Jl Aragones (1986). El estrés ambiental. Introducción a la psicología ambiental. 229-249.

Borrón López de Roda, A., \& Sánchez Moreno, E. (2001). Estructura social, apoyo social y salud mental. Psicothema, 13(1), 17-23.

Bower, G. H. (1981). Mood and memory. American Psychologist, 36(2), 129148. http://doi.org/10.1037/0003-066X.36.2.129

Bowers, K. S. (1973). Situationism in psychology: An analysis and a critique. Psychological Review, 80(5), 307-336. http://doi.org/10.1037/h0021465 Bowlby, J. (1969). Attachment and loss. Vol. I. Loss. Nueva York: Basic Books. Bowlby, J. (1973). Attachment and loss. Vol II: separation, anxiety and anger. London: Tavistock. Trad. Fr.: La Séparation, Angoisse et Colère, Paris, PUF. 
Bowlby, J. (1982). Attachment and loss: retrospect and prospect. American Journal of Orthopsychiatry, 52(4), 664.

Bowling, A. (1991). Social support and social networks: their relationship to the successful and unsuccessful survival of elderly people in the community. An analysis of concepts and a review of the evidence. Fam Pract, 8(1), 68-83. http://doi.org/10.1093/fampra/8.1.68

Broadbent, E., Kahokehr, A., Booth, R. J., Thomas, J., Windsor, J. A., Buchanan, C. M., et al. (2012). A brief relaxation intervention reduces stress and improves surgical wound healing response: a randomised trial. Brain, Behavior, and Immunity, 26(2), 212-217.

Bross, S. D., Schimelmitz, I. J., Arrieta, G. J., Guzmán, U. R., Soriano, D. B., Idi, J. S., et al. (1999). Complicaciones y causas de falla en cirugía endoscópica nasosinusal. An Med Asoc Med Hosp ABC, 44(2), 77-81.

Buela-Casal, G., Guillén-Riquelme, A., \& Seisdedos, N. (2011). STAl: Cuestionario de Ansiedad Estado-Rasgo. Adaptación Española (8a Ed.). Madrid: TEA Ediciones.

Burchfield, S. R. (1979). The stress response: a new perspective. Psychosomatic Medicine, 41(8), 661-672.

Burnside, W. S., \& Snowden, C. (2017, February 1). Preoperative assessment and investigation. Surgery (United Kingdom). Elsevier. http://doi.org/ 10.1016/j.mpsur.2016.11.011

Calvo-Francés, F., \& Alemán-Ruiz, I. (2016). Validation of the Interpersonal Support Links Scale VIDA. Anales de Psicología, 33(1), 168. http://doi.org/ 10.6018/analesps.33.1.232341

Canguilhem, G. (1997). Canguilhem y el estatuto epistemológico del concepto de salud. História, Ciências, Saúde-Manguinhos, 4(2), 287-307.

Cannon, W. (1932). Homeostasis. The Wisdom of the Body. New York: Norton.

Cano-Vindel, Antonio; Miguel-Tobal, J. J. (1999). Evaluación de la ansiedad desd un enfoque interactivo y multidimensional: el inventario de situaciones y respuestas de ansiedad - ISRA. Psicologia Contemporanea, 6(1), 14-21.

Caplan, G. (1963). Types of mental health consultation. American Journal of Orthopsychiatry, 33(3), 470.

Caplan, G. (1974). Social support and community mental health: Lectures on concept development. New York: B Ehavioral Publications. 
Cassel, J. (1976). The contribution of the social environment to host resistance. American Journal of Epidemiology, 104(2), 107-123.

Castro, R., Campero, L., \& Hernández, B. (1997). La investigación sobre apoyo social en salud: situación actual y nuevos desafíos. Revista de Saúde Pública, 37(4), 425-435.

Cereto, M., Rico, A., Heras, C., \& Palop, R. (2005). Las taxonomías enfermeras NANDA, NOC y NIC en la práctica asistencial hospitalaria. Enfermería Clínica, 15(3), 163-166.

Chirveches, E., Arnau, A., Soley, M., Rosell, F., Clotet, G., Roura, P., et al. (2006). Efecto de una visita prequirúrgica de enfermería perioperatoria sobre la ansiedad y el dolor. Enfermeria Clinica, 16(1), 3-10. http:// doi.org/10.1016/S1130-8621(06)71171-8

Cho, M., \& Hong, M. (2001). A study on the effect of supportive nursing care to anxiety reduction of the patient immediately before surgery in the operating room. Journal of Korean Academy of Adult Nursing, 13(4), 632-640.

Cisler, J. M., \& Koster, E. H. W. (2010, March). Mechanisms of attentional biases towards threat in anxiety disorders: An integrative review. Clinical Psychology Review, 30(2), 203-216 http://doi.org/10.1016/j.cpr.20 09.11 .003

Cobb, S. (1976). Social support as a moderator of life stress. Psychosomatic Medicine, 38(5), 300-314. http://doi.org/10.1097/00006842-19760900000003

Cochran, J., \& Ganong, L. H. (1989). A comparison of nurses' and patients' perceptions of intensive care unit stressors. Journal of Advanced Nursing, 14(12), 1038-1043. http://doi.org/10.1111/j.1365-2648.1989.tb01515.x

Cohen, S., \& McKay, G. (1984). Social support, stress and the buffering hypothesis: A theoretical analysis. Handbook of Psychology and Health, 4, 253-267.

Cohen, S., \& Syme, S. L. (1985). Issues in the study and application of social support. Social Support and Health, 3, 3-22.

Cohen, S., \& Wills, T. а. (1985). Stress, social support, and the buffering hypothesis. Psychological Bulletin, 98(2), 310-357. http://doi.org/10.1037/ 0033-2909.98.2.310 
Colomer Mascaró, J., Arias Díaz, J., Barturen Fernández, F., García CabaIlero, J., Gómez Arnau, J. I., \& González Arevalo, A. (2009). Bloque Quirúrgico: estándares y recomendaciones. Informes, estudios e investigación 2009. Madrid: Ministerio de Sanidad y Política Social.

Cowen, E. L. (1977). Baby-steps toward primary prevention. American Journal of Community Psychology, 5(1), 1-22.

Cramer, C., \& Renz, V. R. (1987). Preoperative care unit. An alternative to the holding room. AORN Journal, 45(2), 464-472.

Cremades Puerto, J. (2011). Factores laborales estresantes en profesionales de enfermería que trabajan en unidades hospitalarias con pacientes ingresados por problemas médico-quirúrgicos: una revisión bibliográfica. RECIEN: Revista Electrónica Científica de Enfermería, (2), 4.

Cristina Martín-Crespo Blanco, M., Isabel Caravantes Marín, M., Maria García Mas, J., \& Gómez González, B. (2006). Efecto de la intervención enfermera durante el intraoperatorio en el grado de ansiedad del paciente Quirúrgico en el hospital comarcal Virgen de Altagracia de Manzanares (Ciudad Real) Efecto de la intervención enfermera durante el intraoperatorio en el gr. U.E. Hospital Gregorio Marañón, (123), 1-26.

Cruz, A. C. (2015). Determinación urinaria de cortisol y aplicación de una escala de ansiedad en sujetos sometidos a estrés quirúrgico (tesis doctoral). Universidad Veracruzana, México.

Cui, D. C., \& Geng, J. (1996). Psychological stress and nursing strategies in patients with elective surgery. Chinese Journal of Nursing, 31(12), 692-695.

Cupples, S. A. (1991, November). Effects of timing and reinforcement of preoperative education on knowledge and recovery of patients having coronary artery bypass graft surgery. Heart \& Lung: The Journal of Critical Care, 13(3), 18.

De Ansorena, A., Cobo, J., \& Romero, I. (1983). El constructo ansiedad en psicología: Una revisión. Estudios de Psicología, (16), 31-45. http:// doi.org/10.1080/02109395.1983.10821366

de Araujo, G., Van Arsdel, P. P., Holmes, T. H., \& Dudley, D. L. (1973). Life change, coping ability and chronic intrinsic asthma. Journal of Psychosomatic Research, 17(5), 359-363. 
De la Revilla Ahumada, L, Luna del Castillo, J, Bailón Muñoz, E, Medina Moruno, I. (2005). Validación del cuestionario MOS de apoyo social en Atención Primaria. Medicina de Familia (And), 6, 10-18.

Deak, T., Nguyen, K. T., Cotter, C. S., Fleshner, M., Watkins, L. R., Maier, S. F., $\&$ Spencer, R. L. (1999). Long-term changes in mineralocorticoid and glucocorticoid receptor occupancy following exposure to an acute stressor. Brain Research, 847(2), 211-220. http://doi.org/10.1016/S00068993(99)02050-8

Delgado Hito, P., Sola Prado, A., Mirabete Rodríguez, I., Torrents Ros, R., Blasco Afonso, M., Barrero Pedraza, R., et al. (2001). Modificación de la práctica enfermera a través de la reflexión: Una investigación-acción participativa. Enfermería Intensiva / Sociedad Española de Enfermería Intensiva y Unidades Coronarias, 12(3), 110-126. http://doi.org/10.1016/ S1130-2399(01)78029-7

Deselms, J. A., Duvall, L., \& Ruyle, S. (2016, February 9). Family Visitation in the Postanesthesia Care Unit: Implementation of a Nurse Liaison Role. Journal of Perianesthesia Nursing, pp. 3-9. Elsevier. http://doi.org/ 10.1016/j.jopan.2016.02.009

Díaz, M. (2014). Relación entre personalidad, afrontamiento y apoyo social con Burnout, calidad de vida profesional y salud, en bomberos de Gran Canaria (tesis doctoral). ULPGC, Las Palmas de Gran Canaria.

Díez-álvarez, E., Arrospide, A., Mar, J., Alvarez, U., Belaustegi, A., Lizaur, B., et al. (2012a). Efectividad de una intervención preoperatoria de enfermeria sobre el control de la ansiedad de los pacientes quirurgicos. Enfermeria Clinica, 22(1), 18-26. http://doi.org/10.1016/j.enfcli.2011.09.005

Díez-álvarez, E., Arrospide, A., Mar, J., Alvarez, U., Belaustegi, A., Lizaur, B., et al. (2012b). Efectividad de una intervención preoperatoria de enfermería sobre el control de la ansiedad de los pacientes quirúrgicos. Enfermeria Clinica, 22(1), 18-26. http://doi.org/10.1016/j.enfcli.2011.09.005 Doering, S., Katzlberger, F., Rumpold, G., Roessler, S., Hofstoetter, B., Schatz, D. S., et al. (2000). Videotape Preparation of Patients Before Hip Replacement Surgery Reduces Stress. Psychosomatic Medicine, 62(3), 365-373. http://doi.org/10.1097/00006842-200005000-00010

Dolbier, C. L., \& Steinhardt, M. A. (2000). The development and validation of the Sense of Support Scale. Behavioral Medicine, 25(4), 169-179. http://doi.org/10.1080/08964280009595746 
Dura, E. (1991). La teoría del apoyo social y sus implicaciones para el ajuste psicosocial de los enfermos oncológicos. International Journal of Social Psychology, 6(2), 257-271. http://doi.org/10.1080/02134748. 1991.10821649

Durkheim, E. (1897). El Suicidio. Madrid, España: Fontamara.

Duval, F., González, F., \& Rabia, H. (2010). Neurobiología del estrés. Revista Chilena de Neuro-Psiquiatría, 48(4), 307-318.

Eisenberg, G., Pérez, C., Hernando, M., Taha, M., González, R., Montojo, J., et al. (2008). Cirugía endoscópica nasosinusal como cirugía mayor ambulatoria. Acta Otorrinolaringologica Espanola, 59(2), 57-61. http:// doi.org/10.1016/S0001-6519(08)73263-1

Eltiti, S., Wallace, D., \& Fox, E. (2005). Selective target processing: Perceptual load or distractor salience? Perception \& Psychophysics, 67(5), 876-885.

Endler, N. S. (1973). The person versus the situation-a pseudo issue? A response to Alker. Journal of Personality, 41(2), 287-303. http://doi.org/ 10.1111/j.1467-6494.1973.tb00095.x

Endler, N. S. (1997). Stress, anxiety and coping: The multidimensional interaction model. Canadian Psychology/Psychologie Canadienne, 38(3), 136-153. http://doi.org/10.1037/0708-5591.38.3.136

Escobar-Aguilar, G., Gómez-García, T., Ignacio-García, E., Rodríguez-Escobar, J., Moreno-Casbas, T., Fuentelsaz-Gallego, C., et al. (2013). Entorno laboral y seguridad del paciente: Comparación de datos entre los estudios Seneca y RN4CAST. Enfermeria Clinica, 23(3), 103-113. http:// doi.org/10.1016/j.enfcli.2013.03.005

Esteghamat, S. S., Moghaddami, S., Esteghamat, S. S., Kazemi, H., Kolivand, P. H., \& Gorji, A. (2013). The Course of anxiety and depression in surgical and non-surgical patients. International Journal of Psychiatry in Clinical Practice, 18(1), 16-20. http://doi.org/10.3109/13651501.2013. 878365

Eysenck, M. W., MacLeod, C., \& Mathews, A. (1987). Cognitive functioning and anxiety. Psychological research, 49(2-3), 189-195. http://doi.org/ 10.1007/BF00308686

Fernández Peña, R. (2015). El estudio del apoyo social y la calidad de vida desde las redes personales: el caso del dolor crónico (tesis doctoral). Universidad Autónoma de Barcelona, Barcelona. 
Fernández Sánchez, T., Alonso, M. P. G., Sanz, M. R. L., Ordoqui, Á. N., Gutiérrez, M. T. U., \& Ceruelo, P. U. (2009). Efecto de una intervención enfermera múltiple durante el intraoperatorio sobre el nivel de dolor postoperatorio. NURE Inv., 6(39), 1-14.

Ferrero, B. S., Sandín, B., \& Ferrero, B. S. (2003). El estrés: un análisis basado en el papel de los factores sociales. Revista Internacional de Psicología Clínica y de La Salud (International Journal of Clinical and Health Psychology), 3(1), 141-157.

Flores-Rivera, A. R. (1996). ¿Es útil la clasificación ASA para determinar el riesgo quirúrgico? Cirugía y Cirujanos, 64(1), 8-13.

Freeman, K., \& Denham, S. A. (2008). Improving Patient Satisfaction by Addressing Same Day Surgery Wait Times. Journal of PeriAnesthesia Nursing, 23(6), 387-393. http://doi.org/http://doi.org/10.1016/j.jopan. 2008.08.003

Fuentelsaz-Gallego, C., Moreno-Casbas, T., López-Zorraquino, D., GómezGarcía, T., González-María, E., Martín, A. M. G., et al. (2012). Percepción del entorno laboral de las enfermeras españolas en los hospitales del Sistema Nacional de Salud. Proyecto RN4CAST-España. Enfermeria Clinica, 22(5), 261-268. http://doi.org/10.1016/j.enfcli.2012.09.001

G.K., W., L.F., D., K.C., B., Wyatt, G. K., Donze, L. F., \& Beckrow, K. C. (2004). Efficacy of an in-home nursing intervention following short-stay breast cancer surgery. Research in Nursing \& Health, 27(5), 322-331. http://doi.org/10.1002/nur.20032

Ganster, D. C., \& Victor, B. (1988). The impact of social support on mental and physical health. The British Journal of Medical Psychology, 61 (Pt 1), 17-36. García, A. D., Gallegos, A. M., \& Ochoa, E. M. (2011). Investigación: Una debilidad en Enfermería y su relación con la situación de salud, enfermedades crónicas, políticas y economía nacional. Universidad de Santander UDES. Rev de Investigación Cuidarte, 2(1), 245.

Gilliss, C. L. (1984). Reducing family stress during and after coronary artery bypass surgery. Nursing Clinics of North America, 19(1), 103-112.

Gilliss, C. L., Gortner, S. R., Hauck, W. W., Shinn, J. A., Sparacino, P. A., \& Tompkins, C. (1993). A randomized clinical trial of nursing care for recovery from cardiac surgery. Heart \& Lung: The Journal of Critical Care, 22(2), 125-133 
Giulio, M., Andrea, C., Jacopo, C., Rosanna, F., Angelo, M., Rossi, M., et al. (2016). Surgical Stress Reduction in Elderly Patients Undergoing Elective Colorectal Laparoscopic Surgery within an ERAS Protocol. Chirurgia, 111(6), 476-480. http://doi.org/10.21614/chirurgia.111.6.476

Glasper, E. R., \& DeVries, A. C. (2005). Social structure influences effects of pair-housing on wound healing. Brain, Behavior, and Immunity, 19(1), 61-68. http://doi.org/10.1016/j.bbi.2004.03.002

Goldenberg, I. I. (1971). Build me a Mountain: Youth, Poverty, and the Creation of New Settings. Oxford, England: Massachusetts Inst. of Technology P.

Goldstein, D. S., \& Eisenhofer, G. (2010). Sympathetic Nervous System Physiology and Pathophysiology in Coping with the Environment. In Comprehensive Physiology. Hoboken, NJ, USA: John Wiley \& Sons, Inc. http://doi.org/ 10.1002/cphy.cp070402

González, M. T., \& Landero Hernández, R. (2004). Variables psicosociales como predictoras de la salud en mujeres. Revista de Psicología Social, 19(3), 255-264. http://doi.org/10.1174/0213474041960504

Gortner, S. R., Gilliss, C. L., Shinn, J. A., Sparacino, P. A., Rankin, S., Leavitt, M., et al. (1988). Improving recovery following cardiac surgery: a randomized clinical trial. Journal of Advanced Nursing, 13(5), 649-61. http://doi.org/10.1111/j.1365-2648.1988.tb01459.x

Gottlieb, B. (1976). Lay influences on the utilization and provision of health services: A review. Canadian Psychological Review/Psychologie Canadienne, 17(2), 126.

Gottlieb, B. (1983). Social support as a focus for integrative research in psychology. American Psychologist, 38(3), 278.

Gracia, E., Herrero, J., \& Musitu, G. (1995). El apoyo social. Barcelona: PPU. Granziera, E., Guglieri, I., Del Bianco, P., Capovilla, E., Dona', B., Ciccarese, A. A., et al. (2013). A multidisciplinary approach to improve preoperative understanding and reduce anxiety: a randomised study. European Journal of Anaesthesiology, 30(12), 734-742. http://doi.org/10.1097/ EJA.0b013e3283652c0c

Greenspan S.F., Strewler J.G. (2000). Endocrinologia Básica \& Clínica. Río de Janeiro: Guanabara Koogan, 243-257.

Greszta, E., \& Sieminska, M. J. (2008). Relationship of preoperative anxiety-state and anxiety-trait in patients qualified for coronary artery 
bypass graft surgery to the perception of postoperative pain and other pain complaints. Annales Academiae Medicae Stetinensis, 54(1), 157-163.

Grieve, R. J., \& R.J., G. (2002). Day surgery preoperative anxiety reduction and coping strategies. British Journal of Nursing (Mark Allen Publishing), 11(10), 670-678. http://doi.org/10.12968/bjon.2002.11.10.670

Gurin, G., Veroff, J., \& Feld, S. (1960). Americans view their mental health: A nationwide interview survey. New york: Basic Books.

Gustafsson, U. O., Hausel, J., Thorell, A., Ljungqvist, O., Soop, M., Nygren, J., \& Enhanced Recovery After Surgery Study, G. (2011). Adherence to the enhanced recovery after surgery protocol and outcomes after colorectal cancer surgery. Archives of Surgery, 146(5), 571-577. http:// doi.org/10.1001/archsurg.2010.309

Hämäläinen, H., Smith, R., Puukka, P., Lind, J., Kallio, V., Kuttila, K., \& Ronnemaa, T. (2000). Social support and physical and psychological recovery one year after myocardial infarction or coronary artery bypass surgery. Scandinavian Journal of Public Health, 28(1), 62-70.

Hanson-Heath, C. A., Muller, L. M., \& Cunningham, M. F. (2016). Evaluating Enhancements to a Perioperative Nurse Liaison Program. AORN Journal, 103(4), 414-420. http://doi.org/10.1016/j.aorn.2016.01.017

Helgeson, V. S. (1993). Two Important Distinctions in Social Support: Kind of Support and Perceived Versus Received1. Journal of Applied Social Psychology, 23(10), 825-845.

Helgeson, V. S., \& Lopez, L. (2010). Social Support and Growth Following Adversity. Handbook of Adult Resilience., 309-330.

Heluy de Castro, C., Efigênia de Faria, T., Felipe Cabañero, R., Castelló Cabo, M., Castro, C. H. de, \& Faria, T. E. de (2004). Humanización de la Atención de Enfermería en el Quirófano. Index de Enfermería, 13(44-45), 18-20. Henderson, S. (1980). A Development in Social Psychiatry The Systematic Study of Social Bonds. The Journal of Nervous and Mental Disease, 168(2), 63-69.

Hendrich, A., Chow, M. P., Skierczynski, B. A., \& Lu, Z. (2008). A 36-hospital time and motion study: how do medical-surgical nurses spend their time? The Permanente Journal, 12(3), 25-34. http://doi.org/10.1186/ 1472-6963-11-319 
Hernández-Rodríguez, J. E., Díaz-Hernández, M., Chacón-Ferrera, R., \& Udaeta-Valdivieso, B. (1996). Influencia de la visita preoperatoria en la evolución postquirúrgica. Enfermería Científica, 174-175.

Hines, S., Munday, J., \& Kynoch, K. (2015). Effectiveness of nurse-led preoperative assessment services for elective surgery: a systematic review update. JBI database of systematic reviews and implementation reports, 13(6), 279-317. http://doi.org/10.11124/jbisrir-2015-1996

House, J. S. (1981). Social structure and personality. Social Psychology: Sociological Perspectives, 525-561.

House, J. S., Wells, J. A., Landerman, L. R., McMichael, A. J., \& Kaplan, B. H. (1979). Occupational Stress and Health among Factory Workers. Journal of Health and Social Behavior, 20(2), 139-160. http://doi.org/ $10.2307 / 2136435$

Jakobsen, D. H., Rud, K., Kehlet, H., Egerod, I., Hjort Jakobsen, D., Rud, K., et al. (2014). Standardising fast-track surgical nursing care in Denmark. British Journal of Nursing, 23(9), 471-476. http://doi.org/10.12968/ bjon.2014.23.9.471

Jeong, G., \& Kang, Y. (2016). The Effects of Music Therapy on Anxiety, Sedation, and Stress Responses of Patients Undergoing Surgery with Spinal Anesthesia. Korean Journal of Adult Nursing, 28(5), 525-535.

Jing, L.-S., Feng, J., Tang, F.-M., Ma, Y., Wang, H., \& Tan, H.-M. (2004). Comparison of effect of preoperative informational support system and normal psychological nursing intervention on the terrified anxiety of surgery patients. Chinese Journal of Clinical Rehabilitation, 8(18), 34783480.

Johansson, K., Nuutila, L., Virtanen, H., Katajisto, J., \& Salanterä, S. (2005). Preoperative education for orthopaedic patients: Systematic review. Journal of Advanced Nursing, 50(2), 212-223. http://doi.org/10.1111/ j.1365-2648.2005.03381.x

Johnson, M., Bulechek, G., Butcher, H., McCloskey-Dochterman, J., Maas, M., Moorhead, S., \& Swanson, E. (2006). Interrelaciones NANDA, NOC y NIC: diagnósticos enfermeros, resultados e intervenciones (Vol. 5). España: Elsevier.

Kaplan, B. H., Cassel, J. C., Gore, S., \& Purposes, B. (1977). Social support and health. Medical Care, 15(5), 47-58. 
Kervyn, N., Yzerbyt, V. Y., Judd, C. M., \& Nunes, A. (2009). A question of compensation: The social life of the fundamental dimensions of social perception. Journal of Personality and Social Psychology, 96(4), 828.

Kessler, R. R. C., Price, R. H., \& Wortman, C. B. (1985). Social factors in psychopathology: Stress, social support, and coping processes. Annual Review of Psychology, 36(1), 531-572.

King, L. a., Mattimore, L. K., King, D. W., \& Adams, G. a. (1995). Family support inventory for workers: A new measure of perceived social support from family members. Journal of Organizational Behavior, 16(3), 235-258. http://doi.org/10.1002/job.4030160306

Klein, M. (1948). Sobre la teoría de la ansiedad y la culpa. Obras Completas, Desarrollos En Psicoanálisis, 235-251.

Klein, M., Segal, H., \& Grinberg, L. (1987). El psicoanálisis de niños. Buenos Aires, Argentina: El Ateneo.

Koivula, M., Paunonen-IImonen, M., Tarkka, M. T., Tarkka, M., \& Laippala, P. (2001). Fear and anxiety in patients awaiting coronary artery bypass grafting. Heart \& Lung: The Journal of Critical Care, 30(4), 302-11. http://doi.org/10.1067/mhl.2001.116134

Krohne, H. W. H., \& Slangen, K. E. (2005). Influence of social support on adaptation to surgery. Health Psychology: Official Journal of the Division of Health Psychology, American Psychological Association, 24(1), 101-5. http://doi.org/10.1037/0278-6133.24.1.101

Kulik, J., \& Mahler, H. (1989). Social support and recovery from surgery. Health Psychology, 8(2), 221

Landeta, O., \& Breva, A. (2000). Evolución Histórica en el Estudio del Apoyo Social. Revista de historia de la psicología, 21(2-3), 589-596.

Langer, E., Janis, I., \& Wolfer, J. (1975). Reduction of psychological stress in surgical patients. Journal of Experimental Social Psychology, 11(2), 155-165. Lazarus, R. S. \& Folkman, S. (1986). Estrés y procesos cognitivos. Barcelona, España: Ed. Martínez-Roca.

Leinonen, T., \& Leino-Kilpi, H. (1999). Research in peri-operative nursing care. Journal of Clinical Nursing, 8(2), 123-138. http://doi.org/10.1046/ j.1365-2702.1999.00239.x

Lenz Oscar, B. (2011). Bioseguridad en quirófano y procedimientos. Revista de Actualización Clínica, 15, 880-885. 
Leske, J. S. S. (1993). Anxiety of elective surgical patients' family members. Relationship between anxiety levels, family characteristics. AORN Journal, 57(5), 1091-1092,1096-1103.

Levandovski, R., Cardoso Ferreira, M. B., Loayza Hidalgo, M. P., Konrath, C. A., Lemons da Silva, D., Caumo, W., et al. (2008). Impact of preoperative anxiolytic on surgical site infection in patients undergoing abdominal hysterectomy. American Journal of Infection Control, 36(10), 718-726. http://doi.org/10.1016/j.ajic.2007.12.010

Li-Pin, C., Heng-Hsin, T., Kuan-Chia, L., Yu-Wei, L., Yi-Chun, C., Saint ShiouSheng, C., \& Allen W, C. (2016). Effectiveness of stress management in patients undergoing transrectal ultrasound-guided biopsy of the prostate. Patient Preference and Adherence, 10, 147-52. http://doi.org/ 10.2147/PPA.S96991

Li-Ying, L., \& Ruey-Hsia, W. (2005). Abdominal surgery, pain and anxiety: preoperative nursing intervention. Journal of Advanced Nursing, 57(53), 252-260.

Lim, Y., Suh, I., \& Chung, S. (2010). Effects of surgery information service on one-day surgery patients' anxiety and satisfaction with nursing care. Korean Journal of Adult Nursing, 22(1), 1-10.

Lin, N., Ensel, W. M., \& Dean, A. (1986). The age structure and the stress process. Social Support, Life Events, and Depression, 213-230.

Lin, N., Ye, X., \& Ensel, W. M. (1999). Social support and depressed mood: A structural analysis. Journal of Health and Social Behavior, 40(4), 344359. http://doi.org/10.2307/2676330

Lindenfield, G. (2003). La seguridad emocional. Como conocer y manejar los propios sentimientos. Barcelona, España: Kairó.

Liu, C. Y., Xu, L., \& Zang, Y. L. (2014). Effectiveness of audiovisual interventions on stress responses in adolescents with ENT surgery in hospital: Randomized controlled trial protocol. Journal of Advanced Nursing, 70(6), 1414-1424. http://doi.org/10.1111/jan.12295

Livhits, M., Mercado, C., Yermilov, I., Parikh, J. a., Dutson, E., Mehran, a., et al. (2011). Is social support associated with greater weight loss after bariatric surgery?: A systematic review. Obesity Reviews, 12(2), 142-8. http://doi.org/10.1111/j.1467-789X.2010.00720.x 
Lobo, D. R., López-cortijo, C., De la fuente, R., Laguna, D., Pinilla, M., \& Górriz, C. (2003). Cirugía endoscópica nasosinusal: revisión de 1093 casos. Acta Otorrinolaringológica Española, 54(6), 435-440. http://doi.org/ 10.1016/S0001-6519(03)78433-7

López-Navas, A., Ros, A., Riquelme, A., Martnez-Alarcn, L., Pons, J. A., Miras, M., et al. (2011). Psychological care: Social and family support for patients awaiting a liver transplant. In Transplantation Proceedings (Vol. 43, pp. 701-704). Elsevier. http://doi.org/10.1016/j.transproceed.2011.01.095

Luis Rodrigo, M. T. (2008). Los diagnósticos enfermeros revisión critica y guîa práctica. Barcelona, España: Edic. Masson.

Machado-Alba, J. E., Machado-Duque, M. E., Flórez, V. C., Montoya, A. G., Escobar, F. C., Ruiz, R., \& Catano, J. M. (2013). Estamos controlando el dolor posquirurgico? Revista Colombiana de Anestesiologia, 41(2), 132138. http://doi.org/10.1016/j.rca.2013.02.001

MacLeod, C., \& Rutherford, E. (2004). Information-processing approaches. Generalized anxiety disorder: Advances in research and practice, 109-142. Maguire, P., Brooke, M., Tait, A., Thomas, C., \& Sellwood, R. (1983). The effect of counselling on physical disability and social recovery after mastectomy. Clinical oncology, 9(4), 319-324.

Maidana, P., Bruno, O. D., \& Mesch, V. (2013). Medición de cortisol y sus fracciones: Una puesta al día. Medicina (Buenos Aires), 73(6),579-584.

Maligalig, R. M. (1994). Parents' perceptions of the stressors of pediatric ambulatory surgery. Journal of Post Anesthesia Nursing, 9(5), 278-282. Manterola, C., Asenjo-Lobos, C., \& Otzen, T. (2014). [Hierarchy of evidence: levels of evidence and grades of recommendation from current use]. Revista Chilena de Infectología: Órgano Oficial de La Sociedad Chilena de Infectología, 31(6), 705-18. http://doi.org/10.4067/S0716-1018201400 0600011

Manzano-García, G., \& Ayala-Calvo, J. C. (2014). An overview of nursing in Europe: A SWOT analysis. Nursing Inquiry, 27(4), 358-367. http:// doi.org/10.1111/nin.12069

Martín Abreu, L., \& Pérez Vela, J. (2004). Cirugía para el estudiante y el médico general. Mexico: Méndez Editores.

Martín Díaz, J. F., Hidalgo Gutiérrez, M. J., Cerezo Solana, M. F., Casas Carriazo, M. J., \& Martín Morcillo, J. (2012). Efectividad de una intervención 
enfermera durante la transfusión de concentrados de hematíes sobre la ansiedad estado del paciente receptor. Nure Investigación, (58), 1-5. Martínez, F., \& Ochoa Güerre, S. (2000). Redes sociales de personas con esquizofrenia. Cuadernos de Trabajo Social, (13), 299-322.

Mathews, A. (2015). Cognitive Vulnerability to Emotional Disorders. Annu. Rev. Clin. Psychol. 1, 167-195. http://doi.org/10.1146/annurev.clinpsy.1.10 2803.143916

Mathews, A., \& Mackintosh, B. (1998). A Cognitive Model of Selective Processin g in Anxiety. Therapy, 22(6), 539-560. http://doi.org/10.1023/ A:1018738019346

Maward L., \& Azar, N. (2004). Comparative study of anxiety in informed and non-informed patients in the preoperative period. In Recherche en soins infirmiers, (78), 35-58.

Maxwell, S. (1999). The Meaning and Measurement of Poverty. Poverty Briefing. Londres, Reino Unido: Overseas Development Institute.

McDonald, S., Mj, P., Beringer, K., Wasiak, J., Sprowson, A., Hetrick, S. E., et al. (2014). Pre-operative education for hip or knee replacement. The Cochrane Library, (5). http://doi.org/http://dx.doi.org.libproxy.lib.unc.edu/ 10.1002/14651858.CD003526.pub3

McEwen, B. S. (2007). Physiology and Neurobiology of Stress and Adaptation: Central Role of the Brain. Physiological Reviews, 87(3), 873-904. http://doi.org/10.1152/physrev.00041.2006

Meichenbaum, D. H. (1972). Cognitive modification of test anxious college students. Journal of Consulting and Clinical Psychology, 39(3), 370. Menéndez Villalva, C., Montes Martínez, A., Gamarra Mondelo, T., Núñez Losada, C., Alonso Fachado, A., \& Bujan Garmendia, S. (2003). Influencia del apoyo social en pacientes con hipertensión arterial esencial. Atención Primaria, 37(8), 506-513. http://doi.org/10.1016/S0212-6567 (03)70724-0

Merino, M. (2013). NANDA Internacional: Diagnosticos Enfermeros. Definiciones y Clasificación 2012-2014. España: Nuberos Científica.

Mitchell, M. (2007). Psychological care of patients undergoing elective surgery. Nursing Standard, 27(30), 48-55.

Mitra, R., Jadhav, S., McEwen, B. S., Vyas, A., \& Chattarji, S. (2005). Stress duration modulates the spatiotemporal patterns of spine formation 
in the basolateral amygdala. Proceedings of the National Academy of Sciences of the United States of America, 102(26), 9371-9376.

Mitte, K. (2008). Memory bias for threatening information in anxiety and anxiety disorders: a meta-analytic review. Psychological Bulletin, 134(6), 886-911. http://doi.org/10.1037/a0013343

Mogg, K., \& Bradley, B. P. (1998). A cognitive-motivational analysis of anxiety. Behaviour Research and Therapy, 36(9), 809-48.

Mogg, K., \& Bradley, B. P. (2005). Attentional bias in generalized anxiety disorder versus depressive disorder. Cognitive Therapy and Research, 29(1), 29-45. http://doi.org/DOI 10.1007/s10608-005-1646-y

Morales Asencio, J. M. (2004). Investigación de Resultados en Enfermería:

El camino hacia la efectividad de los cuidados. Index de Enfermería, 13(44-45), 37-41.

Moskovitz, M., \& Maunder, R. (2000). Coping behavior and social support contribute independently to quality of life after surgery for inflammatory bowel disease. Diseases of the colon \& rectum, 43(4), 517-521.

Murphy, L. B., \& Moriarty, A. E. (1976). Vulnerability, coping and growth from infancy to adolescence. Libertas academica 17(3), 549-551. https://doi.org/ 10.1016/S0002-7138(09)62311-6

NANDA International. (2015). Diagnósticos enfermeros. Definiciones y clasificación 2015-2017. (T. H. Herdman \& S. Kamitsuru, Eds.). Barcelona. España: Elsevier.

Nazar, R., Cabrera, N., \& Naser, A. (2013). Septoplastía endoscópica Endoscopic septoplasty. Rev. Otorrinolanringol. Cir. Cabeza Cuello, 73, 288-294.

Neabel, B., Fothergill-Bourbonnais, F., \& Dunning, J. (2000). Family assessment tools: a review of the literature from 1978-1997. Heart \& Lung: The Journal of Critical Care, 29(3), 196-209. http://doi.org/ 10.1067/mhl.2000.106938

Neuling, S., \& Winefield, H. (1988). Social support and recovery after surgery for breast cancer: frequency and correlates of supportive behaviours by family, friends and surgeon. Social Science \& Medicine, 27(4), 385392.

Ng, S. K. S., Chau, A. W. L., \& Leung, W. K. (2004). The effect of pre-operative information in relieving anxiety in oral surgery patients. Community Dentistry and Oral Epidemiology, 32(3), 227-235. http://doi.org/ 10.1111/j.1600-0528.2004.00161.x 
Norbeck J. S., Lindsey, C. (1981). The development of an instrument to measure social support. Nursing Research, 264-269.

Norbeck, J. S. (1981). Social support: A model for clinical research and application. Advances in Nursing Science, 7, 43-59.

Norbeck, J. S., DeJoseph, J. F., \& Smith, R. T. (1996). A randomized trial of an empirically-derived social support intervention to prevent low birthweight among African American women. Social Science \& Medicine, 43(6), 947-954. http://doi.org/10.1016/0277-9536(96)00003-2

Norbeck, J. S., \& Peterson, T. V. (1983). Life Stress, Social Support, and Emotional Disequilibrium in Complications of Pregnancy: A Prospective, Multivariate Study. Journal of Health and Social Behavior, 24(1), 30-46.

Norbeck, J.S., Tilden, V. P., JS, N., \& VP, T. (1988). International nursing research in social support: theoretical and methodological issues. Journal of Advanced Nursing, 13(2), 173-178. http://doi.org/10.1111/j.13652648.1988.tb01405.x

Norris, F. H., \& Kaniasty, K. (1996). Received and perceived social support in times of stress: a test of the social support deterioration deterrence model. Journal of Personality and Social Psychology, 71(3), 498.

O'Reilly, P. (1988). Methodological issues in social support and social network research. Social Science \& Medicine, 26(8), 863-873. http://doi.org/ 10.1016/0277-9536(88)90179-7

Ornaque, I., Carrero, E., Villalonga, A., Roux, C., \& Salvador, L. (2000). Study of presurgical anxiety in urologic, gynecologic, and ophthalmologic surgery as a function of the administration or non-administration of anxiolytic premedication. Revista Española de Anestesiologia y Reanimacion, 47(4), 151-6.

Orth-Gomér, K. (1994). International epidemiological evidence for a relationship between social support and cardiovascular disease. Social Support and Cardiovascular Disease. Boston, Estados Unidos: Springer US.

Ortiz, F. E. (2006). El estrés del cirujano. Revista Argentina de Cirugía, 90(5/6), 211-222.

Paiva, L., Rossi, L. A., Costa, M. C. S., \& Dantas, R. A. S. (2010). The Experiences and Consequences of a Multiple Trauma Event from the Perspective of the Patient. Revista Latino-Americana de Enfermagem, 18(6), 1221-1228. http://doi.org/10.1590/S0104-11692010000600024 
Pasero, C., \& Belden, J. (2006). Evidence-Based Perianesthesia Care: Accelerated Postoperative Recovery Programs. Journal of PeriAnesthesia Nursing, 21(3), 168-176. http://doi.org/http://doi.org/10.1016/j.jopan. 2006.03.010

Payne, R.L., \& Jones, J.G. (1987). Measurement and methodological issues in social support. Stress and Health: Issues in Research Methodology, 167-205. Pearlin, L. I., Menaghan, E. G., Lieberman, M. A., \& Mullan, J. T. (1981). The stress process. Journal of Health and Social Behaviour, 22, 337-356.

Pichot, P. (1995). Los conceptos de trastorno del estado de ánimo y de ansiedad: evolución histórica. Átopos, 4-13.

Pierantognetti, P., Covelli, G., \& Vario, M. (2002). Anxiety, stress and preoperative surgical nursing. Professioni infermieristiche, 55(3), 180-191.

Pierce, G. R., Sarason, I. G., \& Sarason, B. R. (1996). Coping and social support. Handbook of coping. New york, Estados Unidos: Wiley.

Possari, J. F. (2004). Sistematização da Assistência de Enfermagem Perioperatória. Possari JF. Centro Cirúrgico: Planejamento, Organização e Gestão. São Paulo: látria, 209-232.

Price, E. O., \& Thos, J. (1980). Behavioral responses to short-term social isolation in sheep and goats. Applied Animal Ethology, 6(4), 331-339.

Pritchard, M. J. (2009). Managing anxiety in the elective surgical patient. British Journal of Nursing (Mark Allen Publishing), 18(7), 416-9. http:// doi.org/10.12968/bjon.2009.18.7.41655

Rezaei, T., Azarfarin, R., Totonchi, Z., Bakhshandeh, H., Alizadehas, A., \& Fakhari, S. (2017). Effects of a nursing supportive program on anxiety and stress levels in the family members of patients after cardiac surgery in the ICU. Iranian Heart Journal, 17, 36-41.

Rhodes, L., Nash, C., Moisan, A., Scott, D. C., Barkoh, K., Warner, W. C., et al. (2014). Does Preoperative Orientation and Education Alleviate Anxiety in Posterior Spinal Fusion Patients? A Prospective, Randomized Study. Journal of Pediatric Orthopedics, 35(3), 1-4. http://doi.org/ 10.1097/ BPO.0000000000000260

Rivera-Romero V., Pastoriza-Galán P., Díaz-Perianez C., Hilario-Huapaya N. (2013). Revisión crítica de la taxonomía enfermera NANDA internacional 2009-2011. Revista Científica de Enfermería, (6), 6-18. http:// doi.org/10.14198/recien.2013.06.07 
Robles, T. F. (2007). Stress, Social Support, and Delayed Skin Barrier Recovery. Psychosomatic Medicine, 69, 807-815. http://doi.org/10.1097/ PSY.0b013e318157b12e

Rojas, M. J., \& Pérez, D. A. (2013). Estrategia de enfermería para disminuir los niveles de ansiedad en pacientes sometidos a intervención quirúrgica en el hospital universitario antonio patricio de alcalá, cumana, venezuela. SABER. Revista Multidisciplinaria Del Consejo de Investigación de La Universidad de Oriente, 25(3), 273-278.

Roman, C., \& Hernandez, Y. (2011). El estrés académico:Una revisión crítica del concepto desde las ciencias de la educación. Revista Electronica de Psicologia Iztacala, 14(2), 1-14.

Rosenberger, P. H., Jokl, P., \& Ickovics, J. (2006). Psychosocial factors and surgical outcomes: an evidence-based literature review. The Journal of the American Academy of Orthopaedic Surgeons, 14(7), 397-405. http://doi.org/10.1017/CBO9781107415324.004

S. Moscoso, M. (2009). De la mente a la célula: impacto del estrés en psiconeuroinmunoendocrinologia. Liberabit, 15(2), 143-152.

Sadati, L., Pazouki, A., Mehdizadeh, A., Shoar, S., Tamannaie, Z., Chaichian, S., et al. (2013). Effect of preoperative nursing visit on preoperative anxiety and postoperative complications in candidates for laparoscopic cholecystectomy: A randomized clinical trial. Scandinavian Journal of Caring Sciences, 27(4), 994-998. http://doi.org/10.1111/ scs.12022

Salmon, P. (1993). The reduction of anxiety in surgical patients: an important nursing task or the medicalization of preparatory worry? International Journal of Nursing Studies, 30(4), 323-330.

Salmon, P. (1992). Psychological factors in surgical stress: Implications for management. Clinical Psychology Review, 12(7), 681-704. http:// doi.org/10.1016/0272-7358(92)90020-9.

Salleras Sanmartí, L. (1990). Educación sanitaria: principios, métodos y aplicaciones. Madrid, España: Ediciones Díaz de Santos.

Samaranch, F. de P. (1991). Cuatro ensayos sobre Aristóteles: política y ética, metafísica. Madrid, España: Fondo de Cultura Económica.

Sandler, I. N. (1980). Social support resources, stress, and maladjustment of poor children. American Journal of Community Psychology, 8(1), 41-52. 
Sarason, B. R., Sarason, I. G., \& Pierce, G. R. (1990). Social support: An interactional view. New York, Estados Unidos: John Wiley \& Sons.

Sarason, B. B. R., Sarason, I. G. I., Hacker, T. A., \& Basham, R. B. (1985). Concomitants of social support: Social skills, physical attractiveness, and gender. Journal of Personality and Social Psychology, 49(2), 469.

Sarason, I. G., \& Sarason, B. R. (Eds.). (1985). Social support: Theory, research and applications. The Hague, The Netherlands: Martinus Nijhof.

Sarason, I. G.. Levine, H. M., Basham, R. B., \& Sarason, B. R. (1983). Assessing social support: The social support questionnaire. Journal of Personality and Social Psychology, 44, 127-139.

Schoenbach, V. J., Kaplan, B. H., Fredman, L., \& Kleinbaum, D. G. (1986). Social ties and mortality in Evans County, Georgia. American Journal of Epidemiology, 123, 577-591.

Scott, N. B. (2012). Enhanced recovery after surgery- the way forward. Regional Anesthesia and Pain Medicine, 37(5), 128-131. http://doi.org/ 10.1097/AAP.0b013e31826a8366

Selye, H. (1956). The stress of life. New York. United State of America: McGraw-Hill Paperbacks.

Selye, H. (1965). The Stress Syndrome. The American Journal of Nursing, 65(3), 97-99. http://doi.org/10.2307/3453119

Selye, H. (1973). The evolution of the stress concept: The originator of the concept traces its development from the discovery in 1936 of the alarm reaction to modern therapeutic applications of syntoxic and catatoxic hormones. American Scientist, 67(6), 692-699. http://doi.org/10.2307/27844072

Sherbourne, C. D. (1988). The role of social support and life stress events in use of mental health services. Social Science \& Medicine (1982), 27(12), 1393-400. http://doi.org/10.1016/0277-9536(88)90205-5

Sherbourne, C. D., \& Stewart, A. L. (1991). The MOS social support survey. Social Science \& Medicine, 32(6), 705-714. http://doi.org/10.1016/02779536(91)90150-B

Shumaker, S. A., \& Brownell, A. (1984). Toward a theory of social support: Closing conceptual gaps. Journal of Social Issues, 40(4), 11-36.

Sierra, J. C., Ortega, V., \& Zubeidat, I. (2003). Ansiedad, angustia y estrés: tres conceptos a diferenciar. Revista Mal Estar E, 3(1), 10-59. http:// doi.org/10.1093/med/9780199380183.003.0001 
Silva, M. C. (1979). Effects of orientation information on spouses' anxieties and attitudes toward hospitalization and surgery. Research in Nursing \& Health, 2(3), 127-136. http://doi.org/10.1002/nur.4770020308

Spielberger, C. D. (1972). Conceptual and methodological issues in anxiety research. Anxiety: Current Trends in Theory and Research, 2, 481-493.

Spielberger, C., Gorsuch, R., Lushene, R., \& Vagg, P. (1983). State-Trait Anxiety Inventory (STAI). BiB 2010.

Stefan, K. A. (2010). The Nurse Liaison in Perioperative Services: A Family-Centered Approach. AORN Journal, 92(2), 150-157. http://doi.org/ http://doi.org/10.1016/j.aorn.2009.11.070

Tang, Y., Wan, P., \& Qu, D. (2015). The effects of psychological nursing on anxiety of patients in the procedure of impacted teeth extraction. Shanghai Journal of Stomatology, 24(3), 367-9.

Tardy, C. H. (1985). Social support measurement. American Journal of Community Psychology, 13(2), 187-202. http://doi.org/10.1007/BF00905728 Terol M, Lopez, S., Neipp, M. M. del C. M., Rodríguez, J. J. J., Pastor, A., Martín-Aragon, M., et al. (2004). Apoyo social e instrumentos de evaluación: revisión y clasificación. Anuario de Psicología, 35(1), 23-46.

Thoits, P. A. (1982). Conceptual, methodological, and theoretical problems in studying social support as a buffer against life stress. Journal of Health and Social Behavior, 23(2), 145-159. http://doi.org/10.2307/ 2136511

Thorsteinsson, E. B., \& James, J. E. (1999). A Meta-analysis of the effects of experimental manipulations of social support during laboratory stress. Psychology \& Health, 14(5), 869-886. http://doi.org/10.1080/ 08870449908407353

Tomlinson, P. S., Peden-McAlpine, C., \& Sherman, S. A family systems nursing intervention model for paediatric health crisis, 68 Journal of Advanced Nursing 705-714 (2012). http://doi.org/10.1111/j.1365-2648. 2011.05825.x

Torres, L., \& Morales, J. (2004). Participación familiar en el cuidado del paciente crítico: recomendaciones de la Sociedad Andaluza de Enfermería de Cuidados Críticos. Tempus Vitalis. Rev Intern Cuid Pac Crit, 1, 18-25. Tous-Ral, J.M. \& Pueyo, A.A. (1991). Inventario Diferencial de Adjetivos para el Estudio del Estado de Animo (IDDA-EA). Madrid, España:TEA Ediciones. 
Triviño, Z., \& Sanhueza, O. (2005). Paradigmas de investigación en enfermería. Ciencia y Enfermería, 11(1), 17-24.

Tully, P. J., Bennetts, J. S., Baker, R. A., McGavigan, A. D., Turnbull, D. A., \& Winefield, H. R. (2011). Anxiety, depression, and stress as risk factors for atrial fibrillation after cardiac surgery. Heart \& Lung: The Journal of Critical Care, 4O(1), 4-11. http://doi.org/10.1016/j.hrtlng.2009.12.010 Uchino, B., Cacioppo, J., \& Kiecolt-Glaser, J. (1996). The relationship between social support and physiological processes: A review with emphasis on underlying mechanisms and implications for health. Psychological Bulletin, 119(3), 488-531. http://doi.org/10.1037/0033-2909.119.3.488

Vaillant, G. E. (1977). Health consequences of adaptation to life. The American journal of medicine, 67(5), 732-734.

Vargas, T., Maia, E., \& Dantas, R. (2006). Patient feelings during the preoperative period for cardiac surgery. Revista Latino-Americana de Enfermagem, 14(3), 383-388.

Vaux, A. (1988). Social support: theory, research, and intervention. New York. England: Praeger.

Vega Angarita, O. M., \& González Escobar, D. S. (2009). Apoyo social: elemento clave en el afrontamiento de la enfermedad crónica. Enfermería Global, (16). http://doi.org/10.4321/S1695-61412009000200021

Vinaccia, S., \& Quiceno, J. (2014). Calidad de vida, personalidad resistente y apoyo social percibido en pacientes con diagnóstico de cáncer pulmonar. Psicología y... 15(2), 207-220.

Visintainer, M. A., \& Wolfer, J. A. (1975). Psychological preparation for surgery pediatric patients: the effects on children's and parents' stress responses and adjustment. Pediatrics, 56(2), 187-202.

Walburn, J., Vedhara, K., Hankins, M., Rixon, L., \& Weinman, J. (2009). Psychological stress and wound healing in humans: a systematic review and meta-analysis. Journal of psychosomatic research, 67(3),253-271. http://doi.org/10.1016/j.jpsychores.2009.04.002

Wallace, L. M. (1986). Pre-operative state anxiety as a mediator of psychological adjustment to and recovery from surgery. The British Journal of Medical Psychology, 59(3), 253-61.

Walster, E. H., Walster, G. W., \& Berscheid, E. (1978). Equity: Theory and research. Boston: Allyn \& Bacon. 
Weiss, R. (1974). The Provisions of Social Relationships. Doing Unto Others. Weissman, C. (1990). The metabolic response to stress: An overview and update. Anesthesiology, 73(2), 308-327. http://doi.org/10.1097/00000542199008000-00020

Williams, J. M., Watts, F. N., MacLeod, \& Mathews, A. (1997). Cognitive psychology and emotional disorders. Oxford, England: John Wiley \& Sons.

Winemiller, D. R., Mitchell, M. E., Sutliff, J., \& Cline, D. J. (1993). Measurement strategies in social support: a descriptive review of the literature. Journal of Clinical Psychology, 49, 638-648. http://doi.org/10.1002/ 1097-4679

Wu, D., Chen, Y., Wu, Y., Li, H., Fu, M., \& Liu, Y. (2015). Application of Preoperative Visits during the Perioperative Period of Ophthalmic Surgery. Eye science, 30(2), 56-59.

Xie, L.-Q., Deng, Y.-L., Richmond, C. J., Zhang, J.-P., Tang, Y., Zhou, J., et al. (2016). Effects of Progressive Muscle Relaxation Intervention in Extremity Fracture Surgery Patients. Western Journal of Nursing Research, 38(2), 155-168. http://doi.org/10.1177/0193945914551509

Zhou, K., Li, X., Li, J., Liu, M., Dang, S., Wang, D., \& Xin, X. (2015). A clinical randomized controlled trial of music therapy and progressive muscle relaxation training in female breast cancer patients after radical mastectomy: results on depression, anxiety and length of hospital stay. European Journal of Oncology Nursing: The Official Journal of European Oncology Nursing Society, 19(1), 54-59. http://doi.org/10.1016/ j.ejon.2014.07.010 

ANEXO I.
INSTRUMENTOS
DE EVALUACIÓN 


\section{Cuestionario I. Cuestionario Inventario Diferencial de Adjetivos para el Estudio del Estado de Ánimo (IDDA-EA)}

Debajo de este texto, observará una lista de pares de adjetivos separados por siete cuadros horizontales. Ponga una $\mathrm{X}$ donde crea oportuno, según el estado en el que se encuentre en este momento.

\begin{tabular}{|c|c|c|c|c|c|c|c|c|}
\hline \multicolumn{7}{|c|}{ EJEMPLO } \\
\hline & MUCHO & BASTANTE & POCO & NADA & POCO & BASTANTE & MUCHO & \\
\hline JOVEN & & $\mathbf{X}$ & & & & & & VIEJO \\
\hline
\end{tabular}

Si Vd. Ha contestado de este modo es porque su estado de ánimo le hace pensar que se siente BASTANTE JOVEN

\begin{tabular}{|c|c|c|c|c|c|c|c|c|}
\hline & $\mathrm{MUCHO}$ & BASTANTE & $\mathrm{POCO}$ & NADA & POCO & BASTANTE & $\mathrm{MUCHO}$ & \\
\hline 1DÉBIL & & & & & & & & ENÉRGICO \\
\hline 2 CANSADO & & & & & & & & FRESCO \\
\hline 3 RELAJADO & & & & & & & & TENSO \\
\hline 4 MOVILIZADO & & & & & & & & INMOVILIZADO \\
\hline 5 ENDEBLE & & & & & & & & VIGOROSO \\
\hline 6 ADORMILADO & & & & & & & & DESVELADO \\
\hline 7 IMPACIENTE & & & & & & & & \begin{tabular}{|l} 
INDIFERENTE \\
\end{tabular} \\
\hline 8 QUIETO & & & & & & & & INQUIETO \\
\hline 9 PASMADO & & & & & & & & VIVAZ \\
\hline 10 AMODORRADO & & & & & & & & DESPEJADO \\
\hline 11 AGITADO & & & & & & & & SERENO \\
\hline 12 INTRANQUILO & & & & & & & & PLÁCIDO \\
\hline 13 DESBORDANTE & & & & & & & & SOBRIO \\
\hline 14 ATONTADO & & & & & & & & DESPABILADO \\
\hline 15 APRESURADO & & & & & & & & LENTO \\
\hline 16 ALTERADO & & & & & & & & REPOSADO \\
\hline 17 ACTIVO & & & & & & & & PASIVO \\
\hline 18 DESPIERTO & & & & & & & & DORMIDO \\
\hline 19 DECIDIDO & & & & & & & & INDECISO \\
\hline 20 CALMADO & & & & & & & & EXALTADO \\
\hline 21 ABATIDO & & & & & & & & ANIMADO \\
\hline 22 FLOJO & & & & & & & & FUERTE \\
\hline 23 SOSEGADO & & & & & & & & COMBATIVO \\
\hline 24 ACTIVADO & & & & & & & & ENLENTECIDO \\
\hline 25 ORDENADO & & & & & & & & ALBOROTADO \\
\hline 26 TOLERANTE & & & & & & & & INTOLERANTE \\
\hline 27 FATIGADO & & & & & & & & DESCANSADO \\
\hline 28 ALERTA & & & & & & & & ALETARGADO \\
\hline
\end{tabular}

\section{IMPORTANTE}

\section{No ponga más de una señal entre cada par de adjetivos.}

Conteste a todos los pares de adjetivos, aunque para ello deba señalar la casilla Nada. Si tiene alguna duda consúltela en cualquier momento. 


\section{Cuestionario II. Cuestionario Ansiedad Estado y Formulario Datos socio- demográficos}

A continuación encontrará unas frases que se utilizan corrientemente para describirse uno a sí mismo.

Lea cada frase y proceda como en el cuestionario anterior para indicar CóMO SE SIENTE VD AHORA MISMO, EN ESTE MOMENTO. No hay respuestas buenas ni malas. No emplee demasiado tiempo en cada frase y conteste señalando la respuesta que mejor describa su situación presente.

\begin{tabular}{|l|l|l|l|l|}
\hline & NADA & ALGO & BASTANTE & MUCHO \\
\hline 1 ME SIENTO CALMADO & & & & \\
\hline 2 ME SIENTO SEGURO & & & & \\
\hline 3 ESTOY TENSO & & & & \\
\hline 4 ESTOY CONTRARIADO & & & & \\
\hline 5 ME SIENTO CÓMODO (ESTOY A GUSTO) & & & & \\
\hline 6 ME SIENTO ALTERADO & & & & \\
\hline 7 ESTOY PREOCUPADO AHORA POR POSIBLES DESGRACIAS FUTURAS & & & & \\
\hline 8 ME SIENTO DESCANSADO & & & & \\
\hline 9 ME SIENTO ANGUSTIADO & & & & \\
\hline 10 ME SIENTO CONFORTABLE & & & & \\
\hline 11 TENGO CONFIANZA EN MI MISMO & & & & \\
\hline 12 ME SIENTO NERVIOSO & & & & \\
\hline 13 ESTOY DESASOSEGADO & & & & \\
\hline 14 ME SIENTO MUY ATADO (COMO OPRIMIDO) & & & & \\
\hline 15 ESTOY RELAJADO & & & & \\
\hline 16 ME SIENTO SATISFECHO & & & & \\
\hline 17 ESTOY PREOCUPADO & & & & \\
\hline 18 ME SIENTO ATURDIDO Y SOBREEXCITADO & & & & \\
\hline 19 ME SIENTO ALEGRE & & & & \\
\hline 20 EN ESTE MOMENTO ME SIENTO BIEN & & & & \\
\hline
\end{tabular}

Rellene los siguientes datos personales, en cumplimiento de lo dispuesto en el artículo 5 de la Ley Orgánica 15/1999 de Protección de Datos de Carácter Personal, por el que se regula el derecho de información en la recogida de los datos, le informamos que los datos de carácter personal facilitados en el presente formulario, se incluirán y serán tratados con confidencialidad y seguridad en ficheros. Datos Personales: (marque con un círculo)

Sexo: H M Edad: Fumador: NO Sí Cigarrillos al día:

Estado civil: soltero casado unión estable divorciado viudo

Ocupación: Empleado Desempleado Jubilado

Nivel de estudios: Sin estudios Estudios primarios FP grado medio

Educación secundaria FP grado superior Estudios universitario 


\section{Cuestionario III. Cuestionario Ansiedad Rasgo}

A continuación encontrará unas frases que se utilizan corrientemente para describirse uno a sí mismo.

Lea cada frase y proceda como en el cuestionario anterior para indicar COMO SE SIENTE USTED EN GENERAL. No hay respuestas buenas ni malas. No emplee demasiado tiempo en cada frase y conteste señalando la respuesta que mejor describa su situación presente.

\begin{tabular}{|l|l|l|l|l|}
\hline 21 ME SIENTO BIEN & CASI NUNCA & A VECES & A MENUDO & CASI SIEMPRE \\
\hline 22 ME CANSO RÁPIDAMENTE & & & & \\
\hline 23 SIENTO GANAS DE LLORAR & & & & \\
\hline 24 ME GUSTARÍA SER TAN FELIZ COMO OTROS & & & & \\
\hline 25 PIERDO OPORTUNIDADES POR NO DECIDIRME PRONTO & & & & \\
\hline 26 ME SIENTO DESCANSADO & & & & \\
\hline 27 SOY UNA PERSONA TRANQUILA, SERENA Y SOSEGADA & & & & \\
\hline 28 VEO QUE LAS DIFICULTADES SE AMONTONAN Y NO PUEDO CON ELLAS & & & & \\
\hline 29 ME PREOCUPO DEMASIADO POR COSAS SIN IMPORTANCIA & & & & \\
\hline 30 SOY FELIZ & & & & \\
\hline 31 SUELO TOMAR LAS COSAS DEMASIADO SERIAMENTE & & & \\
\hline 32 ME FALTA CONFIANZA EN MI MISMO & & & & \\
\hline 33 ME SIENTO SEGURO & & & & \\
\hline 34 EVITO ENFRENTARME A LAS CRISIS O A LASDIFICULTADES & & & \\
\hline 35 ME SIENTO TRISTE (MELANCÓLICO) & & & & \\
\hline 36 ESTOY SATISFECHO & & & & \\
\hline 37 ME RONDAN Y MOLESTAN PENSAMIENTOS SIN IMPORTANCIA & & & & \\
\hline 38 ME AFECTAN TANTO LOS DESENGAÑOS, QUE NO PUEDO OLVIDARLOS & & & & \\
\hline 39 SOY UNA PERSONA ESTABLE & & & & \\
\hline 40 CUANDO PIENSO SOBRE ASUNTOS Y PREOCUPACIONES ACTUALES, & & & \\
\hline ME PONGO TENSO Y AGITADO & & & & \\
\hline
\end{tabular}




\section{Cuestionario IV. Escala de Vínculos Interpersonales de Apoyo (VIDA)}

A continuación aparecen una serie de afirmaciones sobre el apoyo social que usted percibe tener. Para cada cuestión señale con una X su opinión referida a sus .... (Según la escala poner: familiares, amigos o personas relevantes) de acuerdo a estas categorías: TDA (Totalmente De Acuerdo); DA (De Acuerdo); ED (En Desacuerdo); TED ( Totalmente en Desacuerdo). Por favor, no deje ninguna sin contestar.

Clave de respuesta:

- TDA = Totalmente de acuerdo

- $\mathrm{DA}=$ De acuerdo

- $\mathrm{ED}=$ En desacuerdo

- $\mathrm{TED}=$ Totalmente en desacuerdo

\begin{tabular}{|c|c|c|c|c|c|}
\hline \multicolumn{6}{|c|}{ Escala Familia } \\
\hline İtem & Contenido del ítem & TAD & DA & ED & TED \\
\hline F23 & Obtenga el apoyo emocional que necesito de: Familiar/es & & & & \\
\hline F26 & $\begin{array}{l}\text { Cuando tengo un problema, estoy satisfecho con la ayuda } \\
\text { que recibo de: Familiar/es }\end{array}$ & & & & \\
\hline F27 & $\begin{array}{l}\text { Si tengo problemas me siento bien pidiendo consejo a: } \\
\text { Familiar/es }\end{array}$ & & & & \\
\hline F29 & $\begin{array}{l}\text { Cuando necesito que me alienten o me ocurre algún } \\
\text { acontecimiento importante en mi vida de: Familiar/es }\end{array}$ & & & & \\
\hline F37 & $\begin{array}{l}\text { Si lo necesito, ante un determinado problema, me informan } \\
\text { y me ayudan a aclararme: Familiar/es }\end{array}$ & & & & \\
\hline F39 & $\begin{array}{l}\text { Cuando busco su apoyo me resulta sencillo conseguirlo } \\
\text { en: Familiar/es }\end{array}$ & & & & \\
\hline
\end{tabular}

\begin{tabular}{|l|l|l|l|l|l|}
\hline \multicolumn{2}{|l|}{ Escala Amigos } \\
\hline Ítem & Contenido del ítem & TAD & DA & ED & TED \\
\hline A13 & $\begin{array}{l}\text { Me siento bien aconsejado sobre cómo resolver cualquiera } \\
\text { de mis problemas por: Amigo/s }\end{array}$ & & & \\
\hline A19 & $\begin{array}{l}\text { Cuando tengo un problema obtengo una visión enriquecida } \\
\text { de: Amigo/s }\end{array}$ & & & & \\
\hline A22 & Puedo hablar de mis cosas más privadas con: Amigo/s & & & & \\
\hline A23 & Obtengo el apoyo emocional que necesito de: Amigo/s & & & & \\
\hline A25 & $\begin{array}{l}\text { Cuando alguien está molesto conmigo, me siento } \\
\text { comprendido por: Amigo/s }\end{array}$ & & & & \\
\hline
\end{tabular}




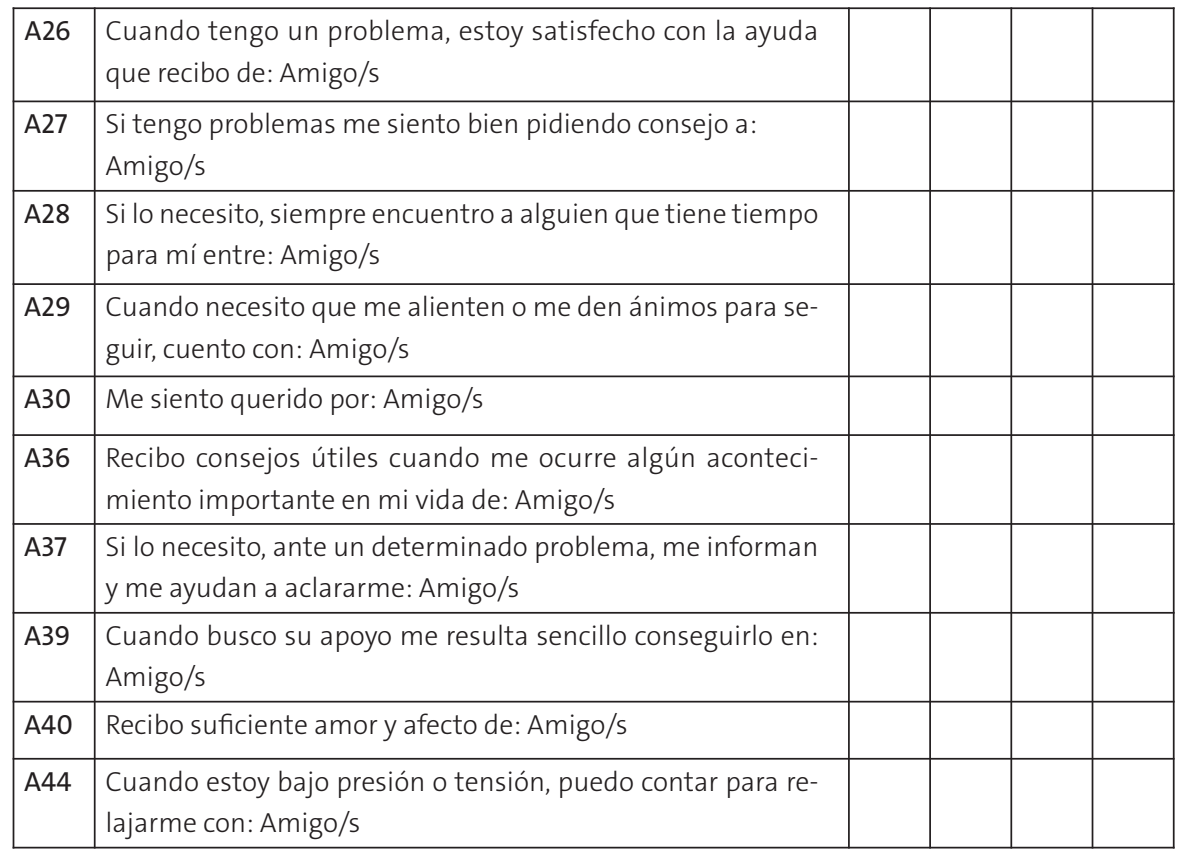

\begin{tabular}{|c|c|c|c|c|c|}
\hline \multicolumn{6}{|c|}{ Escala personas relevantes } \\
\hline Ítem & Contenido del ítem & TAD & DA & ED & TED \\
\hline R55 & $\begin{array}{l}\text { Existe una persona especial con la cual yo puedo compartir mis } \\
\text { penas y alegrías }\end{array}$ & & & & \\
\hline R59 & Siente que tengo a alguien que me quiere mucho & & & & \\
\hline R60 & Existe alguien que realmente es una fuete de bienestar para mí & & & & \\
\hline R62 & $\begin{array}{l}\text { Tengo a alguien con quien puedo contar cuando necesito } \\
\text { hablar de algo muy íntimo }\end{array}$ & & & & \\
\hline R63 & Tengo a alguien ante quien puedo llorar o desahogarme & & & & \\
\hline R64 & Tengo a alguien que me aconseje cómo resolver mis problemas & & & & \\
\hline R65 & Cuento con persona/s que se preocupan por lo que me sucede & & & & \\
\hline R78 & Hay alguien a quien puedo abrazar si lo necesito & & & & \\
\hline R80 & Cuento con alguien que me alienta o da ánimos para seguir & & & & \\
\hline
\end{tabular}

\section{Teléfono personal para contactar con usted, después de la intervención: NÚMERO DE TELÉFONO:}




\section{ANEXO II. FORMULARIO DE RECOGIDA DE DATOS}


Paciente número: $\quad$ Fecha intervención:

Duración cirugía: $\quad$ Técnica quirúrgica:

Complicaciones durante la cirugía: $\square$ NO $\square$ Sí especificar:

Sexo: $\square \mathrm{H} \quad \square \mathrm{M}$ Edad: $\quad$ Fumador: $\square$ NO $\square$ Sí Cigarrillos al día:

Estadocivil: $\square$ Soltero $\square$ Casado $\square$ Unión estable $\square$ Divorciado $\square$ Viudo

Ocupación: $\square$ Empleado $\square$ Desempleado $\square$ Jubilado

Nivel de estudios: $\square$ Sin estudios $\quad \square$ Estudios primarios $\quad \square$ FP grado medio

$\square$ Educación secundaria $\quad \square$ FP gradosuperior $\square$ Estudios universitarios

Antecedentes personales: $\quad$ ASA pre-quirúrgico:

Intervención precias con anestesia general: $\square \mathrm{Sí} \quad \square \mathrm{NO}$

Tiempo ingresado en la unidad de URPA:

Tiempo ingresado en hospitalización:

Analgesia postoperatoria administrada a demanda en URPA:

Analgesia postoperatoria administrada a demanda en hospitalización:

Complicaciones durante su estancia en URPA: $\square$ NO $\square$ Sí especificar:

Complicaciones durante su estancia en Hospitalización: $\square$ NO $\square$ Sí

especificar:

Puntuación escala 1-10, pregunta:

¿Qué nivel de estrés tiene ahora mismo? Antes de entrar al quirófano.

$\begin{array}{lrlllllllr}1 & 2 & 3 & 4 & 5 & 6 & 7 & 8 & 9 & 10 \\ \text { Sin estrés } & & & & & & & \text { Estrés extremo }\end{array}$

Puntuación escala 1-10, pregunta:

¿Qué nivel de ansiedad tiene ahora mismo? Antes de entrar al quirófano

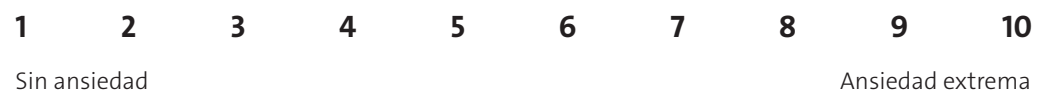


Analgesia post operatoria pautada:

Complicaciones primera semana post-intervención: $\quad \square$ NO $\square$ Sí especificar:

Toma de analgesia durante la primera semana en domicilio:

Puntuación escala STAI Ansiedad Estado en el ingreso:

Puntuación escala STAI Ansiedad Estado postquirúrgicas:

Puntuación escala STAI Ansiedad Rasgo en el ingreso:

Cortisol sérico previo a la intervención:

Puntuación cuestionario Apoyo Social VIDA:

Familiares: $\quad$ Amigos: Personas relevantes:

Puntuación Cuestionario Inventario Diferencial de Adjetivos para el Estudio del Estado de Ánimo IDDA-EA al ingreso:

Puntuación Cuestionario Inventario Diferencial de Adjetivos para el Estudio del Estado de Ánimo IDDA-EA postquirúrgico:

Fecha Alta en el servicio de OTR: 
Paciente número:

Fecha intervención:

Duración cirugía:

Técnica quirúrgica:

\section{QUIRÓFANO}

Extraída muestra de cortisol sérico: $\square$ NO $\square$ Sí incidencias:

Complicaciones durante la cirugía: $\quad \square$ NO $\square$ Sí incidencias:

Puntuación escala 1-10, pregunta:

¿Qué nivel de ESTRÉS tiene ahora mismo? Antes de entrar al quirófano.

$\begin{array}{llllllllll}1 & 2 & 3 & 4 & 5 & 6 & 7 & 8 & 9 & 10\end{array}$

Puntuación escala 1-10, pregunta:

¿Qué nivel de ANSIEDAD tiene ahora mismo? Antes de entrar al quirófano

$\begin{array}{rrrrrrrrrr}1 & 2 & 3 & 4 & 5 & 6 & 7 & 8 & 9 & 10 \\ \text { Sin ansiedad } & & & & & & & & & \text { Ansiedad extrema }\end{array}$

\section{URPA}

Tiempo ingresado en la unidad de URPA:

Analgesia postoperatoria administrada a demanda en URPA:

Complicaciones durante su estancia en URPA: $\square$ NO $\square$ Sí

incidencias: 


\section{ANEXO III. HOJA DE INFORMACIÓN AL PACIENTE Y CONSENTIMIENTO INFORMADO POR ESCRITO}




\section{HOJA DE INFORMACIÓN AL PACIENTE}

\section{TÍTULO DEL ESTUDIO: Descripción y análisis de la influencia del Apoyo So- cial, la Personalidad y el Estrés, en la evolución del paciente postquirúrgico intervenido de cirugía endoscópica nasosinusal (CENS)}

Estimado paciente, le invitamos a tomar parte en un estudio sobre la influencia del Apoyo Social, la Personalidad y el Estrés, en la evolución del paciente postquirúrgico intervenido de cirugía endoscópica nasosinusal (CENS).

Antes de decidir si desea tomar parte, es importante que entienda por qué se realiza este estudio y qué es lo que implica si acepta participar.

Por favor, lea con detenimiento la siguiente información y, si hay algo que no está claro o desea más información, no deje de consultarlo, puede solicitar la ampliación de información al investigador principal o sus colaboradores, o bien a su médico responsable. Le concederemos todo el tiempo que necesite para decidirse o no a participar.

\section{IDENTIFICACIÓN Y DESCRIPCIÓN DEL ESTUDIO}

El estudio consiste en la realización de una entrevista inicial el día de su ingreso en la unidad de hospitalización, previa a la intervención que tiene programada. Se le realizarán una sería de preguntas, para cumplimentar unas escalas, que cuantificarán su nivel de estrés, a poyo social y personalidad previos a la cirugía. El día de la intervención en el momento de la canalización venosa se le realizará un control de los niveles de cortisol en sangre, para relacionar esa información con los datos obtenidos en la entrevista. Durante su postoperatorio inmediato, recibirá la visita del investigador principal para la recogida de datos postquirúrgicos. Una vez obtenida el alta en hospitalización recibirá la llamada en su domicilio del investigador principal, a los 7 días de la intervención, para evaluar la evolución de su postoperatorio.

\section{OBJETIVO Y BENEFICIOS QUE SE ESPERAN ALCANZAR}

El propósito de este estudio es obtener los datos relacionados con el nivel de estrés, apoyo social y personalidad de los pacientes intervenidos de CENS que unidos a los datos relacionados con su evolución postquirúrgica, se intentará ver si esos factores iniciales van a influir en su recuperación postquirúrgica.

La participación es totalmente voluntaria. De ningún modo está obligado a participar $y$, si decide hacerlo, puede cambiar de opinión en todo momento. Todos los aspectos de este estudio, incluidos los resultados, serán tratados de manera estrictamente confidencial. 
Los beneficios son, participar en un estudio que intentará detectar que factores relacionados con estrés, apoyo social y personalidad van a influir en la recuperación postquirúrgica y por ello poder actuar y prevenir, la aparición de complicaciones relacionadas con esos factores.

\section{NÚMERO APROXIMADO Y CARACTERÍSTICAS DE PARTICIPANTES QUE SE PREVÉ INCLUIR EN EL ESTUDIO}

Serán seleccionados todos los paciente que cumplan los criterios de inclusión en el estudio: ser intervenido CENS, no presentar comorbilidad sin ser la propia del motivo de su intervención quirúrgica, ser mayor de edad, presentar una puntuación de 15 pts en la escala GCS (Glasgow Coma Escala) al inicio del estudio.

\section{¿POR QUÉ HA SIDO ELEGIDO?}

Usted ha sido elegido debido a que cumple los criterios de inclusión de la muestra en el estudio, mencionados con anterioridad.

\section{CONFIDENCIALIDAD}

Se garantiza el derecho a la intimidad y a la confidencialidad de todos los datos relativos a su salud, tanto de los obtenidos durante la investigación, como de los que constan en su historia clínica, en los términos establecidos en la Ley 15/1999 de protección de datos de carácter personal y en la Ley 41/2002, reguladora de la autonomía del paciente y de derechos y obligaciones en materia de información y documentación clínica.

Para la finalidad expuesta, a Ud. se le identificará con un código y la información personal de sus archivos no será distribuida o cedida a terceras personas sin su consentimiento previo por escrito. En este sentido, no se le identificará personalmente en las publicaciones escritas o seminarios en los que se pudieran exponer los resultados de este estudio.

\section{CONSIDERACIONES ÉTICAS}

Este estudio se llevará a cabo siguiendo las reglas de buena práctica clínica, y tienen como exclusiva finalidad la observación y análisis de los datos obtenidos de la entrevistas y la muestra de sangre realizada en el momento de la canalización venosa en el quirófano. Esto quiere decir que, al participar en este estudio, a Ud. no se le someterá a ningún procedimiento innecesario, y tampoco dejará de recibir las atenciones necesarias para tratar su intervención quirúrgica, si decide no participar en el estudio. 


\section{DURACIÓN PREVISTA DE SU INCLUSIÓN EN EL ESTUDIO}

El estudio durará 12 meses.

\section{PREGUNTAS QUE PUDIERAN SURGIRLE DURANTE Y DESPUÉS DE SU PAR-} TICIPACIÓN EN EL ESTUDIO

Si alguna vez necesita respuesta a alguna pregunta sobre este estudio, puede contactar con: Pedro Raúl Castellano Santana al teléfono 676151796 o por email al correo:

pcassane@gobiernodecanarias.org

\section{COMPENSACIÓN ECONÓMICA}

Este estudio no tiene ánimo de lucro. Las personas que voluntariamente acepten ser incluidas en este estudio, así como los investigadores que intervienen en el mismo, no recibirán compensación económica alguna por ello. 


\section{CONSENTIMIENTO INFORMADO DEL PACIENTE}

He leído y entendido la Hoja de información al paciente. He tenido la oportunidad de discutir las cuestiones relacionadas con esta información. Mis preguntas y dudas han sido respondidas de forma satisfactoria.

Entiendo que mi participación es voluntaria y que soy libre de abandonar el estudio en cualquier momento y sin que esto vaya en detrimento de mis derechos legales.

Entiendo que es posible que los datos puedan ser utilizados en otros documentos y que los detalles personales serán tratados de forma estrictamente confidencial. Doy autorización para que se acceda a mis informes sin que se revele información personal.

Estoy de acuerdo con que la información relativa a mi participación en este estudio sea comunicada a mi facultativo especialista y médico de cabecera si lo solicita.

He leído la información anterior y acepto participar en el estudio.

\section{PARTICIPANTE}

Nombre y apellidos:

Firma:

Fecha:

\section{INVESTIGADOR}

Nombre y apellidos:

Firma:

Fecha: 


\section{HOJA DE INFORMACIÓN Y CESIÓN DE DATOS PERSONALES}

En cumplimiento de lo dispuesto en el artículo 5 de la Ley Orgánica 15/1999 de Protección de Datos de Carácter Personal, por el que se regula el derecho de información en la recogida de los datos, le informamos que los datos de carácter personal facilitados en el presente formulario, se incluirán y serán tratados con confidencialidad y seguridad en ficheros, responsabilidad de LA DIRECCIÓN GERENCIA DEL COMPLEJO HOSPITALARIO UNIVERSITARIO INSULAR MATERNO INFANTIL, cuya finalidad es realizar UN ESTUDIO DE INVESTIGACIÓN, haciendo uso de las nuevas tecnologías.

El destinatario de los datos es EL EQUIPO DE INVESTIGACIÓN DE Otorrinolaringología, SIENDO RESPONSABLE EL INVESTIGADOR PRINCIPAL Pedro Raúl Castellano Santana, no teniendo previsto realizar cesiones a terceros distintas de las previstas por Ley o, los expresamente autorizados por usted o su representante legal.

Los datos aportados deben ser verdaderos, exactos, completos y actualizados. El interesado se hará responsable de cualquier daño o perjuicio, directo o indirecto, como consecuencia del incumplimiento de tal obligación.

En cumplimiento de principio de calidad de sus datos, la DIRECCION GERENCIA DEL COMPLEJO HOSPITALARIO UNIVERSITARIO INSULAR MATERNO INFANTIL conservará la información consignada con la finalidad descrita. Si desea modificarlos se tendrá que poner en contacto con el investigador principal.

El interesado podrá ejercitar los derechos de acceso, rectificación, cancelación y oposición en los términos establecidos en citada Ley Orgánica 15/1999 y normativa concordante ante la DIRECCION GERENCIA DEL COMPLEJO HOSPITALARIO UNIVERSITARIO INSULAR MATERNO INFANTIL, ubicada en la 6a planta del Edificio Anexo al Hospital Insular de Gran Canaria. Podrá revocar el consentimiento otorgado, sin efectos retroactivos, cuando acredite causa justificada, a través de solicitud por escrito ante EL REGISTRO GENERAL del CHUIMI, Avda. Marítima del Sur, s/n, 35010, Las Palmas de Gran Canaria, haciendo la mención expresa de "Protección de Datos", o por correo electrónico a la siguiente dirección pcassane@gobiernodecanarias.org, o por correo ordinario a la dirección anteriormente reseñada y haciendo entrega de copia de DNI.

\section{PARTICIPANTE}

Nombre y apellidos:

Firma: Fecha:

\section{INVESTIGADOR}

Nombre y apellidos:

Firma: Fecha: 
ANEXO IV.

CERTIFICADOS 


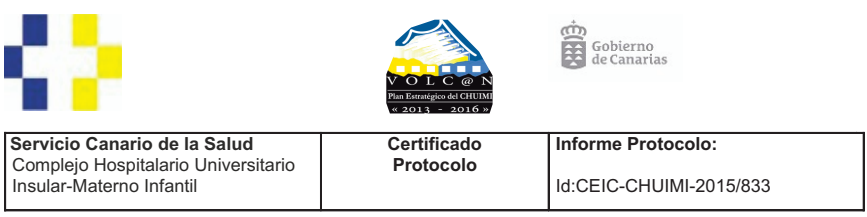

Vicente Olmo Quintana, Presidente del Comité Ético de Investigación Clínica del Complejo Hospitalario Universitario Insular-Materno Infantil,

\section{CERTIFICA:}

Que este Comité, en la sesión celebrada el 17 de diciembre de 2015, ha evaluado la propuesta de D. Pedro Raúl Castellano Santana, Enfermero de Quirófano HUIGC, para que se realice el ensayo clínico abajo señalado, dando por concluidas las alegaciones y estudiadas las mismas, se decide aceptarlas como válidas y emitir informe favorable.

"Descripción y análisis de la influencia del Apoyo Social, la Personalidad y Estrés, en la evolución del paciente postquirúrgico intervenido de amigdalectomía".

Protocolo: Versión enero 2016.

Hoja de Información al Paciente y Consentimiento Informado: Versión enero 2016.

1. Se cumplen los requisitos necesarios de idoneidad del protocolo en relación con los objetivos del estudio y están justificados los riesgos y molestias previsibles para e sujeto.

2. La capacidad del investigador principal, D. Pedro Raúl Castellano Santana, Enfermero de Quirófano HUIGC.

3. Son adecuados tanto el procedimiento para obtener el Consentimiento Informado como la compensación prevista para los sujetos por daños que pudieran derivarse de su participación en el estudio.

4. El alcance de las compensaciones previstas no interfiere con el respeto a los postulados éticos.

5. EI CEIC del Complejo Hospitalario Universitario Insular Materno Infantil, tanto en su composición, como en los PNT cumple con las normas de BPC (CPMP/ICH/135/95).

6. Que se cumplen los preceptos éticos formulados en la orden SAS 3470/2009 y la declaración de Helsinki de la Asociación Médica Mundial sobre principios éticos para las investigaciones medicas en seres humanos y en sus posteriores revisiones, así como aquellos exigidos por la normativa aplicable para este tipo de estudios.

7. La composición actual del CEIC del Complejo Hospitalario Universitario InsularMaterno Infantil es la siguiente:

\section{PRESIDENTE:}

D. Vicente Olmo Quintana Farmacéutico de Atención Primaria

\section{SECRETARIA:}

Da. Alicia Díez Del Pino

Farmacéutica Hospitalaria CHUIMI 


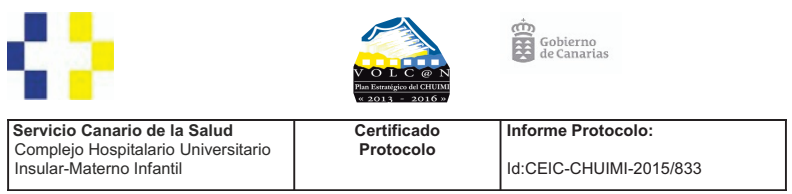

\section{VOCALES:}

$\begin{array}{ll}\text { D. José L Alonso Bilbao } & \text { Epidemiólogo, Área Técnica, Atención Primaria } \\ \text { Da Eva Elisa Álvarez León } & \text { Subdirectora Médica CHUIMI } \\ \text { D. Mauro Boronat Cortés } & \text { Endrocrinólogo, Servicio Endrocrinología CHUIMI } \\ \text { Da. Elisabeth Cheneau } & \text { Enfermera, Docencia Salud Mental } \\ \text { D. José María Limiñana Cañal } & \text { Bioestadístico, ULPGC } \\ \text { D. Félix López Blanco } & \text { Farmacólogo Clínico, Dpto. Farmacología ULPGC } \\ \text { D. Jordi López García } & \text { Neumólogo, Servicio de Neumología CHUIMI } \\ \text { D. José Juan Morales Castro } & \text { Enfermero, Área de Quirófano CHUIMI } \\ \text { Da Beatriz Sánchez Lerma } & \text { Farmacéutica Hospitalaria CHUIMI } \\ \text { D. Julio Ángel de Santiago Angulo } & \text { Asesor Jurídico CHUIMI } \\ \text { D. Antonio Tugores Cester } & \text { Unidad de Investigación, CHUIMI } \\ \text { Da. Blanca Valenciano Fuente } & \text { Pediatra, Servicio de Pediatría HUMIC } \\ \text { Da Teresa Tavío Mendoza } & \text { Secretaria Administrativa CEIC }\end{array}$

8. Este CEIC emite un INFORME FAVORABLE.

9. Y que este CEIC acepta que dicho estudio clínico sea realizado por el investigador principal en el Complejo Hospitalario Universitario Insular Materno Infantil.

Lo que firmo en Las Palmas de Gran Canaria, a 14 de enero de 2016

PRESIDENTE DEL COMITÉ

Dr. D. Vicente J. Olmo Quintana

Id:CEIC-CHUIMI-2015/833 


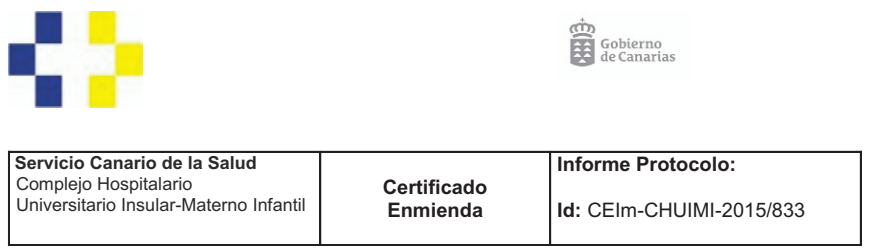

Vicente Olmo Quintana, Presidente del Comité de Ética de la Investigación con medicamentos del Complejo Hospitalario Universitario Insular Materno Infantil,

\section{CERTIFICA:}

Que, vista la solicitud presentada por D. Pedro Raúl Castellano Santana en relación a la modificación en los criterios de inclusión propuestos, no modifican ninguno de los aspectos relacionados con el diseño del estudio, por lo que se ha decidido emitir dictamen favorable a dicha enmienda para el estudio titulado:

"Descripción y análisis de la influencia del Apoyo Social, la Personalidad y Estrés, en la evolución del paciente postquirúrgico intervenido de amigdalectomía".

Investigador Principal: D. Pedro Raúl Castellano Santana, Enfermero de Quirófano HUIGC. Adscrito al Servicio de Otorrinolaringología.

Enmienda Relevante: Modificación de los criterios de inclusión de los pacientes.

1. El CEIC del Complejo Hospitalario Universitario Insular - Materno Infantil, tanto en su composición, como en los PNT cumple con las normas de BPC (CPMP/ICH/135/95).

2. La composición actual del CEIm del Complejo Hospitalario Universitario Insular Materno Infantil es la siguiente:

\section{PRESIDENTE:}

D. Vicente Olmo Quintana Farmacéutico de Atención Primaria SECRETARIA:

$D^{a}$. Alicia Díez Del Pino

Farmacéutica Hospitalaria CHUIMI

VOCALES:

D. José L Alonso Bilbao

$D^{a}$ Eva Elisa Álvarez León

Epidemiólogo, Área Técnica, Atención Primaria

Subdirectora Médica CHUIMI

D. Mauro Boronat Cortés

Endrocrinólogo, Servicio Endrocrinología CHUIMI

$D^{a}$. Elisabeth Cheneau

Enfermera, Docencia Salud Mental

$D^{a}$. Almudena Sánchez Villegas

Bioestadístico, ULPGC

D. Félix López Blanco

Farmacólogo Clínico, Dpto. Farmacología ULPGC

D. Jordi López García

Neumólogo, Servicio de Neumología CHUIMI

D. José Juan Morales Castro

$D^{\text {a }}$ Beatriz Sánchez Lerma

Enfermero, Área de Quirófano CHUIM

Farmacéutica Hospitalaria CHUIMI

D. Julio Ángel de Santiago Angulo Asesor Jurídico CHUIMI

D. Antonio Tugores Cester Unidad de Investigación, CHUIMI 


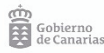

\begin{tabular}{|c|c|c|}
\hline $\begin{array}{l}\text { Servicio Canario de la Salud } \\
\text { Complejo Hospitalario } \\
\text { Universitario Insular-Materno Infantil }\end{array}$ & $\begin{array}{l}\text { Certificado } \\
\text { Enmiendaa }\end{array}$ & $\begin{array}{l}\text { Informe Protocolo: } \\
\text { Id: CEIm-CHUIMI-2015/833 }\end{array}$ \\
\hline $\mathrm{D}^{\mathrm{a}}$. Blanca Valenciar & \multicolumn{2}{|c|}{ Pediatra, Servicio de Pediatría HUMIC } \\
\hline $\mathrm{D}^{\mathrm{a}}$ Teresa Tavío Mend & \multicolumn{2}{|c|}{ Secretaria Administrativa CEIm } \\
\hline
\end{tabular}

Lo que firmo en Las Palmas de Gran Canaria, a 10 de marzo de 2017

PRESIDENTE DEL COMITE

Dr. D. Vicente J Olmo Quintana

Id: CEIC-CHUIMI-2015/833 


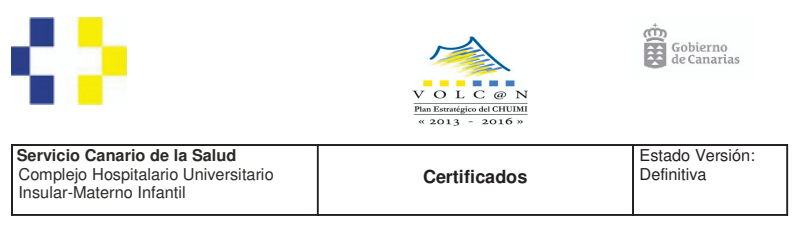

CONFORMIDAD DE LA DIRECCIÓN GERENCIA

VICTOR NARANJO SINTES, DIRECTOR GERENTE DEL COMPLEJO HOSPITALARIO UNIVERSITARIO INSULAR- MATERNO INFANTIL

Vista la autorización del Comité Ético de Investigación Clínica

$$
\text { CERTIFICA: }
$$

Que conoce la propuesta realizada por D. Pedro Raúl Castellano Santana, Enfermero de Quirófano HUIGC, para que se pueda desarrollar en este Centro el protocolo titulado:

"Descripción y análisis de la influencia del Apoyo Social, la Personalidad y Estrés, en la evolución del paciente postquirúrgico intervenido de amigdalectomía".

Protocolo: Versión enero 2016.

Hoja de Información al Paciente y Consentimiento Informado: Versión enero 2016.

Se cumplen los requisitos necesarios de idoneidad de protocolo en relación con los objetivos del estudio y están justificados los riesgos y molestias previsibles para el sujeto.

La capacidad del investigador principal, D. Pedro Raúl Castellano Santana, Enfermero de Quirófano HUIGC.

Id: CEIC-CHUIMI-2015/833 

